\title{
HEALTH PROMOTING EFFECTS OF NUTRITION IN CHILDREN
}

The clinical effects of a dietary advice consisting of beef, green vegetables, whole milk and butter

Ellen José van der Gaag - Heuvel 
Cover design: $\quad$ EJ van der Gaag

Printed by: $\quad$ Gildeprint

Lay-out: $\quad$ XML 2 Publish

ISBN: $\quad 978-90-365-4960-8$

DOI: $\quad 10.3990 / 1.9789036549608$

URL: $\quad$ https: / / doi.org/10.3990/1.9789036549608

(c) 2020 Ellen José Van Der Gaag - Heuvel, The Netherlands. All rights reserved. No parts of this thesis may be reproduced, stored in a retrieval system or transmitted in any form or by any means without permission of the author. Alle rechten voorbehouden. Niets uit deze uitgave mag worden vermenigvuldigd, in enige vorm of op enige wijze, zonder voorafgaande schriftelijke toestemming van de auteur. 


\title{
HEALTH PROMOTING EFFECTS OF NUTRITION IN CHILDREN
}

\author{
The clinical effects of a dietary advice consisting of beef, \\ green vegetables, whole milk and butter
}

PROEFSCHRIFT

\author{
ter verkrijging van \\ de graad van doctor aan de Universiteit Twente, \\ op gezag van de rector magnificus, \\ Prof.dr. T.T.M. Palstra, \\ volgens besluit van het College voor Promoties \\ in het openbaar te verdedigen \\ woensdag 18 maart 2020 om 14.45 uur
}

door

Ellen José Van Der Gaag - Heuvel 
Dit proefschrift is goedgekeurd door:

promotor Prof. dr. J.A.M. van der Palen

\title{
PROMOTIECOMMISSIE:
}

\author{
Voorzitter \\ prof. dr. T.A.J. Toonen \\ Promotor: \\ prof. dr. J.A.M. van der Palen \\ Co-promotor: \\ dr. T.Z. Hummel \\ Leden: \\ prof. dr. M.L. Eggersdorfer \\ prof. dr.ir. M.J.A.M. van Putten \\ prof. dr. J.A.M. van der Palen \\ dr. T.Z. Hummel \\ prof. dr. G.H. Koppelman \\ dr. M.M. Boere - Boonekamp \\ prof. dr. ir. H.F.J. Savelkoul \\ prof. dr. E.G. van Mil
}




\section{CONTENTS}

Chapter 1 Introduction 9

Chapter 2 Food or medication? The therapeutic effects of food on the 27 duration and incidence of upper respiratory tract infections: a review of the literature

Chapter 3 The immunomodulating effect of dietary advice consisting of green vegetables, beef, whole milk and full-fat butter for children with non-specific elevated IgE.

Chapter 4 Could a change in diet revitalize children who suffer from unresolved fatigue?

Chapter 5 Advising consumption of green vegetables, beef and full-fat dairy products has no adverse effects on the lipid profiles in children

Chapter 6 The influence of a dietary advice including of green vegetables, beef and whole dairy products on recurrent upper respiratory tract infections in children: a randomized controlled trial

Chapter 7 A dietary intervention reduces tiredness in children with subclinical hypothyroidism, a randomized controlled trial

Chapter 8 Discussion

Chapter 9 Summary, Nederlandse samenvatting, CV, publications, dankwoord 


\section{PROLOGUE}

I would like to start with a personal note. When I started working as a paediatrician, I was always fascinated by the dietary habits of children. Why do some children eat vegetables, meat, bread and cow's milk, while other children don't like milk or vegetables or don't eat anything at all? What are the somatic consequences of restricted dietary intake? When I work in the outpatient clinic, I always ask about dietary habits, and most children have some issues with their diet. Then, I realized that maybe I did not see many children with normal eating habits, because they have better health. Why do some children get sick and others don't?

To illustrate this, a study group in Baltimore examined the adenoids and tonsils of children after tonsillectomy for the presence of (viral) pathogens. The adenoids or tonsils were removed because of respiratory obstruction due to hypertrophy, not because of recurrent infections. Although these children had no symptoms of infections, in all children, 1 or more pathogens were found in the adenoid or tonsillar tissue. In $40 \%$ of these children, they found more than 3 pathogens. The authors argued there could be a latent or persistent viral infection that explained the positive polymerase chain reaction (PCR) findings[1]. These findings were confirmed by another study group, they found $97 \%$ positive cultures $(29 / 30)$ in an asymptomatic group of children[2]. If many children have positive cultures, indicative for the presence of pathogens, why do some children get ill and others stay only carriers of the virus? Can nutritional deficiency be one of the factors that have a negative effect on the immune system in these children? That was the point when I started with my research, targeting the role of nutrition in children's health in a developing world. 


\begin{abstract}
AIMS
In paediatrics, a lot is known about general or specific aspects of development, growth, infectious diseases, congenital abnormalities and rare diseases. In contrast, much is unknown about common symptoms of modern diseases, such as recurrent upper respiratory tract infections (URTIs) or tiredness. Because much is unknown about these conditions, no treatment options are available. In the absence of medical abnormalities, we tell the parents their child will "grow out" of it. Parents cannot do anything in that period, except for buying medication to relieve the symptoms.
\end{abstract}

This thesis focuses on the effects of nutrition on common symptoms and modern diseases without proper treatment options. 


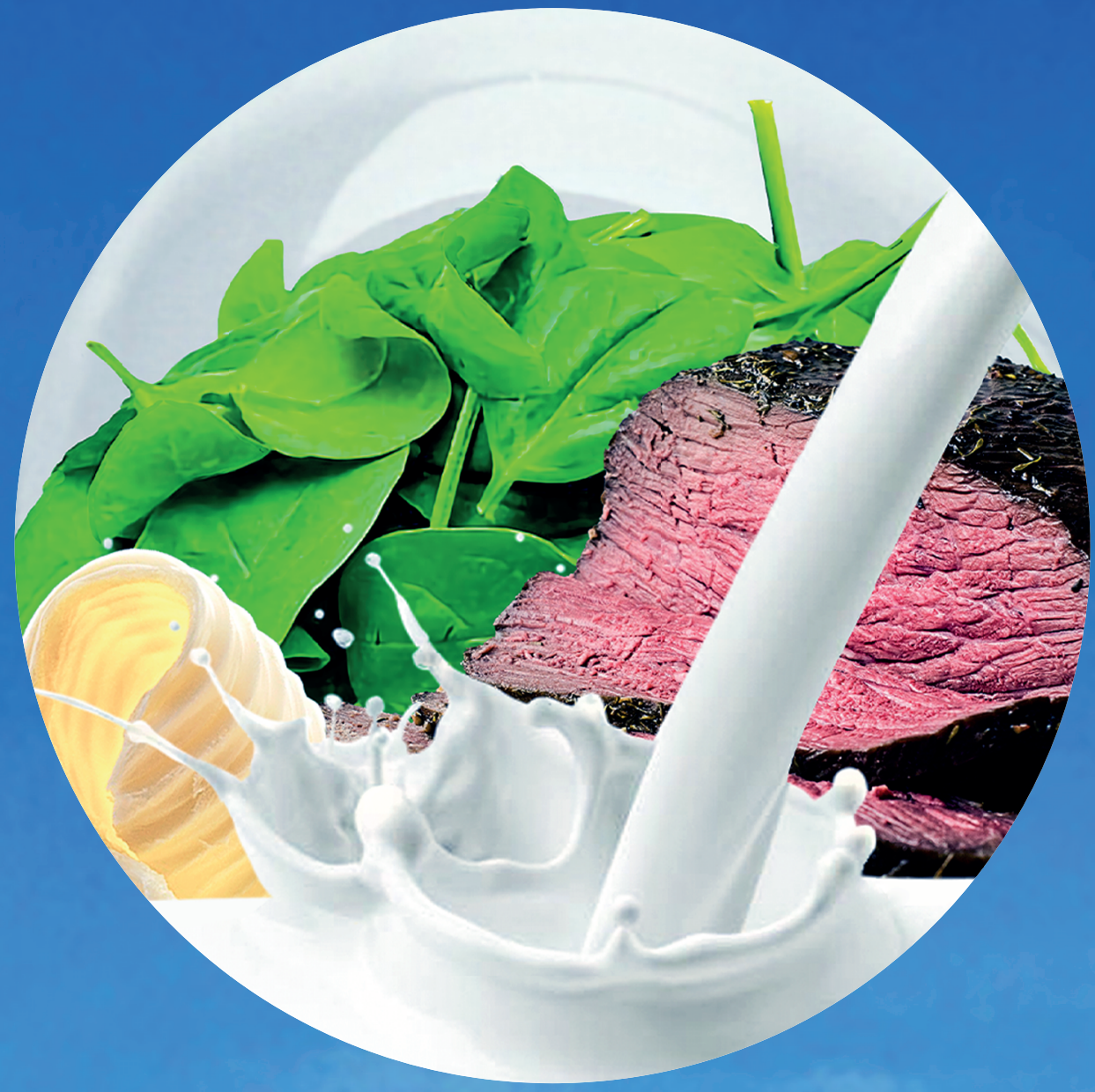




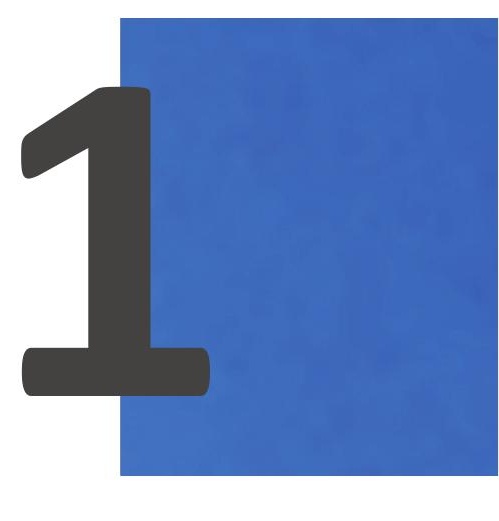

Introduction 



\section{MODERN DISEASES}

In 2007, I interviewed a general practitioner, who was 87 years old at that moment and still practicing as a family doctor, about modern diseases. He started practicing just after the World War II, and the diseases he treated were completely different as compared to the diseases in 2007. In the old days, he treated children with epilepsy, asthmatic diseases, pneumonia in the winter season and sometimes very serious diseases such as cancer or paralysis. The same as in 2007. However, he did not see children with tiredness, recurrent infections, obesity, ADHD or allergic diseases. Also, the number of children visiting his practice differed. In the beginning of his career, he treated only a few children from an entire school, but nowadays, he treats many children from just one classroom. He pointed out that today the doctors have a more difficult job; the origins of the diseases are less clear and, as a result, the treatment options also.

Socioeconomic circumstances have improved since World War II; however, health care consumption has increased instead of declined. The illnesses children present with are less serious, but more common in society.

We selected a few of these modern diseases in children to investigate whether a dietary change can alter the presentation and incidence of these diseases. We chose recurrent upper respiratory tract infections (URTIs), tiredness, subclinical hypothyroidism $(\mathrm{SH})$ and allergic parameters. The incidence of these diseases is high in our Western population, and we do not have a proper treatment or protocol we can use to solve them. Therefore, we can use a possible solution to decrease the impact on the patients suffering from these diseases.

\section{NUTRITION IN CHILDREN}

How do young children eat in The Netherlands? In 2015, a study about dietary habits in 1-4 year old children was performed. This study investigated the food intake over 2 days in 1526 young children. Around $40 \%$ of these children did not meet the recommendations of the "schijf van vijf" = "Wheel of Five"[3]. According to the Dutch Nutrition Centre, following the Wheel of Five gives your body enough of the products that provide health benefits, as well as all the nutrients you need to meet every day head-on. In the 2015 dietary intake study, primarily the intake of fruits, vegetables and fats for preparation of foods were lacking. In this age group, around $68 \%$ did not reach the advised 150 grams of fruit per day, with a mean intake of 128 grams per 
day. Around $38 \%$ of the children did not eat the advised portion of $50-100$ grams of vegetables. The mean intake was only 60 grams of vegetables per day. The consumption of fat for preparation, such as cooking oil or fats, was extremely low; $94 \%$ did not reach the recommended 15 grams per day. The mean intake was 4 grams per day. The advised meat consumption was reached in $40 \%$ of the children. Around $85 \%$ of the children drank more dairy products than advised (300 ml/day). In all, $80 \%$ of these dairy products consisted of semi-skimmed milk, growing up-milk and follow-up milk.

As a result of this insufficient diet, some undesirable effects in nutrient intake are seen. The total energy intake is too high in the young children, mainly because of too much sugar and protein. Total fat intake is too low, as is the fibre intake (because of lower fruit and vegetable intake). For micronutrients, iron intake (low meat intake), omega-3-fatty acids (lack of fish and natural fat intake) and vitamin D (low fat intake) are at risk. Vitamin $\mathrm{A}$ and natrium are taken too much[4].

In 2008, we investigated in our own study population the dietary habits of children with recurrent URTIs. When we asked what they consumed, we did not find any differences between 37 children with URTIs and 39 children in the control group with respect to the intake of bread, meat (products), vegetables, dairy products, fruits et cetera[5]. The children in our study population ate according to the "schijf van vijf", even the recommended amounts, so no deficient intakes were observed [3, 5]. A critical remark about our study, we used a questionnaire about food instead of the 2-day food recall list. These different methods used may be responsible for the differences found between both studies.

When we asked the parents in another study what their children did not eat $(<1$ time a week), we noticed differences. In all, $16 \%$ of the 82 children with URTIs ate vegetables $<1$ time a week as compared to $8 \%$ in 399 control children $(p<0.05)$. They also consumed less beef ( $28 \%$ vs $17 \%<1$ time a week, respectively; $p<0.05$ )[6]. We saw no differences in the fruit or dairy intake. Thus, children with URTIs seemed to eat appropriate amounts, but when the question was asked differently (e.g., what they did not eat?), we noticed significant differences. In line with this finding, we hypothesized that nutrient rich dietary advice could improve the health of children, since a great percentage of children miss important food products.

To accomplish this, we developed dietary advice with four components with respect to our previous findings. Within the vegetable and meat group, respectively, green vegetables and beef contain the largest amounts of nutrients[7]. The intake of fatty acids (with favourable proportions of omega- 3 and -6 fatty acids), proteins and fat 
soluble vitamins was ensured by whole milk and butter (Table 1-4). The dietary advice therefore consisted of 3 times a week beef, 5 times a week green vegetables and daily whole milk and butter-all in age appropriate portions, according to the Dutch recommendations[3]. These products have in common that they all are unprocessed fresh food products, rich in nutrients (Table 5). Above all, the components fit in the traditional Dutch diet, like it was about a century ago. In our study group, children with URTIs, we did not see deficient fruit intake. We therefore did not include fruits in the dietary advice.

In the following paragraphs, we put the investigated dietary advice into perspective to the specific nutritional needs of children.

\section{Proteins}

Proteins are needed for growth and maintenance of the body [8]. In children, higher amounts of proteins are necessary as an important source of nitrogen and indispensable amino acids. To gauge the quality of a dietary protein source, an indicator has been developed. Dietary protein quality is an indicator for the quantity and utilization of indispensable amino acids. Most animal products are considered high quality protein sources, since they contain optimal indispensable amino acids for human needs and are highly digestibility. This is in contrast to plant proteins, whose indispensable amino acid compounds and/or protein digestibility is often lower [9]. Red meat (beef) contains all 8 essential amino acids for adults and all 9 required for children. If excess protein is taken (and proteins have fulfilled their role as components of growth and maintenance), protein is used as an energy source. 
Table 1. Protein composition of parts of the dietary advice as compared to other food products[7].

\begin{tabular}{llll} 
& Total protein & Plant origin & Animal origin \\
& g/100 g & g/100 g & g/100 g \\
Beef rump steak prepared & 29.3 & 0 & 29.3 \\
Beef rib steak prepared & 34.1 & 0 & 34.1 \\
Chicken filet prepared & 30.9 & 0 & 30.9 \\
Pork filet prepared & 28.7 & 0 & 28.7 \\
& & & \\
Spinach cooked & 2.9 & 2.9 & 0 \\
Peas frozen cooked & 6.0 & 6.0 & 0 \\
Chicory cooked & 1.2 & 1.2 & 0 \\
Cauliflower cooked & 1.8 & 1.8 & 0 \\
Carrots cooked & 0.7 & 0.7 & 0 \\
Butter unsalted & & & \\
Margarine 80\% fat <24 g sat FA unsalted & 0 & 0 & 0.7 \\
Cooking fat liquid 97\% fat unsalted & 0.4 & 0 & 0 \\
Olive oil & 0 & 0.4 & 0 \\
& & 0 & 0 \\
Milk 3.4\% fat & 3.3 & 0 & 3.3 \\
Buttermilk & 3.0 & 0 & 3.0 \\
Milk 1.5\% fat & 3.4 & 0 & 3.4 \\
Sweetened dairy drink & 3.3 & 0 & 3.3 \\
Yoghurt drink (Optimel) & 3.0 & & \\
\hline
\end{tabular}

Sat FA=saturated Fatty Acids

\section{Fats}

Dietary fats are a major energy source for the body, but they are also essential structural components of cell membranes, precursors for bioactive molecules, and regulators of gene expression and enzyme activities, which are all essential components for a growing child. Fat is also an important source for essential fatty acids and fat soluble vitamins (A,D,E and K)[9]. Recommended daily fat intake is expressed as a percentage of total energy intake, around $35-40 \%$ of total energy intake for children 1-3 years old, and $20-35 \%$ in children 4 years or older [9]. Young children need higher amounts of dietary fats, partly because their rate of fat oxidation ("burn" energy) is also increased in relation to total caloric expenditure. This might be due to the support of normal growth processes, such as higher rates of protein synthesis, lipid storage, and bone growth [10]. Lower fat intake in young children is associated with an increased risk for inadequate growth and vitamin deficiencies [11]. 
In general, meat from ruminants, such as cows, contains more saturated fatty acids as compared to white meat, since all dietary polyunsaturated fatty acids are hydrogenated by the microbiome during rumination [12]. On the other hand, the total amount of saturated fatty acids in meat is relatively small, but not in butter (Table 2). Saturated fatty acids have been linked to obesity in the last decades, and its benefits are often undermined by the fear of obesity. Mammalian milk, including human milk, contains about $50 \%$ saturated fatty acids [13]. This is the most natural, sometimes only and appropriate food source for young children. From a developmental aspect, saturated fatty acids should bring benefits to a developing and growing body, but it remains at odds with the obesity fear.

Table 2. Fat composition of parts of the dietary advice as compared to other food products[7].

\begin{tabular}{|c|c|c|c|c|c|c|c|c|}
\hline & $\begin{array}{l}\text { Total } \\
\text { fat }\end{array}$ & $\begin{array}{l}\text { Sum fatty } \\
\text { acids }\end{array}$ & SFA & $\begin{array}{l}\text { Trans } \\
\text { fats }\end{array}$ & $\begin{array}{l}\text { MUFA } \\
\text { cis }\end{array}$ & PUFA & Cholesterol & EPA \\
\hline & $\mathrm{g} / 100$ & $\mathrm{~g} / 100 \mathrm{~g}$ & $\mathrm{~g} / 100 \mathrm{~g}$ & $\mathrm{~g} / 100 \mathrm{~g}$ & $\mathrm{~g} / 100 \mathrm{~g}$ & $\mathrm{~g} / 100 \mathrm{~g}$ & $\mathrm{mg}$ & $\mathrm{g} / 100 \mathrm{~g}$ \\
\hline Beef rump steak prepared & 3.2 & 3.0 & 0.9 & 0 & 1.3 & 0.6 & 40.7 & 0 \\
\hline Beef rib steak prepared & 10.4 & 9.9 & 4.2 & 0.3 & 4.1 & 0.9 & 59.8 & 0 \\
\hline Chicken filet prepared & 3.8 & 3.4 & 1.4 & 0 & 1.0 & 0.8 & 89 & 0 \\
\hline Pork filet prepared & 4.7 & 4.3 & 1.4 & 0.1 & 1.8 & 1.0 & 45.1 & 0 \\
\hline Spinach cooked & 0.9 & 0.7 & 0.1 & 0 & 0.1 & 0.6 & 0 & 0 \\
\hline Peas frozen cooked & 0.0 & 0.0 & 0.0 & 0 & 0 & 0 & 0 & 0 \\
\hline Chicory cooked & 0.2 & 0.1 & 0.0 & 0 & 0 & 0.1 & 0 & 0 \\
\hline Cauliflower cooked & 0.4 & 0.3 & 0.1 & 0 & 0 & 0.2 & 0 & 0 \\
\hline Carrots cooked & 0.3 & 0.2 & 0.1 & 0 & 0 & 0.2 & 0 & 0 \\
\hline Butter unsalted & 81.1 & 76.2 & 52.9 & 1.5 & 17.7 & 2.2 & 221 & 0.05 \\
\hline $\begin{array}{l}\text { Margarine } 80 \% \text { fat }<24 \text { g sat FA } \\
\text { unsalted }\end{array}$ & 80 & 76.8 & 15.4 & 1.0 & 22.1 & 38.4 & 2 & 0 \\
\hline $\begin{array}{l}\text { Cooking fat liquid } 97 \% \text { fat } \\
\text { unsalted }\end{array}$ & 97.7 & 93.8 & 10.5 & 1.3 & 35.5 & 46.4 & 2.5 & 0 \\
\hline Olive oil & 100 & 96 & 14.3 & trace & 73.8 & 7.9 & 0 & 0 \\
\hline Milk $3.4 \%$ fat & 3.4 & 3.2 & 2.2 & 0.1 & 0.7 & 0.1 & 11 & 0 \\
\hline Buttermilk & 0.2 & 0.2 & 0.1 & 0 & 0 & 0 & 2.7 & 0 \\
\hline Milk $1.5 \%$ fat & 1.5 & 1.4 & 1.0 & 0 & 0.3 & 0 & 5.6 & 0 \\
\hline Sweetened dairy drink & 0.5 & 0.5 & 0.3 & 0 & 0.1 & 0 & 5 & 0 \\
\hline Yoghurt drink (Optimel) & 0 & 0 & 0 & 0 & 0 & 0 & 0.6 & 0 \\
\hline Beef rump steak prepared & 3.2 & 3.0 & 0.9 & 0 & 1.3 & 0.6 & 40.7 & 0 \\
\hline
\end{tabular}

SFA=saturated fatty acids, MUFA= monounsaturated fatty acids, PUFA= polyunsaturated fatty acids, EPA=eicosapentaenoic acid (omega- 3 fatty acid), Sat FA=saturated Fatty Acids 
Relatively low amounts of polyunsaturated fatty acids (n-3 and n-6) are present in beef. These $n-3$ polyunsaturated fatty acids (alpha-linoleic acid) and $n-6$ polyunsaturated fatty acids (linoleic acid) are essential fatty acids and the $n-3$ polyunsaturated fatty acids can be converted to the beneficial $n-3$ fatty acids eicosapentaenoic acid and docosahexaenoic acid.

Animal products (milk and beef) contain small proportions of trans-fatty acids, predominantly vaccenic acid, which has not been associated with cardiovascular disease [14].

\section{Micronutrients}

Micronutrients play a role in optimizing processes (iron, iodine as part of thyroid hormones, zinc and calcium) or act as structural components (calcium in bone and teeth). Beef is a valuable source of micronutrients (iron and zinc) for children and teenagers $[15,16]$. A positive association was found between the intake of animal meat intake and iron status [17]. By improving the iron status, positive effects can be seen on growth and development, cognitive function, immunity, thermoregulation, physical activity, and fatigue[18, 19]. Another aspect is absorption and bioavailability. Beef contains high amounts of iron and zinc, but can also increase iron and zinc absorption from fibre and phytate-rich plant food [20]. Green vegetables are also relatively high in calcium, iron and zinc (Table 3 ).

\section{Vitamins}

Vitamins have multiple functions and are involved in metabolic processes (vitamins B1, $B 12$, and $C$ ), vision (vitamin $A$ ), infections (vitamins $A$ and $D$ ), genome expression and growth (vitamin $\mathrm{A}$ ), antioxidant function (vitamins $\mathrm{C}$ and $\mathrm{E}$ ), collagen formation (vitamin C), hormone regulation (vitamin D), cell differentiation and antiproliferative actions (vitamin D), bone health (vitamin D), protection of polyunsaturated fatty acids in cell membranes (vitamin E), and prevention of megaloblastic anaemia (vitamin B12)[9].

Beef contains higher amounts of vitamins A, D, and B12 (Table 4) as compared to pork and chicken. Despite these absolute low amounts of vitamins, beef is the most important source of vitamin D and contributes $25-35 \%$ of the vitamin D intake in children. Milk is the other important vitamin D contributor with $28 \%$, especially in young children (1-3 years old)[21]. Green vegetables are good sources of vitamins A, $\mathrm{B} 1$, and $\mathrm{K}$.

The NEVO tables do not include flavonoids or anthocyanins, which are also abundantly present in green vegetables. 
Table 3. Mineral and salt content. _= no values available in the NEVO tables[7].

\begin{tabular}{|c|c|c|c|c|c|c|}
\hline & $\begin{array}{l}\text { Sodium } \\
\mathrm{mg}\end{array}$ & $\begin{array}{l}\text { Potassium } \\
\mathrm{mg}\end{array}$ & $\begin{array}{l}\text { Calcium } \\
\mathrm{mg}\end{array}$ & $\begin{array}{l}\text { Total iron } \\
\mathrm{mg}\end{array}$ & $\begin{array}{l}\text { Zinc } \\
\mathrm{mg}\end{array}$ & $\begin{array}{l}\text { lodine } \\
\mu \mathrm{g}\end{array}$ \\
\hline $\begin{array}{l}\text { Beef rump steak } \\
\text { prepared }\end{array}$ & 53 & 561 & 10 & 2.8 & 5.53 & 2.5 \\
\hline Beef rib steak prepared & 63 & 429 & 14 & 3.6 & 11.21 & 4.3 \\
\hline Chicken filet prepared & 53 & 419 & 7 & 0.7 & 0.74 & 8.0 \\
\hline Pork filet prepared & 57 & 500 & 6 & 0.5 & 1.91 & 0.9 \\
\hline Spinach cooked & 15 & 418 & 84 & 2.4 & 1.2 & 2 \\
\hline Peas frozen cooked & 6 & 163 & 32 & 1.8 & 0.8 & 2 \\
\hline Chicory cooked & 10 & 183 & 24 & 0.2 & 0.17 & 0.4 \\
\hline Cauliflower cooked & 3 & 224 & 25 & 0.3 & 0.26 & 2.5 \\
\hline Carrots cooked & 26 & 214 & 28 & 0.2 & 0.24 & 2.5 \\
\hline Butter unsalted & 5 & 27 & 17 & 0.1 & 0.09 & 1.5 \\
\hline $\begin{array}{l}\text { Margarine } 80 \% \text { fat }<24 \mathrm{~g} \\
\text { sat FA unsalted }\end{array}$ & 0 & 42 & 10 & 0.1 & trace & 1.5 \\
\hline $\begin{array}{l}\text { Cooking fat liquid } 97 \% \\
\text { fat unsalted }\end{array}$ & 43 & 42 & 10 & 0.1 & 0 & 1.5 \\
\hline Olive oil & 0 & 0 & 0 & 0 & 0 & - \\
\hline Milk $3.4 \%$ fat & 42 & 163 & 124 & 0 & 0.46 & 14.9 \\
\hline Milk $1.5 \%$ fat & 42 & 160 & 123 & 0 & 0.41 & 14.9 \\
\hline Buttermilk & 36 & 136 & 109 & 0 & 0.41 & 14.9 \\
\hline Sweetened dairy drink & 45 & 135 & 103 & 0 & 0.37 & 14 \\
\hline Yoghurt drink (Optimel) & 42 & 143 & 100 & 0 & 0.19 & 12 \\
\hline
\end{tabular}

Sat FA=saturated Fatty Acids

\section{Diet and the immune system}

The role of nutrition and immunology is well known. All components of nutrition, including micronutrients, vitamins, fats, fibre, proteins and flavonoids have their specific role in immunity[22]. Micronutrients and vitamins serve as regulators in the immune system and are potent immunomodulatory agents [23]. Fatty acids can serve both as pro-inflammatory and anti-inflammatory agents, depending on the source, characteristics and origin of the fatty acids[24-26]. The aforementioned components are well described [27-31], but less is known about the role of fibre, proteins and flavonoids in immunology. 
$18 \mid$ Chapter 1

Table 4. Vitamin content of components dietary advice as compared to other food products.

\begin{tabular}{|c|c|c|c|c|c|c|c|c|c|c|}
\hline & \multicolumn{5}{|c|}{ Vit } & \multirow{2}{*}{$\begin{array}{l}\text { Vit } \\
\mathrm{K}\end{array}$} & \multirow{2}{*}{$\begin{array}{l}\text { Vit } \\
\text { K1 }\end{array}$} & \multirow{2}{*}{$\begin{array}{l}\text { Vit } \\
\text { B1 }\end{array}$} & \multicolumn{2}{|l|}{ Vit } \\
\hline & RAE & Retinol & D & Vit E & Btoc & & & & B12 & Vit C \\
\hline & $\mu \mathrm{g}$ & $\mu g$ & $\mu g$ & $\mathrm{mg}$ & $\mathrm{mg}$ & & $\mu g$ & $\mathrm{mg}$ & $\mu g$ & $\mathrm{mg}$ \\
\hline Beef rump steak prepared & 25 & 23 & 0.5 & 1.0 & 0 & - & - & 0.05 & 1.70 & 0 \\
\hline Beef rib steak prepared & 29 & 27 & 0.6 & 1.0 & 0 & - & _- & 0.02 & 1.81 & 0 \\
\hline Chicken filet prepared & 18 & 18 & 0.2 & 1.1 & 0 & - & - & 0.08 & 0.29 & 0 \\
\hline Pork filet prepared & 14 & 14 & 0.3 & 1.0 & 0 & - & - & 0.75 & 0.34 & 0 \\
\hline Spinach cooked & 324 & 0 & 0 & 3.5 & 0 & 575 & 575 & 0.06 & 0 & 7 \\
\hline Peas frozen cooked & 38 & 0 & 0 & 0.2 & 0 & 36 & 36 & 0.24 & 0 & 14 \\
\hline Chicory cooked & 1 & 0 & 0 & 0.2 & 0 & - & - & 0.07 & 0 & 0 \\
\hline Cauliflower cooked & 0 & 0 & 0 & 0.1 & 0 & 28.5 & 28.5 & 0.02 & 0 & 22 \\
\hline Carrots cooked & 847 & 0 & 0 & 0.8 & 0.1 & 7.4 & 7.4 & 0.03 & 0 & 3 \\
\hline Butter unsalted & 867 & 829 & 0.3 & 1.9 & 0.1 & 29.9 & 14.9 & 0.01 & 0.3 & 0 \\
\hline $\begin{array}{l}\text { Margarine } 80 \% \text { fat }<24 \mathrm{~g} \\
\text { sat FA unsalted }\end{array}$ & $800^{*}$ & $800^{*}$ & $7.5^{*}$ & - & - & - & - & trace & trace & trace \\
\hline $\begin{array}{l}\text { Cooking fat liquid } 97 \% \text { fat } \\
\text { unsalted }\end{array}$ & $795^{*}$ & $795^{*}$ & $7.5^{*}$ & $32.1^{*}$ & _ & _ & _ & 0 & 0 & 0 \\
\hline Olive oil & 2 & 0 & 0 & 5.1 & - & 53.7 & 53.7 & 0 & 0 & 0 \\
\hline Milk $3.4 \%$ fat & 35 & 34 & 0 & 0.1 & 0 & 1.4 & 0.5 & 0.03 & 0.40 & 0 \\
\hline Milk $1.5 \%$ fat & 16 & 16 & 0 & 0 & 0 & 0.7 & 0.3 & 0.04 & 0.45 & 1 \\
\hline Buttermilk & 2 & 2 & 0 & 0 & 0 & 2.5 & 0 & 0.02 & 0.17 & 0 \\
\hline Sweetened dairy drink & 15 & 14 & 0 & 0 & 0 & 0.6 & 0.2 & 0.03 & 0.18 & 2 \\
\hline Yoghurt drink (Optimel) & 1 & trace & 0 & _ & _ & _ & _- & 0.03 & 0.27 & 1 \\
\hline
\end{tabular}

$\mathrm{RAE}=$ retinol activity equivalence, $\mathrm{Btoc}=$ beta-tocopherol, $=$ no values available in the NEVO tables[7].

Sat $F A=$ saturated Fatty Acids

Dietary fibre contributes to a healthy gut, which includes microbiology, antiinflammatory effects and innate and adaptive immune responses [32]. They show their effect because of cytokine modulation. Dietary fibre stimulates the expression of anti-inflammatory cytokines and decreases the expression of pro-inflammatory cytokines[33]. In humans, dietary fibre can be found in whole grain products, fruits, (green) vegetables and nuts. Diets high in fruits and vegetables show lower levels of inflammatory markers in adolescent boys and adults[34-36]. Dietary fibre is also known as prebiotics. 
Table 5. Summary of the nutritional composition of the dietary advice[7].

$\begin{array}{ll}\begin{array}{l}\text { Component } \\ \text { dietary advice }\end{array} & \begin{array}{l}\text { Substantial amounts of } \\ \text { Beef }\end{array} \\ \begin{array}{ll}\text { Amino acids, minerals (iron, zinc, cupper), fat soluble vitamins, vitamin } \\ \text { Breen vegetables }\end{array} & \begin{array}{l}\text { Water soluble vitamins, minerals (iron, zinc), dietary fibre, flavonoids, } \\ \text { chloroplasts }\end{array} \\ \text { Whole milk } & \begin{array}{l}\text { Amino acids, favourable composition omega-3 and -6 fatty acids, fat } \\ \text { soluble vitamins }\end{array} \\ \text { Butter } & \text { Favourable composition omega-3 and }-6 \text { fatty acids, fat soluble vitamins }\end{array}$

Amino acids (found in animal and plant food, such as meat, dairy products, soy beans and legumes) were traditionally seen as building blocks for proteins, but they are also essential for the immune system. Protein malnutrition decreases concentrations of several amino acids and also impairs the immune system in the developed world[37, 38]. They act in their function as building blocks; several amino acids are responsible for the synthesis of specific proteins (including antibodies and cytokines), but they regulate more processes. Their roles in the immune system are 1) the activation of B- and T- lymphocytes, natural killer cells, and macrophages; 2) lymphocyte proliferation; and 3) the production of antibodies, cytokines and cytotoxic substances. These functions and the role of each specific amino acid are reviewed by Li et al. [39]. Animal products usually are responsible for the largest amount of amino acid intake[40].

Flavonoids are phytonutrients and mainly known as plant pigments, which are the compounds that colour plant products yellow, red or blue. There are around 6000 plant flavonoids known, and they are present in large amounts in fruit, vegetable, cocoa, wine, tea and soy[41, 42]. Subtypes are anthocyanidins, anthoxanthins, flavanones, flavanonols, flavans and isoflavonoids. Flavonoids exhibit antimicrobial, antioxidant, and anti-inflammatory activities[43]. There is evidence from in vitro experiments that flavonoid molecules modulate immune processes by inhibition of Th1 cytokine production[44]. In vivo however, these results are difficult to replicate. Studied immune markers, such as IL-6 and TNF-alpha, were greatly influenced in the in vitro study, but to a lesser extent in vivo as reviewed by Peluso et al. Remarkably, the authors note that the effects were more pronounced in people with a disease as compared to healthy subjects, therefore suggesting that the influence of flavonoid-rich foods on immunity might be more effective in subjects with a more challenged immune system as compared to healthy people with a low degree of inflammation[45].

A self-standing entity are the chloroplasts. They are cell organelles and only found in plants. Their main function is photosynthesis, in which the energy of sunlight is 
converted and stored in energy (ATP and NADPH) with the production of oxygen. Chloroplasts play a crucial role in plant defence, together with the nucleus, cell membrane and endoplasmic reticulum[46]. Besides that, they have anti-inflammatory qualities[47]. Chloroplasts synthesize all the fatty acids in the plant cell. One of these is linoleic acid, which is one of the two essential fatty acids for humans. It is a precursor for omega-3 fatty acids and also modulates COX-2 mechanisms [46, 48]. Chloroplasts also contain carotenoids, cell pigments that inhibit the COX-2 pathway and therefore inhibit pro-inflammatory mechanisms[48].

Green vegetables are green because of the presence of chloroplasts. Especially in dark green vegetables, other plant pigments (yellow, orange and red) are overshadowed by the dark green colour and not visible, but still present.

Since all the components of nutrition have their own specific role, complement each other, and interact in the immune system, we believe the effects of nutrition cannot be split up into equal parts. Illustrative for the complexity of food are the contents of the NEVO tables. These tables contain multiple macro- and micronutrients, but do not contain fibre or flavonoids. The NEVO tables would be too elaborate if they would contain all possible beneficial contents of nutrition.

We hypothesize the effect of nutrition is more than the sum of all the different components (food synergy). The overarching effect of nutrition can only be investigated with whole food (nutrients in their food matrix) or dietary advice, not with supplements or a single nutrient.

\section{OUTLINE OF THE THESIS}

In Chapter 2, we reviewed the influence of food on the duration and prevention of recurrent URTIs. It is the only study that involves both children and adults. We searched for randomized controlled trials, meta-analyses and case-control studies for all kinds of whole foods, including fruits, dairy, probiotics, fats, et cetera. Our focus was on whole foods, which can be bought in a supermarket and are broadly available in developed countries.

Chapter 3, 4 and 5 contain retrospective case-control studies. In 2010, we developed the investigated dietary advice. This dietary advice consisted of age appropriate portions of green vegetables, beef, whole milk and butter. Chapter 3 outlines the effects of the dietary advice on non-specific elevated IgE levels and clinical symptoms. 
Chapter 4 describes the results of the dietary advice on fatigue in otherwise healthy children. Chapter $\mathbf{5}$ is a retrospective study about changes in the lipid profile in children after introducing this dietary advice. These children all had different reasons for starting with this diet.

The next two chapters describe randomized controlled trials. Chapter 6 describes a randomized controlled trial of the dietary advice in 120 children with recurrent URTIs. The effect of coughing, running or blocked nose, fever, sore throat, otitis and visits to the doctor were investigated. Besides that, the possible negative effects on growth (body mass index (BMI)) and lipid profile were studied.

In chapter 7, we investigated the effect of the dietary advice on children with SH. We examined the effect on thyroid function (thyroid hormones and presence of antithyroid antibodies), lipid profile and growth parameters (weight, height and BMI). In addition, we studied the effect of the dietary advice on tiredness, the most common clinical complaint of children in our study with $\mathrm{SH}$.

Chapter 8 contains the discussion about the findings of the different studies and what it can imply for the patients. Also, future directions and recommendations are mentioned.

In chapter 9, a summary of the contents of this thesis is presented, also in Dutch. 


\section{REFERENCES}

1. M. Sato, H. Li, M.R. Ikizler, J.A. Werkhaven, J.V. Williams, J.D. Chappell, Y.W. Tang, P.F. Wright, Detection of viruses in human adenoid tissues by use of multiplex PCR, J Clin Microbiol 47(3) (2009) 771-3.

2. S. Herberhold, A.M. Eis-Hubinger, $M$. Panning, Frequent detection of respiratory viruses by real-time PCR in adenoid samples from asymptomatic children, J Clin Microbiol 47(8) (2009) 2682-3.

3. Voedingscentrum, example diet for young children, The Netherlands Nutrition Centre, https://www.voedingscentrum.nl/nl/mijn-kind-en-ik/ dreumes-en-peuter/voorbeelddagmenu-voor-dreumes-en-peuter.aspx, 2019.

4. C. de Jong-Rubingh, R.A. BauschGoldbohm, Hoe gezond eten ze? De resultaten van het voedselconsumptieonderzoek onder peuters die naar het kinderdagverblijf gaan, Nutricia Early Life Nutrition2015.

5. N. Van Droffelaar, E.J. van der Gaag, Kan eetpatroon een reden tot kwakkelen zijn?, Nederlandse Vereniging van Kindergeneeskunde congres, Veldhoven, The Netherlands, 2008.

6. M. Munow, E.J. van der Gaag, Ailing Toddlers. Is there a relation between behaviour and health?, 27th ESPID Meeting, Brussels, Belgium, 2009.

7. NEVOtables, Dutch Food Composition Database, 2019.

8. L. Wyness, The role of red meat in the diet: nutrition and health benefits, Proc Nutr Soc 75(3) (2016) 227-32.

9. E.F.S.A. (EFSA), Dietary Reference Values for nutrients Summary report, 2017. https: / /www.efsa.europa.eu/sites/ default/files/2017_09_DRVs_summary_report.pdf. (Accessed 02-11-2019 2019).
10. J.C. Kostyak, P. Kris-Etherton, D. Bagshaw, J.P. DeLany, P.A. Farrell, Relative fat oxidation is higher in children than adults, Nutr J 6 (2007) 19.

11. N.F. Butte, Fat intake of children in relation to energy requirements, Am J Clin Nutr 72(5 Suppl) (2000) 1246S$1252 S$.

12. J. Lunn, H.E. Theobald, The health effects of dietary unsaturated fatty acids, Nutrition bulletin 31(3) (2006) 178-224.

13. J.B. German, C.J. Dillard, Saturated fats: a perspective from lactation and milk composition, Lipids 45(10) (2010) 915-23.

14. W.C. Willett, M.J. Stampfer, J.E. Manson, G.A. Colditz, F.E. Speizer, B.A. Rosner, L.A. Sampson, C.H. Hennekens, Intake of trans fatty acids and risk of coronary heart disease among women, Lancet 431(8845) (1993) 581-585.

15. J. Lyons, C. Cocking, L. Kehoe, B.A. McNulty, A.P. Nugent, J. Walton, K. Cashman, A. Flynn, The role of unprocessed beef and lamb in the diets of Irish children and teenagers (5-17 years), FENS (Federation of European Nutrition Societies, Proceedings of the Nutrition Society, Dublin, 2019.

16. G. Cleghorn, Role of red meat in the diet for children and adolescents, Nutrition and dietetics 64(Suppl. 4) (2007) S143-S146.

17. J. Jackson, R. Williams, M. McEvoy, L. MacDonald-Wicks, A. Patterson, Is Higher Consumption of Animal Flesh Foods Associated with Better Iron Status among Adults in Developed Countries? A Systematic Review, Nutrients 8(2) (2016) 89.

18. A. Patterson, M. Blumfield, Iron Deficiency and its prevention in the Australian context: A systematic review of the Literature, in: S.o.H.S. Department of Nutrition and Dietetics, University 
of Newcastle (Ed.) Meat \& Livestock Australia, Meat and Livestock Australia Limited, Australia, 2009.

19. C. Geissler, M. Singh, Iron, meat and health, Nutrients 3(3) (2011) 283-316.

20. R.S. Gibson, Content and bioavailability of trace elements in vegetarian diets, Am J Clin Nutr 59(5 Suppl) (1994) 1223S-1232S.

21. B. Bates, A. Lennox, A. Prentice, C. Bates, P. Page, S. Nicholson, G. Swan, National Diet and Nutrition Survey Results from Years 1, 2, 3 and 4 (combined) of the Rolling Programme (2008/2009 - 2011/2012), National Diet and Nutrition Survey, Public Health England, London, UK, 2014.

22. P.C. Calder, P. Yaqoob, Diet, immunity and inflammation, Woodhead Publishing Limited, Cambridge, UK, 2013.

23. I. Elmadfa, A.L. Meyer, The Role of the Status of Selected Micronutrients in Shaping the Immune Function, Endocr Metab Immune Disord Drug Targets (2019).

24. K.L. Fritsche, The science of fatty acids and inflammation, Adv Nutr 6(3) (2015) 293S-301S

25. M. Li, B. van Esch, G.T.M. Wagenaar, J. Garssen, G. Folkerts, P.A.J. Henricks, Pro- and anti-inflammatory effects of short chain fatty acids on immune and endothelial cells, Eur J Pharmacol 831 (2018) 52-59.

26. J. Tan, C. McKenzie, M. Potamitis, A.N. Thorburn, C.R. Mackay, L. Macia, The role of short-chain fatty acids in health and disease, Adv Immunol 121 (2014) 91-119.

27. C.J. Field, I.R. Johnson, P.D. Schley, Nutrients and their role in host resistance to infection, J Leukoc Biol 71(1) (2002) 16-32.

28. S. Gutierrez, S.L. Svahn, M.E. Johansson, Effects of Omega-3 Fatty Acids on Immune Cells, Int J Mol Sci 20(20) (2019).

29. A. Skrobot, U. Demkow, M. Wachowska, Immunomodulatory Role of Vitamin D: A Review, Adv Exp Med Biol 1108 (2018) 13-23.

30. A.C. Carr, S. Maggini, Vitamin C and Immune Function, Nutrients 9(11) (2017).

31. K. Nishida, R. Uchida, Role of Zinc Signaling in the Regulation of Mast Cell-, Basophil-, and T Cell-Mediated Allergic Responses, J Immunol Res 2018 (2018) 5749120.

32. R. Jha, J.M. Fouhse, U.P. Tiwari, L. Li, B.P. Willing, Dietary Fiber and Intestinal Health of Monogastric Animals, Front Vet Sci 6 (2019) 48.

33. P. Shokryazdan, M. Faseleh Jahromi, B. Navidshad, J.B. Liang, Effects of prebiotics on immune system and cytokine expression, Med Microbiol Immunol 206(1) (2017) 1-9.

34. E.M. Holt, L.M. Steffen, A. Moran, S. Basu, J. Steinberger, J.A. Ross, C.P. Hong, A.R. Sinaiko, Fruit and vegetable consumption and its relation to markers of inflammation and oxidative stress in adolescents, J Am Diet Assoc 109(3) (2009) 414-21.

35. J. Salas-Salvado, A. Garcia-Arellano, R. Estruch, F. Marquez-Sandoval, D. Corella, M. Fiol, E. Gomez-Gracia, E. Vinoles, F. Aros, C. Herrera, C. Lahoz, J. Lapetra, J.S. Perona, D. MunozAguado, M.A. Martinez-Gonzalez, E. Ros, P. Investigators, Components of the Mediterranean-type food pattern and serum inflammatory markers among patients at high risk for cardiovascular disease, Eur J Clin Nutr 62(5) (2008) 651-9.

36. A. Nanri, D. Yoshida, T. Yamaji, T. Mizoue, R. Takayanagi, S. Kono, Dietary patterns and $\mathrm{C}$-reactive protein in Japanese men and women, Am J Clin Nutr 87(5) (2008) 1488-96. 
37. B. Woodward, Protein, calories, and immune defenses, Nutr Rev 56(1 Pt 2) (1998) S84-92.

38. M. Dasgupta, J.R. Sharkey, G. Wu, Inadequate intakes of indispensable amino acids among homebound older adults, J Nutr Elder 24(3) (2005) 85-99.

39. P. Li, Y.L. Yin, D. Li, S.W. Kim, G. Wu, Amino acids and immune function, $\mathrm{Br} \mathrm{J}$ Nutr 98(2) (2007) 237-52.

40. H. Gorska-Warsewicz, W. Laskowski, O. Kulykovets, A. Kudlinska-Chylak, M. Czeczotko, K. Rejman, Food Products as Sources of Protein and Amino AcidsThe Case of Poland, Nutrients 10(12) (2018).

41. S.A. Aherne, N.M. O'Brien, Dietary flavonols: chemistry, food content, and metabolism, Nutrition 18(1) (2002) 7581.

42. J. Perez-Jimenez, V. Neveu, F. Vos, A. Scalbert, Systematic analysis of the content of 502 polyphenols in $\mathbf{4 5 2}$ foods and beverages: an application of the phenol-explorer database, J Agric Food Chem 58(8) (2010) 4959-69.

43. A. Crozier, I.B. Jaganath, M.N. Clifford, Dietary phenolics: chemistry, bioavail- ability and effects on health, Nat Prod Rep 26(8) (2009) 1001-43.

44. E.A. Miles, P. Zoubouli, P.C. Calder, Effects of polyphenols on human Th1 and Th2 cytokine production, Clin Nutr 24(5) (2005) 780-4.

45. I. Peluso, C. Miglio, G. Morabito, F. loannone, M. Serafini, Flavonoids and immune function in human: a systematic review, Crit Rev Food Sci Nutr 55(3) (2015) 383-95.

46. M.S. Padmanabhan, S.P. Dinesh-Kumar, All hands on deck-the role of chloroplasts, endoplasmic reticulum, and the nucleus in driving plant innate immunity, Mol Plant Microbe Interact 23(11) (2010) 1368-80.

47. L. Lahouar, S. El-Bok, L. Achour, Therapeutic Potential of Young Green Barley Leaves in Prevention and Treatment of Chronic Diseases: An Overview, Am J Chin Med 43(7) (2015) 1311-29.

48. S.J. Desai, B. Prickril, A. Rasooly, Mechanisms of Phytonutrient Modulation of Cyclooxygenase-2 (COX-2) and Inflammation Related to Cancer, Nutr Cancer 70(3) (2018) 350-375. 



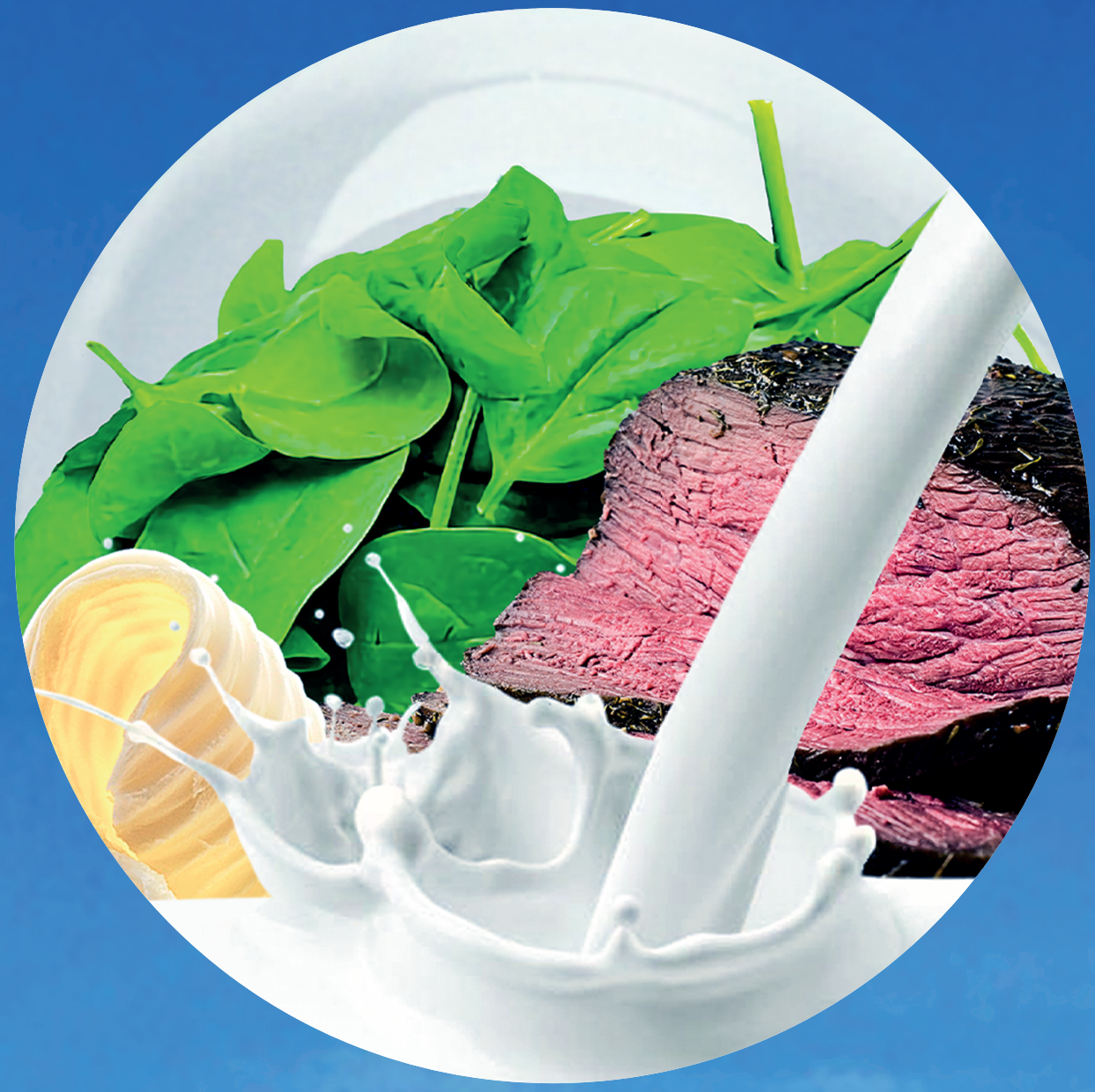




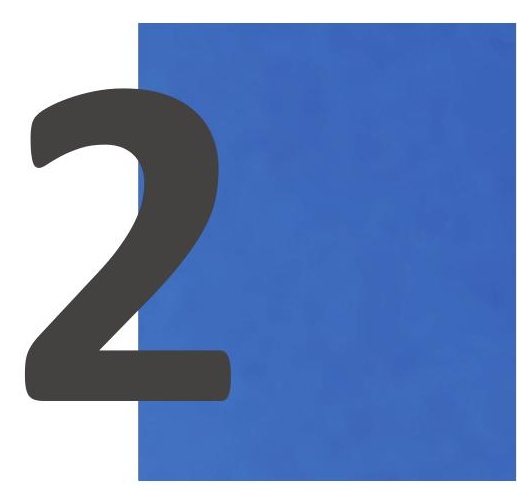

Food or medication? The therapeutic effects of food on the duration and incidence of upper respiratory tract infections: a review of the literature 


\section{ABSTRACT}

Purpose: Upper respiratory tract infections are common in children and adults. Antiviral treatments are only available for specific groups of patients, stimulating the distribution of over-the-counter medication to relieve the symptoms for the other patients. Studies about whole foods and their effect on the incidence and duration of upper respiratory tract infections were reviewed.

Methods: Randomised controlled trials and case-control studies available on MEDLINE, Web of Science, Cochrane Library and Embase were included.

Results: Thirty studies were included. The incidence of respiratory infections or symptoms was shown to be reduced in some studies when probiotics, prebiotics, growing-up milk, fish oil, kiwi, garlic and xylitol were taken. Duration was favourably influenced by the intake of elderberry, kiwi, probiotics and fish oil. Prudent conclusions can be made in selective patient groups. However, the studies were diverse and were only performed by a few study groups.

Conclusions: Food intervention studies are promising for reducing the incidence and duration of upper respiratory tract infections. However, further research is necessary to make clear and widespread conclusions. 


\section{INTRODUCTION}

Acute respiratory infections, including upper and lower respiratory infections, are the most common illnesses in children worldwide [1], and also the main infectious reason that adults visit the emergency department [2]. These infections are largely caused by viruses and are usually self-limiting. In severe infections, only a few antiviral drugs, like zanamivir or oseltamivir, are available for treatment. Since the infections are very common and only severe infections are treated with anti-viral drugs, most patients use over-the-counter drugs like cough syrup or painkillers to relieve the symptoms. However, are there also natural products, such as food, that can decrease the duration of the infection or influence the incidence of the infection?

In Chinese children, food intake has been shown to have an effect on respiratory infections. Mao et al. showed the relation of daily food intake and recurrent respiratory infections through the hair analysis of iron, zinc and copper levels. Children with the lowest levels of hair iron, zinc or copper, indicating a lower nutritional intake, showed more recurrent respiratory tract infections compared to healthy controls, according to this meta-analysis [3]. This study reflects the importance of adequate and varied nutrition over a long period of time in preventing respiratory tract infections.

Food synergy is defined as the combined action of health compounds within foods and of foods working together [4]. This consists not of a single component but of multiple components, all influenced or not by each other. Food consists of macronutrients, i.e., fats, proteins and carbohydrates. Food also includes micronutrients like minerals and vitamins. Besides these well-known components, food also contains components like signal transducers, hormones, sterols, enzymes and enzyme inhibitors, polyphenols and fungicides, among others. These compounds are used by the plant or animal to stay alive and to protect itself against diseases or pathogens [5]. It is now believed that the phytochemicals in plant-based foods are responsible for beneficial health effects. Phytochemicals are plant-derived compounds, which are not considered essential for nutrition nor do they have nutritional value. Approximately 20,000 phytochemicals have been described in plants [6]. Specific phytochemicals responsible for the colour of a plant/vegetable or fruit, such as anthocyanins, carotenoids, lycopene or chlorophyll, are thought to have an effect on health $[7,8]$. The principle of food synergy shows that the combined action of different nutrients has a greater biological effect than the sum of the biological effects acquired by individual nutrients [9].

Different strategies in which food influences the human defence mechanism against pathogens has been previously described. Many berries and plants have antimicrobial 
compounds that can respond to microbial invasion and may modulate the bacterial flora when ingested. Berries like blueberries, lingonberries and cranberries have antibacterial effects against human pathogens $[10,11]$.

Other food components, such omega-3 fatty acids in oily fish or cod liver oil, have immunomodulatory capacities [12]. Another way in which food can be used as a defence against pathogens is to increase the amounts of antioxidants (kiwi) or to strengthen the local, innate or adapted immune system (probiotics). Xylitol can inhibit the growth of Streptococcus pneumoniae [13], possibly via the fructose phosphotransferase system.

With this extended literature review, we describe evidence of the effect of natural everyday food on the duration and incidence of respiratory tract infections in children and adults. Reviews about single foods, like elderberry, probiotics, etc., can be found in the literature. However, to our knowledge, no reviews have been conducted about upper respiratory tract infections and the possible effects of different types of food groups on a specific infection. We did not include studies about supplements or single vitamins, since that does not reflect daily life situations. Instead, we included studies with whole food, pureed food or extracts to review the possible effect of food synergy.

\section{METHODS}

\section{Literature search and study selection}

We systematically searched the Cochrane Library, MEDLINE, Embase and Web of Science up to November 2018. Studies on respiratory infections were identified with the search terms: "respiratory infections", "flu" and "common cold" (both as medical subject headings (MeSH) and free text terms). These were combined, using the set operator "AND", with the terms: "nutrition", "nutritional intervention”, "natural food", "vegetables”, “meat”, “dairy”, “fruits”, “berries”, “fish”, “egg” or "oil” (MeSH or free text terms). Additional strategies for identifying studies included searching the reference lists of the articles included. Acute otitis media (AOM) is often seen as a complication of an upper respiratory tract infection (URTI), therefore, studies found on this subject were also included in this review (Figure 1).

Abstracts were screened for eligibility. Potential eligible studies were retrieved and read in full to assess whether they fulfilled all the inclusion criteria. Inclusion criteria were: (1) children aged 1-18 years or adults; (2) with respiratory tract infections or prone to respiratory infections; (3) not hospitalised or mechanically ventilated, but in an outpatient setting; (4) the food studied should be freely available (e.g. in super- 
markets); (5) the studies should be randomised controlled trials or non-randomised controlled trials.

The screening was conducted by two reviewers (EvdG and TH). Disagreement between the reviewers was resolved by consensus when possible, or by consulting a third reviewer to make the final decision.

\section{RESULTS}

\section{Study selection}

A total of 2688 papers were identified, of which 179 were retrieved for full text review. After reading the full text, 150 studies were excluded (Figure 1). Tables 1,2 and 3 list the characteristics of the remaining 30 studies, which included 25

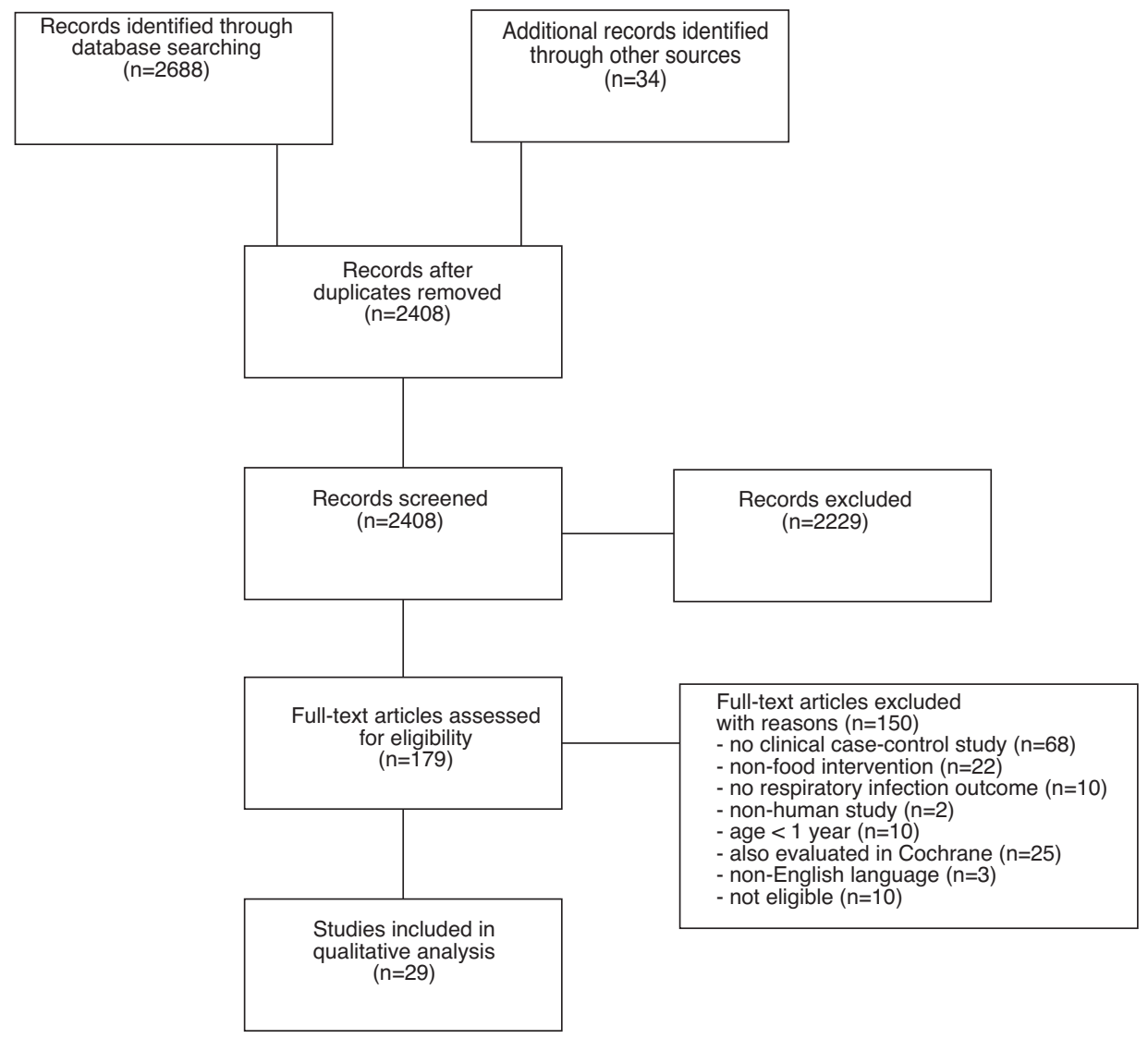

Figure 1. Inclusion flow chart. 

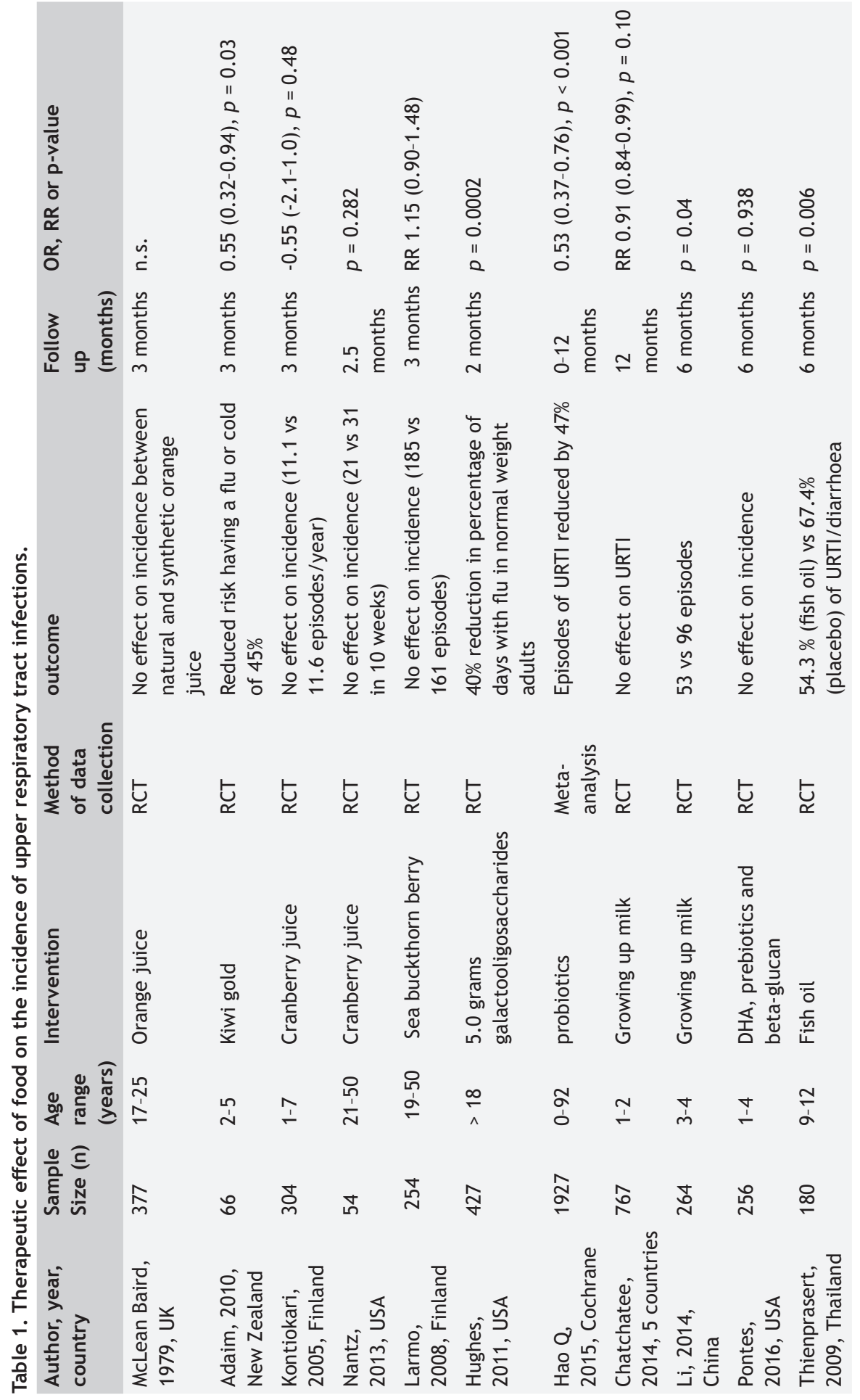







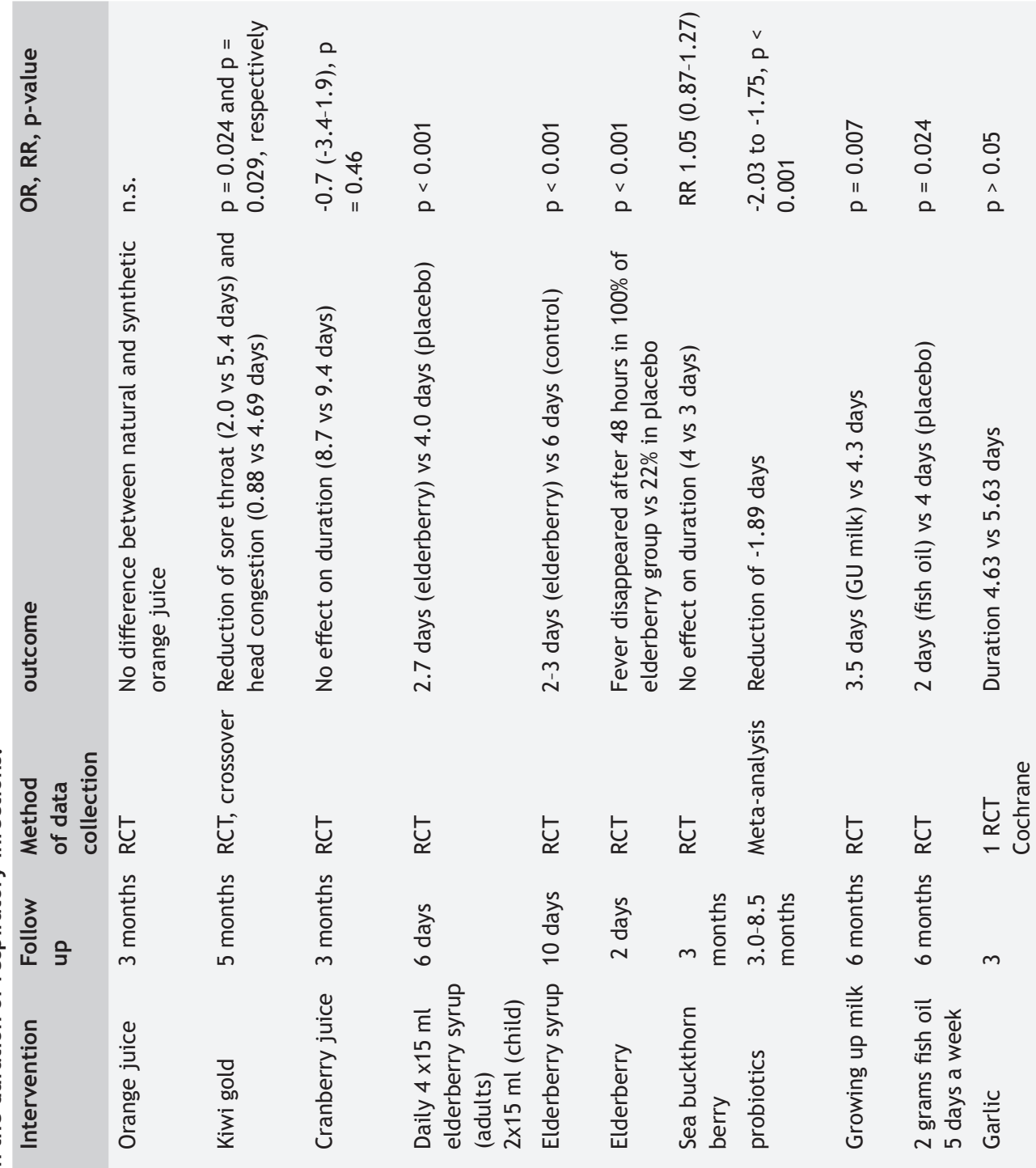

ธ

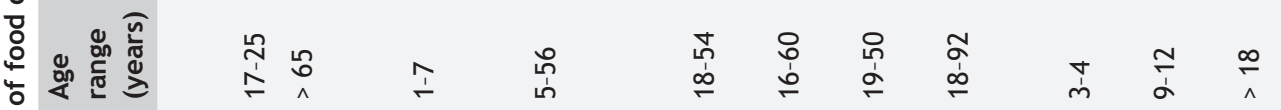

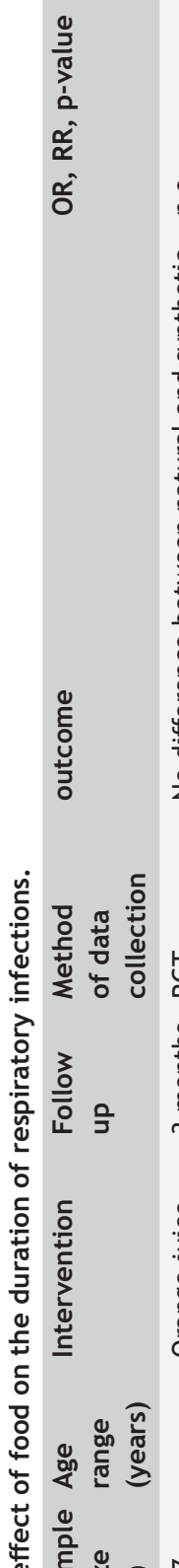

ஸึ่

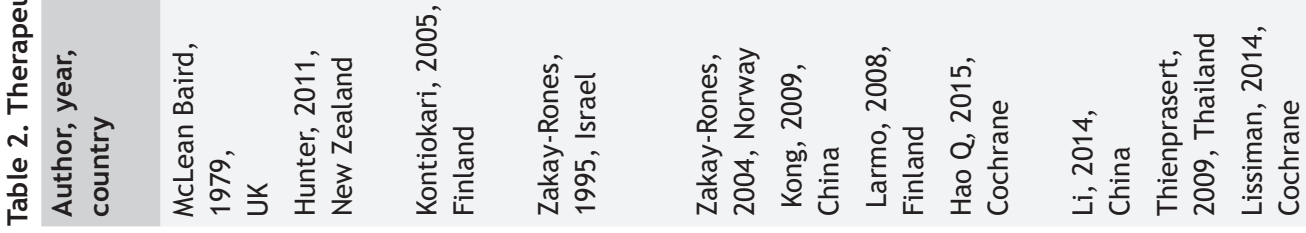


randomised controlled trials and 1 case-control trial, 1 pretest-posttest design study and 3 Cochrane meta-analysis. One Cochrane analysis consisted of just one study, therefore, the original study was evaluated in the review.

The clinical diversity between the studies was large with regards to the studied food and studied population. Therefore, the study data could not be compared for a metaanalysis. We evaluated all studies for the risk of bias (Table 4), and half of the studies had a low risk of bias.

\section{Fruits}

\section{Orange juice}

The oldest study concerning respiratory infections and fruit was conducted in 1979 and investigated how orange juice affected symptoms of the common cold. This study examined the effects of the daily intake of $180 \mathrm{ml}$ of synthetic orange juice (no vitamin ( added), synthetic orange juice with $80 \mathrm{mg}$ artificial added vitamin $\mathrm{C}$, or natural orange juice with $80 \mathrm{mg}$ of natural vitamin C, in 362 young adults (ages 17-25 years) for a period of 72 days [14]. Symptoms of the common cold were noted daily by the participants. The total symptoms recorded by the participants, the duration and number of episodes of illness in that winter period significantly favoured both natural orange juice and synthetic orange juice with added vitamin C. Natural orange juice contains flavonoids as well as vitamin $\mathrm{C}$. Other studies have indicated that flavonoids can modify the metabolism of vitamin C under defined experimental conditions [15] and potentiate its nutritional activity. In the study from 1979, the effect of natural orange juice (containing both flavonoids and vitamin C) was not superior to that of synthetic orange juice which contained just high doses of vitamin $\mathrm{C}$ and no flavonoids. Vitamin $C$ is known to stimulate the immune system (increase the activity of natural killer (NK) cells, lymphocyte proliferation, chemotaxis and as an antioxidant) as reviewed by the groups of Ran et al. and Wintergerst et al. $[16,17]$.

\section{Kiwifruit}

In mouse models, puree kiwifruit (gold) has been shown to enhance immune function by stimulating antigen-specific antibody production (total Ig and lgG) and the proliferation of mesenteric lymph node cells in the gut. Kiwifruit also modulates markers of innate immune function (phagocytosis, oxidative burst, T-cell activation, cytokine production and NK cells) $[18,19]$. Two randomised crossover studies were performed using kiwifruit (and banana as control fruit) as the intervention for respiratory infections. For 32 healthy adults aged over 65 years, the intervention consisted of consuming four gold kiwifruits or two bananas daily for four weeks. For 66 children 
aged 2-5 years, the intervention consisted of two gold kiwifruits or one banana, five days a week, also for four weeks.

In the adult population, the incidence of URTI did not decrease in the kiwifruit period, but the symptoms during the respiratory tract infection were reduced. The severity and incidence of a sore throat and head congestion were reduced significantly.

The adult study was supported by laboratory research. Consumption of kiwifruit showed significantly higher blood levels of vitamin C, a-tocopherol, lutein/zeaxanthin and red blood cell folate compared to consuming bananas, therefore, suggesting that intake of vitamin-rich food can increase vitamin levels in humans and can strengthen the host by reducing infectious symptoms [20].

For children, the clinical differences were even more evident. The odds of not having a cold- and flu-like illness was 1.8 times greater during the kiwifruit segment of the intervention compared to the banana segment of the intervention (Odds Ratio (OR) $=0.55 ; 95 \%$ confidence interval $(\mathrm{Cl}) 0.32-0.94 ; p=0.03)$. When the symptoms were scored on a severity scale (Canadian Acute Respiratory Illness Flu Scale, CARIFS), functional complaints (i.e. symptoms that measure the impact of disease on the child's day-to-day activity) improved most in the kiwifruit period $(p=0.006)$. During the kiwifruit period, the children had a better appetite, felt better, had more energy and cried less than the period in which they are bananas [21].

\section{Cranberry}

Cranberry juice has an effective preventive capacity against urinary tract infections $[22,23]$. Cranberries produce antimicrobial compounds such as proanthocyanidins. These proanthocyanidins are thought to act by inhibiting the adhesion of Escherichia coli to uroepithelial cells. However, do these antimicrobial capacities also provide protection in respiratory tract infections? A randomised controlled trial was performed in 341 children aged 1-7 years who received five $\mathrm{ml} / \mathrm{kg}$ (up to $300 \mathrm{ml}$ ) of cranberry juice or a placebo per day, for three months.

The number of respiratory infections and the duration of symptoms did not differ between the cranberry group and the placebo group [24].

Oral bacterial carriage and the bacterial fatty acid composition in stools did not change, even though cranberries have been found to reduce the adhesion of some bacteria in vitro [24]. 
Another randomised double-blind, placebo-controlled study was performed in 45 healthy adults. The subjects drank $450 \mathrm{ml} /$ day of cranberry juice or a placebo for 10 weeks. In the cranberry group, the incidence of illness was not reduced, however, significantly fewer symptoms of cold and influenza were reported $(p=0.031)$. The duration of the illness, scored in days missed from work/school, did not differ between the two groups. Laboratory parameters showed the improved ability of gamma delta


as lower the production of an inflammatory cytokine, interleukin 6 (IL-6) [25].

\section{Elderberry}

Elderberry, or Sambucus nigra L., has been used in folk medicine as a remedy for the common cold and influenza [26]. Elderberry is reported to contain high doses of flavonoids and has antiviral [27], antioxidant, anti-inflammatory and immune-modulating capacities [28]. It contains anthocyanins, which are considered to be the active component of the elderberry [29]. Besides these components, elderberries are rich in vitamins (A, B1, B2, B6, B9, C and E), trace elements, minerals and phytochemicals, such as carotenoids, phytosterols and polyphenols [30].

Holst et al. reviewed the efficacy of elderberry extract in pregnant women. All clinical studies $(n=3)$ included in this review showed improvement. Although the total number of patients using the elderberry extract from all three studies was only 77 [31], symptoms were relieved significantly faster in all elderberry groups [31].

When given as an oral syrup to 60 adult Norwegian patients with proven influenza A or $B$ infection, the symptoms were relieved significantly earlier compared to the control group. The usage of painkillers and nasal sprays was also significantly less in the elderberry group [32]. A study in Panama showed that the same syrup also relieved the symptoms significantly earlier in 27 influenza B patients [33].

In China, 64 patients with flu symptoms were also treated with elderberry extract. A quick improvement was seen after $24 \mathrm{~h}$ in four of six symptom scores (headache, nasal congestion fever, muscle aches, but not cough or mucus discharge). After $48 \mathrm{~h}$, all six symptoms improved in the elderberry group, whereas the symptoms worsened in the placebo group [34].

In 312 economy class air travellers, the risk of developing a respiratory infection was present due to stressful circumstances and air conditioning. When the travellers took $300 \mathrm{mg}$ of elderberry extract 10 days prior to their overseas travel until 4 days 
after arrival, the incidence was not influenced, but the duration of the symptoms was influenced [30].

\section{Sea buckthorn berries}

Sea buckthorn berries were investigated in 254 healthy volunteers in a double blind, randomised placebo-controlled trial because of their known immunomodulatory properties and positive effects on health. They contain flavonoids and polyphenolic compounds, which influence the immune system and inflammatory cells, and they have antimicrobial properties. The frozen sea buckthorn puree contained $16.7 \mathrm{mg}$ of flavonol glycosides (mostly isorhamnetin) and low doses of vitamin C and E. No clinical effect was seen in the number or duration of respiratory tract infections in healthy volunteers [35].

\section{Dairy products, pre- and probiotics}

\section{Prebiotics}

Prebiotics are defined as "non-digestible food ingredients that beneficially affect the host by selectively stimulating the growth and/or activity of a limited number of bacterial species in the colon" [36]. Prebiotics like galacto- and fructooligosaccharides aim to increase the load of lactobacilli and bifidobacteria to promote health in the host [37]. They also increase faecal short chain fatty acids, which have been associated with decreased epithelial permeability [38]. In children, infant formula is usually supplemented with prebiotics, which is usually consumed by children younger than one year of age. These studies were excluded from this review since this age group was in the exclusion criterion. In adults, galactooligosaccharides are supplied in packets and can be mixed into any beverage. In the study by Hughes, 427 healthy students with stress due to their final exams took 2.5 or $5.0 \mathrm{~g}$ of prebiotics or placebo for eight weeks. There was no difference in the incidence of common cold or flu between the groups. However, galactooligosaccharide supplementation attenuated the cold/flu symptoms in specific groups (normal, healthy weight but not in obese subjects; moderately stressed but not at highly stressed) [39].

\section{Fermented dairy/probiotics}

Probiotics are defined as "live microorganisms administered in adequate amounts which confer a beneficial physiological effect on the host". The natural mechanism of action for probiotics is fermentation, one of the oldest techniques for preserving dairy food, and their natural occurrence is therefore in fermented food (yoghurt, cheese). Nowadays, they are usually administered in milk products or in capsules. The exact mechanisms by which probiotics may improve health are not completely clear. 
There might be several mechanisms like immunomodulation of innate and acquired immunity, but also enhancement of local immunity (reviewed in [40]). In our search, almost half of the articles about food and respiratory infections studied the effect of probiotics.

A Cochrane review in 2015, which involved 3720 participants, concluded that probiotics were better than a placebo in reducing the number of participants who experienced episodes of acute URTI by $47 \%$. The mean duration of an episode of acute URTI was reduced by about 1.89 days; antibiotic use and cold-related school absences were also reduced. In children, the effect of reducing the number of episodes of URTI was greater than in adults, and almost no effect was seen in elderly people. The authors concluded that the results favour the probiotic group, however, the quality of the evidence was low or very low [41].

Since that review, nine articles that fit our inclusion criteria have been published about probiotics and respiratory infections. They are summarised in Table 3 [42-50]. In these studies, the study populations and the species of probiotics were different (Table 3).

Six of the nine studies showed a decreased incidence of URTI $[47,49,50,48,44,45]$, while the other three studies showed no effect of the probiotics on incidence $[42,46,43]$. The effect of the probiotics on duration was described in four of the nine studies. Two studies showed a decreased duration $[43,45]$, and the other two studies showed no effect on the number of days with symptoms $[42,46]$.

Most studies about probiotics are performed with single strain probiotics, but, can mixtures with multiple strains have an additive positive effect? A few studies with multiple strains have been conducted. There are several indications for mixtures with multiple strains, however, evidence is lacking for their effect on respiratory infections [51]. One study that investigated a mixture of 12 strains in 1062 children found that the same reduction in doctors' visits and incidence of infections was described compared to single strains. Only a decrease in gastrointestinal infections was seen in the mixture group [52].

\section{Follow-up/growing-up milk}

Follow-up/growing-up milk can contain several added compounds and is usually given to children beyond the age of one year as a replacement for cow's milk. Chatchatee studied giving 767 healthy children, with a mean age of 1.5 years, $400-750 \mathrm{ml}$ of growing-up milk alone or supplemented with prebiotic short-chain galactooligosac- 

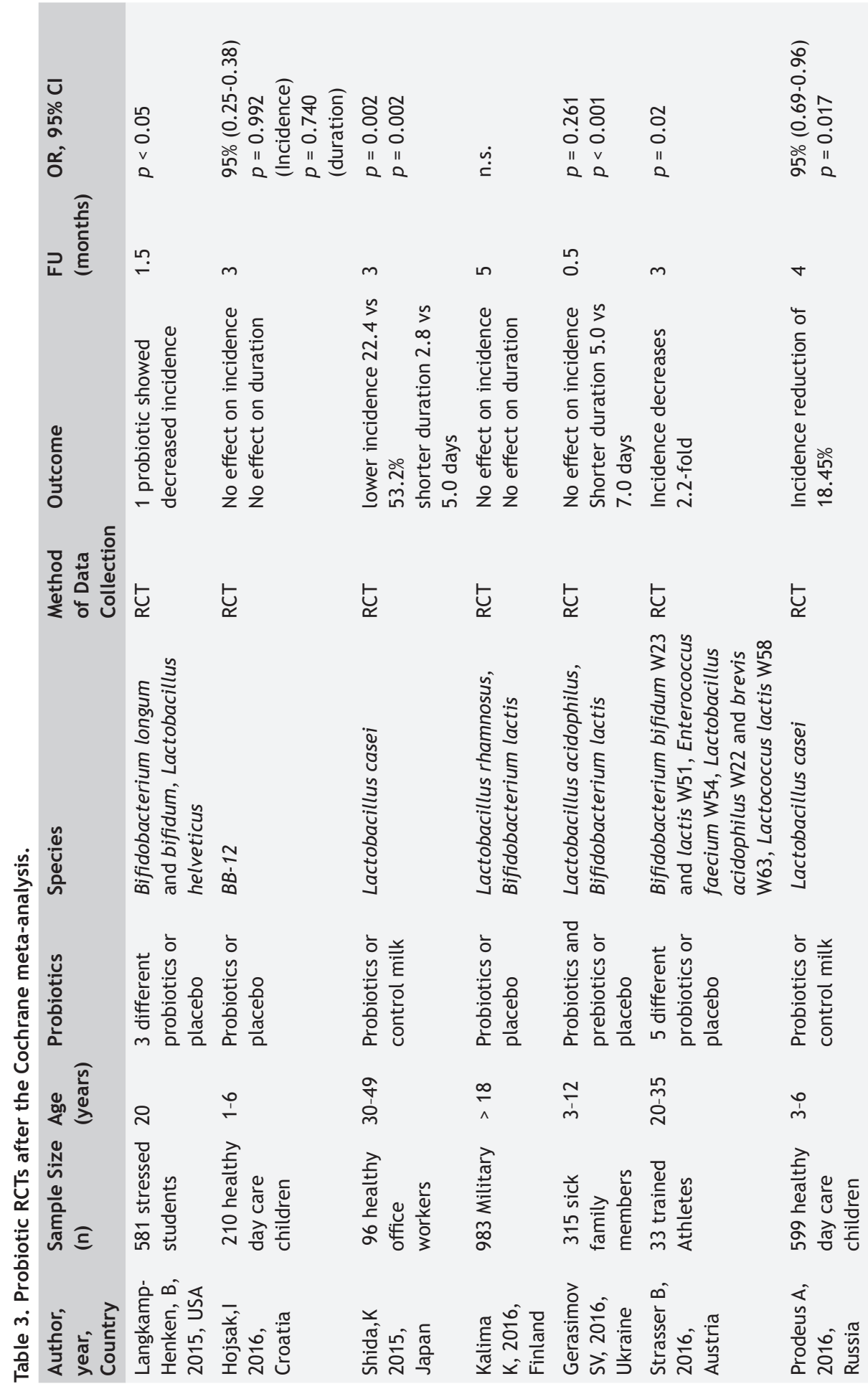


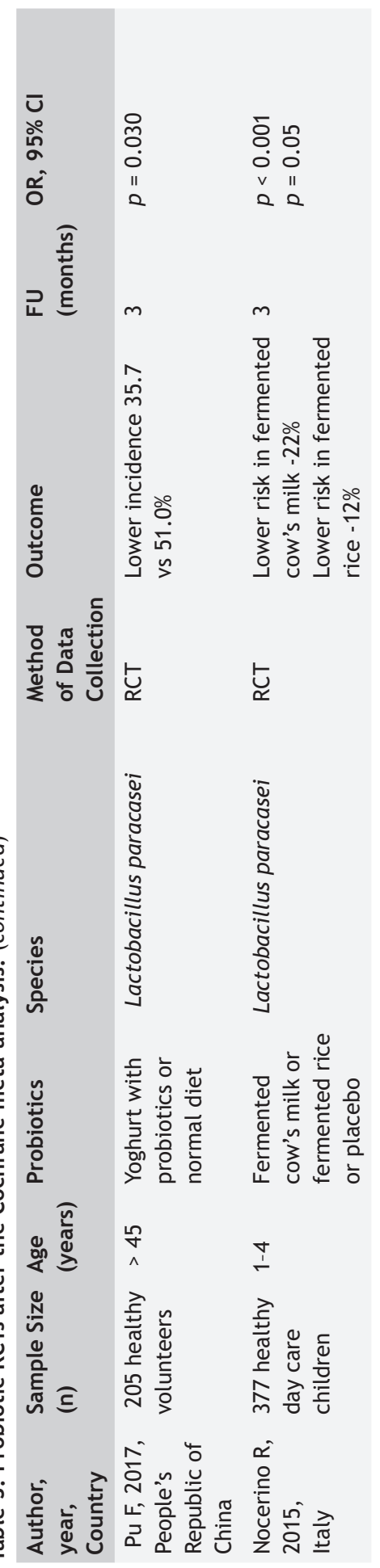


charides (scGOS) and long-chain fructooligosaccharides (lcFOS) and with n-3 longchain polyunsaturated fatty acids (LCPUFAs) for 52 weeks. The primary outcome, a decreased risk of at least one infection, was borderline significant. A trend towards a protective effect for respiratory infections by using growing-up milk was observed, though, not very strong despite the large number of participants [53].

In China, Li et al. studied a combination of follow-up milk with docosahexaenoic acid (DHA), prebiotics (polydextrose and galactooligosaccharides) and yeast B-glucan in 264 children aged three to four years of age. In this group, there were fewer episodes and a shorter duration of acute respiratory infections [54].

The same combination of supplements from the Chinese study was used in another study in Brazil, with a cow's milk-based beverage given to children one to four years of age. This group was younger, and the incidence of asthmatic disease in Brazil is higher than in the Asian population, which makes the studies less comparable with respect to the study population. In the 256 Brazilian children, there was no beneficial effect on the incidence of acute respiratory infections when children were given the supplemented drinks for 28 weeks [55].

\section{Fats}

\section{LCPUFAs, fish oil and cod liver oil}

The LCPUFAs of interest include the omega-3 LCPUFAs, eicosapentaenoic acid (EPA) and DHA, and the omega-6 LCPUFA arachidonic acid (ARA), which are all synthesised endogenously from the precursors, alpha-linolenic acid (ALA, omega-3) and linoleic acid (LA, omega-6). LCPUFAs are important fatty acids for immune cells. There should be a balance between n-3 and n-6 LCPUFAs, in favour of n-3 LCPUFAs. Most Western diets have an imbalanced intake, with too much of the pro-inflammatory n-6 LCPUFAs. Increasing n-3 LCPUFAs should optimise the regulation, maturation and response of the immune system [56].

DHA, EPA and ARA serve as cell membrane components as well as precursors for several biologic mediators, and they have essential roles in inflammation and immune function [12,57]. The human body cannot convert $n-6$ fatty acids to $n-3$ fatty acids or vice versa. Therefore, the major source of $n-3$ fatty acids comes from dietary sources.

In Thailand, 170 schoolchildren in aged 9-12 years were supplied with $2 \mathrm{~g}$ of either soybean or fish oil in their chocolate milk. Fish oil contains the (very long) long-chain $\mathrm{n}-3$ PUFAs, EPA and DHA. In the case of this study, the children received $200 \mathrm{mg}$ of EPA 
and $1 \mathrm{~g}$ DHA daily, for 6 months. Significantly fewer children who consumed fish oil experienced an illness, and the total days of illness was significantly lower in the fish oil group (two days compared to four days in the soybean-oil group, which is rich in n-6 LCPUFAs). The authors did not make a difference between diarrhoea illnesses or respiratory infections. They mention that the illnesses were "mainly upper respiratory tract infections" [58].

Malan et al. performed a study in 321 iron-deficient South African children, to investigate if fish oil (DHA/EPA) could have a beneficial effect. Iron supplementation in iron-deficient patients is known to reduce infectious morbidity due to the optimisation of the immune system $[59,60]$. However, iron supplementation can also increase morbidity from infections because of the dependence of pathogenic microorganisms on iron $[61,62]$. When iron-deficient children were supplemented with iron, in combination with DHA and EPA, versus iron alone, the increase in infections because of the iron supplementation was attenuated compared to iron supplementation alone [63]. One possible mechanism for this outcome is the incorporation of DHA and EPA into the macrophage phospholipid bilayers, with improved phagocytosis and less extracellular iron, needed for pathogen growth, left unbound. Another mechanism could be DHA/ EPA protection against iron-induced oxidative stress, with reduced immune cell damage and improved immune response [64].

Cod liver oil is a fish-derived oily product, which has been available for hundreds of years and contains vitamin A, vitamin D and long-chain omega- 3 fatty acids. Cod liver oil was first described in 1932 by Holmes to reduce absenteeism from work because of colds and respiratory diseases [65,66]. No randomised trials could be found. In 2004, Linday et al. investigated the effect of supplementation with one teaspoon of cod liver oil and a multivitamin-mineral in 47 children with URTIs in a case control study. The total number of infections was not influenced by the cod liver oil. No data were available about the duration of the illness [67]. Now, cod liver oil has been displaced by synthetic vitamins like vitamin $D$, with a more pleasant taste. However, a major source of fatty acids is lost with this replacement.

\section{Other}

\section{Garlic}

Garlic contains numerous compounds, some of which are known for their antimicrobial and antiviral properties that relieve the common cold. Garlic has been investigated in extracts, not as bulbs of garlic. The extract contains immunomodifying compounds like apigenin (a flavonoid), a Maillard reaction product, lectins and fructooligosac- 
charides, and it has been shown to improve the proliferation of T cells and NK cells [68-70]. Eight studies were investigated for a Cochrane review, of which one met the inclusion criteria of both the Cochrane review and our own [71,72].

A garlic supplement (with $180 \mathrm{mg}$ of allicin content) or placebo was administered to 146 participants that were randomly divided into two groups. The incidence and duration of the common cold decreased significantly in the garlic group [72].

\section{Xylitol}

Xylitol is a polyol sugar alcohol, which can be produced from birch trees. Natural sources of xylitol include plums, strawberries, raspberries and rowanberries [73]. Several studies have been performed with xylitol chewing gum and otitis media. In a Cochrane review [74], the authors included four randomised controlled trials (RCTs) in a meta-analysis, of which three RCTs were with healthy Finnish children attending day care. They showed a reduced risk of AOM in these three RCTs, with a total of 1826 healthy children, with a relative risk of $0.75(95 \% \mathrm{Cl} 0.65-0.88)$ [75-77].

The other RCT included 1277 children, also Finnish, suffering from recurrent respiratory infections. In this group, xylitol did not reduce the occurrence of AOM [78]. Xylitol chewing gum was superior to xylitol syrup in preventing $A O M$ in healthy children. The authors' conclusion was that there is fair evidence for a prophylactic administration of xylitol in healthy children attending day care centres to reduce the occurrence of AOM from $30 \%$ to $22 \%$, but not in sick children or among otitis-prone children [74].

\section{Combinations}

A combination of fish oil, vitamin $D$ and wheat protein or a placebo drink was given to 42 female athletes for 16 weeks. There were no differences in the number of URTI episodes between the groups. When a URTI was present, there were no differences in either the severity or duration of the episodes. However, the total number of symptom days reported was significantly lower in the supplement group [79].

One study investigated the effect of a mixture of probiotics, xylitol and $50 \mathrm{mg}$ vitamin C or a placebo (xylitol chewing gum) in 69 healthy children. In the intervention group, the incidence rate of URTI dropped 33\% $(p=0.002)$ and the duration of days with symptoms also decreased with $51 \%(p=0.006)$ [80].

Using a pretest-posttest design, Calatayud et al. investigated the effect of the Mediterranean diet in 128 children with recurring colds. The Mediterranean diet consisted of multiple food products (e.g. fresh fruits, vegetables, dairy products, fish, water, 
eggs and red meat in moderation) and advices (e.g. consuming unprocessed and locally produced foods, physical activity, etc.). The incidence rate dropped 2 .9-fold ( $p<$ 0.001 ). Besides the lower incidence, favourable side effects were mentioned, such as decreased antibiotic use, emergency room and hospital admissions or complications of the infections [81].

\section{DISCUSSION}

In this systematic review about whole foods and their effect on URTIs in children and adults, 29 studies were included. 25 of them were randomised controlled trials, 1 was a case control study, 1 was a pretest-posttest design and 2 were Cochrane meta-analyses. In these 29 studies, 16 food products were investigated-12 single food products, 3 combination food products, and 1 dietary advice. Nine of the fifteen food products, which were investigated for their effect on the prevention of URTIs, showed a significant positive effect. Of the 11 studies about shortening the duration of the URTI, 7 showed a positive effect in selective patient groups. All seven food products reduced the duration of symptoms by three to four days (elderberry and kiwi), approximately two days (probiotics and fish oil) or one day (growing-up milk) (Table 2). To put whole foods into perspective, it is necessary to examine the effect of alternative treatments reported in the literature.

Studies that investigated supplements also showed favourable results. A meta-analysis on vitamin C was non-conclusive due to heterogeneity of the studies. When extra therapeutic doses of vitamin $C$ were added to routine supplements, it was able to shorten the duration by a small amount [16]. The orange juice study suggests an effect of vitamin C supplementation [14]. However, no consistent effect of vitamin C was seen on the duration or severity of colds in a Cochrane meta-analysis [82]. Trials with vitamin $D$ supplements were not conclusive in terms of shortening the duration of viral URTIs, but most of them did not show any therapeutic effects [83]. Zinc is an essential nutrient for normal function of the immune system. Supplementation of zinc appears to be promising, but also conflicting based on results in its efficacy for respiratory infections in childhood $[84,85]$.

No studies were found that directly compared medication and food. When we examined separate studies on drugs like zanamivir or oseltamivir (both antiviral medications), the reduction in duration of the illness was shown to be 1-2.5 days and 1.5 days, respectively [86-89]. Ergoferon is an antiviral complex drug containing released-active forms of antibodies to interferon gamma, CD4 and histamine. It was 
investigated for efficacy compared to oseltamivir, and both were found to be equally effective in reducing the duration of flu-related symptoms [90].

The studies on food products, supplements and drugs cannot be compared to each other because of a lack of uniformity in the populations studied and outcomes measured. However, some food products seem to show a diverse but favourable trend. This underscores the concept of food synergy, that the combination of all phytochemicals, micro- and macronutrients, is superior to the sum of each individual component $[91,4,5]$. This is underlined by the supplement studies, since they do not show a clear positive effect. Different foods have different pathways by which they influence host immunity or the invasiveness of pathogens. In theory, they can also be used simultaneously, though this has not been investigated. One combination (probiotics, xylitol and vitamin $\mathrm{C}$ ) of food products and the Mediterranean diet did show a significant positive effect, but there was no investigation of whether it is superior compared to one food group alone [79].

Other food products, such as synbiotics, honey and raw cow's milk, have also been investigated for recurrent URTIs, but are not included in our review, because none of the studies fitted our inclusion criteria [92-96].

\section{Implications for clinical practice}

We carried out the review on food products that are easily available, so, there is no barrier to using or obtaining the food products.

The literature implicates that antiviral drugs or supplements are not clearly superior to food, and therefore, food can serve as a good alternative. The individual patient can buy food with health benefits without a prescription or having to visit a doctor.

Another aspect to be considered is health costs. A treatment with oseltamivir, for example, costs \$46-\$116 per treatment, depending on the age and weight of the patient [89]. The above amount is only the price of the medication, other costs like the number of outpatient visits, costs of other medications, emergency department visits or hospitalisation were not considered. Also, the costs of adverse effects of oseltamivir (gastrointestinal or neuropsychiatric problems) or oseltamivir resistance were not considered. The prices of kiwifruit or elderberry are much lower and do not depend on health insurance policies. 


\section{Methodological limitations of the studies reviewed}

Because of a lack of uniformity, the studies could not be used for a meta-analysis or comparisons between the different food products. As with clinical intervention studies, there was some risk for bias (Table 4). Several studies used self-reported symptoms, which increases the risk of bias. Furthermore, small sample sizes could have resulted in a limited statistical power. Moreover, most of the food products were investigated in single studies. When there was more than one study, most of them were performed by the same research group.

Table 4. Risk of bias. The studies of Catalayud et al. and Linday et al. were not included since they are not RCTs. The Cochrane meta-analyses were also not included.

\begin{tabular}{|c|c|c|c|c|c|c|}
\hline & 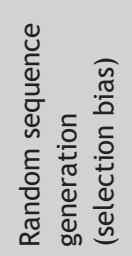 & 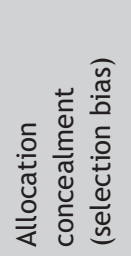 & 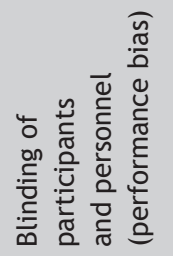 & 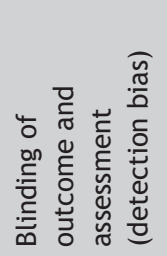 & 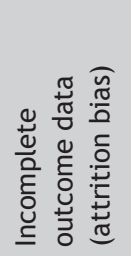 & 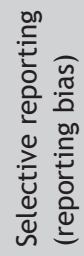 \\
\hline Adaim, 2010 & $\oplus$ & $\oplus$ & - & - & $\oplus$ & $\oplus$ \\
\hline Chatchatee, 2014 & $\oplus$ & $\oplus$ & $\oplus$ & $\oplus$ & $\oplus$ & $\oplus$ \\
\hline Da Boit, 2015 & $?$ & $?$ & $?$ & $?$ & - & $\oplus$ \\
\hline Garaiova, 2015 & $\oplus$ & $\oplus$ & $\oplus$ & $\oplus$ & $\oplus$ & $\oplus$ \\
\hline Gerasimov, 2016 & $\oplus$ & $\oplus$ & $\oplus$ & $?$ & $\oplus$ & $\oplus$ \\
\hline Hojsak, 2016 & $\oplus$ & $\oplus$ & $\oplus$ & $\oplus$ & $\oplus$ & $\oplus$ \\
\hline Hughes, 2011 & $\oplus$ & $\oplus$ & $\oplus$ & $\oplus$ & $\oplus$ & $?$ \\
\hline Hunter, 2012 & - & - & - & - & $\oplus$ & $\oplus$ \\
\hline Kalima, 2016 & $\oplus$ & $\oplus$ & $\oplus$ & $\oplus$ & - & $\oplus$ \\
\hline Kong, 2009 & $\oplus$ & $\oplus$ & $\oplus$ & $\oplus$ & $\oplus$ & $\oplus$ \\
\hline Kontiokari, 2005 & $\oplus$ & $\oplus$ & $\oplus$ & $\oplus$ & $\oplus$ & $\oplus$ \\
\hline Langkamp-Henken, 2015 & $\oplus$ & $\oplus$ & $\oplus$ & $\oplus$ & $?$ & $\oplus$ \\
\hline Larmo, 2008 & $\oplus$ & $\oplus$ & $\oplus$ & $\oplus$ & $\oplus$ & $\oplus$ \\
\hline Li, 2014 & $\oplus$ & $\oplus$ & $\oplus$ & $?$ & $\oplus$ & $\oplus$ \\
\hline Josling, 2001 & $\oplus$ & $\oplus$ & - & $\oplus$ & $\oplus$ & $?$ \\
\hline McLean Baird, 1979 & $?$ & $?$ & $\oplus$ & $\oplus$ & $\oplus$ & $?$ \\
\hline Nantz, 2013 & $\oplus$ & $\oplus$ & $\oplus$ & $?$ & $\oplus$ & $\oplus$ \\
\hline Nocerino, 2015 & $\oplus$ & $\oplus$ & $\oplus$ & $\oplus$ & $\oplus$ & $\oplus$ \\
\hline Pontes, 2016 & $\oplus$ & $\oplus$ & $\oplus$ & $\oplus$ & $\oplus$ & $\oplus$ \\
\hline Prodeus, 2016 & $\oplus$ & $\oplus$ & $\oplus$ & $\oplus$ & $\oplus$ & $\oplus$ \\
\hline Pu, 2017 & $\oplus$ & $\oplus$ & - & $?$ & $\oplus$ & $\oplus$ \\
\hline Shida, 2015 & $?$ & $?$ & $?$ & $?$ & $\oplus$ & $\oplus$ \\
\hline Strasser, 2016 & $\oplus$ & $\oplus$ & $\oplus$ & $?$ & $\oplus$ & $?$ \\
\hline Zakay-Rones, 1995 & $\oplus$ & $\oplus$ & $\oplus$ & $?$ & - & $\oplus$ \\
\hline Zakay-Rones, 2004 & $\oplus$ & $\oplus$ & $\oplus$ & $\oplus$ & $\oplus$ & $\oplus$ \\
\hline
\end{tabular}


Because of the diversity in study populations, the results are not generalisable. One food group can show distinct effects in different age or patient groups. This implicates that the benefits found in a specific study group may not be beneficial to everyone.

\section{Comparison with other reviews}

Until now, only (Cochrane) reviews have been published on food and URTIs concerning a single food product $[74,41,71]$. This is the first study to review all whole food products studied and their effect on URTIs. Therefore, our study gives an overview and is an important addition to this field of research.

\section{Conclusion}

Food interventions are promising for reducing the incidence (growing-up milk, probiotics, prebiotics, fish oil, kiwi, garlic, Mediterranean diet and xylitol) and duration (elderberry, probiotics, kiwi, growing-up milk and fish oil) of respiratory infections or symptoms in selective patient groups. Still, the studies are diverse and have only been performed by a few study groups. Further research is necessary to make clear and widespread conclusions.

\section{Acknowledgements}

We like to thank professor Job van der Palen, University Twente, for critically reading our manuscript. 


\section{REFERENCES}

1. Black RE, Cousens S, Johnson HL, Lawn JE, Rudan I, Bassani DG, Jha P, Campbell $\mathrm{H}$, Walker CF, Cibulskis R, Eisele T, Liu L, Mathers C, Child Health Epidemiology Reference Group of WHO, Unicef (2010) Global, regional, and national causes of child mortality in 2008: a systematic analysis. Lancet 375 (9730):1969-1987. doi:10.1016/S0140-6736(10)60549-1

2. U.S. Department of Health and Human Services CfDCaP (2017) National Hospital Ambulatory Medical Care Survey: 2013 Emergency Department Summary Tables.Table 10

3. Mao S, Zhang A, Huang S (2014) Metaanalysis of $\mathrm{Zn}, \mathrm{Cu}$ and $\mathrm{Fe}$ in the hair of Chinese children with recurrent respiratory tract infection. Scand J Clin Lab Invest 74 (7):561-567. doi:10.3109/ 00365513.2014.921323

4. Jacobs DR, Jr., Gross MD, Tapsell LC (2009) Food synergy: an operational concept for understanding nutrition. Am J Clin Nutr 89 (5):1543S-1548S. doi:10.3945/ajen.2009.26736B

5. Jacobs DR, Jr., Tapsell LC (2007) Food, not nutrients, is the fundamental unit in nutrition. Nutr Rev 65 (10):439-450

6. Scalbert A, Andres-Lacueva C, Arita M, Kroon P, Manach C, Urpi-Sarda M, Wishart D (2011) Databases on food phytochemicals and their health-promoting effects. J Agric Food Chem 59 (9):4331-4348. doi:10.1021/jf200591d

7. Gross J (1991) Pigments in vegetablesChlorophylls and Carotenoids. Springer US, New York

8. Linus Pauling Institute OSU (2019) Flavonoids. Phytochemicals. Micronutrient Information Center,

9. Yeum KJ, Beretta G, Krinsky NI, Russell RM, Aldini G (2009) Synergistic interactions of antioxidant nutrients in a biological model system. Nutri- tion 25 (7-8):839-846. doi:10.1016/j. nut.2009.01.011

10. Heinonen M (2007) Antioxidant activity and antimicrobial effect of berry phenolics--a Finnish perspective. Mol Nutr Food Res 51 (6):684-691. doi:10.1002/ mnfr.200700006

11. Nohynek LJ, Alakomi HL, Kahkonen MP, Heinonen M, Helander IM, OksmanCaldentey KM, Puupponen-Pimia RH (2006) Berry phenolics: antimicrobial properties and mechanisms of action against severe human pathogens. Nutr Cancer 54 (1):18-32. doi:10.1207/ s15327914nc5401_4

12. Calder PC (2015) Marine omega-3 fatty acids and inflammatory processes: Effects, mechanisms and clinical relevance. Biochim Biophys Acta 1851 (4):469-484. doi:10.1016/j. bbalip.2014.08.010

13. Kontiokari T, Uhari M, Koskela M (1995) Effect of xylitol on growth of nasopharyngeal bacteria in vitro. Antimicrob Agents Chemother 39 (8):1820-1823

14. Baird IM, Hughes RE, Wilson HK, Davies JE, Howard AN (1979) The effects of ascorbic acid and flavonoids on the occurrence of symptoms normally associated with the common cold. Am J Clin Nutr 32 (8): 1686-1690

15. Wilson HK, Price-Jones C, Hughes RE (1976) The influence of an extract of orange peel on the growth and ascorbic acid metabolism of young guinea-pigs. J Sci Food Agric 27 (7):661-666

16. Ran L, Zhao W, Wang J, Wang H, Zhao Y, Tseng Y, Bu H (2018) Extra Dose of Vitamin C Based on a Daily Supplementation Shortens the Common Cold: A MetaAnalysis of 9 Randomized Controlled Trials. Biomed Res Int 2018:1837634. doi:10.1155/2018/1837634

17. Wintergerst ES, Maggini S, Hornig DH (2006) Immune-enhancing role of vitamin $C$ and zinc and effect on clinical 
conditions. Ann Nutr Metab 50 (2):8594. doi:10.1159/000090495

18. Hunter DC, Denis M, Parlane NA, Buddle BM, Stevenson LM, Skinner MA (2008) Feeding ZESPRI GOLD Kiwifruit puree to mice enhances serum immunoglobulins specific for ovalbumin and stimulates ovalbumin-specific mesenteric lymph node cell proliferation in response to orally administered ovalbumin. Nutr Res 28 (4):251-257. doi:10.1016/j. nutres.2008.01.009

19. Skinner MA, Loh JM, Hunter DC, Zhang J (2011) Gold kiwifruit ( Actinidia chinensis 'Hort16A') for immune support. Proc Nutr Soc 70 (2):276-280. doi:10.1017/ S0029665111000048

20. Hunter DC, Skinner MA, Wolber FM, Booth CL, Loh JM, Wohlers M, Stevenson LM, Kruger MC (2012) Consumption of gold kiwifruit reduces severity and duration of selected upper respiratory tract infection symptoms and increases plasma vitamin $\mathrm{C}$ concentration in healthy older adults. $\mathrm{Br} \mathrm{J}$ Nutr 108 (7):1235-1245. doi:10.1017/ S0007114511006659

21. Adaim A (2010) Investigating the effect of gold kiwifruit consumption on the incidence and symptoms of upper respiratory tract infections in pre-school children.. Massey University, New Zealand., http://mro.massey.ac.nz/bitstream/handle/10179/2351/02_whole. pdf?sequence $=1$

22. Kontiokari $T$, Sundqvist $K$, Nuutinen $M$, Pokka T, Koskela M, Uhari M (2001) Randomised trial of cranberry-lingonberry juice and Lactobacillus GG drink for the prevention of urinary tract infections in women. BMJ 322 (7302):1571

23. Stothers $L(2002)$ A randomized trial to evaluate effectiveness and cost effectiveness of naturopathic cranberry products as prophylaxis against urinary tract infection in women. Can J Urol 9 (3):1558-1562

24. Kontiokari T, Salo J, Eerola E, Uhari M (2005) Cranberry juice and bacterial colonization in children--a placebocontrolled randomized trial. Clin Nutr 24 (6):1065-1072. doi:10.1016/j. clnu.2005.08.009

25. Nantz MP, Rowe CA, Muller C, Creasy R, Colee J, Khoo C, Percival SS (2013) Consumption of cranberry polyphenols enhances human gammadelta- $T$ cell proliferation and reduces the number of symptoms associated with colds and influenza: a randomized, placebocontrolled intervention study. Nutr J 12:161. doi:10.1186/1475-2891-12-161

26. Association BHM (1983) British Herbal Pharmacopoeia. BHMA Publications. Bournemouth,

27. Roschek B, Jr., Fink RC, McMichael MD, Li D, Alberte RS (2009) Elderberry flavonoids bind to and prevent H1N1 infection in vitro. Phytochemistry 70 (10):1255-1261. doi:10.1016/j.phytochem.2009.06.003

28. Badescu M, Badulescu O, Badescu L, Ciocoiu M (2015) Effects of Sambucus nigra and Aronia melanocarpa extracts on immune system disorders within diabetes mellitus. Pharm Biol 53 (4):533539. doi:10.3109/13880209.2014.93144 1

29. Mikulic-Petkovsek $M$, Ivancic A, Todorovic B, Veberic R, Stampar F (2015) Fruit Phenolic Composition of Different Elderberry Species and Hybrids. J Food Sci 80 (10):C2180-2190. doi:10.1111/1750-3841.13008

30. Tiralongo E, Wee SS, Lea RA (2016) Elderberry Supplementation Reduces Cold Duration and Symptoms in AirTravellers: A Randomized, Double-Blind Placebo-Controlled Clinical Trial. Nutrients 8 (4):182. doi:10.3390/nu8040182 
31. Holst L, Havnen GC, Nordeng H (2014) Echinacea and elderberry-should they be used against upper respiratory tract infections during pregnancy? Front Pharmacol 5:31. doi:10.3389/ fphar.2014.00031

32. Zakay-Rones Z, Thom E, Wollan T, Wadstein J (2004) Randomized study of the efficacy and safety of oral elderberry extract in the treatment of influenza $A$ and $B$ virus infections. $J$ Int Med Res 32 (2): $132-140$

33. Zakay-Rones Z, Varsano N, Zlotnik M, Manor O, Regev L, Schlesinger M, Mumcuoglu M (1995) Inhibition of several strains of influenza virus in vitro and reduction of symptoms by an elderberry extract (Sambucus nigra L.) during an outbreak of influenza B Panama. J Altern Complement Med 1 (4):361-369

34. Kong FK (2009) Pilot clinical study on the proprietary elderberry extract:efficacy in adressing influenza symptoms. Online J Pharmacol Pharmacokin 5:32-43

35. Larmo $P$, Alin J, Salminen $E$, Kallio $H$, Tahvonen R (2008) Effects of sea buckthorn berries on infections and inflammation: a double-blind, randomized, placebo-controlled trial. Eur J Clin Nutr 62 (9):1123-1130. doi:10.1038/ sj.ejcn.1602831

36. Orrhage K, Nord CE (1999) Factors controlling the bacterial colonization of the intestine in breastfed infants. Acta Paediatr Suppl 88 (430):47-57

37. Bouhnik $Y$, Flourie B, D'Agay-Abensour L, Pochart P, Gramet G, Durand M, Rambaud JC (1997) Administration of transgalacto-oligosaccharides increases fecal bifidobacteria and modifies colonic fermentation metabolism in healthy humans. J Nutr 127 (3):444448. doi:10.1093/jn/127.3.444

38. Mariadason JM, Barkla DH, Gibson PR (1997) Effect of short-chain fatty acids on paracellular permeability in
Caco-2 intestinal epithelium model. Am J Physiol 272 (4 Pt 1):G705-712. doi:10.1152/ajpgi.1997.272.4.G705

39. Hughes C, Davoodi-Semiromi Y, Colee JC, Culpepper T, Dahl WJ, Mai V, Christman MC, Langkamp-Henken B (2011) Galactooligosaccharide supplementation reduces stress-induced gastrointestinal dysfunction and days of cold or flu: a randomized, double-blind, controlled trial in healthy university students. Am J Clin Nutr 93 (6):13051311. doi:10.3945/ajcn.111.014126

40. Hao Q, Lu Z, Dong BR, Huang CQ, Wu T (2011) Probiotics for preventing acute upper respiratory tract infections. Cochrane Database Syst Rev (9):CD006895. doi:10.1002/14651858.CD006895.pub2

41. Hao Q, Dong BR, Wu T (2015) Probiotics for preventing acute upper respiratory tract infections. Cochrane Database Syst Rev 2:CD006895. doi:10.1002/14651858.CD006895.pub3

42. Hojsak I, Mocic Pavic A, Kos T, Dumancic J, Kolacek S (2016) Bifidobacterium animalis subsp. lactis in prevention of common infections in healthy children attending day care centers - Randomized, double blind, placebo-controlled study. Clin Nutr 35 (3):587-591. doi:10.1016/j.clnu.2015.05.004

43. Gerasimov SV, Ivantsiv VA, Bobryk LM, Tsitsura 00, Dedyshin LP, Guta NV, Yandyo BV (2015) Role of short-term use of L. acidophilus DDS-1 and B. lactis UABLA-12 in acute respiratory infections in children: a randomized controlled trial. Eur J Clin Nutr. doi:10.1038/ejcn.2015.171

44. Langkamp-Henken B, Rowe CC, Ford AL, Christman MC, Nieves C, Jr., Khouri L, Specht GJ, Girard SA, Spaiser SJ, Dahl WJ (2015) Bifidobacterium bifidum R0071 results in a greater proportion of healthy days and a lower percentage of academically stressed students report- 
ing a day of cold/flu: a randomised, double-blind, placebo-controlled study. Br J Nutr 113 (3):426-434. doi:10.1017/ S0007114514003997

45. Shida K, Sato T, lizuka R, Hoshi R, Watanabe $\mathrm{O}$, Igarashi T, Miyazaki $\mathrm{K}$, Nanno M, Ishikawa $F$ (2015) Daily intake of fermented milk with Lactobacillus casei strain Shirota reduces the incidence and duration of upper respiratory tract infections in healthy middle-aged office workers. Eur J Nutr. doi:10.1007/ s00394-015-1056-1

46. Kalima K, Lehtoranta L, He L, Pitkaniemi J, Lundell R, Julkunen I, Roivainen M, Narkio M, Makela MJ, Siitonen S, Korpela R, Pitkaranta A (2016) Probiotics and respiratory and gastrointestinal tract infections in Finnish military conscripts - a randomised placebocontrolled double-blinded study. Benef $\begin{array}{ll}\text { Microbes } 7 \text { (4):463-471. doi:10.3920/ } & \text { (4) }\end{array}$ BM2015.0172

47. Nocerino R, Paparo L, Terrin G, Pezzella V, Amoroso A, Cosenza L, Cecere G, De Marco G, Micillo M, Albano F, Nugnes R, Ferri P, Ciccarelli G, Giaccio G, Spadaro R, Maddalena Y, Berni Canani F, Berni Canani R (2017) Cow's milk and rice fermented with Lactobacillus paracasei CBA L74 prevent infectious diseases in children: A randomized controlled trial. Clin Nutr 36 (1):118-125. doi:10.1016/j. clnu.2015.12.004

48. Strasser B, Geiger D, Schauer M, Gostner JM, Gatterer H, Burtscher M, Fuchs D (2016) Probiotic Supplements Beneficially Affect Tryptophan-Kynurenine Metabolism and Reduce the Incidence of Upper Respiratory Tract Infections in Trained Athletes: A Randomized, Double-Blinded, Placebo-Controlled Trial. Nutrients 8 (11). doi:10.3390/ nu8110752

49. Pu F, Guo Y, Li M, Zhu H, Wang S, Shen X, He M, Huang C, He F (2017)
Yogurt supplemented with probiotics can protect the healthy elderly from respiratory infections: A randomized controlled open-label trial. Clin Interv Aging 12:1223-1231. doi:10.2147/CIA. S141518

50. Prodeus A, Niborski V, Schrezenmeir J, Gorelov A, Shcherbina A, Rumyantsev A (2016) Fermented Milk Consumption and Common Infections in Children Attending Day-Care Centers: A Randomized Trial. J Pediatr Gastroenterol Nutr 63 (5):534-543. doi:10.1097/ MPG.0000000000001248

51. Chapman CM, Gibson GR, Rowland I (2011) Health benefits of probiotics: are mixtures more effective than single strains? Eur J Nutr 50 (1):1-17. doi:10.1007/s00394-010-0166-z

52. Lin JS, Chiu YH, Lin NT, Chu CH, Huang KC, Liao KW, Peng KC (2009) Different effects of probiotic species/strains on infections in preschool children: A double-blind, randomized, controlled study. Vaccine 27 (7):1073-1079. doi:10.1016/j.vaccine.2008.11.114

53. Chatchatee P, Lee WS, Carrilho E, Kosuwon P, Simakachorn N, Yavuz Y, Schouten B, Graaff PL, Szajewska H (2014) Effects of growing-up milk supplemented with prebiotics and LCPUFAs on infections in young children. J Pediatr Gastroenterol Nutr 58 (4):428-437. doi:10.1097/MPG.0000000000000252

54. Li F, Jin X, Liu B, Zhuang W, Scalabrin D (2014) Follow-up formula consumption in 3- to 4-year-olds and respiratory infections: an RCT. Pediatrics 133 (6):e1533-1540. doi:10.1542/ peds.2013-3598

55. Pontes MV, Ribeiro TC, Ribeiro $\mathrm{H}$, de Mattos AP, Almeida IR, Leal VM, Cabral GN, Stolz S, Zhuang W, Scalabrin DM (2016) Cow's milk-based beverage consumption in 1- to 4-year-olds and 
allergic manifestations: an RCT. Nutr J 15:19. doi:10.1186/s12937-016-0138-0

56. Simopoulos AP (2002) The importance of the ratio of omega-6/omega-3 essential fatty acids. Biomed Pharmacother $56(8): 365-379$

57. Calder PC (2012) The role of marine omega-3 (n-3) fatty acids in inflammatory processes, atherosclerosis and plaque stability. Mol Nutr Food Res 56 (7):1073-1080. doi:10.1002/ mnfr.201100710

58. Thienprasert A, Samuhaseneetoo $S$, Popplestone K, West AL, Miles EA, Calder PC (2009) Fish oil n-3 polyunsaturated fatty acids selectively affect plasma cytokines and decrease illness in Thai schoolchildren: a randomized, double-blind, placebo-controlled intervention trial. J Pediatr 154 (3):391-395. doi:10.1016/j.jpeds.2008.09.014

59. de Silva A, Atukorala S, Weerasinghe I, Ahluwalia N (2003) Iron supplementation improves iron status and reduces morbidity in children with or without upper respiratory tract infections: a randomized controlled study in Colombo, Sri Lanka. Am J Clin Nutr 77 (1):234241. doi:10.1093/ajen/77.1.234

60. Tielsch JM, Khatry SK, Stoltzfus RJ, Katz J, LeClerq SC, Adhikari R, Mullany LC, Shresta S, Black RE (2006) Effect of routine prophylactic supplementation with iron and folic acid on preschool child mortality in southern Nepal: community-based, cluster-randomised, placebo-controlled trial. Lancet 367 (9505):144-152. doi:10.1016/S01406736(06)67963-4

61. Cherayil BJ (2010) Iron and immunity: immunological consequences of iron deficiency and overload. Arch Immunol Ther Exp (Warsz) 58 (6):407-415. doi:10.1007/s00005-010-0095-9

62. Murray MJ, Murray $A B$, Murray $M B$, Murray CJ (1978) The adverse effect of iron repletion on the course of certain infections. Br Med J 2 (6145):1113-1115

63. Malan L, Baumgartner J, Calder PC, Zimmermann MB, Smuts CM (2015) n-3 Long-chain PUFAs reduce respiratory morbidity caused by iron supplementation in iron-deficient South African schoolchildren: a randomized, doubleblind, placebo-controlled intervention. Am J Clin Nutr 101 (3):668-679. doi:10.3945/ajcn.113.081208

64. Appay V, Sauce D (2008) Immune activation and inflammation in HIV-1 infection: causes and consequences. J Pathol 214(2):231-241

65. Holmes ADP, M.G.; Sawyer,W.A.;Comstock,L.

Vitamins aid reduction of lost time in industry. Indust Eng Chem 24:1058-1060

66. Holmes ADP, M.G.; Sawyer,W.A.;Comstock,L. (1936) Cod liver oil. A five-year study of its value for reducing industrial absenteeism caused by colds and respiratory diseases. Indust Med 5:359-361

67. Linday LA, Shindledecker RD, TapiaMendoza J, Dolitsky JN (2004) Effect of daily cod liver oil and a multivitaminmineral supplement with selenium on upper respiratory tract pediatric visits by young, inner-city, Latino children: randomized pediatric sites. Ann Otol Rhinol Laryngol 113 (11):891-901

68. Nantz MP, Rowe CA, Muller CE, Creasy RA, Stanilka JM, Percival SS (2012) Supplementation with aged garlic extract improves both NK and gammadelta-T cell function and reduces the severity of cold and flu symptoms: a randomized, double-blind, placebocontrolled nutrition intervention. Clin Nutr 31 (3):337-344. doi:10.1016/j. clnu.2011.11.019

69. Chandrashekar PM, Venkatesh YP (2009) Identification of the protein components displaying immunomodula- 
tory activity in aged garlic extract. J Ethnopharmacol 124 (3):384-390. doi:10.1016/j.jep.2009.05.030

70. Chandrashekar PM, Prashanth KV, Venkatesh YP (2011) Isolation, structural elucidation and immunomodulatory activity of fructans from aged garlic extract. Phytochemistry 72 (2-3):255-264. doi:10.1016/j.phytochem.2010.11.015

71. Lissiman E, Bhasale AL, Cohen M (2014) Garlic for the common cold. Cochrane Database Syst Rev 11:CD006206. doi:10.1002/14651858.CD006206.pub4

72. Josling $P$ (2001) Preventing the common cold with a garlic supplement: a double-blind, placebo-controlled survey. Adv Ther 18 (4):189-193

73. Makinen KK (1980) Comparison between xylitol and glucose in a peroral feeding study in rats with special consideration of exocrine gland and gut wall biochemistry. Int J Vitam Nutr Res 50 (1):84-91

74. Azarpazhooh A, Lawrence HP, Shah PS (2016) Xylitol for preventing acute otitis media in children up to 12 years of age. Cochrane Database Syst Rev (8):CD007095. doi:10.1002/14651858. CD007095.pub3

75. Hautalahti O, Renko M, Tapiainen T, Kontiokari T, Pokka T, Uhari M (2007) Failure of xylitol given three times a day for preventing acute otitis media. Pediatr Infect Dis J 26 (5):423-427. doi:10.1097/01.inf.0000259956.21859. dd

76. Uhari M, Kontiokari T, Niemela M (1998) A novel use of xylitol sugar in preventing acute otitis media. Pediatrics 102 (4 Pt 1):879-884

77. Uhari $M$, Kontiokari T, Koskela $M$, Niemela M (1996) Xylitol chewing gum in prevention of acute otitis media: double blind randomised trial. BMJ 313 (7066):1180-1184

78. Tapiainen $\mathrm{T}$, Luotonen $\mathrm{L}$, Kontiokari T, Renko M, Uhari M (2002) Xylitol administered only during respiratory infections failed to prevent acute otitis media. Pediatrics 109 (2):E19

79. Da Boit M, Gabriel BM, Gray P, Gray SR (2015) The Effect of Fish Oil, Vitamin D and Protein on URTI Incidence in Young Active People. Int J Sports Med 36 (5):426-430. doi:10.1055/s-0034-1394464

80. Garaiova I, Muchova J, Nagyova Z, Wang D, Li JV, Orszaghova Z, Michael DR, Plummer SF, Durackova Z (2015) Probiotics and vitamin $C$ for the prevention of respiratory tract infections in children attending preschool: a randomised controlled pilot study. Eur J Clin Nutr 69 (3):373-379. doi:10.1038/ ejcn.2014.174

81. Calatayud FM, Calatayud B, Gallego JG, Gonzalez-Martin C, Alguacil LF (2017) Effects of Mediterranean diet in patients with recurring colds and frequent complications. Allergol Immunopathol (Madr) 45 (5):417-424. doi:10.1016/j. aller.2016.08.006

82. Hemila H, Chalker E (2013) Vitamin C for preventing and treating the common cold. Cochrane Database Syst Rev (1):CD000980. doi:10.1002/14651858. CD000980.pub4

83. Yamshchikov AV, Desai NS, Blumberg HM, Ziegler TR, Tangpricha V (2009) Vitamin $D$ for treatment and prevention of infectious diseases: a systematic review of randomized controlled trials. Endocr Pract 15 (5):438-449. doi:10.4158/EP09101.ORR

84. Basnet S, Mathisen M, Strand TA (2015) Oral zinc and common childhood infections--An update. J Trace Elem Med Biol 31:163-166. doi:10.1016/j. jtemb.2014.05.006

85. Singh M, Das RR (2013) Zinc for the common cold. Cochrane Database Syst Rev (6):CD001364. doi:10.1002/14651858. CD001364.pub4 
86. Makela MJ, Pauksens K, Rostila T, Fleming DM, Man CY, Keene ON, Webster A (2000) Clinical efficacy and safety of the orally inhaled neuraminidase inhibitor zanamivir in the treatment of influenza: a randomized, double-blind, placebo-controlled European study. J Infect 40 (1):42-48. doi:10.1053/ jinf.1999.0602

87. Matsumoto K, Ogawa $\mathrm{N}$, Nerome $\mathrm{K}$, Numazaki Y, Kawakami Y, Shirato K, Arakawa M, Kudoh S, Shimokata K, Nakajima S, Yamakido M, Kashiwagi S, Nagatake T (1999) Safety and efficacy of the neuraminidase inhibitor zanamivir in treating influenza virus infection in adults: results from Japan. GG167 Group. Antivir Ther 4 (2):61-68

88. Nicholson KG, Aoki FY, Osterhaus AD, Trottier S, Carewicz O, Mercier $\mathrm{CH}$, Rode A, Kinnersley N, Ward P (2000) Efficacy and safety of oseltamivir in treatment of acute influenza: a randomised controlled trial. Neuraminidase Inhibitor Flu Treatment Investigator Group. Lancet 355 (9218):1845-1850

89. Lavelle TA, Uyeki TM, Prosser LA (2012) Cost-effectiveness of oseltamivir treatment for children with uncomplicated seasonal influenza. J Pediatr 160 (1):67-73 e66. doi:10.1016/j. jpeds.2011.07.001

90. Rafalsky V, Averyanov A, Bart B, Minina E, Putilovskiy M, Andrianova E, Epstein O (2016) Efficacy and safety of Ergoferon versus oseltamivir in adult outpatients with seasonal influenza virus infection: a multicenter, open-label, randomized trial. Int J Infect Dis 51:4755. doi:10.1016/j.ijid.2016.09.002

91. Jacobs DR, Tapsell LC (2013) Food synergy: the key to a healthy diet. Proc Nutr Soc 72 (2):200-206. doi:10.1017/ S0029665112003011
92. Sazawal $S$, Dhingra U, Hiremath $G$, Sarkar A, Dhingra P, Dutta A, Verma P, Menon VP, Black RE (2010) Prebiotic and probiotic fortified milk in prevention of morbidities among children: community-based, randomized, double-blind, controlled trial. PLoS One 5 (8):e12164. doi:10.1371/journal.pone.0012164

93. Schrezenmeir J, Heller K, McCue M, Llamas C, Lam W, Burow H, KindlingRohracker M, Fischer W, Sengespeik HC, Comer GM, Alarcon P (2004) Benefits of oral supplementation with and without synbiotics in young children with acute bacterial infections. Clin Pediatr (Phila) 43 (3):239-249

94. Cohen HA, Rozen J, Kristal H, Laks $Y$, Berkovitch M, Uziel Y, Kozer E, Pomeranz A, Efrat H (2012) Effect of honey on nocturnal cough and sleep quality: a double-blind, randomized, placebocontrolled study. Pediatrics 130 (3):465471. doi:10.1542/peds.2011-3075

95. Paul IM, Beiler J, MCMonagle A, Shaffer ML, Duda L, Berlin CM, Jr. (2007) Effect of honey, dextromethorphan, and no treatment on nocturnal cough and sleep quality for coughing children and their parents. Arch Pediatr Adolesc Med 161 (12):1140-1146. doi:10.1001/ archpedi.161.12.1140

96. Loss G, Depner M, Ulfman LH, van Neerven RJ, Hose AJ, Genuneit J, Karvonen AM, Hyvarinen A, Kaulek V, Roduit C, Weber J, Lauener R, Pfefferle PI, Pekkanen J, Vaarala O, Dalphin JC, Riedler J, Braun-Fahrlander C, von Mutius E, Ege MJ, group Ps (2015) Consumption of unprocessed cow's milk protects infants from common respiratory infections. J Allergy Clin Immunol 135 (1):56-62. doi:10.1016/j. jaci.2014.08.044 









\section{The immunomodulating effect} of dietary advice consisting of green vegetables, beef, whole milk and full-fat butter for children with Non-specific elevated IgE. 


\section{ABSTRACT}

Background: Non-specific elevated IgE and allergies are common in children and their prevalence is increasing. Dietary changes could be a plausible explanation for this increase. Zinc, iron, vitamins $\mathrm{A}, \mathrm{C}$ and $\mathrm{E}$, and polyunsaturated fatty acids all play possible roles in the aetiology and possible treatment of allergies due to their numerous immunomodulating properties.

Objectives: To investigate the immunomodulating effect of a nutrient-rich dietary advice consisting of green vegetables, beef, whole milk and full-fat butter.

Methods: We conducted a case-control, non-randomised, retrospective study. Children between the ages of 12 months and 18 years with non-specific elevated IgE were included. Baseline and follow-up measurements of serum total IgE and clinical outcomes were retrospectively collected and compared for 49 children who received the dietary advice (consisting of green vegetables, beef, whole milk and full-fat butter) and 56 children who did not.

Results: The initial analysis showed a significantly larger decrease in IgE in the intervention group compared to the control group; a $9.2 \mathrm{kU} / \mathrm{l}$ versus a $0.1 \mathrm{kU} / \mathrm{l}$ decrease, respectively $(P=0.02)$. However, when supplement (vitamin $D)$ use was taken into account, no significant difference was produced by the dietary effect alone (unstandardized coefficient $=71.3 \mathrm{kU} / \mathrm{l}, \mathrm{P}=0.16) .53 .2 \%$ of participants in the intervention group reported considerable improvement in symptoms versus $28.6 \%$ in the control group $(P<0.001)$.

Conclusion: Overall, the effects of nutrients and vitamins on the decrease in IgE are promising. The separate contributions of dietary advice and/or supplements need to be investigated in the future. 


\section{INTRODUCTION}

Atopic diseases, such as allergic rhinitis, asthma and constitutional eczema, are common ailments in paediatric medicine and there is evidence that their incidence is increasing in Western countries [1-3]. The burden of atopic disease, such as high use of medical facilities and high healthcare costs [4], should not be neglected and atopic disease is a major public health issue that urgently needs to be addressed.

An important factor in the aetiology of allergy in children is believed to be the immaturity of the immune system and an imbalance between T-helper(Th)-1-lymphocyte and Th-2-lymphocyte driven immunity. In young children Th-2-type reactions, which play a role in immunity against parasites and allergens, often dominate. For effective protection against viral and bacterial infections a shift towards Th1-type reactions is required [5]. A diagnostic tool in the management of allergic disease is the total serum immunoglobulin $\mathrm{E}$ (IgE). IgE plays a central role in the aetiology of type I allergic reactions via stimulation of mast cell activation and the subsequent release of inflammatory mediators such as histamine [6,7]; elevated levels of total serum IgE have a high specificity for the diagnosis of allergy [8]. The production of IgE is stimulated by the Th2-cytokine interleukin-4 (IL-4) and inhibited by the Th1-cytokine interferon- $\gamma$ (IFN- $\gamma)[5,9,10]$, suggesting that a shift from Th2- to Th1-mediated immunity should also lead to a decrease in IgE.

There is increasing evidence in the literature that suggests nutrition could play an essential role in the development and function of the immune system, including achieving the balance between Th1- and 2-type reactions [11]. Due to the fact that the increase in allergy incidence is not as marked in developing countries, a popular theory is that the increase is related to the changes in dietary habits and/or nutrient status seen in developed countries. It is suggested that a more "Western" diet high in refined grains and saturated fats and low in vegetables and fish is a risk factor for the development of allergic disease $[2,12,13]$. Two hypotheses regarding nutrition and atopy are the lipid hypothesis and the antioxidant hypothesis.

\section{The lipid and antioxidant hypotheses}

The potential health benefits of PUFA (polyunsaturated fatty acids), and especially n-3 long-chain PUFA, which can be found in fish oil, have been studied extensively [1417]. In recent years the dietary intake of $n-6$ PUFA has increased in the Western world while the intake of $n-3$ has decreased, and it is thought that this imbalance plays a key role in the increased incidence of allergies $[18,19]$. Arachidonic acid (AA), a n-6 PUFA, is found in many immune cells and is a substrate for the synthesis of different 
eicosanoid mediators, such as prostaglandins (PG) and leukotrienes, which modulate inflammatory responses. $\mathrm{PGE}_{2}$ promotes the production of IgE via stimulating Th0 (naïve T cells) cells to produce IL-4 and -5 . N-3 PUFA competes with n-6 PUFA for incorporation in the membranes of inflammatory cells. If $n-3$ PUFA partially replace the $\mathrm{AA}$ in cells, then the production of pro-inflammatory eicosanoids decreases. N-3 PUFA are therefore thought to be anti-inflammatory $[15,20]$. However, the exact net effect of (dietary) PUFA on the production of various cytokines, and consequently the balance between Th1- and Th2-mediated immunity, remains unclear [21].

The increase in atopy incidence has also been linked to the fact that the Western diet is increasingly deficient in antioxidants due to a decrease in vegetable consumption, especially green vegetables and potatoes $[12,22]$. Oxidative stress is thought to play a key role in the pathogenesis of asthma and allergies; therefore, increasing the dietary intake of antioxidants could have a beneficiary effect on these diseases [23]. Vitamins C, E, and, to a lesser extent, A all act as antioxidants [11,12]. Furthermore, all three vitamins play a role in lymphocyte proliferation, thereby further supporting the functioning of the immune system [11,24]. Vitamin $E$ has numerous anti-antioxidant properties such as the stimulation of Th1-reactions [25]. Higher dietary intake of vitamin $\mathrm{E}$ has also been found to decrease serum IgE [26].

\section{A nutrient-rich dietary advice}

Using information from the Dutch Nutrient Database, Leegsma et al. [27] composed a dietary advice of nutrient-rich products consisting of age dependent, child adequate portions of green vegetables five times a week, beef three times a week and daily consumption of full-fat milk/yogurt and butter. This dietary advice contains a more balanced composition of n-3 PUFA and n-6 PUFA and more antioxidants compared to comparable alternative food groups [28]. Ten Velde et al. [29] performed a pilot study to assess the clinical effect of this diet in children with recurrent respiratory tract infections. The result was a significant increase in illness-free days and a decrease in the use of antibiotics. In the discussion the authors hypothesised that the clinical effect of the dietary advice could be caused by a shift from Th2- to Th1-mediated immunity.

The aim of the present pilot study is to investigate the immunomodulating effect of this dietary advice in children with non-specific elevated lgE. To measure this effect, total serum IgE was used as a marker of the balance between Th1 and Th2 mediated immunity. 


\section{SUBJECTS AND METHODS}

\subsection{Study design and study population}

The study was a case-control, non-randomised, retrospective study performed at the general paediatric outpatient clinic of Hospital Group Twente (ZGT), The Netherlands. The participating children with indications for allergy were referred by a general practitioner and were evaluated by one of the eleven paediatricians on the paediatric outpatient clinic. Presenting symptoms were recurrent upper respiratory tract infections, unexplained fatigue, atopic syndrome or bronchial hyper-responsiveness. The inclusion period was from October 2008 to March 2012. Children between twelve months and eighteen years of age who presented with allergy symptoms and a nonspecific elevated total serum IgE were included. An elevated total serum IgE was defined according to the age-related reference values of the laboratory [30]. For example, children under the age of 4 years should have IgE values below $10 \mathrm{kIU} / \mathrm{l}$. Under ten years the IgE should not exceed $50 \mathrm{kIU} / \mathrm{l}$. An additional criteria for inclusion was a follow-up IgE measurement within one year after $\mathrm{t}=0$. Exclusion criteria were immunological abnormalities upon laboratory analysis, like immunoglobulin deficiencies or neutropenia. Other exclusion criteria were complicated medical disorders like anatomical or chromosomal abnormalities (schisis, 22q11 deletion), milk allergy, malabsorption syndromes and treatment with anti-parasitic medication.

In standard patient care, when only a non-specific elevated IgE is found, no medical therapy is indicated. In our hospital, these patients received a scheduled follow up appointment in 3-6 months to evaluate the allergy symptoms and repeat the blood tests. The control group received this standard care.

To find an alternative way to lower IgE production, the hypothesis for the nutrient rich diet was introduced in 2011. We asked the parents of children with allergy symptoms who visited the outpatient clinic from 2011-2012 to consume the nutrient rich dietary advice. The intervention group was included in a 2 year time period from 2011-2012. They also received a scheduled appointment in 3-6 months to evaluate clinical findings together with the blood test results. All data was analysed retrospectively. Control patients, receiving standard care, could be collected back to 2008. This was a large database, so the two groups could be matched based on age upon inclusion, IgE at $t=0$, follow-up duration and gender.

\subsection{Intervention}

The participants in the intervention group received a dietary advice consisting of age-appropriate quantities of green vegetables five times a week, beef three times 
$62 \mid$ Chapter 3

a week, $200 \mathrm{ml}$ of whole milk or yogurt daily and full-fat butter on one to two sandwiches daily (Table 1). These age appropriate quantities were advised on a diet sheet, which parents could take with them.

Table 1. Advised age appropriate portions for children aged 1-4 years

$\begin{array}{ll}\text { Product } & 1-4 \mathrm{y} \\ \text { green vegetables with supper } 5 \text { times a week; } & 50-100 \mathrm{~g} \\ \text { beef with supper } 3 \text { times a week; } & 50-60 \mathrm{~g} \\ 200 \mathrm{~mL} \text { of whole bovine milk daily; } & 200 \mathrm{~mL} \\ \text { whole dairy butter on bread daily. } & 5 \mathrm{~g} / \text { slice }\end{array}$

Otherwise the participants were permitted to follow their usual dietary pattern. The dietary advice was implemented for three months with a follow-up appointment around that time.

The control group consisted of patients with the same symptoms and non-specific elevated IgE. Since no medical therapy was indicated, they received standard patient care, which was a scheduled follow up appointment to evaluate the allergy symptoms and repeat the blood tests. No changes to their dietary habits were made.

\subsection{Measurements}

Upon presentation the included participants were evaluated for immunological disorders according to the Dutch flow chart for the evaluation of immunological disorders [31]. During the intake consultation with the paediatrician, the symptoms were documented along with the baseline length and weight. The Z-score of the weight for height was calculated via paediatric calculators on UpToDate [32-34]. One month later, the blood results were discussed with the parents of the child. When a medical condition was found, this condition was treated.

Non-specific elevated IgE was measured in the serum of non-fasting children. We used a serum blood tube from Becton Dikison. We analysed fresh samples with the Solid Phase Chemiluminiscent Immunometric Assay, Siemens. CVs at 50, 107, 223 and 600 $\mathrm{IU} / \mathrm{ml}$ are respectively, 5.1, 6.7, 6.7 and $6.4 \%$.

After approximately three months the participants returned to the outpatient clinic for a follow-up appointment and the serum IgE analysis was repeated. The duration of the follow-up was recorded as the difference between publication of the intake and follow-up blood analyses. During the follow-up consultation the parents were asked if they had noticed a subjective change in symptoms compared to their previous visit. 
This was recorded in the database as 'none', 'moderate' or 'considerable'. The weight and height measurements were repeated. If this was omitted during the follow-up consultation, measurements up to one and a half months around the consultation date were included in the database.

Because the dietary advice included full fat milk/yogurt and butter, we measured growth parameters before and after the dietary advice.

Finally, in the intervention group compliance with the dietary advice was determined based on oral feedback. Compliance (adherence to the dietary advice) was calculated based upon each component of the diet separately and for the dietary advice as a whole. Less than $50 \%$ compliance was recorded as 'no compliance', between 50 and $75 \%$ as 'moderate compliance' and $>75 \%$ as 'full compliance'. The overall compliance was the sum of the partial compliance scores.

\subsection{Statistical analysis}

Continuous normally distributed and non-normally distributed baseline characteristics were recorded as the mean and standard deviation (SD) or the median with the 25th and 75th percentiles, respectively. Categorical baseline characteristics were recorded as amounts with percentages of the total. Differences in continuous variables between two groups were compared using the Student's T-test or the Mann-Whitney U test, depending on normal distribution. Categorical variables were analysed using the Chisquared test. Where the association between two continuous variables was analysed, the Spearman's rank or Pearson's test was used as appropriate. Repeated measurements were compared with a paired t-test or Wilcoxon signed rank test depending on normal distribution. Multivariate linear regression was used to analyse the effect of a group on change in IgE corrected for confounders.

A value of $p<0.05$ was considered significant. All analyses were conducted using IBM SPSS Statistics (version 20.0.0, 2011, IBM Corp.).

\subsection{Ethics}

This study was a retrospective study using information from the patients' files. Therefore evaluation by an ethical committee was not required. In 2008 the Central Committee on Research involving Human Subjects was consulted for the dietary advice. They judged the dietary advice that was used as intervention contained ageappropriate standard nutritional components and confirmed that it did not constitute a major lifestyle change. 


\section{RESULTS}

\subsection{Description of study subjects}

In total 105 patients were included. Forty-nine received the dietary advice and were evaluated in the intervention group, and the control group consisted of 56 patients who did not receive a dietary advice. The characteristics of both groups are shown in Table 2. There was no significant difference found between age upon inclusion, baseline IgE and gender because the groups were matched for these criteria. The follow-up duration was longer in the control group compared to the intervention group. The use of medication was significantly different between the intervention group and the control group. The intervention group used more vitamin D supplements and less inhalation medication or histamine antagonists. Vitamin D supplementation was given as single therapy, not with combination medications or cod liver oil. The possible effect of confounders is described in section 3.3.

Table 2. Descriptive characteristics of the Intervention and Control groups.

\begin{tabular}{|c|c|c|c|}
\hline & $\begin{array}{l}\text { Intervention } \\
(n=49)\end{array}$ & $\begin{array}{l}\text { Control } \\
(n=56)\end{array}$ & $P$-value \\
\hline Age at inclusion (years) ${ }^{a}$ & $4.73(2.13-9.14)$ & $4.57(2.10-9.69)$ & 0.93 \\
\hline Baseline IgE (kIU/l) ${ }^{a}$ & $150.0(34.3-452.0)$ & $142.0(29.7-472.8)$ & 0.88 \\
\hline Follow-up duration (months) ${ }^{a}$ & $3.80(3.45-4.78)$ & $6.22(3.08-9.48)$ & 0.09 \\
\hline Males ${ }^{\text {b }}$ & $30(61.2 \%)$ & $32(57.1 \%)$ & 0.67 \\
\hline \multicolumn{4}{|l|}{ Indication/presenting symptoms ${ }^{\text {b }}$} \\
\hline $\begin{array}{l}\text { Recurrent upper respiratory tract } \\
\text { infections }\end{array}$ & $22(44.9 \%)$ & $17(30.4 \%)$ & 0.12 \\
\hline Fatigue/general malaise & $12(24.5 \%)$ & $10(17.9 \%)$ & 0.41 \\
\hline $\begin{array}{l}\text { Asthma/bronchial hyper } \\
\text { responsiveness }\end{array}$ & $8(16.3 \%)$ & $17(30.4 \%)$ & 0.09 \\
\hline Other & $7(14.3 \%)$ & $12(21.4 \%)$ & 0.34 \\
\hline \multicolumn{4}{|l|}{ Medication ${ }^{\mathrm{b}}$} \\
\hline None & $17(34.7 \%)$ & $9(16.1 \%)$ & 0.03 \\
\hline Inhalation medication & $7(14.3 \%)$ & $31(55.4 \%)$ & $<0.001$ \\
\hline Vitamin D supplementation & $20(40.8 \%)$ & $7(12.5 \%)$ & 0.001 \\
\hline Histamine antagonist & $6(12.2 \%)$ & $13(23.2 \%)$ & 0.15 \\
\hline Other & $10(20.4 \%)$ & $15(26.8 \%)$ & 0.44 \\
\hline Ear, nose, throat operation ${ }^{\mathrm{b}}$ & $3(6.1 \%)$ & $6(10.7 \%)$ & 0.50 \\
\hline
\end{tabular}

\subsection{Change in lgE: intervention versus control group}

Table 3 compares the change in IgE between the intervention group and control group before taking the effect of possible confounders into account. The absolute 
value of the median follow up IgE was lower in the intervention group, but the wide interquartile range could have an effect on its significance. The median decrease in IgE was higher in the intervention group, with a decrease of $9.2 \mathrm{kU} / \mathrm{l}$ vs. $0.1 \mathrm{kU} / \mathrm{l}$ in the control group, and this was significant $(p=0.02)$. The IgE value normalised in $11 \mathrm{pa-}$ tients in total, of which four were in the intervention group. This was not significantly different from the control group.

Table 3. Change in IgE depending on the Study group.

$\begin{array}{llll} & \text { Intervention } & \text { Control } & p \text {-value } \\ \text { Baseline IgE }(\mathrm{kU} / \mathrm{l})^{\mathrm{a}} & 150.0(34.3-452.0) & 142.0(29.7-472.8) & 0.88 \\ {\text { Follow-up IgE }(\mathrm{kU} / \mathrm{l})^{\mathrm{a}}}^{\mathrm{a}} & 94.7(25.5-394.0) & 130.5(35.4-576.8) & 0.41 \\ \text { Decrease in } \operatorname{lgE}(\mathrm{kU} / \mathrm{l})^{\mathrm{a}} & 9.2(-5.1-83.3) & 0.1(-78.3-21.5) & 0.02^{*}\end{array}$

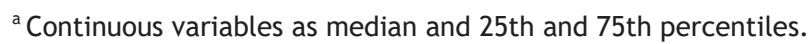

"Significant values $(p<0.05)$ are printed in bold.

\subsection{Selection of confounders}

The effect of presentation with recurrent upper respiratory tract infections or asthma/ bronchial hyper-responsiveness was found to have no significant effect on the change in IgE. There was no significant difference in change in IgE between the patients who used medication and those who used none $(p=0.54)$. The use of histamine antagonists was also found not to have a significant effect on the decrease in $\lg E(p=0.70)$. Patients who used vitamin D had a larger decrease in IgE, $49 \mathrm{kU} / \mathrm{l}$ vs. $0.5 \mathrm{kU} / \mathrm{l}$, than those who did not use vitamin $\mathrm{D}$. This difference was found to be significant, with a $\mathrm{p}$-value of $<0.001$. The use of inhalation medication had the opposite effect; those who used inhalation medication had a lower decrease in IgE than those who did not (0.5 vs. $5.6 \mathrm{kU} / \mathrm{l}$ with $\mathrm{p}=0.07$ ). Therefore, vitamin $\mathrm{D}$ use and inhalation medication use were included as confounders in the multivariate linear regression analysis.

\subsection{Change in lgE: multivariate linear regression}

In the first multivariate linear regression model inhalation medication was not found to be a significant confounder for the decrease in $\operatorname{lgE}(p=0.83)$. This variable was therefore excluded as a confounder from the final analysis.

In the intervention group the IgE decrease was $71.3(\mathrm{kU} / \mathrm{l})$ more than in the control group when vitamin D use was taken into account. However, this difference was not found to be significant ( $p=0.16$ ). Vitamin $D$ use was still found to be a significant factor for determining the decrease in IgE in this final model, with a $p$-value of 0.048 . 


\subsection{Secondary outcomes}

The change in symptoms was recorded for 47 of 49 patients in the intervention group (95.9\%) and all of the control patients (Figure 1).

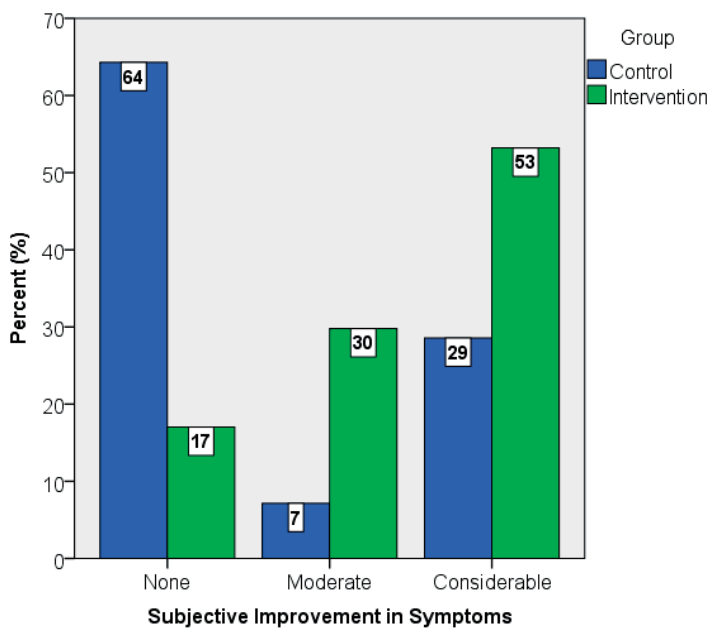

Figure 1: Subjective Improvement in Symptoms

More patients reported a considerable improvement in symptoms in the intervention group than in the control group, with percentages of $53.2 \%$ vs. $28.6 \%$, respectively. Only $17 \%$ reported no improvement in symptoms in the intervention group compared with $64.3 \%$ in the control group. This difference in symptom improvement was significant $(\mathrm{P}<0.001)$.

Compliance data was available for 42 patients with regard to the use of full fat products $(85.7 \%)$ and for 44 patients with regard to the use of beef and green vegetables (89.8\%). Total compliance was calculated for 43 patients (87.8\%). A smaller percentage of patients were compliant for the use of full fat products than for the use of beef and green vegetables, with $38 \%$ vs. $70 \%$ of patients having full compliance, respectively. In total, only $2 \%$ had less than $50 \%$ compliance to the entire dietary advice.

In the intervention group the height and weight was recorded for 35 children at intake (71\%) and 29 children at follow-up (59\%). The mean Z-scores are shown in Table 4. No significant change in the weight for height Z-score was found during the study period in either the intervention group or the control group. 
Table 4. Weight for Height Z-scores at Intake and Follow-up.

$\begin{array}{lllll} & \text { Intake }(n=35) & \text { Follow-up }(n=29) & \text { Difference }(n=25) & p \text {-value * } \\ \text { Intervention group }^{\text {a }} & -0.02 \pm 1.25 & -0.03 \pm 1.09 & 0.20 \pm 0.71 & 0.18 \\ \text { Control group }^{\text {a }} & -0.37 \pm 1.18 & -0.32 \pm 1.29 & 0.11 \pm 0.56 & 0.32\end{array}$

**ignificant values $(p<0.05)$ are printed in bold.

${ }^{\text {a }}$ Mean Z-score \pm SD.

\section{DISCUSSION}

In this study we found a beneficial effect of nutrients and/or vitamin D supplementation on total IgE levels in children with non-specific allergic complaints. We started to investigate the effect of dietary advice consisting of beef, green vegetables, whole milk or yogurt and full fat butter on serum total IgE. The initial results were promising, showing a significantly larger decrease in IgE in the study group when compared to the group that did not receive dietary advice $(p=0.02)$. However, we found that the intervention group also used vitamin $D$ supplementation more frequently. When this confounder was included in the final analysis, the dietary advice alone was found to have no significant effect on IgE $(p=0.16)$.

Vitamin D was found to have a significant effect on the decrease in IgE in our final analysis. The children who used vitamin D supplementation had an IgE decrease that was $20 \%$ higher when compared to those who did not take vitamin D. Vitamin $D$ has many known effects on the immune system, including modulating the balance between Th1 and Th2 responses [13,35,36], and deficiency has been found to increase IgE level [37]. Was there also a higher vitamin D content in the dietary advice? In absolute terms, the dietary advice was not rich in vitamin D. The vitamin D content of beef is suggested as a dietary source of vitamin $D$ [46], but since there is no consensus upon bioavailability factors, this remains a subject for discussion [47]. Bioavailability is also a subject of discussion concerning whole milk and butter. The absolute content of the fat soluble vitamin D in whole milk and butter is lower compared to artificially fortified butter, but the bioavailability has not been investigated.

Although there are multiple studies discussing the theoretical and in vitro immunomodulatory effects of nutrition on allergic markers, the epidemiological and clinical evidence is still inconclusive. Kremmyda et al. [15] carried out a systematic review of the literature regarding the effect of dietary n-3 PUFA. They found that 9 out of 14 epidemiological studies "showed a protective effect of fish intake during infancy or childhood on atopic outcomes" although the decrease in risk varied greatly between these studies. The effect of maternal fish intake during pregnancy seems more 
promising. Studies by Litonjua et al. [13], Devereux et al. [12] and Nurmatov et al. [38] reviewing the literature regarding the effect of vitamin status and supplementation on the incidence of allergy did not find a significant beneficial effect of these vitamins. They all concluded that further research is needed, especially in the form of clinical trials.

Calder et al. [20] suggested that a possible reason for the varying clinical benefits of n-3 PUFA supplementation in atopic disease could be that the intervention is given too late, an opinion shared by Devereux et al. [12]. This could explain the lack of any significant effect of the dietary advice on IgE in our study, as the mean age of the children in our intervention group was almost five years upon inclusion. At this age it is possible that the development of allergy is already finalised and any dietary interventions need to have taken place earlier; either during the first few years of infancy or via maternal supplementation.

Although the effect of the dietary advice itself on IgE was not proven, the participants in the intervention group subjectively experienced a significantly better improvement in symptoms when compared to the control group. The aetiology of allergies is complex, and the previous view that a skewed Th1/Th2-response balance in favour of Th2-responses is the most important underlying cause is currently being replaced by newer theories. This is especially so due to the fact that there is no definitive evidence that Th1-reactions are impaired in the case of atopy [16]. It is therefore plausible that the dietary advice did have a positive immunomodulatory effect, but one that did not have an effect on IgE. It is also possible that the significant differences in clinical outcomes were solely due to the difference in vitamin D usage.

We found greater compliance with the use of beef and green vegetables than with the use of full-fat products. This was expected, due to the negative views regarding the use of full-fat products that many parents voiced when the dietary advice was given. The American Heart Association also recommends fat-free or low-fat dairy products for children [39], mainly due to the generally accepted view that increased intake of full-fat products leads to increased incidence of obesity and obesity-related diseases [40]. In our study population we addressed this concern and found no significant increase in weight for height Z-score, either in the intervention group or the control group. This is in concordance with multiple recent studies suggesting that the intake of full-fat dairy products is not associated with increased body mass index in preschoolers [41,42]. Although our preliminary results were positive, the long-term effects of the dietary advice on weight and health still remain to be investigated. 
There were also major limitations to this study. First, the dietary advice did not consist of absolute amounts of each product, but parents were advised to give "ageappropriate servings" and were given freedom as to choice in application of the diet. The wide variations in nutrient content in different products and the fact that the exact dietary intake of neither the intervention nor the study group was investigated make it difficult to draw conclusions concerning the exact differences in nutrient intake between the two study groups. Although a stricter diet and/or vitamin/nutrient supplementation may be a better intervention to achieve the desired immunomodulatory effect, we believe that the ease of application of the dietary advice is a crucial advantage of this intervention that leads to better compliance. This is reflected in our results; around $50 \%$ of participants were fully compliant with the dietary advice. This is contrary to what is generally reported in the literature, namely, that changes in dietary patterns are difficult to adhere to $[43,44]$. However, it is possible that greater compliance with the dietary advice was reported than was the case in reality [45].

Another major limitation is that the study was a case-control, non-randomised, retrospective study. The discrepancies in duration of follow-up and the frequency of use of certain medications between the two study groups, which had a significant effect on the outcome of the study, highlight these limitations. The greater use of inhalation medication could be reflected in a higher burden of illness in the control group, but it could also be an attempt to improve symptoms, since doing nothing is frustrating for some parents. Also, due to the small population size, we included patients of the paediatrician who gave the dietary advice and other paediatricians in the control group, but only patients of the paediatrician who gave the dietary advice in the intervention group. This increased the chance of selection bias in the intervention group, as it is plausible that the parents who were motivated to try the dietary advice also have a healthier lifestyle in general.

In the study design, the change in IgE as the primary outcome is a clear outcome. The secondary outcomes, however, are less objectified, like oral feedback related to the dietary intake and subjective evaluation of the improvement. These subjective changes can also be caused by the Hawthorne effect; the patients improved in their behaviour in response to their awareness of being observed. In the control group this was not the case, since this group was studied retrospectively.

We calculated the additional costs of the dietary advice, which was $€ 0.67$ / week. Most parents did not think the costs formed an obstacle to starting the diet. In the future, further research is needed in the form of a randomised controlled trial to further study the possible effects of the dietary advice. 
$70 \mid$ Chapter 3

\section{Conclusion}

Overall, the benefits of nutrition and vitamin D on the decrease in IgE are promising. A dietary advice consisting of beef, green vegetables, full-fat butter and whole milk and/or yogurt and vitamin D supplements did decrease IgE levels in children with nonspecific allergic symptoms when compared to children who did not receive the dietary advice. Due to methodological flaws in this pilot study, the separate contributions of the dietary advice and/or supplements need to be investigated in the future. 


\section{BIBLIOGRAPHY}

1. Bach JF. (2002) The effect of infections on susceptibility to autoimmune and allergic diseases. N Engl J Med.;347(12):911-920.

2. Flohr C. (2011) Recent perspectives on the global epidemiology of childhood eczema. Allergol Immunopathol (Madr). 39(3):174-182.

3. Asher MI, Montefort S, Bjorksten B, et al. (2006) Worldwide time trends in the prevalence of symptoms of asthma, allergic rhinoconjunctivitis, and eczema in childhood: ISAAC phases one and three repeat multicountry cross-sectional surveys. Lancet. 368(9537):733743.

4. Weiss KB, Sullivan SD, Lyttle CS. (2000) Trends in the cost of illness for asthma in the united states, 1985-1994. J Allergy Clin Immunol. 106(3):493-499.

5. Zuhair K Ballas M. UpToDate: "T helper subsets: Differentiation and role in disease". http://www.uptodate.com/ contents/t-helper-subsets-differentiation-and-role-in-disease. Updated 2013. Accessed August, 2013.

6. Burton OT, Oettgen HC. (2011) Beyond immediate hypersensitivity: Evolving roles for IgE antibodies in immune homeostasis and allergic diseases. Immunol Rev. 242(1):128-143.

7. Gould HJ, Sutton BJ. (2008) IgE in allergy and asthma today. Nat Rev Immunol. 8(3):205-217.

8. Carosso A, Bugiani M, Migliore E, Anto JM, DeMarco R.(2007) Reference values of total serum IgE and their significance in the diagnosis of allergy in young european adults. Int Arch Allergy Immunol. 142(3):230-238.

9. Guyton AC, Hall JE. (2006) Textbook of medical physiology. 11th ed. Philadelphia, PA: Elsevier Saunders; 1116.
10. Rijkers GT. (2009) Immunologie. 1e dr ed. Houten: Bohn Stafleu van Loghum; 408.

11. Field CJ, Johnson IR, Schley PD. (2002) Nutrients and their role in host resistance to infection. J Leukoc Biol. 71(1):16-32.

12. Devereux G, Seaton A. (2005) Diet as a risk factor for atopy and asthma. J Allergy Clin Immunol. 115(6):1109-17; quiz 1118.

13. Litonjua AA.(2012)Fat-soluble vitamins and atopic disease: What is the evidence? Proc Nutr Soc. 71(1):67-74.

14. Calder PC, Yaqoob P. (2009) Omega-3 polyunsaturated fatty acids and human health outcomes. Biofactors. 35(3):266-272.

15. Kremmyda LS, Vlachava M, Noakes PS, Diaper ND, Miles EA, Calder PC. (2011) Atopy risk in infants and children in relation to early exposure to fish, oily fish, or long-chain omega-3 fatty acids: A systematic review. Clin Rev Allergy Immunol. 41(1):36-66.

16. Prescott SL, Calder PC. (2004) N-3 polyunsaturated fatty acids and allergic disease. Curr Opin Clin Nutr Metab Care. 7(2):123-129.

17. Sala-Vila A, Miles EA, Calder PC. (2008) Fatty acid composition abnormalities in atopic disease: Evidence explored and role in the disease process examined. Clin Exp Allergy. 38(9):1432-1450.

18. Black PN, Sharpe S. (1997) Dietary fat and asthma: Is there a connection? Eur Respir J. 10(1):6-12.

19. Hodge L, Peat JK, Salome C. (1994) Increased consumption of polyunsaturated oils may be a cause of increased prevalence of childhood asthma. Aust $\mathrm{N}$ Z J Med. 24(6):727.

20. Calder PC, Miles EA. (2000) Fatty acids and atopic disease. Pediatr Allergy Immunol. 11 Suppl 13:29-36. 
21. Calder PC. (1998) Dietary fatty acids and lymphocyte functions. Proc Nutr Soc. 57(4):487-502.

22. Seaton A, Godden DJ, Brown K. (1994) Increase in asthma: A more toxic environment or a more susceptible population? Thorax. 49(2):171-174.

23. Riedl MA, Nel AE. (2008) Importance of oxidative stress in the pathogenesis and treatment of asthma. Curr Opin Allergy Clin Immunol. 8(1):49-56.

24. Maggini S, Wenzlaff S, Hornig D. (2010) Essential role of vitamin $C$ and zinc in child immunity and health. J Int Med Res. 38(2):386-414.

25. Han SN, Wu D, Ha WK, et al. (2000) Vitamin $\mathrm{E}$ supplementation increases $\mathrm{T}$ helper 1 cytokine production in old mice infected with influenza virus. Immunology. 100(4):487-493.

26. Fogarty A, Lewis $S$, Weiss S, Britton J. (2000) Dietary vitamin E, IgE concentrations, and atopy. Lancet. 356(9241):1573-1574.

27. Leegsma MAJ. Kwakkelkleuters: Diagnoses en immuunmodulatie door voeding. http://irs.ub.rug.nl/dbi/4b56fb822 ae01. Updated 2010. Accessed July, 2013.

28. National Institute for Public Health and the Environment (RIVM)/the Kingdom of the Netherlands. NEVO online version 2011/3.0, Bilthove. http:// nevo-online.rivm.nl/. Updated 2011. Accessed August, 2013.

29. Ten Velde LGH, Leegsma J, Van der Gaag EJ. (2013) Dietary advice can reduce recurrent upper respiratory tract infections in children; the influence of green vegetables, beef, whole milk and butter. Food Nutr Sci. 4(10A).

30. Medlon medische diagnostiek: Referentiewaarden (version 14). http:// www.medlon.nl/professional/referentiewaarden/. Accessed May, 2013.
31. de Vries E. (2006) Clinical Working Party of the European Society for Immunodeficiencies (ESID). Patient-centred screening for primary immunodeficiency: A multi-stage diagnostic protocol designed for non-immunologists. Clin Exp Immunol. 145(2):204-214.

32. UpToDate: "calculator: Body mass index (BMI) percentiles for boys (2 to 20 years)" . http://www.uptodate.com/contents/ calculator-body-mass-index-bmipercentiles-for-boys-2-to-20-years. Accessed July/30, 2013.

33. UpToDate: "calculator: Body mass index (BMI) percentiles for girls (2 tot 20 years)". http://www.uptodate. com/contents/calculator-body-massindex-bmi-percentiles-for-girls-2-to20-years. Accessed July/30, 2013.

34. UpToDate: "calculator: $\mathrm{CDC} / \mathrm{NCHS}$ infant weight for length percentiles (<36 months)". http://www.uptodate. com/contents/calculator-cdc-nchsinfant-weight-for-length-percentilesless-than36-months. Accessed July/30, 2013.

35. Yang CY, Leung PS, Adamopoulos IE, Gershwin ME. (2013) The implication of vitamin D and autoimmunity: A comprehensive review. Clin Rev Allergy Immunol.

36. Reinholz M, Ruzicka T, Schauber J. (2012)Vitamin D and its role in allergic disease. Clin Exp Allergy. 42(6):817826.

37. Brown KH, Peerson JM, Baker SK, Hess SY. (2009) Preventive zinc supplementation among infants, preschoolers, and older prepubertal children. Food Nutr Bull. 30(1 Suppl):S12-40.

38. Nurmatov U, Devereux G, Sheikh A. (2011) Nutrients and foods for the primary prevention of asthma and allergy: Systematic review and meta-analysis. J Allergy Clin Immunol. 127(3):724-33. e1-30. 
39. Gidding SS, Dennison BA, Birch LL, et al. (2006) Dietary recommendations for children and adolescents: A guide for practitioners. Pediatrics. 117(2):544559.

40. Patel Al, Cabana MD. (2010) Encouraging healthy beverage intake in child care and school settings. Curr Opin Pediatr. 22(6):779-784.

41. Huh SY, Rifas-Shiman SL, Rich-Edwards JW, Taveras EM, Gillman MW. (2010) Prospective association between milk intake and adiposity in preschool-aged children. J Am Diet Assoc. 110(4):563570.

42. Scharf RJ, Demmer RT, DeBoer MD. (2013) Longitudinal evaluation of milk type consumed and weight status in preschoolers. Arch Dis Child. 98(5):335340.

43. Truswell AS. (2000) Family physicians and patients: Is effective nutrition interaction possible? Am J Clin Nutr. 71(1):6-12.

44. Mant D. (1997) Effectiveness of dietary intervention in general practice. Am J Clin Nutr. 65(6 Suppl):1933S-1938S.

45. LaFleur J, Oderda GM. (2004) Methods to measure patient compliance with medication regimens. J Pain Palliat Care Pharmacother. 18(3):81-87.

46. van Rossum CTM, Fransen HP, VerkaikKloosterman J, Buurma-Rethans EJM,Okce MC. Dutch National Food Consumption Survey 2007-2010, Ministry of Health, Welfare and Sports, The Netherlands.

47. Ovesen L, Brot C, Jakobsen J. (2003) Food contents and biological activity of 25-hydroxyvitamin D: a vitamin D metabolite to be reckoned with? Ann Nutr Metab. 47(3-4):107-13. 


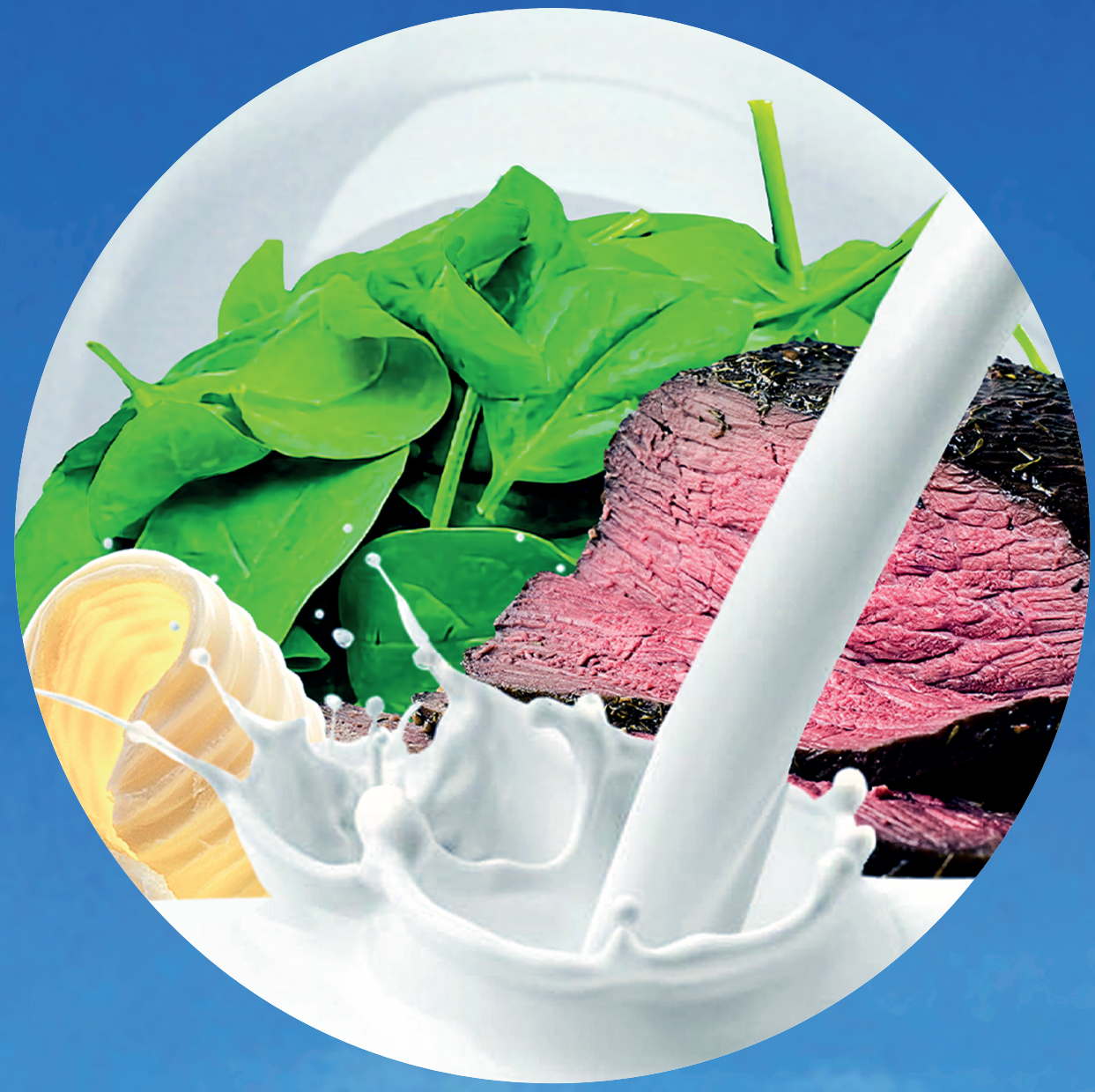




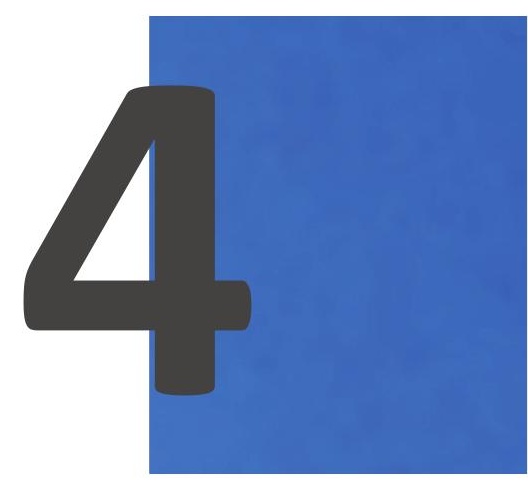

\section{Could a Change in Diet Revitalize Children Who Suffer from Unresolved Fatigue?}

Steenbruggen TG, Hoekstra SJ, van der Gaag EJ.

Nutrients. 2015 Mar 13;7(3):1965-77. doi: 10.3390/nu7031965. 


\section{ABSTRACT}

Many children deal with fatigue for which no proper treatment can be given. A possible explanation for their fatigue is a micro deficiency of minerals and vitamins. In this non-randomized controlled trial, we clinically evaluated symptoms of fatigue in children for whom a nutrient-rich diet was advised. A group of 98 children (2-18 years old) with unexplained symptoms of fatigue was examined. The dietary modifications consisted of green vegetables, beef, whole milk and full-fat butter. Children in the intervention group were asked to follow the diet for three months, whereas the controlgroup followed their normal diet. The primary outcome was symptoms of fatigue, as determined by a PedsQL Multidimensional Fatigue Scale, and secondary outcomes were compliance with the diet and BMI. Children, who followed the diet showed a significant decrease in the need to sleep $(\mathrm{Cl} 0.83 ; 14.86, \mathrm{p}=0.03)$. They slept better through the night and took fewer naps. When analyzing components of the advised diet separately, a significant larger decrease in cognitive fatigue symptoms was seen for eating green vegetables according to the diet guidelines $(\mathrm{Cl} 2.27 ; 30.63, \mathrm{p}=$ 0.024). Furthermore, a lower need to sleep was seen when whole milk was consumed almost daily $(\mathrm{Cl} 0.02 ; 14.62, \mathrm{p}=0.049)$. Our study showed that nutritional advice is an elegant, and effective method for decreasing some symptoms of medically unresolved fatigue in children. 


\section{INTRODUCTION}

Unresolved fatigue affects many children: $1.4 \%$ of children under $12 \%$ and $2.6 \%$ of children between 12 and 18 in the Netherlands experience fatigue, as reported by general practitioners [1]. Self-reporting of fatigue is even higher at $23 \%-26 \%$ in children under 12 and up to $34 \%-46 \%$ in teenagers [1,2,3]. Fatigue in children can cause many problems. They experience cognitive problems such as decreased concentration and school absenteeism, often resulting in less or a lower level of education $[1,4,5]$. Children who suffer from fatigue are less resilient, have lower immune resistance [6], and experience sleep disturbances [7]. Although fatigue is hard to define, it is often under-diagnosed by both general practitioners and pediatricians.

Fatigue can have many different causes; however, without a medical cause for the fatigue, pediatricians or general practitioners cannot start a therapy. Once infections, anemia, chronic disease, and psychosocial imbalance are ruled out, there is still a group of patients without a clear cause and children for whom adequate medical therapy does not help. A possible cause for children with unresolved fatigue is a micro deficiency of vitamins and minerals, which can be difficult to detect $[8,9]$. Iron deficiency without anemia has been shown to cause fatigue and impair cognitive function in children and adolescent girls [10,11]. Individual micronutrients including iron [10,11], magnesium [12,13], vitamin B [14], vitamin C [15], vitamin E [16,17], and fatty acids $[18,19]$ have been shown to have an effect on fatigue. Clinical studies show that approximately $20 \%$ of children under eight do not eat enough fruit and vegetables and do not reach the minimum level of dairy intake (according to European guidelines: EFSA) [20,21,22].

A further problem that can develop is chronic fatigue syndrome (CFS). More research has been done about the effects of nutrients on clinical symptoms in patients with CFS. A diet with enhanced vitamins and minerals in combination with psychological training significantly improves symptomatology and fatigue in CFS-patients [23]. However, the patients in the CFS study were individually selected for the combined intervention and without a control group it is difficult to prove statistical significance and apply their results in the clinic.

Finally, previous studies in our hospital have shown that a nutrient-rich diet had a positive effect on recurrent upper airway infections and on subclinical hypothyroidism in children [6,24]. The components were chosen based on their high vitamin and mineral content [25]. The advised diet contains more vitamins A, B2, B12, C, D and E, 
iron, folic acid, zinc, calcium, phosphorus, Beta-carotene, and (alpha)-linoleic acid than a regular diet (Table 1 and Table S1 in supplementary materials) [25].

This study was conducted as a prospective, non-randomized controlled trial, which focuses on a dietary advice as an intervention to reduce fatigue in children.

\section{EXPERIMENTAL SECTION}

\subsection{Study Population}

Children (2-18 years old) who were referred by a general practitioner to a pediatrician with (subjective) complaints of fatigue between September 2011 and February 2012 were included in this study. Their fatigue could not be explained by interview, physical examination, or laboratory blood tests $(\mathrm{Hb}, \mathrm{Ht}, \mathrm{MCV}, \mathrm{MCH}, \mathrm{MCHC}, \mathrm{RDW}$, thrombocytes, leukocytes (including differentiation), TSH, FT4, 25-OH-vitamin-D3, IgE and allergy screening). In cases of a possible medical condition, a treatment was started and they were no longer appropriate for this study.

Children with fatigue due to an untreated underlying somatic or mental disease or with low pediatric quality of life inventory (PedsQL) scores (>98.0) were excluded.

When children were treated for their underlying somatic disease, and there was no improvement of the fatigue with appropriate treatment (e.g., supplementation of vitamin D or the use of anti-histamine), they could also be included.

The control group consisted of children that visited the same outpatient clinic for fatigue symptoms, in the period from March 2011 until August 2011 (six months before the treatment group). The same inclusion and exclusion criteria were used for both the control and the intervention group. 
Table 1. Comparison regular diet and advised diet based on regular dietary intake for a child 7 years of age.

\begin{tabular}{lll} 
Dependent variable & Regular Diet & Advised Diet \\
\hline Vitamin A $(\mu \mathrm{g})$ & 169.00 & 198.80 \\
Vitamin C $(\mathrm{mg})$ & 38.25 & 47.75 \\
Vitamin D $(\mu \mathrm{g})$ & 1.57 & 0.51 \\
Vitamin E $(\mathrm{mg})$ & 2.79 & 12.56 \\
Vitamin B2 $(\mathrm{mg})$ & 2.39 & 2.30 \\
Vitamin B12 $(\mu \mathrm{g})$ & 4.82 & 5.29 \\
Iron $(\mathrm{mg})$ & 4.37 & 5.42 \\
Zinc $(\mathrm{mg})$ & 5.48 & 11.24 \\
Folic Acid $(\mu \mathrm{g})$ & 192.51 & 337.96 \\
Phosphor $(\mathrm{mg})$ & 1745.80 & 1710.30 \\
Calcium $(\mathrm{mg})$ & 1485.80 & 1327.30 \\
Beta-caroten $(\mu \mathrm{g})$ & 5122.90 & 6035.90 \\
(alpha)-linoleic acid $(\%)$ & 40.62 & 44.74
\end{tabular}

The portions are based on a normal day menu according to the recommended daily intake for a child, 7 years of age, from the "Voedingscentrum", the Netherlands.

\subsection{Ethics}

All children and their parents received oral information about the study and were asked to give their informed consent. The central committee on research involving human subjects judged that dietary advice that includes regular food is not a major lifestyle change, and therefore an evaluation by an ethics committee was not necessary for this study. The control group was treated with standard care and followed up as usual as no extra interventions were necessary.

\subsection{Intervention}

Both groups received standard care. Standard care includes advice to keep an active lifestyle and to not spend too much time in bed. Furthermore a pediatrician followed up with regular checkups for all of the children. Children in the intervention group together with their parents received dietary advice from a pediatrician, which was comprised of four key components: green vegetables, beef, whole milk, and full-fat butter. Green vegetables should be eaten 5 times per week, in appropriate portions for the child's age (e.g., 2-3 tablespoons per day for toddlers). Beef should be eaten 3 times per week (e.g., 1-2 tablespoons per day for toddlers). Furthermore, one cup $(200 \mathrm{~mL})$ of whole milk per day and full-fat butter on bread was recommended. All parts of the diet were weighted equally, with a total possible score of $100 \%$ (e.g., vegetables 4 times per week is $80 \%$ compliance for the vegetable part, and $20 \%$ of the 
total compliance score). For children under 12 years of age, their parents were asked to cook together with the children and keep a diary to measure compliance. The pediatrician checked up monthly to control compliance with a specific questionnaire. The pediatrician (E. van der Gaag) designed a questionnaire, which has been used in earlier studies $[6,24]$.

The intervention was started one month after the screening and laboratory blood tests were done. The diet was followed over the course of at least 3 months, in which a pediatrician saw the children twice and checked up with them by phone monthly. After three months all children were evaluated with the PedsQL questionnaire.

\subsection{Measurements}

The PedsQL multidimensional fatigue scale (MAPI Research Trust), designed by Varni and colleagues, was used to evaluate fatigue before starting the diet and three months after the advice was given [26]. The PedsQL scale is a validated method to measure fatigue in children [26,27]. Fatigue was measured in three different ways: general fatigue, cognitive fatigue, and the need to sleep or rest, with 6 questions for each type. General fatigue measures the level of energy for normal daily activities (e.g., "I feel too tired to do the things I like."), cognitive fatigue measures the impact of fatigue on the level of concentration (e.g., "It is hard for me to keep my attention on things."), and the need to sleep measures how much time a child spends in bed or needs to rest (e.g., "I rest a lot."). Each question was answered on a five-point scale $(0$ = never, 1 = almost never, 2 = sometimes, 3 = almost always and 4 = always $)$. Each score from the questionnaire was transformed to a 0-100 scale, where a higher score reflects a lower impact of symptoms. Results were excluded when less than half of the questionnaire was filled out.

To check the compliance to the diet we used a simple questionnaire, which has been used in earlier studies with the same advised diet $[6,24]$.

Furthermore, weight and height were measured with the same measurement devices at the start and after 3 months so that body mass index (BMI) changes could be evaluated.

\subsection{Statistics}

Continuous variables are displayed as means (standard deviation (SD)) and categorical variables are displayed as numbers with corresponding percentages.

We used descriptive statistics to explore our results. A chi-square test was used to compare baseline categorical characteristics of the intervention and control groups, 
whereas an independent sample t-test was used for continuous variables, such as BMI. Afterwards, compliance with the diet between both groups was analyzed with an independent sample t-test. Furthermore, the effect of the diet on fatigue was analyzed with an analysis of covariance (ANCOVA). The data were first analyzed on an "intention to treat" basis, comparing the intervention group with the control group. Finally, a "per protocol" analysis was done, in which patients that did not follow the diet were removed, to evaluate the maximum possible effect. In the "per protocol" analysis children following the diet with a great than $75 \%$ score were included in the study. To correct for possible confounders, a multiple linear regression analysis was done for the overall diet and for the separate components.

To analyze the correlation between the compliance to the advised diet and change in score on the PedsQL a Spearman rank correlation analysis was performed.

For all analyses a p-value of 0.05 was used to define a significant difference. For the selection of confounders a p-value of 0.15 was used.

All statistical analyses were done with the program SPSS version 22.0.

\section{RESULTS}

\subsection{Study Population}

109 children were recruited, of which 98 were analyzed: 48 children were included between March 2011 and September 2011 and served as controls, 50 children were included between September 2011 and March 2012 and were put in the intervention group. Eleven children were excluded, as they did not meet the inclusion criteria: 3 children had an explanation for their fatigue, 2 children were too young, 3 children scored too high on the PedsQL questionnaire (PedsQL > 98; which means their subjective feeling of fatigue could not be found in objective questionnaires), and 3 children from the control group were lost to follow-up. In the "per protocol" analysis 88 children were included: 48 in the control group and 40 in the intervention group.

Demographic characteristics of the study population are shown in Table 2 . In the intervention group 27 children (54\%) had comorbidity on top of their fatigue, compared to 26 children (54\%) in the control group. These comorbidities included asthma or upper respiratory tract infection (URTI) or subclinical hypothyroidism and were similar for both groups (see Table S2 for more details). 


\subsection{Compliance of Intervention Group}

At the start of the study, children from the control group already followed the dietary advice for $29 \%$, whereas children in the intervention group did also for $29 \%$. The compliance increased spontaneously to $32 \%$ in the control group and to $85 \%$ in the intervention group. This difference in compliance was statistically significant $(95 \% \mathrm{Cl}$ $-0.58 ;-0.44, p=0.00$ ).

\subsection{Clinical Outcomes}

A decline in symptoms was seen across all components of the total PedsQL score in both groups, but with a stronger decline in the intervention group (see Table 3). In the intervention group the mean score for the need to sleep or rest increased with 12.0 points, compared to an increase of 4.4 points in the control group $(95 \% \mathrm{Cl} 0.83 ; 14.86$, $p=0.03)$. This means, the children showed a decreased need to sleep or take naps and spent less time in bed during the day. General fatigue improved with 9.5 points compared to 6.4 points in the control group and cognitive fatigue with 8.1 points and 2.9 for the intervention and control group respectively. However, the results were not significantly different (general fatigue: $95 \% \mathrm{Cl}-3.35 ; 11.09, \mathrm{p}=0.29$; cognitive fatigue: $95 \% \mathrm{Cl}-6.58 ; 11.90, \mathrm{p}=0.57$, respectively).

Table 2. Demographic characteristics baseline.

\begin{tabular}{|c|c|c|c|}
\hline$N=98$ & Intervention Group $(n=50)$ & ) Control Group ( $n=48)$ & p-value \\
\hline $\operatorname{Sex}(M / F)$ & $24 / 26$ & $21 / 27$ & 0.69 \\
\hline Age mean (SD) (years) & $7.44(5.0)$ & $7.0(4.8)$ & 0.66 \\
\hline FU time mean (SD) (days) & $137.1(67.0)$ & $141.9(72.8)$ & 0.73 \\
\hline General fatigue * & $49.6(19.0)$ & $47.9(24.2)$ & 0.70 \\
\hline Cognitive fatigue * & $55.3(22.1)$ & $60.0(24.6)$ & 0.33 \\
\hline Sleep/need to rest * & $57.1(20.4)$ & $55.8(18.7)$ & 0.74 \\
\hline Comorbid diagnosis (\%) & $27(54) \S$ & $26(54) \S$ & 0.41 \\
\hline Medication (\%) & $25(50) \S$ & $28(58) \S$ & 0.99 \\
\hline Compliance to the total diet (\%) & 29.8 & 29.3 & 0.91 \\
\hline $\begin{array}{l}\text { Compliance to green vegetables } \\
\text { (\%) }\end{array}$ & 47.1 & 56.5 & 0.26 \\
\hline Compliance to beef (\%) & 40.6 & 54.9 & 0.13 \\
\hline Compliance to whole milk (\%) & 17.0 & 8.6 & 0.24 \\
\hline Compliance to full fat butter (\%) & 12.5 & 2.5 & 0.09 \\
\hline
\end{tabular}

* Expressed as points on PedsQL scale (range 0-100); § Specified in Table S2 in supplementary materials. 
Table 3. Mean scores (range) after following the diet for three months and change (SD) in symptoms of fatigue measured by pediatric quality of life (PedsQL) scores.

\begin{tabular}{|c|c|c|}
\hline Dependent variable & Intervention Group $(\mathrm{N}=40)$ & Control Group ( $\mathrm{N}=48)$ \\
\hline \multicolumn{3}{|c|}{ Second score (range) PedsQL } \\
\hline General fatigue & $59.1(16.7-91.7)$ & $54.4(4.2-100.0)$ \\
\hline Cognitive fatigue & $66.7(0.0-100.0)$ & $63.8(16.7-100.0)$ \\
\hline Need to sleep & $66.5(29.2-95.8)$ & $60.1(16.7-100.0)$ \\
\hline \multicolumn{3}{|c|}{ Change (SD) in score PedsQL } \\
\hline General fatigue & $9.5(17.5)$ & $6.4(19.2)$ \\
\hline Cognitive fatigue & $8.1(21.4)$ & $2.9(18.4)$ \\
\hline Need to sleep & $12.0 *(17.8)$ & $4.4^{*}(16.3)$ \\
\hline
\end{tabular}

Analyzing the correlation between the rate of compliance and the effect of the advised diet showed similar results. A significant correlation was only seen for the variable "need to sleep" (data shown in Figure S1 in supplementary materials).

The difference in fatigue symptoms was also studied for the individual components of the diet, while taking confounders into account (e.g., first measurement of fatigue symptoms and a change in $\mathrm{BMI}$ ).

Green vegetables were shown to have a significant effect on cognitive fatigue (difference: $16.45,95 \% \mathrm{Cl} 2.27 ; 30.63, \mathrm{p}=0.024$ ). Green vegetables also showed a trend to improve general fatigue and reduced the need to sleep but not to significant difference. Furthermore, whole milk had a significant impact on the need to sleep (difference: 7.32, 95\% Cl 0.02; 14.62, $\mathrm{p}=0.049$ ) (Table 4).

Table 4. Analysis of Covariance of the effect of components of the diet on symptoms of fatigue.

\begin{tabular}{llllllllll} 
Dependent variable & \multicolumn{2}{c}{ Green Vegetables } & \multicolumn{2}{c}{ Beef } & \multicolumn{2}{c}{ Whole Milk } & \multicolumn{2}{c}{ Full-Fat Butter } \\
N = 88 & B * & $95 \% \mathrm{Cl}$ & $\mathbf{B} *$ & $95 \% \mathrm{Cl}$ & $\mathbf{B} *$ & $95 \% \mathrm{Cl}$ & $\mathbf{B} *$ & $95 \% \mathrm{Cl}$ \\
General fatigue & 8.88 & $-1.23 ; 18.99$ & 1.32 & $-10.12 ; 12.75$ & 3.62 & $-6.26 ; 13.50$ & -2.55 & $-12.07 ; 6.97$ \\
Cognitive fatigue & 16.45 & $2.27 ; 30.63$ & 3.83 & $-7.44 ; 15.10$ & -1.70 & $-11.26 ; 7.86$ & -1.20 & $-10.47 ; 8.08$ \\
Need to sleep & 8.12 & $-2.74 ; 18.98$ & 7.56 & $-0.94 ; 16.06$ & 7.32 & $0.02 ; 14.62$ & 2.63 & $-4.69 ; 9.96$
\end{tabular}

All analyses were corrected for the baseline values of the fatigue symptoms as well as for the change in BMI between the baseline and follow-up measurement. * $B$ represents the difference between the intervention and control group. A positive difference is in favor of the intervention group. 


\subsection{Impact on BMI}

For 35 children a change in BMI was measured (17 in the control group, 18 in the intervention group. Generally, full-fat products like whole milk and butter are expected to lead to weight gain. However, measurements before and after the diet showed a change in $\mathrm{BMI}$ in the control group of -0.39 and in the intervention group of 0.06 (95\% $\mathrm{Cl}-0.147 ; 1.03, \mathrm{p}=0.139$ ).

\section{DISCUSSION}

\subsection{Benefits of a Nutrient-Rich Diet}

This non-randomized controlled study showed a decline in clinical complaints of fatigue in children following the advised diet, especially in the need to rest and sleep. Patients took fewer naps and spent less time in bed during the day when following the advised diet. The observed positive effect on fatigue can be explained by an increased intake of minerals, vitamins and fatty acids $[18,19,28,29]$. Four further factors can explain these results, including a beneficial effect of combining nutrients, effects of anti-oxidants, better sleep behavior due to the high concentration of melatonin in milk [30], and an improvement of the immune function.

Vitamins and minerals have been shown to mutually benefit their absorption when consumed simultaneously. The intake of green vegetables appeared to have the strongest impact on fatigue, especially for cognitive fatigue. This could be because vitamins $A$ and $C$ in green vegetables improve the absorption of other minerals such as zinc [31,32], magnesium [33] and iron [34]. Vitamin A can even reduce iron-dependent anemia $[34,35]$. Previous studies focused on individual nutritional supplements rather than on diets, which do not fully take into account this mutually beneficial effect. On top of this, it has been shown that pure nutrients are absorbed better than artificial nutrients [33]. For example, a study with an artificial polynutrient supplement (multivitamin pill) did not result in a significant difference in the feeling of fatigue [36]. A stronger impact on fatigue could therefore be explained by the pure nutrients in the advised diet versus artificial supplements.

Beside vitamins and minerals, green vegetables and melatonin in whole milk contain many anti-oxidants, which can reduce oxidative stress in the human body $[30,37,38]$, which is associated with fatigue in children [16,39]. A reduction of oxidative stress by an increased consumption of green vegetables and whole milk could partly explain the decrease in fatigue. 
Melatonin has more beneficial properties on fatigue, especially on sleep behavior. Whole milk is known to contain high melatonin levels [40], which has been shown to be effective in improving sleep onset, maintenance of sleep, and prolongation of sleep $[30,40]$. Our study demonstrated that whole milk is significantly associated with a decreased need to sleep or rest, and that there was a stronger decline in fatigue in children who drank more whole milk than in children who drank less whole milk. As most children did not drink whole milk before the start of the diet, an increased supply of melatonin may have improved their sleeping behavior and feeling of wellbeing as well.Surprisingly, the effect of drinking whole milk was not related to the time it was consumed, as the result was also found when it was consumed in the morning or afternoon. We hypothesize that an increased ingestion of melatonin stimulates the body's own production of melatonin at night.

Additionally, the components of the advised diet can improve the immune function in children. Earlier studies in our hospital showed that this diet has a beneficial effect on recurrent upper respiratory tract infections [6]. This is supported in the literature by an improvement of the immune functions by vitamins and minerals, which are present in high concentrations in the advised diet $[41,42]$. Even without recurrent infections, improvement of the immune system can be reflected in the general wellbeing, and an increase in energy due to less pro-inflammatory cytokines [43].

Finally, no significant change in BMI was measured in our study. We evaluated the effect of the advised diet on the BMI as full fat dairy products are generally not advised for children [44]. However, beneficial effects of full fat dairy products on asthma [45] and metabolic syndrome in children have been observed before, without an increase in BMI $[29,46,47,48,49,50]$. We therefore encourage the advised normal portions of full fat dairy products.

As the prevalence of fatigue in children is high, therapeutic options are limited, and there is little research on the impact of nutrition, this study is highly clinically relevant. We saw a clear clinical improvement in fatigue, which was also noticed by the children's parents. Children seemed healthier and more resilient, and their parents observed less need to sleep or rest and more energy for daily activities. Moreover, the diet is an elegant, safe, low-cost, and easy treatment for fatigue and can be combined with therapy for other medical conditions.

\subsection{Limitations and Future Perspectives}

Although the results of this study are highly relevant, there are several limitations. Firstly, the study groups were small and not randomized because this was the first 
trial to investigate the effect between a nutrient rich diet and fatigue. Furthermore, the intervention was not performed in a double-blind fashion. Although the PedsQL is a validated method for objectifying fatigue $[26,27]$, it remains a subjective measure. The group of children studied consists of children who are simply fatigued and children with comorbidities and use of medication. The percentage of children with comorbidities and medication-usage was the same in both groups but could still influence the effect of the advised diet. A sensitivity analysis showed that the difference in effect observed in PedsQL between the children with and without the diet was even greater. While the children with the advised diet showed similar results, children in the control group showed minimal improvement (data not shown). This indicates that also in children without comorbidities and use of medication, the observed effect of the advised diet was present and that this effect might even be underestimated. However, the group in which the sensitivity analysis was performed was very small and therefore statically relevant conclusions cannot be drawn from this analysis.

Second, laboratory markers were not analyzed to show the effect or the mechanism of the diet on micronutrient deficiencies, as this study focused on the clinical effect. In our study group, laboratory values could not be used, since micro deficiencies are not measurable and patients were excluded once abnormalities were found in the initial laboratory research. It would be interesting to measure laboratory markers, to clarify the mechanism through which the effect of the diet has occurred. A future study could focus on measuring laboratory markers and further quantifying the mechanism of the diet.

A third restraint is the possibility that the period in which children were included in the control group and intervention group affects the results. The control group was studied in the summer (March to August), whereas the intervention group was studied in the winter (September to February). Children visit a general practitioner or pediatrician more often during the winter months than in summer for all kinds of illnesses [51,52], and a decrease in vitality is reported during winter in adolescent girls [53]. This suggests that within both the intervention group and the control group, children could be on the up- or the downswing of a seasonal cycle. For example, a child that starts the diet in February may feel less tired in May regardless of the diet. Overall, it would be interesting (and fair) to evaluate the effect of the advised diet in a simultaneous period and potentially with a longer follow-up.

Fourth, the different components of the diet were valued at the same level. However, this does not reflect the consumption of each of the components, and potentially 
does not reflect the relative benefits of each of the components. Furthermore, the questionnaire used to measure compliance is not validated.

Finally, parents and children only received advice and an explanation about why the components in the diet are important, rather than a prescription to follow the diet. We used a non-validated questionnaire to check the compliance to the advised diet. However, this questionnaire appeared adequate in other studies in which we used it to check the compliance to the same advised diet $[6,24]$. The "per protocol" analysis showed that the effect of the diet was stronger when it was followed more strictly ("intention to treat" analysis is not shown). Furthermore, a significant relationship between the degree of compliance and the need to sleep was found, which mirrors the results for the total sample.

In a new study, more rigorous check-ups with parents and children to ensure it is followed could increase the effectiveness of the diet.

\section{CONCLUSIONS}

Many children deal with the impact of fatigue for which an explanation is lacking and good treatment is unavailable. A nutrient-rich diet is an elegant, effective, and lowcost method to demonstrate clinical improvement in children with these unexplained symptoms of fatigue. The micronutrients in green vegetables and in whole milk have an especially strong effect on fatigue. More research in a larger, randomized trial with more supervision on the dietary intake could further validate the results shown here. 


\section{REFERENCES}

1. Wijga, A.H.; Beckers, M.C.B. Klachten En Kwalen Bij Kinderen in Nederland. Ned. Tijdschr. Geneeskd. 2011, 155, A3464.

2. Luntamo, T.; Sourander, A.; Santalahti, P.; Aromaa, M.; Helenius, H. Prevalence changes of pain, sleep problems and fatigue among 8-year-old children: Years 1989, 1999, and 2005. J. Pediatr. Psychol. 2012, 37, 307-318.

3. Rimes, K.A.; Goodman, R.; Hotopf, M.; Wessely, S.; Meltzer, H.; Chalder, T. Incidence, prognosis, and risk factors for fatigue and chronic fatigue syndrome in adolescents: A Prospective Community Study. Pediatrics 2007, 119, e603-e609.

4. Crawley, E.; Sterne, J.A. Association between School Absence and physical function in paediatric chronic fatigue syndrome/myalgic encephalopathy. Arch. Dis. Child. 2009, 94, 752-756.

5. Fowler, T.; Duthie, P.; Thapar, A.; Farmer, A. The Definition of disabling fatigue in children and adolescents. BMC Fam. Pract. 2005, 6, 33, doi:10.1186/14712296-6-33.

6. Ten Velde, L.G.H.; Leegsma, J.; van der Gaag, E.J. Recurrent upper respiratory tract infections in children; the influence of green vegetables, beef, whole milk and butter. Food Nutr. Sci. 2013, 4, 71, doi:10.4236/fns.2013.410A011 .

7. Crawley, E. The epidemiology of chronic fatigue syndrome/myalgic encephalitis in children. Arch. Dis. Child. 2014, 99, 171-174.

8. Hoeft, B.; Weber, P.; Eggersdorfer, M. Micronutrients $-A$ global perspective on intake, health benefits and economics. Int. J. Vitam. Nutr. Res. 2012, 82, 316-320.

9. Kurpad, A.V.; Edward, B.S.; Aeberli, I. Micronutrient supply and health outcomes in children. Curr. Opin. Clin. Nutr. Metab. Care 2013, 16, 328-338.

10. Bruner, A.B.; Joffe, A.; Duggan, A.K.; Casella, J.F.; Brandt, J. Randomised study of cognitive effects of iron supplementation in non-anaemic iron-deficient adolescent girls. Lancet 1996, 348, 992-996.

11. Verdon, F.; Burnand, B.; Stubi, C.L.; Bonard, C.; Graff, M.; Michaud, A.; Bischoff, T.; de Vevey, M.; Studer, J.P.; Herzig, L.; et al. Iron supplementation for unexplained fatigue in non-anaemic women: Double blind randomised placebo controlled trial. BMJ 2003, 326, 1124, doi:10.1136/bmj. 326.7399.1124.

12. Baars, E.W.; Gans, S.; Ellis, E.L. The effect of hepar magnesium on seasonal fatigue symptoms: A Pilot Study. J. Altern. Complement. Med. 2008, 14, 395-402.

13. Kelishadi, R.; Ataei, E.; Ardalan, G.; Nazemian, M.; Tajadini, M.; Heshmat, R.; Keikha, M.; Motlagh, M.E. Relationship of serum magnesium and vitamin $\mathrm{d}$ levels in a nationally-representative sample of Iranian adolescents: The CASPIAN-III Study. Int. J. Prev. Med. 2014, 5, 99-103.

14. Ellis, F.R.; Nasser, S. A pilot study of vitamin B12 in the treatment of tiredness. Br. J. Nutr. 1973, 30, 277-283.

15. Kodama, M.; Kodama, T.; Murakami, $M$. The value of the Dehydroepiandrosterone-annexed vitamin C infusion treatment in the clinical control of chronic fatigue syndrome (CFS). II. Characterization of CFS patients with special reference to their response to a new vitamin $C$ infusion treatment. In Vivo 1996, 10, 585-596.

16. Miwa, K.; Fujita, M. Increased oxidative stress suggested by low serum vitamin $\mathrm{E}$ concentrations in patients with chronic fatigue syndrome. Int. J. Cardiol. 2009, 136, 238-239. 
17. Monsen, E.R. Dietary reference intakes for the antioxidant nutrients: Vitamin C, vitamin E, selenium, and carotenoids. J. Am. Diet. Assoc. 2000, 100, 637-640.

18. Puri, B.K. Long-chain polyunsaturated fatty acids and the pathophysiology of myalgic encephalomyelitis (chronic fatigue syndrome). J. Clin. Pathol. 2007, 60, 122-124.

19. Yehuda, S.; Rabinovitz-Shenkar, S.; Carasso, R.L. Effects of essential fatty acids in iron deficient and sleep-disturbed attention deficit hyperactivity disorder (ADHD) children. Eur. J. Clin. Nutr. 2011, 65, 1167-1169.

20. Walton, J.; Hannon, E.M.; Flynn, A. Nutritional quality of the school-day diet in Irish children (5-12 years). J. Hum. Nutr. Diet. 2014, 28, 73-82.

21. Walton, J.; McNulty, B.A.; Nugent, A.P.; Gibney, M.J.; Flynn, A. Diet, lifestyle and body weight in Irish children: Findings from Irish universities nutrition alliance national surveys. Proc. Nutr. Soc. 2014, 73, 190-200.

22. Nederlands Centrum Jeugdgezondheidszorg. Voeding En Vitamines: Cijfers; Nederlands Centrum Jeugdgezondheidszorg: Utrecht, The Netherlands, 2011.

23. Arroll, M.A.; Howard, A. A Preliminary prospective study of nutritional, psychological and combined therapies for myalgic encephalomyelitis/chronic fatigue syndrome (ME/CFS) in a private care setting. BMJ Open 2012, 2, doi:10.1136/bmjopen-2012-001079.

24. Kuiper, M.W.J.; van der Gaag, E.J. Subclinical hypothyroidism in children can normalize after changes in dietary intake. Food Nutr. Sci. 2012, 3, 411-416.

25. Dutch Food Center. NEVO-Tabel 2013: Nederlands Voedingsstoffenbestand; Dutch Food Center: The Hague, The Netherlands, 2013.
26. Varni, J.W.; Beaujean, A.A.; Limbers, C.A. Factorial invariance of pediatric patient self-reported fatigue across age and gender: A multigroup confirmatory factor analysis approach utilizing the pedsql multidimensional fatigue scale. Qual. Life Res. 2013, 22, 2581-2594.

27. Gordijn, M.; Cremers, E.M.; Kaspers, G.J.; Gemke, R.J. Fatigue in children: Reliability and validity of the Dutch PedsQL multidimensional fatigue scale. Qual. Life Res. 2011, 20, 1103-1108.

28. Behan, P.O.; Behan, W.M.; Horrobin, D. Effect of high doses of essential fatty acids on the Postviral fatigue syndrome. Acta Neurol. Scand. 1990, 82, 209-216.

29. Zevenbergen, H.; de Bree, A.; Zeelenberg, M.; Laitinen, K.; van Duijn, G.; Floter, E. Foods with a high fat quality are essential for healthy diets. Ann. Nutr. Metab. 2009, 54 (Suppl. 1), 15-24.

30. Sanchez-Barcelo, E.J.; Mediavilla, M.D.; Reiter, R.J. Clinical uses of melatonin in pediatrics. Int. J. Pediatr. 2011, 2011, 892624.

31. Christian, P.; West, K.P., Jr. Interactions between zinc and vitamin A: An update. Am. J. Clin. Nutr. 1998, 68, 435S-441S.

32. Rahman, M.M.; Wahed, M.A.; Fuchs, G.J.; Baqui, A.H.; Alvarez, J.O. Synergistic effect of zinc and vitamin $A$ on the biochemical indexes of vitamin $A$ nutrition in children. Am. J. Clin. Nutr. 2002, 75, 92-98.

33. Fine, K.D.; Santa Ana, C.A.; Porter, J.L.; Fordtran, J.S. Intestinal absorption of magnesium from food and supplements. J. Clin. Investig. 1991, 88, 396-402.

34. Al-Mekhlafi, H.M.; al-Zabedi, E.M.; al-Maktari, M.T.; Atroosh, W.M.; alDelaimy, A.K.; Moktar, N.; Sallam, A.A.; Abdullah, W.A.; Jani, R.; Surin, J. Effects of vitamin A supplementation on iron status indices and iron deficiency 
anaemia: A randomized controlled trial. Nutrients 2013, 6, 190-206.

35. Michelazzo, F.B.; Oliveira, J.M.; Stefanello, J.; Luzia, L.A.; Rondo, P.H. The influence of vitamin A supplementation on iron status. Nutrients 2013, 5, 4399-4413.

36. Brouwers, F.M.; van der Werf, S.; Bleijenberg, G.; van der Zee, L.; van der Meer, J.W. The Effect of a polynutrient supplement on fatigue and physical activity of patients with chronic fatigue syndrome: A double-blind randomized controlled trial. QJM 2002, 95, 677-683.

37. Clarkson, P.M.; Thompson, H.S. Antioxidants: What role do they play in physical activity and health? Am. J. Clin. Nutr. 2000, 72, 637S-646S.

38. Konig, D.; Wagner, K.H.; Elmadfa, I.; Berg, A. Exercise and oxidative stress: significance of antioxidants with reference to inflammatory, muscular, and systemic stress. Exerc. Immunol. Rev. 2001, 7, 108-133.

39. Kennedy, G.; Khan, F.; Hill, A.; Underwood, C.; Belch, J.J. Biochemical and vascular aspects of pediatric chronic fatigue syndrome. Arch. Pediatr. Adolesc. Med. 2010, 164, 817-823.

40. Cummings, C.; Canadian Paediatric Society, Community Paediatrics Committee. Melatonin for the management of sleep disorders in children and adolescents. Paediatr. Child. Health 2012, 17, 331-336.

41. Prasad, A.S. Zinc in human health: Effect of zinc on immune cells. Mol. Med. 2008, 14, 353-357.

42. Aydogan, F.; Aydin, E.; Tastan, E.; Arslan, N.; Senes, M.; Unlu, I.; Kavuzlu, A. Is there a relationship between serum levels of vitamin A, vitamin E, copper and zinc and otitis media with effusion in children? Indian. J. Otolaryngol. Head. Neck. Surg. 2013, 65, 594-597.
43. Myers, J.S. Proinflammatory cytokines and sickness behavior: Implications for depression and cancer-related symptoms. Oncol. Nurs. Forum 2008, 35, 802-807.

44. Gidding, S.S.; Dennison, B.A.; Birch, L.L.; Daniels, S.R.; Gillman, M.W.; Lichtenstein, A.H.; Rattay, K.T.; Steinberger, J.; Stettler, N.; van Horn, L.; et al. Dietary recommendations for children and adolescents: A guide for practitioners. Pediatrics 2006, 117, 544-559.

45. Wijga, A.H.; Smit, H.A.; Kerkhof, M.; de Jongste, J.C.; Gerritsen, J.; Neijens, H.J.; Boshuizen, H.C.; Brunekreef, B. Association of consumption of products containing milk fat with reduced asthma risk in pre-school children: The PIAMA Birth Cohort Study. Thorax 2003, 58, 567-572.

46. Crichton, G.E.; Bryan, J.; Buckley, J.; Murphy, K.J. Dairy consumption and metabolic syndrome: A systematic review of findings and methodological issues. Obes. Rev. 2011, 12, e190-e201.

47. Noel, S.E.; Ness, A.R.; Northstone, K.; Emmett, P.; Newby, P.K. Milk intakes are not associated with percent body fat in children from ages 10 to 13 years. J. Nutr. 2011, 141, 2035-2041.

48. Pfeuffer, M.; Schrezenmeir, J. Milk and the metabolic syndrome. Obes. Rev. 2007, 8, 109-118.

49. Bigornia, S.J.; LaValley, M.P.; Moore, L.L.; Northstone, K.; Emmett, P.; Ness, A.R.; Newby, P.K. Dairy intakes at age 10 years do not adversely affect risk of excess adiposity at 13 years. J. Nutr. 2014, 144, 1081-1090.

50. Barba, G.; Troiano, E.; Russo, P.; Venezia, A.; Siani, A. Inverse association between body mass and frequency of milk consumption in children. Br. J. Nutr. 2005, 93, 15-19. 
51. Bruijnzeels, M.A.; Foets, M.; van der Wouden, J.C.; van den Heuvel, W.J.; Prins, A. Everyday symptoms in childhood: Occurrence and general practitioner consultation rates. Br. J. Gen. Pract. 1998, 48, 880-884.

52. Marshall, P.S.; O'Hara, C.; Steinberg, P. Effects of seasonal allergic rhinitis on fatigue levels and mood. Psychosom. Med. 2002, 64, 684-691.
53. Kristjansdottir, J.; Olsson, G.I.; Sundelin, C.; Naessen, T. Self-reported health in adolescent girls varies according to the season and its relation to medication and hormonal contraception-A Descriptive Study. Eur. J. Contracept. Reprod. Health Care 2013, 18, 343-354. 
92 Chapter 4

\section{SUPPLEMENTARY MATERIALS}

Table S1. Nutrients per 100 gram.

\begin{tabular}{|c|c|c|c|c|c|}
\hline \multirow{2}{*}{ Dependent variable } & \multicolumn{2}{|c|}{ Green Vegetables } & \multirow{2}{*}{ Beef } & \multirow{2}{*}{ Full-Fat Butter } & \multirow{2}{*}{ Whole Milk } \\
\hline & Salad & Spinach & & & \\
\hline \multicolumn{6}{|c|}{ Vitamins } \\
\hline Vit A1 (ug) & 0.00 & 0.00 & 62.00 & 829.00 & 34.00 \\
\hline Vit B1 (mg) & 0.04 & 0.05 & 0.07 & 0.01 & 0.03 \\
\hline Vit B2 (mg) & 0.05 & 0.15 & 0.16 & 0.03 & 0.18 \\
\hline Vit B12 (ug) & 0.00 & 0.00 & 2.31 & 0.30 & 0.39 \\
\hline Vit B6 total (mg) & 0.06 & 0.08 & 0.17 & 0.00 & 0.034 \\
\hline Folate (ug) & 24.50 & 124.50 & 12.80 & Trace & 6.50 \\
\hline Vit C (mg) & 2.00 & 7.00 & 7.00 & 0.00 & 0.00 \\
\hline Vit D total (mg) & 0.00 & 0.00 & 0.50 & 1.20 & 0.00 \\
\hline Vit E total (mg) & 0.20 & 3.50 & 2.40 & 1.90 & 0.10 \\
\hline \multicolumn{6}{|c|}{ Essential fatty acids } \\
\hline Linoleic acid (mg) & - & - & - & 1.30 & 1.70 \\
\hline a-Linoleic acid (mg) & - & - & - & 0.60 & 1.10 \\
\hline \multicolumn{6}{|c|}{ Minerals } \\
\hline Sodium (mg) & 14.00 & 15.00 & 440.00 & - & 43.00 \\
\hline Potassium (mg) & 300.00 & 711.00 & 424.00 & - & 165.00 \\
\hline Calcium (mg) & 51.00 & 84.00 & 19.00 & - & 102.00 \\
\hline Phosphor (mg) & 35.00 & 71.00 & 218.00 & - & 102.00 \\
\hline Magnesium (mg) & 14.00 & 77.00 & 27.00 & - & 12.00 \\
\hline Iron total (mg) & 0.80 & 2.40 & 2.80 & - & 0.00 \\
\hline Iron haem (mg) & 0.00 & 0.00 & 1.60 & - & 0.00 \\
\hline Iron non haem (mg) & 0.80 & 2.40 & 1.20 & - & 0.00 \\
\hline Copper (mg) & 0.04 & 0.08 & 0.10 & - & 0.00 \\
\hline Selenium (ug) & 0.00 & 0.00 & 11.00 & - & 1.00 \\
\hline Zinc (mg) & 0.33 & 1.20 & 6.27 & - & 0.46 \\
\hline lodine (ug) & 1.90 & 2.00 & 5.20 & - & 7.00 \\
\hline
\end{tabular}


Table S2. Specification of comorbid diagnosis and medication.

\begin{tabular}{|c|c|c|}
\hline Dependent variable & $\begin{array}{l}\text { Intervention Group }(n=50) \\
\text { norbid diagnosis }\end{array}$ & Control Group $(n=48)$ \\
\hline Asthma/URTI & 12 & 9 \\
\hline Subclinical hypothyroidism & 5 & 6 \\
\hline Hyperthyroidism & 0 & 1 \\
\hline Concentration disorder & 3 & 3 \\
\hline Hypovitaminosis D & 3 & 2 \\
\hline Anemia & 1 & 2 \\
\hline Thalassemia & 0 & 1 \\
\hline Obstipation & 1 & \\
\hline Coeliac disease & 2 & 1 \\
\hline Sleep apnea & 2 & 1 \\
\hline Migraine & 1 & 0 \\
\hline IgA deficiency & 1 & 0 \\
\hline $\begin{array}{l}\text { Selective immunoglobulin synthesis } \\
\text { defect }\end{array}$ & 0 & 1 \\
\hline Diabetes mellitus type 1 & 1 & 0 \\
\hline Down syndrome & 1 & 0 \\
\hline Epilepsy & 0 & 2 \\
\hline Recidivate tachycardia & 0 & 1 \\
\hline Hearing loss & 0 & 2 \\
\hline \multicolumn{3}{|c|}{ Medication } \\
\hline Vitamin D & 14 & 9 \\
\hline Inhalation sympathicomimetica & 9 & 3 \\
\hline Inhalation corticosteroids & 3 & 3 \\
\hline Inhalation antihistamine & 4 & 1 \\
\hline Polyethylene glycol electrolyte solution & 3 & 1 \\
\hline Clarithromycin & 1 & 0 \\
\hline Co-trimoxazole & 1 & 0 \\
\hline Amoxicillin & 0 & 1 \\
\hline Ferrofumarate tablets & 1 & 6 \\
\hline Thyrax & 1 & 3 \\
\hline Insulin pomp & 1 & 0 \\
\hline Levonorgestrel/-ethinylestradiol & 1 & 1 \\
\hline Ritalin. & 0 & 1 \\
\hline Depakine & 0 & 1 \\
\hline Melatonin & 0 & 2 \\
\hline
\end{tabular}





Figure S1. Correlation between the compliance to the advised diet and change in symptoms of fatigue (second score minus baseline score). (a) Correlation between compliance to the diet and change in the general fatigue score on the PedsQL; (b) Correlation between compliance to the diet and change in the cognitive fatigue score on the PedsQL; (c) Correlation between compliance to the diet and change in the need to sleep score on the PedsQL. * Correlation is significant at the 0.05 level (2-tailed).

( $) 2015$ by the authors; licensee MDPI, Basel, Switzerland. This article is an open access article distributed under the terms and conditions of the Creative Commons Attribution license (http:// creativecommons.org/licenses/by/4.0/). 










Advising consumption of green vegetables, beef and full-fat dairy products has no adverse effects on the lipid profiles in children

Ellen José van der Gaag, Romy Wieffer and Judith van der Kraats Nutrients. 2017 May 19;9(5). pii: E518. doi: 10.3390/nu9050518. 


\section{ABSTRACT}

In children, little is known about lipid profiles and the influence of dietary habits. In the past, we developed a dietary advice for optimizing the immune system, which comprised green vegetables, beef, whole milk, and full-fat butter. However, there are concerns about a possible negative influence of the full-fat dairy products of the diet on the lipid profile. We investigated the effect of the developed dietary advice on the lipid profile and BMI (body mass index)/BMI-z-score of children. In this retrospective cohort study, we included children aged 1-16 years, of whom a lipid profile was determined in the period between June 2011 and November 2013 in our hospital. Children who adhered to the dietary advice were assigned to the exposed group and the remaining children were assigned to the unexposed group. After following the dietary advice for at least three months, there was a statistically significant reduction in the cholesterol/HDL (high-density lipoproteins) ratio $(p<0.001)$ and non-HDL-cholesterol $(p=0.044)$ and a statistically significant increase in the HDLcholesterol $(p=0.009)$ in the exposed group, while there was no difference in the BMI and BMI z-scores. The dietary advice has no adverse effect on the lipid profile, BMI, and BMI Z-scores in children, but has a significant beneficial effect on the cholesterol/ HDL ratio, non-HDL-cholesterol, and the HDL-cholesterol.

\section{INTRODUCTION}

Little is known about cholesterol and lipid profiles in children, except from children known to have familiar dyslipidemia. However, concerns about the cholesterol levels are troubling parents when doctors advise to give full-fat dairy products to their children. Are these concerns realistic or not? At this moment, adult recommendations are also used for children. There are circumstances when full-fat dairy products are investigated for their possible positive contribution to different health aspects in children. One aspect is the functioning of the immune system, which is partly dependent on the nutritional status. Nutrients, such as vitamins and minerals, play an important role in the strengthening of the immune system. As a consequence, an adequate nutritional status, and thereby a strong immune system, might prevent infections [1-7].

In a previous study, we compared the dietary intake of children with recurrent respiratory infection (without immunological disorders) and healthy children [8]. These children usually have respiratory complaints without an adequate explanation, like immunological deficiencies. The outcomes showed that the group of children with 
recurrent infections eats less beef, natural milk, and green vegetables compared to the healthy children.

Following this study, a nutrient-rich diet has been developed as a possible intervention for recurrent infections using the NEVO (Nederlands Voedingsstoffenbestand) tables, a Dutch nutrient database containing information about the nutrients of each food [9]. There are more international databases containing macro and micronutrients. We choose this database because this database contains the most information about the regular food that is eaten and sold in The Netherlands.

The diet is based on foods high in nutrients that could support the immune system, namely green vegetables, beef, whole milk, and butter (Table 1). This are also the food groups that are not frequently consumed by children with recurrent infections. Compared to other vegetables, green vegetables contain more zinc, vitamin A, and vitamin C. Beef contains more iron, zinc, vitamin A and vitamin $\mathrm{E}$ compared with other types of meat [9]. These nutrients have immune supporting effects and play a role in the antiviral mechanisms, which could positively affect recurrent upper respiratory tract infections [2-7]. Looking at the full-fat dairy products, whole milk, and butter are a source of lipids, vitamins, and essential fatty acids, such as linoleic acid and alpha-linolenic acid [9]. The lipids can act as a carrier for vitamins A, D, E, and K, [10] which can have a positive effect on the immune system $[9,10]$. In addition, the extra fats in whole milk have anti-microbial properties and can act as bacteriostatics $[9,11]$.

This previous study showed that the dietary advice had significant positive effects on the length and gravity of respiratory tract infections in children [14]. Furthermore, another study showed that the same dietary advice decreases some symptoms of medically unresolved fatigue in children $[1,15]$.

Strengthening the immune system just by changing food habits might be a solution for many patients with recurrent infections but without an immunological disorder or for patients with medically unresolved fatigue. However, there are thoughts that the saturated fats in the recommended whole milk and butter could have a negative influence on the lipid profile and/or the risk of cardiovascular disease. The National Heart Foundation of Australia states that the intake of saturated fatty acids is highly associated with an increased risk of coronary heart disease due to elevated LDLcholesterol (low-density lipoproteins cholesterol) and serum cholesterol levels [16]. The American Heart Association (AHA) and American Academy of Pediatrics advise the use of dairy products that are fat-free or low in fat, in order to minimize the intake of saturated fat. They mention that a decline in saturated fat and cholesterol intake has 


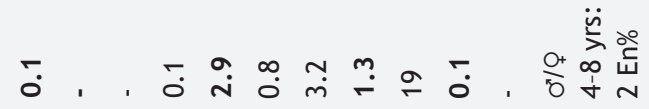

哭

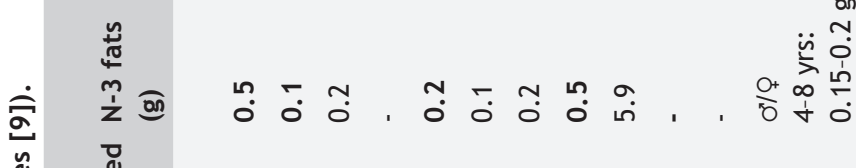

党劳

$\hat{0}$ กั



속

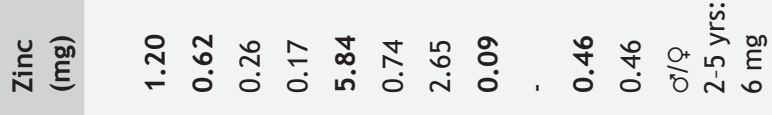

흐 ڤิ w

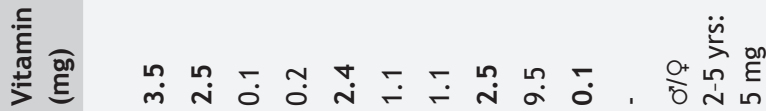

?

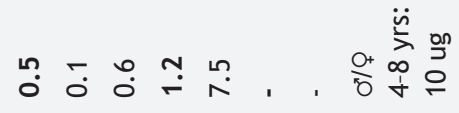

$\varangle$

款

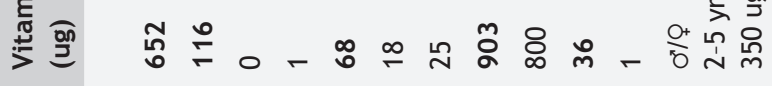

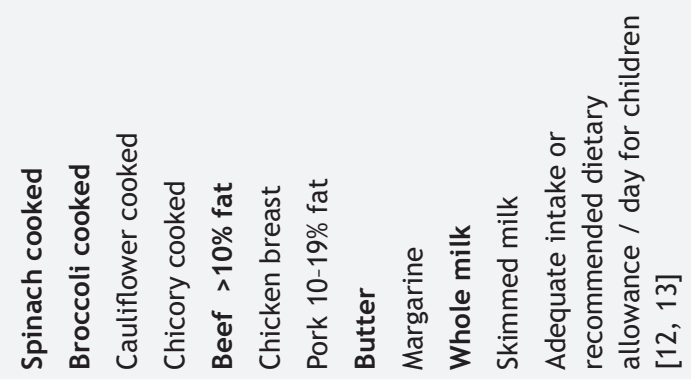


been associated with a reduction in cardiovascular disease [17]. The Dutch Centre of Food recommends replacing saturated fats with unsaturated fats, which should lower the risk of cardiovascular disease [18].

Recently, conflicting findings have been reported regarding the association of saturated fats and the risk of cardiovascular disease. Several studies show no evidence for the assumed association and some even describe an inverse association [19-21].

The aim of our study was to determine whether the developed dietary advice-relatively high in saturated fats-has an influence on the BMI (body mass index) of children and on risk factors of cardiovascular disease. The total cholesterol/HDL (high-density lipoproteins) ratio is an important predictor of later risk of cardiovascular disease $[22,23]$. Additionally, the American Academy of Pediatrics recommends non-HDL concentration as an important benchmark for the screening of cardiovascular risk in children [24]. Therefore, we used the lipid profile of children in order to determine whether the dietary advice with its beneficial effect on at least respiratory tract infections in children can be safely used.

\section{MATERIALS AND METHODS}

The present study is a non-randomized retrospective cohort study. The determination of the lipid profile of the children was executed by blinded laboratory workers. The measurements of weight and height were not blindly executed.

We performed a laboratory search in our laboratory database for patient blood samples. Included in the search were children aged from 1 to 16 years with at least two measurements of a lipid profile in the period between June 2011 and November 2013 at hospital ZGT (Hospital Group Twente) Hengelo/Almelo in the Netherlands. Patient charts were hand-searched for dietary habits/advice.

If no details were given in the patient charts, dietary habits were addressed as unknown. When no abnormalities were noted, we assumed it was according to the Dutch dietary guidelines [12]. Children who had followed the dietary advice were assigned to the exposed group and the remaining children were assigned to the unexposed group. A schematic overview of the data collection is shown in Figure 1.

The aim of our study was to determine whether the developed dietary advice-relatively high in saturated fats-has an influence on the BMI (body mass index) of children 
and on risk factors of cardiovascular disease. The total cholesterol/HDL (high-density lipoproteins) ratio is an important predictor of later risk of cardiovascular disease $[22,23]$. Additionally, the American Academy of Pediatrics recommends non-HDL concentration as an important benchmark for the screening of cardiovascular risk in children [24]. Therefore, we used the lipid profile of children in order to determine whether the dietary advice with its beneficial effect on at least respiratory tract infections in children can be safely used.

\section{MATERIALS AND METHODS}

The present study is a non-randomized retrospective cohort study. The determination of the lipid profile of the children was executed by blinded laboratory workers. The measurements of weight and height were not blindly executed.

We performed a laboratory search in our laboratory database for patient blood samples. Included in the search were children aged from 1 to 16 years with at least two measurements of a lipid profile in the period between June 2011 and November 2013 at hospital ZGT (Hospital Group Twente) Hengelo/Almelo in the Netherlands. Patient charts were hand-searched for dietary habits/advice. If no details were given in the patient charts, dietary habits were addressed as unknown. When no abnormalities were noted, we assumed it was according to the Dutch dietary guidelines [12]. Children who had followed the dietary advice were assigned to the exposed group and the remaining children were assigned to the unexposed group. A schematic overview of the data collection is shown in Figure 1.

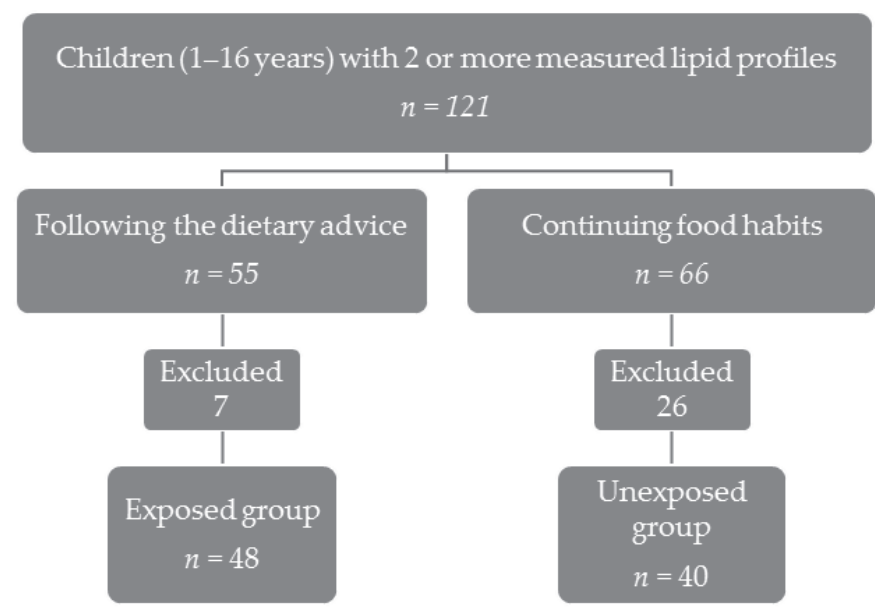

Figure 1. Schematic overview of the data collection. 
We excluded all children with a disorder that might influence the lipid profile, such as familiar hypercholesterolemia, hypothyroidism, diabetes mellitus type I and II, obesity, metabolic disorders, and medication which influences the lipid profile (according to [25]). As shown in Table 2, in the exposed group six patients were excluded based on the exclusion criteria described above, and one patient withdrew informed consent. Following the exclusion criteria, 26 patients were excluded in the unexposed group. The children visited the pediatric outpatient clinic for several complaints. In the exposed group, most of them suffered from recurrent infections, subclinical hypothyroidism or tiredness. The unexposed group consisted of children with recurrent infections, abdominal complaints, epilepsy, failure to thrive, behavioral disorders. Children (1-16 years) with 2 or more measured lipid profiles

Table 2. Overview of excluded patients

$\begin{array}{llll}\text { Exposed group } & (\mathbf{n = 5 5 )}- & \text { Unexposed group } & (\mathbf{n = 6 6 )}- \\ \text { Incomplete lipid profile } & 2 & \text { Incomplete lipid profile } & 5 \\ \text { Familiar hypercholesterolaemia } & 2 & \text { Familiar hypercholesterolaemia } & 3 \\ \text { Obesity } & 1 & \text { Obesity } & 13 \\ \text { Age }<1 \text { year or }>16 \text { years } & 1 & \text { Age }<1 \text { year or }>16 \text { years } & 1 \\ \text { Diabetes mellitus } & 0 & \text { Diabetes mellitus } & 3 \\ \text { Metabolic disorder } & 0 & \text { Metabolic disorder } & 1 \\ \text { Medication } & 0 & \text { Medication } & 0 \\ \text { Dropouts } & 1 & \text { Dropouts } & 0 \\ \text { Exposed group } & \mathbf{( n = 4 8 )} \text { Unexposed group } & \mathbf{( n = 4 0 )}\end{array}$

The dietary advice, based on the NEVO tables [9], consists of eating beef three times a week, green vegetables five times a week (both age-related portions, according to the Dutch Center of Food), at least one glass $(200 \mathrm{~mL})$ of full-fat milk ( $3.4 \%$ fat) each day, and the use of five grams per slice of bread of natural butter ( $80 \%$ fat) for at least three months. Each item of the advice counted for $25 \%$ and children had to score at least $75 \%$ to meet the criteria of the exposed group. All other dietary habits remained unchanged. The children who did not follow the dietary advice were included in the unexposed group. For ethical reasons we were not allowed to approach them and had to assume that there were no large changes in their food habits during the period of follow-up.

We recorded information of all children from both groups: gender, age, weight, height, duration, and degree of following the dietary advice, lipid profile at the time of presentation, and follow-up. The height of the children was measured with a vertical ruler. The children were weighed in underwear and all measurements were performed by a pediatrician. The children's BMI was calculated by dividing their weight in kilo- 
grams by the square of their height in meters. The BMI Z-score is calculated on the basis of gender, age, height, and weight [26]. The BMI z-score can be calculated only from the age of 24 months. This means that no BMI z-score was calculated in children younger than two years. These data were calculated, but not added in the tables, due to lacking data in the younger children.

Both for the start of the dietary advice, and at the end of the follow-up, the lipid profile was determined in all children. At the time of blood collection by venapuncture the children had an empty stomach, as nutrition can affect LDL and triglyceride concentrations [27]. The lipids from the lipid profile are total cholesterol, high-density lipoprotein cholesterol (HDL-C), cholesterol/HDL ratio, low-density lipoprotein cholesterol (LDL-C), triglycerides (TG), and non-HDL. The lipid profile was measured by enzymatic colorimetric techniques with the COBAS 6000 (Roche Diagnostics, Almere, The Netherlands). The LDL was calculated with Friedewald's formula: LDL=total cholesterol-HDL-(0.45xTG). The primary outcome of this study, the cholesterol/HDL ratio, was calculated by dividing the total cholesterol by HDL cholesterol [23]. The non-HDL can be calculated by the following formula: total cholesterol-HDL cholesterol = non-HDL cholesterol (non-HDL).

We used SPSS Statistics 20 (SPSS Inc., Chicago, IL, USA) to execute our data analysis. Normality was checked by visual expectation of histograms and Shapiro-Wilk test. Continuous variables were expressed as the mean with the standard deviation (SD) or the median with the interquartile range (IQR); categorical variables were expressed as counts with corresponding percentages. Differences in baseline characteristics between groups was tested using an independent t-test or Mann-Whitney (continuous variables) or Pearson's chi-square (categorical). To test changes of the lipid profile between measurements within each group a paired T-test or Wilcoxon was used. Concerning the BMI and BMI Z-score, several data were lacking. Therefore, the BMI and $\mathrm{BMI}$ z-scores were tested using mixed models analysis. For all comparisons, a p-value $<0.05$ was regarded as significant.

\section{RESULTS}

\subsection{Baseline Data}

The baseline data of the unexposed and exposed group are presented in Table 3 . The demographic characteristics, period of follow-up, the lipid profiles, and the BMI characteristics did not differ significantly at the start of this study. 
Table 3. Baseline characteristics of the unexposed and exposed group

$\begin{array}{llll} & \begin{array}{l}\text { Unexposed group } \\ \mathrm{n}=40\end{array} & \begin{array}{l}\text { Exposed group } \\ \mathrm{n}=48\end{array} & \text { P-value } \\ \begin{array}{l}\text { Gender (n,\%) } \\ \quad \begin{array}{l}\text { Men } \\ \quad \text { Women }\end{array}\end{array} & \begin{array}{l}24(60 \%) \\ 16(40 \%)\end{array} & \begin{array}{l}25(52 \%) \\ 23(48 \%)\end{array} & .457 \\ \begin{array}{l}\text { Age (years) (median, IQR) } \\ \text { Follow-up (months) }\end{array} & 4.7(2.3-9.0) & 2.6(1.6-8.0) & .102 \\ \begin{array}{l}\text { (median, IQR) } \\ \text { BMI (median, IQR) }\end{array} & 5.0(4.0-8.0) & 4.5(4.0-8.8) & .744 \\ & 15.9(15.1-17.5) & 16.7(15.4-18.5) & .408\end{array}$

IQR (interquartile range); SD (standard deviation).

\subsection{Changes within Groups}

The baseline, follow up and differences in lipid profile within the two groups between the start and follow-up are shown in Table 4. In the exposed group, the HDL-cholesterol increased significantly with $0.14 \mathrm{mmol} / \mathrm{L}(\mathrm{p}=0.009), 95 \% \mathrm{Cl}(-0.24$ to -0.04$)$ (confidence interval). The cholesterol/HDL ratio was significantly reduced $(p<0.001)$, $95 \% \mathrm{Cl}(0.35-0.84)$, as was the non-HDL $(p=0.044), 95 \% \mathrm{Cl}(0.01-0.34)$. The decrease in the cholesterol/HDL is caused by the significant increase in the HDL-cholesterol. The total cholesterol did not change significantly and barely affects the cholesterol/ $\mathrm{HDL}$ ratio. No significant changes occurred in the BMI and BMI Z-score (a change of -0.06) in the exposed group. There were no significant changes of the lipid profile or $\mathrm{BMI}$ and BMI Z-score (change of 0.09) in the unexposed group.

\section{DISCUSSION}

Our research shows that consumption of green vegetables, beef, whole milk, and butter has no adverse effect on the lipid profile in children. The dietary advice, no advice with respect to carbohydrate intake, but relatively high in saturated fats is even shown to have a favorable effect on the lipid profile: it gave a significant increase in HDL cholesterol, and a decrease in non-HDL cholesterol and the cholesterol/HDL ratio.

In a previous study the dietary advice has been shown to have a significant improving effect on the incidence and duration of recurrent respiratory tract infections [15]. This nutritional advice will probably be discouraged by major national and international organizations since the idea exists that saturated fats have a negative effect on the lipid profile and/or the cholesterol/HDL ratio and, thus, increases the risk of cardiovascular disease. 


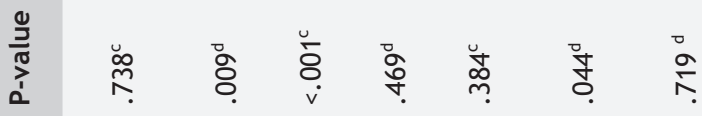

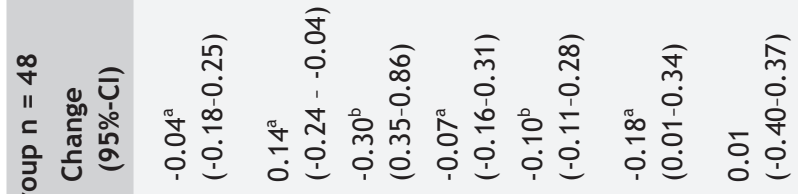

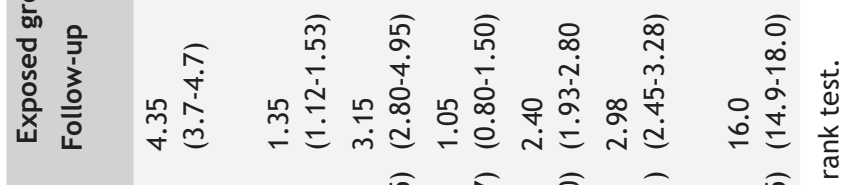

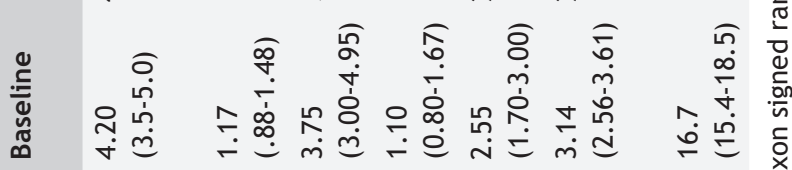

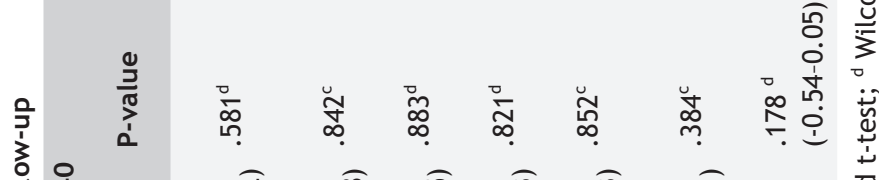

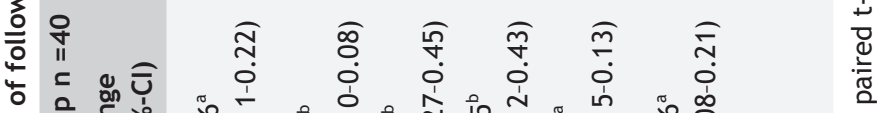



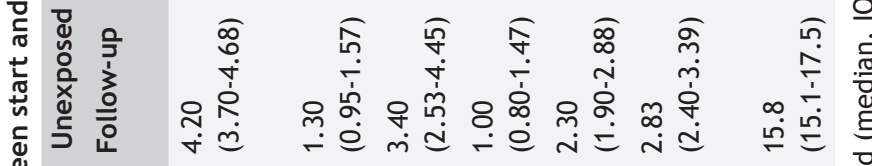

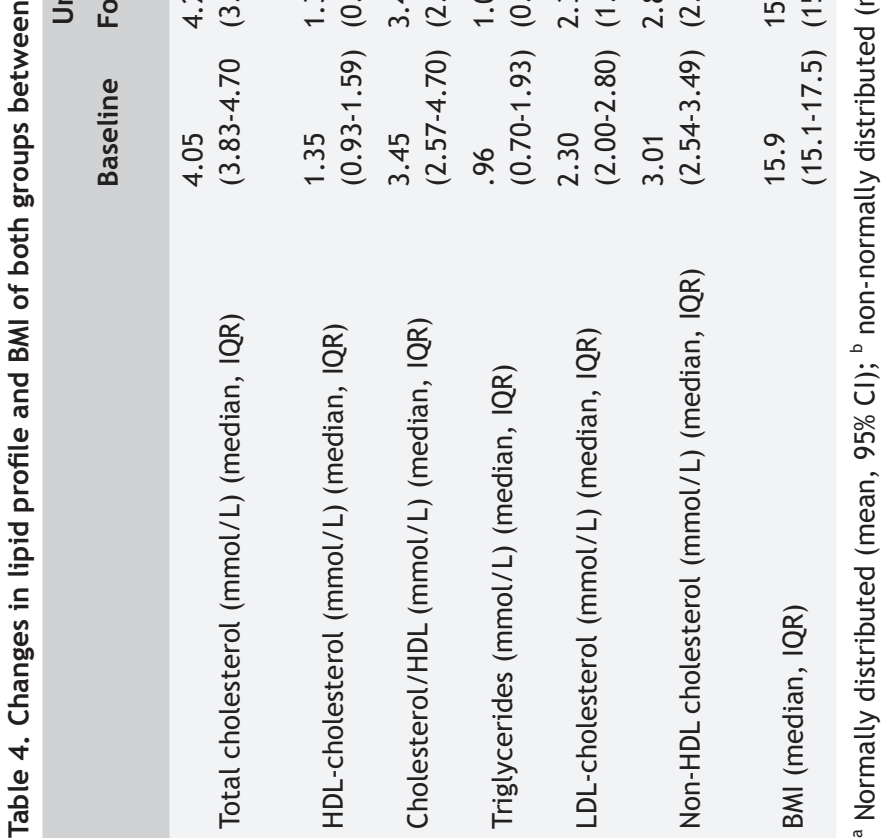


The American Heart Association and the American Academy of Pediatrics recommend not offering any whole-milk products to children, because of the higher concentrations of saturated fats and, therefore, the increased risk of later cardiovascular disease [17]. The Dutch Nutrition Centre recommends that children should not eat full-fat products at all, due to the relatively high concentration of saturated fats. According to the nutrition center the intake of saturated fats has a negative impact on the cholesterol/HDL ratio and, therefore, increases the risk of cardiovascular disease [18].

Over the years, various studies have been published discussing the relationship between saturated fatty acids and cardiovascular disease. The idea that consuming saturated fats can lead to death from cardiovascular disease has certainly not been confirmed by all studies. A meta-analysis of randomized trials showed that saturated fat has an increasing effect on HDL cholesterol. The increase in the HDL-cholesterol is greater when consuming saturated fats, compared to consuming unsaturated fats [28], which can contribute to a decrease in total cholesterol/HDL cholesterol ratio [29]. The Lancet published a systematic review of 61 prospective studies, which showed that higher HDL cholesterol levels reduce the risk of death from cardiovascular disease [30].

Contrary to expectations, a large meta-analysis by Siri-Tarino and colleagues shows that there is no significant link between the consumption of saturated fats and an increased risk of cardiovascular disease in general and coronary heart disease in particular [20]. In line with this, a meta-analysis by Skeaf and Miller commissioned by the World Health Organization concluded that the amount of saturated fats in a diet does not have an impact on the risk of coronary heart disease [31]. The American Heart Association claims that replacing saturated fat with carbohydrates lowers the risk of cardiovascular disease. In contrast, a meta-analysis of prospective studies shows that replacing saturated fat with carbohydrates leads to a significantly increased risk of cardiovascular disease [32].

This is supported by Musunuru, who concluded that it is not the saturated fats, but the carbohydrates in a diet that cause atherogenic dyslipidemia [33]. Next to the inconsistent data about dairy fats and cardiovascular risk factors, there are also inconsistent data about the risk of dairy fat on developing diabetes mellitus. A recent study from the Nurses' Health Study and the Health Professionals Follow-Up Study show a protective effect of high plasma dairy fatty acid concentrations and lower incidence of diabetes mellitus [34]. 
As an alternative to butter with its saturated fats, margarine was developed. This "skinny" dairy product is enriched with "healthy" omega-6 fatty acids. However, the replacement of saturated fatty acids and trans-fatty acids by omega- 6 fatty acids is associated with an increased risk of coronary heart disease and overall mortality [35]. We now know that omega-6 fatty acids have pro-inflammatory characteristics while omega- 3 fatty acids have anti-inflammatory ones. A diet with a large amount of omega- 6 fatty acids and a high omega-6/omega- 3 ratio enhances the development of diseases such as cancer, cardiovascular disease, inflammatory and autoimmune diseases. In contrast, high levels of omega-3 fatty acids have suppressive effects on those diseases [36]. The investigated dietary advice contributes to a good fattyacid balance due to its green vegetables, which contain a relatively high amount of omega- 3 fatty acids and are low in omega- 6 fatty acids [9]. Recently, a study showed that people who eat a lot of green leafy vegetables have a $32 \%$ lower risk of myocardial infarction [37].

In addition, green vegetables have other positive effects concerning health, such as reducing the risk of many forms of cancer [38,39]. Additionally, the dietary advice contributes to the inhibition of oxidation of LDL cholesterol, a crucial step in atherosclerosis, with its relatively high levels of Vitamin A and $\mathrm{E}$ in beef, compared to other types of meat [40].

The BMI and BMI z-scores in the exposed group did not significantly change during the months of follow-up. If we calculate the caloric intake of the dietary advice, using age-adequate quantities advised by the Dutch Food Center [12], the diet contains 94 more calories compared to a diet with identical quantities of low-fat milk and margarine [9]. By contrast, beef contains 1.5 times fewer calories compared to, for example, pork, which has 82 calories per serving [9,41]. This almost neutralizes the extra calories ingested by a child with the intake of whole milk and butter. Additionally, whole milk has a favorable glycemic control and, thereby, possibly an inhibitory effect on appetite and food intake [42]. Several investigations show that a higher intake of dairy products does not increase body weight, results that are consistent with the results of our study $[43,44]$.

This study suggests that diet quality can have some benefits for children. However, one of the limitations of this study is the retrospective design. Adherence to the dietary advice was retrospectively controlled through evaluative questions during the consultation with the pediatrician. A more reliable way of checking the nutritional advice is to let patients fill out a daily food questionnaire. 
Due to the retrospective design the food habits of the unexposed group could not all be traced. In this case we had to assume that they did not consume full fat dairy (in The Netherlands semi-skimmed milk and low-fat butter are advised) and no changes in diet occurred during follow-up. In a research design such as a randomized controlled trial, the unexposed group could also fill out a food questionnaire so that any changes in diet can be detected. Following the retrospective design of this study the unexposed and exposed group could not be randomized. A probable advantage is that the patients (and/or their parents) in the exposed group were possibly more motivated to follow the diet given the fact that they chose to follow the diet themselves.

There were missing values in the BMI and, thereby, the BMI z-scores of the children, so that the conclusions of $\mathrm{BMI}$ and $\mathrm{BMI} \mathrm{Z}$-score are based on a smaller number of patients than we included.

Furthermore, the mean period of follow-up was 4.4 months, which means that we cannot draw conclusions about these outcomes in the long term. We require longterm follow-up studies to evaluate the course of the lipid profile.

\section{CONCLUSIONS}

This retrospective study shows diet quality in childhood can have some useful benefits. Earlier, it was shown that a dietary advice of green vegetables, beef, whole milk, and full-fat butter reduces the number of days with a respiratory tract infection in children. In this study we have shown that the dietary advice has no adverse effect on the lipid profile, BMI, and BMI z-score in children. Conversely, the dietary advice has a significant beneficial effect on the HDL-cholesterol, cholesterol/HDL ratio, and non-HDL-cholesterol. The dietary advice can, therefore, be safely recommended and might be beneficial for children with recurrent respiratory tract infections. However, the findings of this retrospective study should be further investigated in randomized controlled trials. 


\section{REFERENCES}

1. Field, C.J.; Johnson, I.R.; Schley, P.D. Nutrients and their role in host resistance to infection. J. Leukocyte Biol. 2002, 71, 16-32. [PubMed]

2. Jimenez, C.; Leets, I.; Puche, R.; Anzola, E.; Montilla, R.; Parra, C.; Aguilera, A.; Garcia-Casal, M.N. A single dose of vitamin A improves haemoglobin concentration, retinol status and phagocytic function of neutrophils in preschool children. Brit. J. Nutr. 2010, 103, 798-802. [CrossRef] [PubMed]

3. Maggini, S.; Wenzlaff, S.; Hornig, D. Essential role of vitamin $C$ and zinc in child immunity and health. J. Int. Med. Res. 2010, 38, 386-414. [CrossRef] [PubMed]

4. Prasad, A.S. Zinc: Role in immunity, oxidative stress and chronic inflammation. Curr. Opin. Clin. Nutr. 2009, 12, 646-652. [CrossRef] [PubMed]

5. Wintergerst, E.S.; Maggini, S.; Hornig, D.H. Immune-enhancing role of vitamin $C$ and zinc and effect on clinical conditions. Ann. Nutr. Metab. 2006, 50, 85-94. [CrossRef] [PubMed]

6. Cherayil, B.J. Iron and immunity: Immunological consequences of iron deficiency and overload. Arch. Immunol. Ther. Exp. 2010, 58, 407-415. [CrossRef] [PubMed]

7. Ekiz, C.; Agaoglu, L.; Karakas, Z.; Gurel, N.; Yalcin, I. The effect of iron deficiency anemia on the function of the immune system. Hematol. J. 2005, 5, 579-583. [CrossRef] [PubMed]

8. Munow, M.; van der Gaag, E.J. Ailing Toddlers: Is There a Relation between Behavior and Health? Book of Abstracts 27th Annual Meeting of the European Society for Pediatric Infectious Diseases; 2009; p. 764. Available online: http:// www.scirp.org/\%28S\%28351jmbntvnsjt 1aadkposzje\%29\%29/reference/ Refer-
encesPapers. aspx?ReferencelD $=962833$ (accessed on 18 May 2017).

9. National Institute for Public Health and the Environment (RIVM)/the Kingdom of the Netherlands. Dutch Food Composition Database 2014. Available online: http://nevo-online.rivm.nl/ (accessed on 12 May 2014).

10. German, J.B. Dietary lipids from an evolutionary perspective: Sources, structures and functions. Matern. Child Nutr. 2011, 7, 2-16. [CrossRef] [PubMed]

11. Batovska, D.; Todorova, I.; Tsvetkova, I.; Najdenski, H. Antibacterial study of the medium chain fatty acids and their 1-monoglycerides: Individual effects and synergistic relationships. Pol. J. Microbiol. 2009, 58, 43-47. [PubMed]

12. Dietary Reference Intakes: Energy, Proteins, Fats and Digestible Carbohydrates. Health Council Neth. Available online: https://www.narcis.nl/publication/RecordID/oai:cris.maastrichtuniversity.nl: publications\%2Fdc7e056ba $54 d-471 d$ - a 496 - ec 334 fd 5 ad 1 e (accessed on 13 June 2013).

13. Brink, E.J.; Breedveld, B.C.; Peters, J.A.C. Aanbevelingen Voor Vitamines, Mineralen en Spoorelementen. Factsheet The Netherlands Nutrition Centre. Available online: http:// www. voedingscentrum.nl/Assets / Uploads/voedingscentrum/Documents/ Professionals/Pers/Factsheets/Factsheet $\% 20$ Aanbevelingen $\% 20$ voor $\% 20$ vitamines, $\% 20$ mineralen $\% 20$ en $\% 20$ spoorelementen.pdf (accessed on 15 December 2016).

14. Ten Velde, L.G.H.; Leegsma, J.; van der Gaag, E.J. Recurrent upper respiratory tract infections in children; the influence of green vegetables, beef, whole milk and butter. Food Nutr. Sci. 2013, 4, 71-77. [CrossRef] 
15. Steenbruggen, T.G.; Hoekstra, S.J.; van der Gaag, E.J. Could a change in diet revitalize children who suffer from unresolved fatigue? Nutrients 2015, 7 , 1965-1977. [CrossRef] [PubMed]

16. Shrapnel, W.S.; Calvert, G.D.; Nestle, P.J.; Truswell, A.S. Diet and coronary heart disease. Natl. Heart Found. Aust. Med. J. Aust. 1992, 156, S9-S16.

17. Gidding, S.S.; Dennison, B.A.; Birch, L.L.; Daniels, S.R.; Gillman, M.W.; Lichtenstein, A.H.; Rattay, K.T.; Steinberger, J.; Stettler, N.; van Horn, L. Dietary recommendations for children and adolescents: A guide for practitioners. Pediatrics 2006, 117, 544-559. [CrossRef] [PubMed]

18. The Netherlands Nutrition Centre. Verzadigd vet. Available online: http:// www.voedingscentrum. nl/encyclopedie/verzadigd-vet.aspx (accessed on 15 May 2016).

19. Muskiet, F.A.J.; Muskiet, M.H.A.; Kuipers, R.S. Het faillissement van de verzadigd vethypothese van cardiovasculaire ziektes. Ned. Tijdschr. Klin. Chem. Labgeneesk 2012, 37, 192-211. (In Dutch).

20. Siri-Tarino, P.W.; Sun, Q.; Hu, F.B.; Krauss, R.M. Meta-analysis of prospective cohort studies evaluating the association of saturated fat with cardiovascular disease. Am. J. Clin. Nutr. 2010, 91, 535-546. [CrossRef] [PubMed] Nutrients 2017, 9, 5189 of 10

21. Kratz, M.; Baars, T.; Guyenet, S. The relationship between high-fat dairy consumption and obesity, cardiovascular, and metabolic disease. Eur. J. Nutr. 2013, 52, 1-24. [CrossRef] [PubMed]

22. Kinosian, B.; Glick, H.; Garland, G. Cholesterol and coronary heart disease predicting risks by levels and ratios. Ann. Intern. Med. 1994, 121, 641-647. [CrossRef] [PubMed]
23. The Netherlands Nutrition Centre. Cholesterol. Available online: http://www. voedingscentrum.nl/encyclopedie/ cholesterol.aspx (accessed on 16 May 2016).

24. Department of Health and Human Services. National Heart Lung and Blood Institute. Expert Panel on Integrated Guidelines for Cardiovascular Health and Risk Reduction in Children and Adolescents. Available online: https://www.nhlbi.nih.gov/files/docs/ guidelines/peds_guidelines_full.pdf (accessed on 15 January 2017).

25. The Netherlands National Health Care Institute. Farmacotherapeutisch kompas. Available online: https:// www. farmacotherapeutischkompas.nl/ (accessed on 5 January 2014).

26. U.S. Department of Health and Human Services. National Center for Health Statistics, Z-Score Data Files. Available online: https://www.cdc.gov/ growthcharts/zscore.htm (accessed on 14 February 2014).

27. Kubo, T.; Takahashi, K.; Furujo, M.; Hyodo, Y.; Tsuchiya, H.; Hattori, M.; Fujinaga, S.; Urayama, K. Usefulness of non-fasting lipid parameters in children. J. Pediatr. Endocr. Metab. 2017, 30, 77-83. [CrossRef] [PubMed]

28. Mensink, R.P.; Zock, P.L.; Kester, A.D.; Katan, M.B. Effects of dietary fatty acids and carbohydrates on the ratio of serum total to HDL cholesterol and on serum lipids and apolipoproteins: A meta-analysis of 60 controlled trials. Am. J. Clin. Nutr. 2003, 77, 1146-1155. [PubMed]

29. Huth, P.J.; Park, K.M. Influence of dairy product and milk fat consumption on cardiovascular disease risk: A review of the evidence. Adv. Nutr. 2012, 3, 266-285. [CrossRef] [PubMed]

30. Lewington, S.; Whitlock, G.; Clarke, R.; Sherliker, P.; Emberson, J.; Halsey, 
J.; Qizilbash, N.; Peto, R.; Collins, R. Blood cholesterol and vascular mortality by age, sex, and blood pressure: A meta-analysis of individual data from 61 prospective studies with 55,000 vascular deaths. Lancet 2007, 370, 1829-1839. [CrossRef] [PubMed]

31. Skeaf, C.M.; Miller, J. Dietary fat and coronary heart disease: Summary of evidence from prospective cohort and randomized controlled trails. Ann. Nutr. Metab. 2009, 55, 173-201. [CrossRef] [PubMed]

32. Jakobsen, M.U.; O'Reilly, E.J.; Heitmann, B.L.; Pereira, M.A.; Bälter, K.; Fraser, G.E.; Goldbourt, U.; Hallmans, G.; Knekt, P.; Liu, S. Major types of dietary fat and risk of coronary heart disease: A pooled analysis of 11 cohort studies. Am. J. Clin. Nutr. 2009, 89, 1425-1432. [CrossRef] [PubMed]

33. Musunuru, K. Atherogenic dyslipidemia: Cardiovascular risk and dietary intervention. Lipids 2010, 45, 907-914. [CrossRef] [PubMed]

34. Yakoob, M.Y.; Shi, P.;Willet,W.C.; Rexrode, K.M.; Campos, H.; Orav, E.J.; Hu, F.B.; Mozaffarian, D. Circulating Biomarkers of dairy fat and risk of incident diabetes mellitus among men and women in the United States in two large prospective cohorts. Circulation 2016, 133, 1645-1654. [CrossRef] [PubMed]

35. Ramsden, C.E.; Hibbeln, J.R.; Majchrzak, S.F.; Davis, J.M. N-6 fatty acid-specific and mixed polyunsaturate dietary interventions have different effects on CHD risk: A meta-analysis of randomised controlled trials. Brit. J. Nutr. 2010, 104, 1586-1600. [CrossRef] [PubMed]

36. Simopoulos, A.P. The importance of the Omega-6/Omega-3 fatty-acid ratio in cardiovascular disease and other chronic diseases. Exp. Biol. Med. 2008, 233, 674-688. [CrossRef] [PubMed]
37. Ahmed, F. Health: Edible advice. Nature 2010, 468, S10-S12. [CrossRef] [PubMed]

38. Cohen, J.H.; Kristal, A.R.; Standford, J.L. Fruit and vegetable intakes and prostate cancer risk. J. Natl. Cancer Inst. 2000, 92, 61-68. [CrossRef]

39. Ambrosone, C.B.; McCann, S.E.; Freudenheim, J.L.; Marshall, J.R.; Zhang, Y.; Shields, P.G. Breast cancer risk in premenopausal women is inversely associated with consumption of broccoli, a source of isothiocyanates, but is not modified by GST genotype. J. Nutr. 2004, 134, 1134-1138. [PubMed]

40. Zhang, P.Y.; Xu, X.; Li, X.C. Cardiovascular diseases: Oxidative damage and antioxidant protection. Eur. Rev. Med. Pharmacol. Sci. 2014, 18, 3091-3096. [PubMed]

41. The Netherlands Nutrition Centre. Hoeveel en wat kan ik per dag eten? Available online: http://www.voedingscentrum.nl/nl/schijf-van-vijf/ eet-niet-teveel-en-beweeg/hoe-eet-ikniet-te-veel.aspx (accessed on 21 March 2014). Nutrients 2017, 9, 51810 of 10

42. Haug, A.; Høstmark, A.T.; Harstad, O.M. Bovine milk in human nutrition-A review. Lipids Health Dis. 2007, 6, 25. [CrossRef] [PubMed]

43. Snijder, M.B.; van der Heijden, A.A.W.A.; van Dam, R.M.; Stehouwer, C.D.A.; Hiddink, G.J.; Nijpels, G.; Heine, R.J.; Bouter, L.M.; Dekker, J.M. Is higher dairy consumption associated with lower body weight and fewer metabolic disturbances? Am. J. Clin. Nutr. 2007, 85, 989-995. [PubMed]

44. Rautiainen, S.; Wang, L.; Lee, I.M.; Manson, J.E.; Buring, J.E.; Sesso, H.D. Dairy consumption in association with weight change and risk of becoming overweight or obese in middle-aged and older woman: A prospective cohort study. Am. J. Clin. Nutr. 2016, 103, 979-988. [CrossRef] [PubMed] 



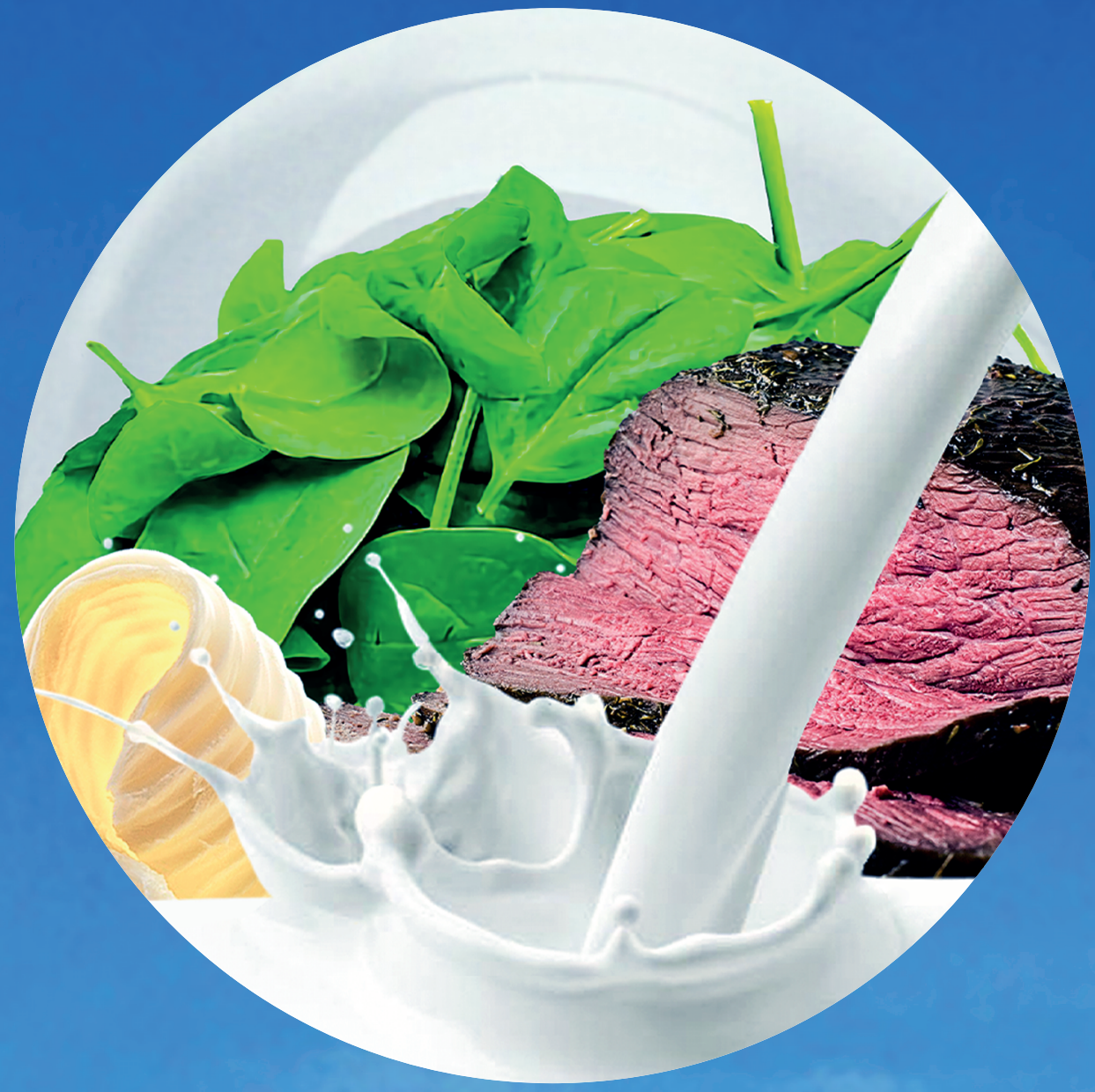




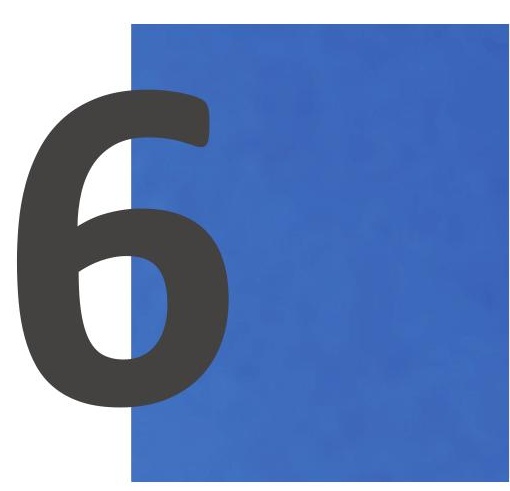

The influence of a dietary advice including of green vegetables, beef and whole dairy products on recurrent upper respiratory tract infections in children: a randomized controlled trial. 
$116 \mid$ Chapter 6

\section{ABSTRACT}

Background: Since no treatment exists for children suffering from upper respiratory tract infections (URTIs) without immunological disorders, we searched for a possible tool to improve the health of these children.

Aim: We evaluated whether dietary advice (based on food matrix and food synergy), including standard supportive care, can decrease the number and duration of URTIs in children with recurrent URTIs.

Design and Setting: This study was a multicenter randomized controlled trial in two pediatric outpatient clinics in the Netherlands, with 118 children aged one to four years with recurrent URTIs. The dietary advice group received dietary advice plus standard supportive care, while the control group received standard supportive care alone for six months. The dietary advice consisted of green vegetables five times per week, beef three times per week, $300 \mathrm{~mL}$ whole milk per day, and whole dairy butter on bread every day. Portion sizes were age-appropriate.

Results and Conclusion: Children in the dietary advice group had 4.8 (1.6-9.5) days per month with symptoms of an URTI in the last three months of the study, compared to $7.7(4.0-12.3)$ in the control group $(p=0.028)$. The total number of URTIs during the six-month study period was $5.7( \pm 0.55)$ versus $6.8( \pm 0.49)$, respectively $(p=$ 0.068 ). The use of antibiotics was significantly reduced in the dietary advice group, as well as visits to a general practitioner, thereby possibly reducing healthcare costs. The results show a reduced number of days with symptoms of a URTI following dietary advice. The number of infections was not significantly reduced. 


\section{INTRODUCTION}

Upper respiratory tract infections (URTIs) are the most frequently diagnosed diseases in children, especially those aged one to six years. On average, the youngest children have six to eight infections per year [1-3]. Incidence varies seasonally with peaks in autumn and winter [1]. The severity and frequency of URTIs is inversely proportional to age, suggesting a build-up in immunity through repeated contact with causative viruses [2, 4]. In children with frequent, long-lasting, or clinically severe infections, the clinician should consider an immunodeficiency [5]. Despite the majority of episodes being self-limiting, URTIs cause frequent and unnecessary prescription of antibiotics and absences from work for parents [6, 7]. This antibiotic prescription incurs substantial costs for health care systems, especially when a substantial proportion consists of non-indicated and ineffective treatments [8]. The use of more than two antibiotic courses for a respiratory infection in the preceding year for a child is a good prognostic marker for response failure to the present treatment of the respiratory infection [9], implying a need to minimize antibiotic prescriptions for these respiratory infections in young children.

Multiple clinical and non-clinical trials investigated the role of varied single nutrient supplementation on (respiratory) infection. The results of these trials are unclear. For example, administration of vitamin $D$ and iron showed conflicting results, whereas vitamin C administration showed a 18\% decrease in duration of colds in children [1013]. The lack of success of some supplementations may be due to a single nutrient model lacking synergy with other nutrients as part of a dietary lifestyle [14]. However, the effects of dietary interventions (with multiple components) on upper respiratory tract infections have not been widely investigated. Calatayud et al. studied the effect of a change toward the Mediterranean lifestyle in a prospective before-after comparison study. They found that the Mediterranean diet (fresh, locally produced, and non-processed food) had a significantly beneficial effect in patients with recurrent common cold and respiratory infections [15]. In a Nordic country (Sweden), with other locally produced food, a prospective population-based study showed no effect of this locally produced diet (Nordic diet) on URTIs. Only high physical activity was associated with lower URTI risk [16].

The Netherlands are located in between the Nordic and Mediterranean countries, and also the origins of the Dutch diet are in between the Nordic and Mediterranean [17]. In the Netherlands, a large proportion of the total diet traditionally consists of dairy products [18], mostly cheese, milk, yoghurt, and butter. In 2009, we investigated the dietary patterns of children with recurrent URTI compared to control children. 
Questionnaires about dietary habits showed that children with URTIs consumed significantly fewer vegetables and beef compared to control children [19]. These products, however, have a high nutrient density [20]. Combining these findings, we selected four nutrient-dense food products to compose dietary advice fitting the latitude-specific food habits: green vegetables, beef, whole milk, and butter. The diet was constructed using data from the Dutch Food Composition Database (NEVO) and the Netherlands Nutrition Centre (for age-appropriate amounts) for optimal nutritional values of iron, zinc, and vitamins A, C, D, and E (Table S1) [20, 21].

Later, we performed a prospective before-after pilot study in children with dietary advice consisting of green vegetables, beef, and whole dairy products that were fresh and locally produced. We observed a drop in days with symptoms of the common cold of four days per month during the treatment period [22].

In the present study, we hypothesised that dietary advice could decrease the number and duration of upper respiratory tract infections compared with standard supportive care alone in children aged one to four years with recurrent upper respiratory tract infections. We also assessed whether the advice would reduce the number of days of parental absence from work and the number of prescribed antibiotics.

\section{MATERIALS AND METHODS}

\subsection{Study Design}

We conducted a randomized controlled trial out in outpatient clinics of the Hospital Group Twente and the Medical Spectrum Twente. Both regional hospitals lie in the eastern part of the Netherlands. After inclusion, subjects were randomly allocated through minimization on a central remote computer, stratifying for age, day care attendance, and parental smoking. The MinimPy Program 0.3 (available at http:// minimpy.sourceforge.net) was used for this purpose. All paediatricians who included patients had to log into the central computer with a code, which was conducted in the presence of the child and their parents. The parents and the child witnessed, but could not influence, the process when the central computer allocated the group.

Both groups (intervention and control group) received standard supportive care for (recurrent) URTIs, e.g., painkillers, resting in bed, and antibiotics if necessary prescribed by their own, independent, general physician. The dietary advice group additionally received dietary advice. A detailed explanation (orally and a printed version) of the diet was offered only to the dietary advice group after randomization. 
Explanation about the dietary intervention took about 3-5 minutes. No behavioural approaches were offered or used during the study period. The control group did not receive dietary advice and were supposed to continue their usual dietary habits. The governing medical ethics committee of both hospitals approved the protocol (METC Enschede P14-39, NL50373.044.14). The trial was registered in the Dutch Trial Register (NTR4898, www.trialregister.nl).

\subsection{Participants}

Children 1-4 years, referred by their general physician with recurrent URTIs, were recruited if they had a minimum of 3 URTIs in the last 3 months. This had to be confirmed by the physician in the outpatient clinic by completing a daily questionnaire for a minimum of 1 month and asking the parents if this was representative for the last months. If more than two URTI episodes were noted and representative, they were included. If one or no URTI episode was noted, they were asked whether they had 3 episodes within 3 months. An URTI was defined as any combination of at least two of the following symptoms: cough, fever, blocked or running nose, sore throat, wheeze, and/or ear discharge. A new URTI was counted after a minimum of two days with only one or zero symptoms; this definition is similar to that used in other studies [23].

Exclusion criteria included immunological deficiencies, cow's milk allergy, intestinal malabsorption, prophylactic use of antibiotics for longer periods, disorders requiring a special diet, or any relevant congenital abnormality, anatomical abnormality, chromosomal disorder, or severe disease (altering metabolism and immune function). Written informed consent was obtained from parents and/or legal custodians.

\subsection{Intervention}

Participants in the dietary advice group were advised to follow dietary advice consisting of five times per week green vegetables at dinner, three times per week of beef at dinner, $300 \mathrm{~mL}$ whole cow's milk daily, and whole dairy butter on each slice of bread. The advice was provided with age-specific portion sizes adhering to the guidelines and advice of the Netherlands Nutrition Centre (Table S2).

The paediatrician instructed parents during the visit in the outpatient clinic. The control group was not informed about the contents of the dietary advice. They continued their normal dietary habits consisting of the national advice by the Netherlands Nutrition Centre. The national advice only specifies not to eat processed or fatty meat; it provides no differentiation between types of vegetables and it suggests dairy intake should mainly come from regular or skimmed products [20]. A run-in period of 
one month was used before incorporation of the advice into daily life, which served as a baseline measurement of respiratory complaints. We scheduled contacts with the clinic at three and six months. To minimize seasonal influences, participants were included in 2 consecutive years all year round.

\subsection{Data Collection}

Baseline data and patient characteristics were collected around the inclusion period by the clinician. Parents recorded cough, fever, blocked or runny nose, sore throat, wheeze, respiratory distress, and/or ear complaints daily via a monthly diary for a run-in period of 1 month and for 6 months during the dietary intervention. Parents used selfdiagnosis diaries to report the URTI symptoms. This is assumed to be the most reasonable approach to record common cold symptoms for clinical research studies [24, 25].

Parents also reported contacts with physicians, antibiotics administered, and parental absence from work due to the illness of the child. Parents of children in the dietary advice group recorded their adherence to the dietary advice weekly (e.g., how many days a week did they drink whole milk, eat butter on bread, green vegetables, or beef). Adherence to the diet was expressed in percentages. These percentages were derived by dividing the number of portions patients provided, according to their diaries, by the total number of portions they were instructed to take. For example, when the children ate green vegetables four times, this was $4 / 5(80 \%)$ of the recommended amount of green vegetables that week. Green vegetables are one of the four products and therefore composed $25 \%$ of the total dietary advice, so $80 \%$ of $25 \%=20 \%$ of the total advice. The same calculation was used for the other food groups. The intake was calculated per week for 6 months. Parents of children in the control group recorded their children's dietary routine via a grouped checklist for the products advised for the dietary advice group, which was less specific (e.g., what type of milk, butter, meat, or vegetables did they eat on a daily basis). The same method was used to calculate their weekly intake with respect to the parts of the dietary intake they spontaneously took. Diaries were collected and children were checked and measured at the clinic visits. Blood samples were obtained prior to the intervention and after six months at least seven days after an infectious episode. The complete blood count with differential, C-reactive protein, ferritin, immunoglobin A ( $\lg A)$, $\lg G$, IgM, IgE, zinc, and cholesterol profile were measured.

\subsection{Outcome Measures}

The primary outcome measures were (1) the number of days per month with two or more symptoms of an upper respiratory tract infection in the last three months of the study, assuming a certain delay for the diet to impact on immunity, gathered through 
the monthly diaries; $(2)$ the total number of upper respiratory tract infections during the 6-month study period.

Secondary outcome measures were the number of days of parental absence from work due to a child with a URTI during the study, the number of prescribed antibiotics during the study, and differences in the total cholesterol: HDL (High-Density Lipoprotein)-ratio between groups and over time (since full fat products are a major part of the dietary advice).

\subsection{Sample Size}

According to a previous pilot study, the hypothesis was that dietary advice could reduce the number of days with at least two symptoms of a URTI from $12( \pm 8)$ to 8 ( \pm 6$)$ days per month [22]. This reduction was deemed achievable and clinically relevant in our patient population with recurrent URTIs. Calculations showed that 53 subjects were required in each group, with a power of $80 \%$ with two-sided testing at a significance level of 0.05 , and assuming a non-normal distribution. A total of 120 patients were required for inclusion, assuming a $10 \%$ loss to follow up.

\subsection{Statistical Methods}

Descriptive statistics describe baseline demographic features. The primary and secondary outcome measures were analyzed according to their characteristics with a Mann-Whitney $U$, Wilcoxon signed rank, and independent or paired sample $t$-tests, as appropriate. Data are reported as mean $({ } \mathrm{SD})$ or a median (inter-quartile range, $\mathrm{IQR}$ ) depending on the distribution. Some data (mean days on antibiotics and parental absence from work) were not normally distributed with median values are 0 . In these cases, mean values with SD instead of median values are presented in Table 2 for interpretability, but tests were performed with Mann-Whitney $U$ tests. For growth parameters, a mixed model analysis was used, where group and measurement were both added as fixed variables. The model we used for body mass index (BMI) SD = group measurement group $\times$ measurement. The interaction term group $\times$ measurement was added to analyze differences between groups over time. This was conducted for height, weight, weight for height, and BMI.

If, despite randomisation, relevant differences in baseline characteristics between the two groups existed, these were analyzed for influence on the outcome measures. Baseline characteristics that differed between the study groups $(p \leq 0.10)$ were tested for an association with the primary outcome variable (the number of days per month with 2 or more symptoms of an URTI in the last 3 months of the study, which was highly skewed) and considered as potential confounders if $p \leq 0.10$. To assess 
122 Chapter 6

the relationship between continuous independent variables (e.g., age, BMI) and the outcome variable, a Spearman rank correlation analysis was performed. For categorical variables (e.g., sex) a Mann-Whitney $U$ test was performed. Ultimately, as can be expected in a randomized controlled trial, no corrections for confounders were necessary. The analyses were conducted according to the modified intention-to-treat principle. Patients lost to follow up before the start of the first month of measuring were excluded from the analyses. A $p$-value of $<0.05$ was considered statistically significant. Statistical analyses were performed using the software SPSS Statistics version 25 (IBM, Chicago, Illinois, USA).

Table 1. Baseline characteristics of the subjects in the dietary advice and control group with median with interquartile range or mean $\pm \mathrm{SD}$.

\begin{tabular}{|c|c|c|}
\hline Variable & $\begin{array}{l}\text { Dietary advice } \\
(n=58)\end{array}$ & $\begin{array}{l}\text { Control group } \\
(n=60)\end{array}$ \\
\hline \multicolumn{3}{|l|}{ Personal characteristics } \\
\hline Age (years) & $2.4 \pm 1.1$ & $2.4 \pm 1.0$ \\
\hline Girls (\%) & $21(37 \%)$ & $36(63 \%)$ \\
\hline BMI-for-age standard score & $-0.13 \pm 1.16$ & $-0.06 \pm 1.26$ \\
\hline Height-for-age standard score & $0.02 \pm 1.20$ & $-0.25 \pm 0.89$ \\
\hline \multicolumn{3}{|l|}{ Perinatal characteristics } \\
\hline Delivery (vaginal) & $33(46 \%)$ & $39(54 \%)$ \\
\hline Gestational age (weeks) & $39.0(38-40)$ & $38.5(38-40)$ \\
\hline Birth weight (kg) & $3.5 \pm 0.6$ & $3.2 \pm 0.7$ \\
\hline Duration of breastfeeding (months) & $1(0-3)$ & $1(0-3)$ \\
\hline \multicolumn{3}{|l|}{ Clinical characteristics } \\
\hline $\begin{array}{l}\text { Two or more symptoms of URTI in the run-in period (days/ } \\
\text { month) }\end{array}$ & $14.5 \pm 7.9$ & $14.4 \pm 9.0$ \\
\hline Infection episodes in run in period ( $\mathrm{n} /$ month) & $2.0(1.0-3.0)$ & $1.5(1.0-2.0)$ \\
\hline Day care attendance (days/week) & $2.0 \pm 1.5$ & $1.9 \pm 1.5$ \\
\hline Parental smoking & $35(60 \%)$ & $31(52 \%)$ \\
\hline $\begin{array}{l}\text { Number of children (\%) with } 1 \text { or more antibiotic treatments in } \\
\text { run in period }\end{array}$ & $14(25 \%)$ & $13(22 \%)$ \\
\hline
\end{tabular}

\section{RESULTS}

\subsection{Population}

Between March 2015 and October 2017, 156 patients with recurrent URTIs were eligible for inclusion after being examined by a paediatrician. A total of 125 patients $(80 \%)$ 
agreed to participate and informed consent was provided by parent(s) or caregiver(s). These patients were randomized to the dietary advice plus supportive care (dietary advice group), or supportive care alone (control group). Their characteristics are listed in Table 1. No differences were found in the parental demographics in terms of educational attainment or socio-economic status. After inclusion, seven patients (6\%, two in the intervention and five in the control group) dropped out during the first three months of the study and were not included in the analyses. The reasons for these exclusions were failure to record infectious episodes and symptoms in the diary $(n=3)$ or complete loss to follow up $(n=4)$. Their characteristics were similar compared with the subjects who completed the trial.

Table 2. Primary and secondary outcome measures and their relevant components in the dietary advice group and control group.

$\begin{array}{llll}\text { Characteristic } & \begin{array}{l}\text { Dietary } \\ \text { advice } \\ (n=58)\end{array} & \begin{array}{l}\text { Control Group } \\ (n=60)\end{array} & \begin{array}{l}\text { RR }(95 \% \mathrm{Cl}), \\ \text { mean difference } \\ (95 \% \mathrm{Cl} \text {, or } p \text {-value }\end{array}\end{array}$

Primary outcome measurements

Two or more symptoms of an URTI (days/

month)

In the last 3 months of the study (median,

$4.8(1.5-9.5) \quad 7.7(4.0-12.3) \quad p=0.028^{a}$

IQR)

No. of infection periods/month (mean, SD)

$0.95( \pm 0.55) \quad 1.13( \pm 0.49)$

$-0.2(-0.39 ; 0.1)^{c}$

Secondary outcome measurements

Mean days on antibiotics in 6 months (mean, SD)

Number of children (\%) with 1 or more

antibiotic treatments in 6 months

$2.9( \pm 12.7) \quad 5.0( \pm 9.4) \quad p=0.002^{b}$

$10(17.2 \%) \quad 27(45 \%) \quad 0.39(0.20 ; 0.72)^{d}$

Days of parental absence of work in 6

months

$0.2( \pm 0.45) \quad 0.3( \pm 0.66) \quad p=0.893^{b}$

(mean, SD)

Symptoms in last 3 months;

no. of days/month

Coughing (mean, SD)

$5.3( \pm 4.9) \quad 8.2( \pm 6.0) \quad-3.0(-5.0 ;-1.0)^{c}$

Fever (mean, SD)

$1.2( \pm 1.4) \quad 2.1( \pm 1.9)$

$-0.9(-1.5 ;-0.3)^{\mathrm{c}}$

Blocked nose (mean, SD)

$2.5( \pm 3.9) \quad 4.6( \pm 5.8)$

$-2.1(-3.9 ;-0.3)^{\mathrm{c}}$

Runny nose (mean, SD)

$6.2( \pm 6.2) \quad 8.0( \pm 7.0)$

$-1.8(-4.2 ; 0.65)^{c}$

Sore throat (mean, SD)

$1.0( \pm 2.0) \quad 1.1( \pm 1.7)$

$-0.1(-0.8 ; 0.58)^{c}$

Wheezing (mean, SD)

$3.5( \pm 6.7)$

$4.0( \pm 7.2)$

$-0.6(-3.1 ; 2.0)^{\mathrm{c}}$

Otitis (mean, SD)

$1.6( \pm 5.1)$

$0.6( \pm 1.6)$

$0.9(-0.45 ; 2.3)^{\mathrm{c}}$

URTI, upper respiratory tract infection; HDL, high density lipoprotein; ${ }^{a}$ continuous variable, not normally distributed, with median >0; median (IQR) and $p$-value of Mann-Whitney $\mathrm{U}$ test are presented. ${ }^{b}$ continuous variables, not normally distributed, with median $=0$; mean (SD) and $p$-value of MannWhitney $\mathrm{U}$ test are presented. ${ }^{\mathrm{c}}$ continuous variables, normally distributed; mean (SD) and mean difference $(95 \% \mathrm{Cl})$ are presented. ${ }^{d}$ categorical variables, relative risk (RR) and $95 \% \mathrm{Cl}$ are presented 
$124 \mid$ Chapter 6

\subsection{Adherence to Dietary Advice}

The adherence to the dietary advice was $88 \%$ for the whole diet during the six months of the study. Adherence was lowest for green vegetables (82\%) compared to beef, whole milk, and whole butter $(92 \%, 90 \%$, and $91 \%$, respectively). The regular dietary intake (without dietary advice) of the control group reported by their diaries followed $34 \%$ of the dietary advice, mainly by their intake of beef and green vegetables. The regular dietary intake of the control group met $48 \%$ of the green vegetable advice, $60 \%$ of the beef advice, $10 \%$ of the whole milk, and $18 \%$ of the butter advice.

\subsection{Outcome Measures}

\subsubsection{Primary Outcome Measures: Duration and Number of Infections}

The median (IQR) number of days per month with two or more symptoms of a URTI in the last three months of the study was 4.8 (1.6-9.5) in the dietary advice group compared to $7.7(4.0-12.3)$ in the control group $(p=0.028)$. The total number of URTI episodes during the study period of 6 months was $5.7( \pm 0.55)$ in the intervention group compared to $6.8( \pm 0.49)$ episodes in the control group. The primary and secondary outcome measures are presented in Table 2.

Some data were not normally distributed (e.g., days on antibiotics and parental absence), and median values were zero. In these cases, mean values are presented in Table 2 for interpretability, but Mann-Whitney $U$ tests were performed.

\subsubsection{Other Clinical Outcomes}

The number of days with antibiotic use and the percentage of children who received antibiotic treatment during the six months of study were significantly lower in the dietary advice group. We noted a significant difference between groups in the number of days with fever in the last three months of the study; the median was $0.83(0.0-1.7)$ in the dietary advice group versus $1.7(0.7-3.0)$ in the control group $(p<0.01)$. The days the children coughed and suffered from a blocked nose were fewer in the intervention group (Table 2 ).

In the control group, parents visited their general practitioner more often during the six months with a mean of 1.6 (SD 2.3) visits in six months compared to 0.9 (SD 1.5) visits in the dietary advice group (Mann-Whitney $U$ test, $p=0.031$ ). Parents in the dietary advice group were not significantly less absent from work due to child illness. 


\subsubsection{Other Outcome Measures}

To investigate whether the dietary advice would produce its effect by immunomodulation, we performed laboratory investigations. The only laboratory parameter that showed a between-group difference was C-reactive protein (CRP). In the dietary advice group, CRP decreased from 5.35 to $2.46 \mathrm{mg} / \mathrm{L}(p=0.044)$, but remained unchanged in the control group ( $p=0.82$ ) with a difference between groups over time $(p=0.034)$, possibly suggestive of a lower grade of inflammation in the intervention group. The clinical meaning of this decrease should be used with caution since CRP values $<10 \mathrm{mg} / \mathrm{L}$ are regarded as non-elevated values. Other laboratory values did not differ between the groups after six months of follow up (Table S3).

Laboratory analyses showed that the cholesterol/HDL ratio was slightly lowered in both groups during the study (dietary advice group -0.56, $p<0.001$ ); control group $-0.36, p=0.06)$ but not different between both groups $(p=0.40)$. Within groups, we observed some slight increases or decreases during the six months of follow up. In the dietary advice group, hemoglobin $(\mathrm{Hb})$, Mean Corpuscular Volume (MCV), zinc, IgE, total cholesterol, and HDL increased, while leucocytes, lymphocytes, ferritin, $\lg M$, and triglycerides decreased significantly compared with the starting values after six months of following the dietary advice. In the control group, zinc increased, and triglycerides and lymphocytes decreased significantly for the same period.

We found no significant changes in height or weight gain between groups. Table 3 provides full details on biometry values. No harmful or unintended effects were noted during the study.

Table 3. Biometrics of participants (SD according to standardized Dutch growth graphs).

\begin{tabular}{llllllll} 
Parameter & \multicolumn{3}{c}{ Dietary advice } & \multicolumn{3}{c}{ Control Group } & $p$-value \\
& $T=0$ & $T=3$ & $T=6$ & $T=0$ & $T=3$ & $T=6$ & \\
Weight in SD & -0.101 & -0.061 & -0.053 & -0.231 & -0.141 & -0.089 & 0.6 \\
Height in SD & 0.023 & 0.086 & 0.052 & -0.228 & -0.217 & -0.295 & 0.6 \\
Weight for height in SD & -0.074 & -0.072 & -0.020 & -0.073 & 0.016 & 0.178 & 0.4 \\
BMI in SD & -0.136 & -0.111 & -0.098 & -0.061 & 0.038 & 0.207 & 0.14
\end{tabular}

Mixed model analysis. $p$-values indicate the group $\times$ measurement interaction. $T=0,3$ and 6 months after inclusion.

\section{DISCUSSION}

The dietary advice significantly decreased the number of days with a URTI and taking antibiotics as well as the number of children using antibiotics, and symptoms of 
$126 \mid$ Chapter 6

coughing, fever, and blocked nose. No difference in the number of URTIs was observed. This suggests a shorter duration of infection. The diet did not reduce the number of days of parental absence from work. The study was, however, not designed to detect differences between groups in these secondary outcome measurements. Laboratory parameters did not significantly change over time between the two groups to explain the observed clinical differences.

The main strength of this study is the uniqueness of applying a randomized controlled trial (RCT) design to evaluate the effects of a full diet intervention. We tried to adhere to the most frequently used outcome measures in nutritional interventions in children with respiratory infections, as indicated by the COMMENT Initiative as well as daily questionnaires on common cold symptoms $[24,26]$. We incorporated a RCT design with normal eating practices, providing valid reflection of possible effects on daily life [27]. Our dietary advice was based on the qualities of the food matrix and food synergy in relation to fresh, locally produced, and traditional food. The food matrix is based on structural capacities of foods, in which macro and micronutrients are offered. This food structure makes the difference between biological and health outcomes [28]. Food synergy is based on the proposition that the interrelations between constituents in foods are important, as well as the interactions between foods, and that the total effect on health is greater than just the sum of all individual effects [14]. The studies mentioned in the introduction focused on a limited number of supplementations, each with their own working mechanism [10-13]. Our dietary advice provides the proper nutritional values while leaving the food matrix intact. However, the specific mechanisms of action are still unknown.

The dietary advice was based on food composition derived from the Dutch Food Composition Database [20]. The diet contains proper quantities of vitamins A, C, D, and $\mathrm{E}$, zinc, iron, and fatty acids (Table $\mathrm{S} 1$ ). All these components show potential to positively influence the immune response in children. Numerous immunological effects of various nutrients have been published as well as the routing of the activated immune cells to the airways, thereby linking the dietary components to chronic inflammation by means of the intestine-airway axis [12, 29-32].

Studies with RCTs and whole foods for URTI are scarce. Positive effects on the duration or prevention of URTIs in adults or children were observed with the intake of probiotics, prebiotics, milk, fish oil, kiwi fruit, garlic, xylitol , and elderberry [33-40]. The studies focused on a single whole food product, not a combination of food products. In another study, the combination of food products was investigated with the Mediterranean diet. In a before-after comparison after the adoption of the Mediterranean 
diet, Calatayud et al. found a reduction in URTIs from $7.45 \pm 1.74$ to $2.88 \pm 1.60$ episodes over one year in children aged one to five years [15]. Due to the absence of a control group, it was hard to assess causality, since the number of infections declines with advancing age [1].

Due to public opinion, parents are sometimes afraid about possible side effects of adhering to dietary advice including beef and whole dairy products. Red meat has been under scrutiny due to possible carcinogenic attributes. The role of beef in this matter remains questionable, since red meat is a catch-all for beef, pork, veal, lamb, horse, etc. The carcinogenic role of meat seems to be more applicable to processed meat instead of red meat [41].

Our results showed that consuming whole dairy products does not increase the cholesterol/HDL ratio during six months of following this dietary advice, in line with other reports [42, 43]. Dairy products consumption has been associated with a lower risk of mortality and major cardiovascular disease events in a diverse multinational cohort, without added risk by intake of whole fat dairy products [44]. These findings are consistent with insights that fats from animal origin (intake from fats by dairy or meat consumption) increase HDL levels and decrease the cholesterol/HDL ratio [45].

Some limitations must be considered. The loss to follow up was slightly greater in the control group, but the number of patients dropping out was small ( $3 \%$ from the control group vs. $8 \%$ from the intervention group). We therefore think that these patients did not influence the results.

Blinding of participants to the dietary advice was impossible. Although parents in the control group were not aware about the specifics of the dietary advice, it is possible that subjects in the control group may had heard about it due to earlier studies by the primary investigator. They may have chosen to incorporate (parts of) the diet into their daily lives. Data from the diaries of both groups showed this influence to be limited: children in the intervention group adhered to the dietary advice by $89 \%$ versus $34 \%$ in the control group. We interpreted the diet of the control group as normal child eating habits in our region. Possible contamination bias in the control group would therefore only complicate the detection of differences between groups.

The finding that fewer antibiotic courses were prescribed and a lower number of visits to the general practitioner was reported in the dietary advice group may also be influenced by not blinding participants. Parents may have been influenced by knowing 
they were in the group receiving treatment and therefore were less demanding of antibiotic treatment when visiting a physician.

\subsection{Implications for Research and/or Practice}

Our results showed a significant reduction of days with URTIs and symptoms but failed to show a significant reduction in the number of episodes with a URTI. This could be due to an assumed delay for the diet to impact immunity but also suggests that adjusting the dietary intake can influence the course or duration of infections rather than preventing the child from falling ill. The Cochrane review on vitamin $\mathrm{C}$ also showed beneficial effects of vitamin $C$ on the common cold [12]. We do not think that the effect of the investigated dietary advice is solely explained by the vitamin $C$ content of the diet, since other food products low in vitamin C (like probiotics or fish oil) also shorten the duration of URTI in children [33-36, 39]. We think that the combination of products like in a dietary advice has its operating mechanism in multiple immune-fortifying mechanisms, and not just by one mechanism. Overall, exposure to certain viral pathogens in childhood is necessary for achieving a proper immune function. Normal exposure to pathogens and decreasing severity of contracted illness shows the adaptability that reflects a good state of health [46].

Since healthcare costs are high for URTI and several often ineffective antibiotic treatments are prescribed, dietary intervention can potentially reduce healthcare costs through reducing the use of antibiotics and visits to the general practitioner [8]. Due to decreased antibiotic prescriptions, the treatment could help reduce antibiotic resistance or response failure in the future.

Our findings can further strengthen the scientific evidence supporting national and global nutritional guidelines. The low-cost nature of the intervention makes the dietary advice easily applicable for widespread preventive care for parents. The costs are a little higher due to the higher costs of beef compared to chicken or pork. Due to the small portion sizes consumed by young children, the estimated extra costs in the Netherlands are $€ 0.67$ per week. Since no treatment exists for children suffering from URTI without immunological disorders, this diet provides parents with a tool to improve the health of their children.

\section{CONCLUSIONS}

We found that a diet of green vegetables, beef, and whole dairy products in children with recurrent URTIs can decrease the number of days per months with multiple 
symptoms of a URTI. The dietary advice also leads to fewer prescribed antibiotics and can therefore be a possible tool to help reduce antibiotic prescriptions. 


\section{REFERENCES}

1. C. Gruber, T. Keil, M. Kulig, S. Roll, U. Wahn, V. Wahn, M.A.S.S. Group, History of respiratory infections in the first 12 yr among children from a birth cohort, Pediatr Allergy Immunol 19(6) (2008) 505-12.

2. T. Heikkinen, A. Jarvinen, The common cold, Lancet 361(9351) (2003) 51-9.

3. R.B. Turner, Epidemiology, pathogenesis, and treatment of the common cold, Ann Allergy Asthma Immunol 78(6) (1997) 531-9; quiz 539-40.

4. T.M. Ball, C.J. Holberg, M.B. Aldous, F.D. Martinez, A.L. Wright, Influence of attendance at day care on the common cold from birth through 13 years of age, Arch Pediatr Adolesc Med 156(2) (2002) 121-6.

5. E. de Vries, T.W. Kuijpers, M.J. van Tol, J.W. van der Meer, C.M. Weemaes, J.J. van Dongen, [Immunology in medical practice. XXXV. Screening of suspected immunodeficiency: diagnostic protocols for patients with opportunistic or recurrent severe infections, wasting and failure to thrive], Ned Tijdschr Geneeskd 144(46) (2000) 2197-203.

6. G.M. Lee, J.F. Friedman, D. RossDegnan, P.L. Hibberd, D.A. Goldmann, Misconceptions about colds and predictors of health service utilization, Pediatrics 111(2) (2003) 231-6.

7. T.J. Bramley, D. Lerner, M. Sames, Productivity losses related to the common cold, J Occup Environ Med 44(9) (2002) 822-9.

8. A.G. Mainous, 3rd, W.J. Hueston, The cost of antibiotics in treating upper respiratory tract infections in a medicaid population, Arch Fam Med 7(1) (1998) 45-9.

9. O. van Hecke, A. Fuller, C. Bankhead, S. Jenkins-Jones, N. Francis, M. Moore, C. Butler, K. Wang, Antibiotic exposure and 'response failure' for subsequent respiratory tract infections: an observational cohort study of UK preschool children in primary care, $\mathrm{Br} \mathrm{J}$ Gen Pract (2019) e638-e646.

10. M.Y. Yakoob, R.A. Salam, F.R. Khan, Z.A. Bhutta, Vitamin D supplementation for preventing infections in children under five years of age, Cochrane Database Syst Rev 11 (2016) CD008824.

11. F.A. Jonker, M. Boele van Hensbroek, Anaemia, iron deficiency and susceptibility to infections, J Infect 69 Suppl 1 (2014) S23-7.

12. H. Hemila, E. Chalker, Vitamin C for preventing and treating the common cold, Cochrane Database Syst Rev (1) (2013) CD000980.

13. A.R. Martineau, D.A. Jolliffe, R.L. Hooper, L. Greenberg, J.F. Aloia, P. Bergman, G. Dubnov-Raz, S. Esposito, D. Ganmaa, A.A. Ginde, E.C. Goodall, C.C. Grant, C.J. Griffiths, W. Janssens, I. Laaksi, S. Manaseki-Holland, D. Mauger, D.R. Murdoch, R. Neale, J.R. Rees, S. Simpson, Jr., I. Stelmach, G.T. Kumar, M. Urashima, C.A. Camargo, Jr., Vitamin D supplementation to prevent acute respiratory tract infections: systematic review and meta-analysis of individual participant data, BMJ 356 (2017) $i 6583$.

14. D.R. Jacobs, Jr., M.D. Gross, L.C. Tapsell, Food synergy: an operational concept for understanding nutrition, Am J Clin Nutr 89(5) (2009) 1543S-1548S.

15. F.M. Calatayud, B. Calatayud, J.G. Gallego, C. Gonzalez-Martin, L.F. Alguacil, Effects of Mediterranean diet in patients with recurring colds and frequent complications, Allergol Immunopathol (Madr) 45(5) (2017) 417-424.

16. E. Fondell, S.E. Christensen, O. Balter, K. Balter, Adherence to the Nordic Nutrition Recommendations as a measure of a healthy diet and upper respira- 
tory tract infection, Public Health Nutr 14(5) (2011) 860-9.

17. P.P. Huijbregts, E.J. Feskens, L. Rasanen, A. Alberti-Fidanza, M. Mutanen, F. Fidanza, D. Kromhout, Dietary intake in five ageing cohorts of men in Finland, Italy and The Netherlands, Eur J Clin Nutr 49(11) (1995) 852-60.

18. FAO, Food balance sheets, http://www. fao.org/faostat/en/\#home, 2019.

19. M. Munow, E.J. van der Gaag, Ailing Toddlers. Is there a relation between behaviour and health?, 27th ESPID Meeting, Brussels, Belgium, 2009.

20. N. tables, Dutch Food Composition Database, https://nevo-online.rivm. $\mathrm{nl} /$.

21. T.N.N. Centre, example diet for young children, Voedingscentrum, https: / / www. voedingscentrum.nl/nl/ mijn-kind-en-ik/dreumes-en-peuter/ voorbeelddagmenu-voor-dreumes-enpeuter.aspx, 2019.

22. L.L. ten Velde, J; van der Gaag, EJ, Recurrent Upper Respiratory Tract Infections in Children: The Influence of Green Vegetables, Beef, Whole Milk and Butter, Food and Nutrition Sciences 4 (2013) 71-77.

23. P. Chatchatee, W.S. Lee, E. Carrilho, P. Kosuwon, N. Simakachorn, Y. Yavuz, B. Schouten, P.L. Graaff, H. Szajewska, Effects of growing-up milk supplemented with prebiotics and LCPUFAs on infections in young children, J Pediatr Gastroenterol Nutr 58(4) (2014) 428-37.

24. R. Eccles, Is the common cold a clinical entity or a cultural concept?, Rhinology 51(1) (2013) 3-8.

25. L. Burke, T. Stifano, Guidance for industry: patient-reported outcome measures: use in medical product development to support labeling claims: draft guidance, Health Qual Life Outcomes (2006) 4-79.
26. A. Guarino, E. Bruzzese, A. Lo Vecchio, R. Dagan, M. Tsolia, Definitions and outcomes of nutritional interventions in children with respiratory infections: the approach of the COMMENT initiative, Ann Nutr Metab 63(3) (2013) 248-55.

27. B. Penders, A. Wolters, E.F. Feskens, F. Brouns, M. Huber, E.L.M. Maeckelberghe, G. Navis, T. Ockhuizen, J. Plat, J. Sikkema, M. Stasse-Wolthuis, P. van 't Veer, M. Verweij, J. de Vries, Capable and credible? Challenging nutrition science, Eur J Nutr 56(6) (2017) 20092012.

28. M.L. Wahlqvist, Food structure is critical for optimal health, Food Funct 7(3) (2016) 1245-50.

29. T.H. Hassan, M.A. Badr, N.A. Karam, M. Zkaria, H.F. El Saadany, D.M. Abdel Rahman, D.A. Shahbah, S.M. Al Morshedy, M. Fathy, A.M. Esh, A.M. Selim, Impact of iron deficiency anemia on the function of the immune system in children, Medicine (Baltimore) 95(47) (2016) e5395.

30. C. Jimenez, I. Leets, R. Puche, E. Anzola, R. Montilla, C. Parra, A. Aguilera, M.N. Garcia-Casal, A single dose of vitamin A improves haemoglobin concentration, retinol status and phagocytic function of neutrophils in preschool children, $\mathrm{Br} \mathrm{J}$ Nutr 103(6) (2010) 798-802.

31. O. Perdijk, M. van Splunter, H.F.J. Savelkoul, S. Brugman, R.J.J. van Neerven, Cow's Milk and Immune Function in the Respiratory Tract: Potential Mechanisms, Front Immunol 9 (2018) 143.

32. M. van Splunter, E. van Hoffen, E.G. Floris-Vollenbroek, H. Timmerman, E.L. de Bos, B. Meijer, L.H. Ulfman, B. Witteman, J.M. Wells, S. Brugman, H.F.J. Savelkoul, R.J.J. van Neerven, Oral cholera vaccination promotes homing 
of $\lg \mathrm{A}(+)$ memory $\mathrm{B}$ cells to the large intestine and the respiratory tract, $\mathrm{Mu}$ cosal Immunol 11(4) (2018) 1254-1264.

33. Q. Hao, B.R. Dong, T. Wu, Probiotics for preventing acute upper respiratory tract infections, Cochrane Database Syst Rev 2 (2015) CD006895.

34. C. Hughes, Y. Davoodi-Semiromi, J.C. Colee, T. Culpepper, W.J. Dahl, V. Mai, M.C. Christman, B. Langkamp-Henken, Galactooligosaccharide supplementation reduces stress-induced gastrointestinal dysfunction and days of cold or flu: a randomized, double-blind, controlled trial in healthy university students, Am J Clin Nutr 93(6) (2011) 1305-11.

35. F. Li, X. Jin, B. Liu, W. Zhuang, D. Scalabrin, Follow-up formula consumption in 3- to 4-year-olds and respiratory infections: an RCT, Pediatrics 133(6) (2014) e1533-40.

36. A. Thienprasert, S. Samuhaseneetoo, K. Popplestone, A.L. West, E.A. Miles, P.C. Calder, Fish oil $n-3$ polyunsaturated fatty acids selectively affect plasma cytokines and decrease illness in Thai schoolchildren: a randomized, doubleblind, placebo-controlled intervention trial, J Pediatr 154(3) (2009) 391-5.

37. A. Adaim, Investigating the effect of gold kiwifruit consumption on the incidence and symptoms of upper respiratory tract infections in pre-school children., Massey University, New Zealand., http://mro.massey.ac.nz/bitstream/handle/10179/2351/02_whole. pdf?sequence=1, 2010, p. 191.

38. E. Lissiman, A.L. Bhasale, M. Cohen, Garlic for the common cold, Cochrane Database Syst Rev 11 (2014) CD006206.

39. A. Azarpazhooh, H.P. Lawrence, P.S. Shah, Xylitol for preventing acute otitis media in children up to 12 years of age, Cochrane Database Syst Rev (8) (2016) CD007095.
40. Z. Zakay-Rones, E. Thom, T. Wollan, J. Wadstein, Randomized study of the efficacy and safety of oral elderberry extract in the treatment of influenza $A$ and $B$ virus infections, $J$ Int Med Res 32(2) (2004) 132-40.

41. I.T. Johnson, The cancer risk related to meat and meat products, Br Med Bull 121(1) (2017) 73-81.

42. S. Engel, M. Elhauge, T. Tholstrup, Effect of whole milk compared with skimmed milk on fasting blood lipids in healthy adults: a 3-week randomized crossover study, Eur J Clin Nutr 72(2) (2018) 249-254.

43. E.J. van der Gaag, R. Wieffer, J. van der Kraats, Advising Consumption of Green Vegetables, Beef, and Full-Fat Dairy Products Has No Adverse Effects on the Lipid Profiles in Children, Nutrients 9(5) (2017).

44. M. Dehghan, A. Mente, S. Rangarajan, P. Sheridan, V. Mohan, R. Iqbal, R. Gupta, S. Lear, E. Wentzel-Viljoen, A. Avezum, P. Lopez-Jaramillo, P. Mony, R.P. Varma, R. Kumar, J. Chifamba, K.F. Alhabib, N. Mohammadifard, A. Oguz, F. Lanas, D. Rozanska, K.B. Bostrom, K. Yusoff, L.P. Tsolkile, A. Dans, A. Yusufali, A. Orlandini, P. Poirier, R. Khatib, B. Hu, L. Wei, L. Yin, A. Deeraili, K. Yeates, R. Yusuf, N. Ismail, D. Mozaffarian, K. Teo, S.S. Anand, S. Yusuf, i. Prospective Urban Rural Epidemiology study, Association of dairy intake with cardiovascular disease and mortality in 21 countries from five continents (PURE): a prospective cohort study, Lancet 392(10161) (2018) 2288-2297.

45. Y. Liu, S. Poon, E. Seeman, D.L. Hare, M. Bui, S. Iuliano, Fat from dairy foods and 'meat' consumed within recommended levels is associated with favourable serum cholesterol levels in institutionalised older adults, J Nutr Sci 8 (2019) e10. 
46. M. Huber, M.H. Bakker, W. Dijk, H.A. Prins, F.A. Wiegant, The challenge of evaluating health effects of organic food; operationalisation of a dynamic concept of health, J Sci Food Agric 92(14) (2012) 2766-73. 
$134 \mid$ Chapter 6

\section{SUPPLEMENTARY MATERIALS}

Table S1. Average daily nutritional values from the dietary advice alone[20]. This does not contain additional nutrients from other meals, snacks and beverages.

\begin{tabular}{ccccccccccccc} 
& \multicolumn{3}{c}{ Vit A $(\mu \mathrm{g})$} & \multicolumn{2}{c}{ Vit C $(\mathrm{mg})$} & \multicolumn{2}{c}{ Vit $\mathrm{D}(\mu \mathrm{g})$} & \multicolumn{2}{c}{ Vit E $(\mathrm{mg})$} & \multicolumn{2}{c}{ Zinc $(\mathrm{mg})$} & \multicolumn{2}{c}{ Iron $(\mathrm{mg})$} \\
\hline & Diet & RDA & Diet & RDA & Diet & RDA & Diet & RDA & Diet & RDA & Diet & RDA \\
Minimum & 275 & & 14 & & 0.9 & & 1.9 & & 4.7 & & 2.1 & \\
Maximum & 445 & 400 & 18 & 40 & 0.9 & $10^{*}$ & 2.6 & 5.5 & 7.9 & 4 & 2.8 & 7
\end{tabular}

* Supplementation according to national guidelines. RDA = recommended daily allowance.

Table S2. The dietary advice with age specific portion sizes[21].

$\begin{array}{lll}\text { Product } & \text { Frequency } & \text { Portion size (1-4y) } \\ \text { Green vegetables } & 5 \text { times per week } & 50-100 \mathrm{~g} \\ \text { Beef } & 3 \text { times per week } & 50-60 \mathrm{~g} \\ \text { Bovine milk } & \text { Daily } & 300 \mathrm{~mL} \\ \text { Whole dairy butter on bread } & \text { Daily } & 5 \mathrm{~g} / \mathrm{slice}\end{array}$

Table S3. Laboratory values of both groups at baseline (T0). at 6 months (T6) and p-values for differences between groups and in time.

\begin{tabular}{|c|c|c|c|c|c|c|c|}
\hline & \multicolumn{3}{|c|}{$\begin{array}{l}\text { Dietary Advice } \\
\qquad N=58\end{array}$} & \multicolumn{3}{|c|}{$\begin{array}{c}\text { Control Group } \\
\qquad N=60\end{array}$} & \multirow[t]{2}{*}{$\begin{array}{c}\mathrm{p} \text {-value } \\
\text { (between groups) }\end{array}$} \\
\hline & $T=0$ & $T=6$ & $\mathrm{p}$-value & $T=0$ & $T=6$ & $\mathrm{p}$-value & \\
\hline $\mathrm{Hb}(\mathrm{mmol} / \mathrm{l})$ & 7.34 & 7.59 & $<0.001$ & 7.36 & 7.54 & 0.003 & 0.4 \\
\hline MCV (fl) & 77.9 & 78.8 & 0.007 & 78.5 & 78.9 & 0.18 & 0.3 \\
\hline Leucocytes $\left(\times 10^{9}\right)$ & 10.3 & 9.26 & 0.024 & 9.35 & 8.88 & 0.36 & 0.3 \\
\hline Lymphocytes (x109) & 4.91 & 4.34 & 0.007 & 4.81 & 4.15 & 0.019 & 0.8 \\
\hline Neutrophils $\left(x 10^{9}\right)$ & 4.04 & 3.88 & 0.41 & 3.34 & 3.57 & 0.54 & 0.3 \\
\hline CRP (mg/l) & 5.35 & 2.46 & 0.044 & 2.98 & 3.02 & 0.83 & 0.034 \\
\hline Ferritin (ug/l) & 43.3 & 33.0 & 0.08 & 51.6 & 41.5 & 0.38 & 0.7 \\
\hline Zinc (umol/l) & 11.2 & 12.8 & $<0.001$ & 11.5 & 12.3 & 0.033 & 0.2 \\
\hline $\lg A(g / l)$ & 0.62 & 0.58 & 0.82 & 0.67 & 0.68 & 0.27 & 0.5 \\
\hline $\lg G(g / l)$ & 7.25 & 7.21 & 0.73 & 7.74 & 7.49 & 0.40 & 0.7 \\
\hline $\lg M(g / l)$ & 0.97 & 0.89 & 0.018 & 0.96 & 0.89 & 0.48 & 0.4 \\
\hline $\lg E(g / l)$ & 33.9 & 58.9 & 0.004 & 37.1 & 62.0 & 0.31 & 0.16 \\
\hline Cholesterol (mmol/l) & 3.99 & 4.12 & 0.047 & 3.97 & 3.97 & 0.93 & 0.20 \\
\hline Triglycerides (mmol/l) & 1.46 & 1.08 & 0.005 & 1.45 & 1.20 & 0.042 & 0.6 \\
\hline $\mathrm{HDL}(\mathrm{mmol} / \mathrm{l})$ & 1.11 & 1.29 & $<0.001$ & 1.14 & 1.21 & 0.16 & 0.11 \\
\hline LDL (mmol/l) & 2.22 & 2.35 & 0.05 & 2.29 & 2.28 & 0.85 & 0.20 \\
\hline Cholesterol/HDL ratio & 3.95 & 3.32 & $<0.001$ & 3.77 & 3.47 & 0.06 & 0.4 \\
\hline
\end{tabular}

Normally distributed, student -test and mean values; Hb, MCV, leucocytes, lymphocytes, Neutrophils, IgA, IgG, Cholesterol, triglycerides, HDL, LDL, Cholesterol/HDL ratio Not normally distributed, Mann Whitney test and median values; CRP, ferritin, IgM, IgE 










\section{A dietary intervention reduces tiredness in children with subclinical hypothyroidism, a randomized controlled trial}

Ellen van der Gaag, Job van der Palen, Pim Schaap, Mirthe van Voorthuizen and Thalia Hummel 


\section{ABSTRACT}

Background; Subclinical hypothyroidism (SH) in children and adults is a subject for discussion whether to treat it or not with respect to the short-term clinical implications and consequences of $\mathrm{SH}$ for the long term. If treatment with thyroxine supplementation is not indicated, no other treatment is available. We investigated whether a dietary intervention improves or normalizes SH or decreases Thyroid Stimulating Hormone (TSH) and/or tiredness.

Methods; we randomized children aged 1-18 years with SH to the control group (standard care $=$ no treatment) or intervention group (dietary intervention). The dietary intervention consisted of green vegetables, beef, whole milk and butter for 6 months. The rest of the diet remained unchanged. We measured TSH, FreeT4, Lipid profile, $\mathrm{BMI}$ and Pediatric Quality of Life (PedQL) multidimensional fatigue scale scores.

Findings; 62 children were included. After 6 months, TSH decreased in both groups without a significant difference between the groups $(p=0.98)$. PedQL fatigue scores for sleep $(p=0.032)$ and total fatigue scores $(p=0.039)$ improved significantly in the intervention group, compared to the control group. No unfavorable effects occurred in the lipid profile or BMI.

Interpretation; The dietary intervention did not normalize SH and TSH levels, but it significantly reduced tiredness. These results suggest that children's well-being can be improved without increasing risk factors for the long term. 


\section{INTRODUCTION}

Subclinical hypothyroidism (SH) is a biochemical condition defined as subclinical because only the serum level of thyroid stimulating hormone (TSH) is slightly increased. Other thyroid hormones like FreeT4 (FT4) are in the normal range (1). Subclinical hypothyroidism is present in about $2 \%$ of the children compared to about $15 \%$ in adults (2-5). A chronic auto-immune thyroiditis is the most common cause for $\mathrm{SH}$ (about 50 $80 \%$ ), with or without high thyroid peroxidase antibodies (6). About $1 \%$ of the children with SH develops a clinical hypothyroidism (4).

In theory, a child with subclinical hypothyroidism would not have any clinical symptoms, since only the TSH is increased and the functional hormone (FT4) is not involved. Despite the apparent lack of relation between thyroid biochemical parameters and clinical symptoms, multiple complaints related to $\mathrm{SH}$ have been found in daily practice and medical surveys. Tiredness, weight gain, disturbed lipid profiles, impaired growth velocity, excessive sleepiness and physical weakness are described $(2,7,8)$. Children and adults with $\mathrm{SH}$ have higher incidences of panic attacks, problems with their short term memory, and concentration problems $(9,10)$.

On the long term, children with $\mathrm{SH}$ have higher blood pressure levels and dyslipidemia. Higher levels of triglycerides and LDL can be found, as well as decreased levels of HDL. The mechanism however is unknown at this moment $(5,11-13)$. Finally, SH causes higher cardiovascular morbidity and mortality in young adulthood (14).

A treatment for $\mathrm{SH}$ is lacking, except for supplementation of thyroxine when TSH rises above $10 \mathrm{mU} / \mathrm{l}$, with some exceptions (e.g. goiter or clear symptoms of hypothyroidism)(15, 16). A meta-analysis in adults with SH studied the benefits of thyroid supplementation and its effect on thyroid related symptoms. In this analysis of 21 studies, the TSH levels decreased to normal ranges after hormone therapy, but the thyroid related symptoms, such as tiredness, and quality of life did not improve (17). In a study in children no relation was shown between the neurocognitive function of children (and their developing brain) and the use of thyroxin therapy (8). This shows the unclear relationship between clinical complaints and disturbed biochemical thyroid values.

Alternative approaches to treat $\mathrm{SH}$ have been tested, such as the supplementation of nutrients, selenium in particular. Selenium is used for the production of selenoproteins, essential for protection and metabolism of the thyroid gland. Nutritional sources of selenium are meats, dairy, grains and seafood. Dietary selenium intake 
measured with food frequency questionnaires showed an inverse association with $\mathrm{SH}$, independent of the intake of energy ( $\mathrm{kcal}$ ) and other nutrients. The more selenium Brazilian adults consumed with their daily food intake, the lower the incidence of $\mathrm{SH}$ (18). When evaluated in a meta-analysis, selenium as a supplement did not alter thyroid function nor did it improve clinical symptoms (19). Selenium rich foods (e.g. higher selenium content) instead of a single selenium supplement could therefore be related to prevention of $\mathrm{SH}$.

With this present study, we aimed to investigate the effect of a nutrient rich dietary advice intervention on TSH levels in children with $\mathrm{SH}$, since single nutrient supplementation was not successful. We chose a diet with multiple ingredients instead of one or two supplements because we wanted to study the influence of nutrition instead of supplementation.

The dietary advice consisted of unprocessed food: beef, green vegetables, whole milk and butter. The dietary advice intervention is particularly rich in minerals like selenium, vitamin A, iron and omega-3 fatty acids (20). We hypothesized that the dietary intervention can replenish possible (subclinical) deficiencies and thus improve thyroid functioning. In our outpatient clinic, parents often report tiredness in their child with SH as the main clinical complaint. Therefore, we also looked at tiredness with sub scores on general tiredness, sleep and cognitive functioning. To evaluate the possible negative long-term effects of the dietary intervention, we looked at the BMI and lipid profile to investigate the development of potentially unfavorable dyslipidemia profiles. As far as we know, this is the first randomized controlled trial with a dietary intervention for children with $\mathrm{SH}$.

\section{MATERIAL AND METHODS}

\section{Population}

The research population consisted of children with $\mathrm{SH}$ at the outpatient clinics (general paediatrics) of 2 medium sized hospitals in the eastern region of The Netherlands. Inclusion criteria were age 1-18 years, diagnosis of SH confirmed by a paediatrician, understanding of the Dutch language by the parents. Exclusion criteria were clinical hypothyroidism ( $\mathrm{FT} 4<10 \mathrm{pmol} / \mathrm{l}$ ), treatment with thyroid hormone (like (levo)thyroxine), immunological abnormalities, cow's milk allergy, known or suspected disorder of the intestinal absorption (e.g. celiac disease), disorders requiring a special diet, any relevant congenital or anatomical abnormality, chromosomal disorder or severe disease. 


\section{Recruitment and randomisation}

General physicians or paediatricians referred the children with $\mathrm{SH}$ to the investigators if there was a diagnosis of subclinical hypothyroidism (TSH $>4,2 \mathrm{mU} / \mathrm{l}$ and FT4 within the normal range). The children's' parent(s) and/or legal guardian(s) (hereafter named parents) were provided with an information brochure of the study and an appointment with one of the paediatricians participating in the study was scheduled. The paediatrician saw the child in the outpatient clinic, took a history, and performed a physical investigation including measurements of weight and height. If there were any suggestions of an underlying disease causing the subclinical hypothyroidism, the paediatrician investigated and treated accordingly.

The investigator answered any questions parents might have. If parents agreed for the child to participate in the study, informed consent was signed. Parents had a period of one week to rethink the information before signing. After the signing of informed consent, the child was randomised into either the treatment or control group. The children were randomised with the MinimPy minimisation software (Minimpy 0.3) on a central computer. The (known and potential) confounders age and BMI were equally distributed between the two groups.

\section{Study protocol}

After randomisation the dietary advice was revealed to the dietary intervention group, but not to the control group. The control group was advised to continue their dietary habits as usual.

Parents and subjects of both groups received the information about the nature of subclinical hypothyroidism, the natural course, and the standard supportive care (conservative management, no intervention required). The diary to record compliance to the dietary advice was handed out to the parents, along with the explanation how to use it properly. The control group filled out a diary to specify their intake of dairy products, vegetables and meat.

Visits to the clinic were scheduled at inclusion, 3 and 6 months. Laboratory diagnostics were performed at inclusion and about one to two weeks before the visit at 3 months and 6 months. A telephone consultation was scheduled after the inclusion to discuss the lab results, the paediatrician excluded a child from the study if necessary. During each visit, PedQL multidimensional fatigue scale questionnaires were filled out by the parents, height and weight were measured. 
The protocol was approved by the local medical ethical committee and registered in the Netherlands National Trial Register (NL4891 (NTR5138)). All parents gave permission for the study in a written informed consent.

\section{INTERVENTION}

The intervention was a dietary advice consisting of beef 3 times a week, green vegetables 5 times a week, and a daily portion of full fat milk $(300 \mathrm{ml})$ and butter $(5$ grams on each slice of bread). All components in age appropriate portions according to the Dutch guidelines (21). All the other dietary habits remained unchanged. Parents were advised to follow it for 6 months. These foods were chosen because they are rich in the most important nutrients for thyroid: iron, selenium, vitamin $\mathrm{A}$, and, to a lesser extent, iodine $(20,22,23)$.

\section{Measurements}

Subclinical hypothyroidism is defined as an increased TSH (>4,2 $\mathrm{mU} / \mathrm{l})$ and a normal Ft4 (10-25 pmol/l) (1). Both before the start of the dietary advice, at $t=3$ months and $\mathrm{t}=6$ months, TSH, FT4 and the lipid profile was determined in all children. At $\mathrm{t}=0$ and $\mathrm{t}=6$ months, anti-TPO values were measured. TSH was measured with electrochemiluminescence sandwich immunoassay and FT4 with 2 step ECLIA (both on COBAS 6000 Roche Diagnostics). Anti-TPO was measured with chemiluminescence immune assay (Advia Centaur, Siemens). The lipids from the lipid profile are total cholesterol, high-density lipoprotein cholesterol (HDL-C), cholesterol/HDL ratio, low-density lipoprotein cholesterol (LDL-C), triglycerides (TG), and non-HDL. The lipid profile was measured by enzymatic colorimetric techniques with the COBAS 6000 (Roche Diagnostics, Almere, The Netherlands). The LDL was calculated with Friedewald's formula: $\mathrm{LDL}=$ total cholesterol $-\mathrm{HDL}-(0.45 \times \mathrm{TG})$.

The height of the children was measured with a vertical ruler. The children were weighed in underwear and all measurements were performed by a pediatrician. The children's BMI was calculated by dividing their weight in kilograms by the square of their height in meters. The BMI Z-score was calculated on the basis of gender, age, height, and weight.

\section{Questionnaires}

Tiredness questionnaires were filled out by the parents (age-dependent for 2-4y, 5-7y, 8-12y) or by the children themselves (13-18y) (recorded by Paediatric QoL Multidimensional Fatigue Scale, kindly provided by Mapi Research Trust). Scores could be 
noted in 5 ways; never, almost never, sometimes, almost always, or always. Scores were inversely related; the higher the score on a scale from 0-100, the less tiredness the child showed.

Parents received a questionnaire with various baseline characteristics (e.g. family history of thyroid disorders, social environment, educational levels of parents, and presence of tiredness). The intervention and control group kept a daily diary about their intake concerning the four components; what kind of milk, butter, meat or vegetables they ate that week.

\section{STATISTICAL ANALYSIS}

Data was analysed with the software program SPSS ${ }^{\circ}$ for Windows version 25 (IBM, Chicago, IL, USA). Between-group differences in patient characteristics, growth parameters and lipid profiles at baseline were compared with Student's t-test when Normally distributed, or a Mann Whitney test when not Normally distributed. Categorical values were evaluated with crosstabs and Chi-square tests. Repeated measurements of TSH, lipid profile and growth parameters over time were analysed mixed model repeated measurements analysis. Corrections for $\mathrm{BMI}-\mathrm{z}$ and $\mathrm{TSH} 1$ at $\mathrm{t}=0$ are used for all PedQL fatigue scale scores, growth parameters (except BMI), thyroid values (except TSH), and lipid profile values during the follow up in time, not at baseline measurements. Correlation between TSH start levels and PedQL total fatigue scores were evaluated with a Pearson correlation test. For all comparisons, a $p$-value $\leq 0.05$ was regarded as significant.

Power analysis was performed based on a spontaneous normalisation rate of $40 \%$ in TSH in children (24). In a previously performed case-control study with the investigated dietary advice, we found a normalisation rate of $72 \%$ (25). An expected difference between the groups in normalisation rate of $35 \%$ was used for power analysis. A power of 0.8 was used and with a significance of $p<0.05$ a minimum of 54 patients was required.

\section{Outcomes}

Primary outcomes were TSH level and FT4 level at $\mathrm{t}=0, \mathrm{t}=3$ and $\mathrm{t}=6$ months. Secondary outcomes were the presence or change in anti-TPO ( $t=0$ and $t=6$ months), growth parameters (height, weight, BMI-z scores), multidimensional fatigue scale questionnaires and the lipid profile at $\mathrm{t}=0, \mathrm{t}=3$ and $\mathrm{t}=6$ months. 


\section{RESULTS}

\section{Patient descriptives}

In a period of two and a half years (January 2016-September 2018), 65 patients were included. Four patients dropped out of the study, three in the intervention group and one in the control group. One patient thought the study was finished after three months and discontinued the dietary intervention. One patient (the parents) found they already ate healthy and saw no benefits of changing their diet. One patient repeatedly was a no show and the last patient (from the control group) was not motivated to finish the study. Of the included patients, 29 comprised the intervention group and 32 the control group. Patient characteristics did not differ between both groups (table 1).

Table 1. Patient characteristics

\begin{tabular}{|c|c|c|c|}
\hline & $\begin{array}{l}\text { Intervention group } \\
\mathrm{n}=29\end{array}$ & $\begin{array}{l}\text { Control group } \\
n=32\end{array}$ & $\mathrm{p}$-value \\
\hline Male:female & $15: 14$ & $16: 16$ & 0.89 \\
\hline Age in years (SD) & $7.7(3.1)$ & $8.1(3.3)$ & 0.67 \\
\hline 2-Parents family & $27(51 \%)$ & $26(49 \%)$ & 0.23 \\
\hline Parental education (only primary or high school) & $6(20.6)$ & $1(3.3 \%)$ & 0.32 \\
\hline Tiredness (according to parents) & $23(79 \%)$ & $22(73 \%)$ & 0.59 \\
\hline Positive family history for thyroid diseases (\%) & $16(55 \%)$ & $15(52 \%)$ & 0.55 \\
\hline TSH start (mlU/l) (SD) & $6.14(1.4)$ & $5.69(1.4)$ & 0.15 \\
\hline FT4 start (pmol/l) (SD) & $16.6(2.1)$ & $15.7(1.6)$ & 0.06 \\
\hline Anti-TPO positive (\%) start & $2(7 \%)$ & $4(12 \%)$ & 0.46 \\
\hline Total Cholesterol (mmol/l) (SD) & $4.16(0.7)$ & $4.35(0.7)$ & 0.29 \\
\hline $\mathrm{HDL}-\mathrm{C}(\mathrm{mmol} / \mathrm{l})(\mathrm{SD})$ & $1.44(0.4)$ & $1.45(0.4)$ & 0.93 \\
\hline Cholesterol/HDL ratio (mmol/l) (SD) & $3.07(0.9)$ & $3.28(1.2)$ & 0.44 \\
\hline TG (mmol/l) (IQR) & $0.9(0.7-1.3)$ & $1.00(0.6-1.4)$ & 0.88 \\
\hline LDL-C (mmol/l) (SD) & $2.22(0.6)$ & $2.37(0.7)$ & 0.35 \\
\hline Height $(\mathrm{cm})(\mathrm{SD})$ & $126(18)$ & $132(24)$ & 0.26 \\
\hline Weigth (kg) (IQR) & $24.9(21-34)$ & $31.1(20-46)$ & 0.16 \\
\hline $\mathrm{BMI}(\mathrm{kg} / \mathrm{m} 2)(\mathrm{IQR})$ & $16.0(15-17)$ & $17.0(16-20)$ & 0.05 \\
\hline
\end{tabular}

(Chi square tests; sex, 2-parents family, parental education, tiredness, family history, presence anti-TPO. Independent t-test; age, TC, HDL, Cholesterol/HDL ratio, LDL, height. Mann Whitney; TG, weight, BMI.

\section{Outcomes}

No significant changes were seen in TSH levels after 6 months between the groups (table 2). The intervention group started with higher TSH values compared to the 
control group. In both groups, TSH values decreased over time. No effect was seen by introduction of the dietary intervention. No significant differences were seen in FT4 values between the groups. Once the TPO antibodies were present, they remained present. No patients became anti-TPO positive during the course of the study or lowered their antibodies. In the control group, one patient increased with his TSH levels above 12 , therefore meeting the criteria to start with thyroxine supplementation. In the intervention group, all TSH levels stayed below 10.

Table 2. thyroid hormones and fatigue scale scores during the 6-months intervention.

\begin{tabular}{llllllll} 
& \multicolumn{3}{c}{ Intervention } & \multicolumn{2}{c}{ Control } \\
& $\mathrm{t}=\mathbf{0}$ & $\mathrm{t}=\mathbf{3}$ & $\mathrm{t}=6$ & $\mathrm{t}=\mathbf{0}$ & $\mathrm{t}=3$ & $\mathrm{t}=6$ & $\mathrm{p}$-value \\
TSH (mIU/L) & 6.14 & 5.48 & 5.24 & 5.69 & 4.75 & 4.82 & 0.98 \\
FT4 (pmol/l) & 16.6 & 17.1 & 16.6 & 15.7 & 16.1 & 15.4 & 0.51 \\
PedQL total & 61.8 & 67.9 & 74.1 & 70.9 & 70.5 & 72.8 & 0.04 \\
PedQl general & 59.4 & 65.6 & 72.9 & 67.2 & 67.9 & 72.3 & 0.14 \\
PedQl sleep & 62.5 & 69.9 & 77.8 & 72.5 & 73.1 & 75.9 & 0.03 \\
PedQl cognitive & 62.9 & 67.1 & 70.4 & 73.9 & 71.4 & 71.1 & 0.19
\end{tabular}

\section{Tiredness}

During the 6 months of the study, the intervention group showed an improvement over time on all PedQL fatigue scale domains (table 2). In comparison to the control group, the intervention group showed significant improvement in the total PedQL fatigue scale scores and PedQL sleep scores.

In the control group, most of the PedQL fatigue scale domains and its sub scores remained in the same range during the study period (table 2 ).

The control group started with slightly higher PedQl fatigue scale scores compared to the intervention group, so this group started with higher energy levels compared to the intervention group. To see if there was a relation with the higher PedQL fatigue scale scores and the lower TSH levels, we performed a correlation analysis but there was no correlation $(r=0.0 ; p=0.99)$.

\section{Growth}

No significant changes were seen in growth parameters (table 3 ). At the start of the study, children in the intervention group had slightly lower heights and weights compared to the control group. This remained the same during the study period. They grew a bit more than expected, as well in height as weight, but not significantly. 
$146 \mid$ Chapter 7

Table 3. growth parameters and lipid profile during the 6-month intervention

\begin{tabular}{llllllll} 
& \multicolumn{3}{c}{ Intervention } & \multicolumn{3}{c}{ Control } \\
& $\mathrm{t}=0$ & $\mathrm{t}=3$ & $\mathrm{t}=6$ & $\mathrm{t}=0$ & $\mathrm{t}=3$ & $\mathrm{t}=6$ & \\
SD height & -0.28 & -0.29 & -0.21 & 0.1 & 0.16 & 0.11 & 0.18 \\
SD weight & 0.18 & 0.2 & 0.28 & 0.78 & 0.83 & 0.8 & 0.24 \\
SD BMI & 0.34 & 0.37 & 0.4 & 0.83 & 0.84 & 0.84 & 0.89 \\
TC (mmol/l) & 4.23 & 4.33 & 4.34 & 4.29 & 4.19 & 4.22 & 0.16 \\
HDL (mmol/l) & 1.4 & 1.44 & 1.52 & 1.47 & 1.43 & 1.46 & 0.20 \\
cholesterol/HDL ratio & 3.21 & 3.15 & 2.99 & 3.19 & 3.14 & 3.09 & 0.78 \\
TG (mmol/l) & 1.14 & 1.32 & 0.91 & 1.15 & 0.98 & 0.98 & 0.35 \\
LDL (mmol/l) & 2.31 & 2.38 & 2.42 & 2.3 & 2.31 & 2.3 & 0.57
\end{tabular}

\section{Lipid profile}

As for long term risk factors like disturbed lipid profiles, no significant changes were seen at the end and during the study period. Minor, non-significant trends were seen; total cholesterol values and LDL values increased slightly in the intervention group, but also favourable lipids. HDL increased in time, and the ratio total cholesterol/HDL as well as triglycerides decreased in time.

\section{Compliance to the diet}

The overall compliance to the diet was $88.5 \%$ in the intervention group and $40 \%$ in the control group $(p<0.001)$. The consumed amounts were not normally distributed; some children ate almost $100 \%$ of the dietary advice, others only a few components. From the four components of the dietary advice, the control group consumed a median of $58.5 \%$ of the beef advice (e.g. $100 \%$ beef advice is 3 times beef per week), $0 \%$ whole milk (e.g. 100\%=every day $300 \mathrm{ml}$ whole milk), 0\% butter (e.g. 100\%= every day butter on their bread) and $80 \%$ of the green vegetables advice (e.g. 100\%=5 times green vegetables per week). The intervention group consumed a median of $81 \%$ of the green vegetables, a median $96.5 \%$ of the beef advice, a median $94.2 \%$ of the whole milk and a median $94.2 \%$ of the butter advice.

\section{DISCUSSION}

While TSH levels of the children with SH decreased during the course of this study, this decrease cannot be attributed to our dietary intervention since both groups decreased in their TSH levels to the same extent. Furthermore, FT4 values did not change during the course of the study. Therefore, advising green vegetables, beef, whole milk and butter did not change thyroid functioning. However, short term clinical parameters 
such as total PedQL fatigue scale scores and sleep quality, did improve during the dietary intervention.

Hence, the effect of the dietary intervention seemed to work independently from thyroid functioning. The absence of the relation between thyroid hormones and clinical parameters was also described by Feller et al. They reviewed clinical parameters in adults with $\mathrm{SH}$ including $\mathrm{BMI}$, blood pressure, general quality of life and/ or neurocognitive functioning after supplementation with thyroxine. Even though the biochemical values were normalized, clinical complaints remained unchanged as evaluated in their meta-analysis (17). Tiredness was investigated in the TRUST study in elderly people with $\mathrm{SH}$. They received low dose thyroxine ( 25 or 50 ug/day). After 1 year, no improvement was seen in tiredness, yet the mean TSH levels normalized(26). In our study, tiredness in children was measured in various domains with the PedQL multidimensional fatigue scale: general tiredness, sleep quality, cognitive functioning and the sum of these three (total score). Sleep and the total score both improved significantly. In children without $\mathrm{SH}$, the same dietary advice also improved tiredness scores. In that case-control study, mainly the sleep domain was improved by the diet and the intake of green vegetables and whole milk showed to have the strongest relation with the improvement (27). In our present study, the control group also consumed many green vegetables. This minimal difference in green vegetable intake might have suppressed some effects of the dietary intervention, in respect to the findings of the previous study.

The Mediterranean diet and its effect on fatigue was studied in two studies. Exercise performance (endurance) improved in healthy adults (mean age 28 years) despite similar heart rates and efforts after using a Mediterranean diet for 4 days compared to a Western diet for 4 days (28). A Mediterranean-style eating pattern also improved fatigue in overweight adults, independent of the intake of red meat (beef or pork) (29).

Possible mechanisms of nutrition to minimize fatigue are to supplement deficiencies like iron or vitamin $D$ deficiency $(30,31)$. Antioxidants can be supplied, which reduce free radicals and possibly improve the function of mitochondria (32, 33). Another possible mechanism is by adding $n-3$ polyunsaturated fatty acids ( $n-3$ PUFA) to prevent metabolic dysfunction of skeletal muscle, however evidence for this is not convincing (34).Our studied dietary advice is rich in minerals and vitamins like iron and vitamin D, has a favourable n-3 PUFA n-6 PUFA ratio and contains antioxidants (20). 
Cardiovascular risks are a possible consequence of $\mathrm{SH}$ in children, although consensus has not been reached yet $(11,12,35)$. Besides the thyroid functioning, an elevated $\mathrm{BMI}$ is a possible additional risk factor. Our dietary advice consisted both of high energy products (whole milk and butter) and low energy products (green vegetables and beef). When all four components are consumed, it should not largely increase the total energy intake. As a possible result, the intervention group started and stayed with their BMI a little above the 0 SD line (normal values). BMI was therefore not influenced by the dietary advice. Dyslipidaemia is another possible risk factor, especially low HDL and/or high Cholesterol/HDL ratio. In the children following our dietary intervention, HDL tended to increase, and the Cholesterol/HDL ratio tended to decrease, both moving towards the prognostic favourable values. Although these changes were not significant, they are indicating a favourable effect that is in line with previous findings (27).

\section{Limitations and future directions}

This study included several possible sources of bias. First, the design of the study is open and not blinded. Since the parents had to prepare the food based on the dietary advice, it was not possible to blind the studied intervention. Secondly, the children in the control group had higher PedQL multidimensional fatigue scale scores at the start of the study compared to the intervention group. The parents filled out the PedQL questionnaire after they were randomised, we noticed these differences after processing the questionnaires. Thirdly, we noted some overlap in diet: both the control group and the intervention group ate considerable amounts of green vegetables and beef. The big differences were found in the consumed amount of whole milk and butter and to a lesser extent beef. The control group was not informed about the diet, but they might have heard about it informally.

A suggestion for further research could be to investigate other risk markers for cardiovascular disease in $\mathrm{SH}$ like serum concentrations of dimethylarginine (marker for endothelial dysfunction) or intima thickness. These measurements are influenced by prolonged elevated TSH levels. What will happen to these markers when TSH stays high? TSH levels are not influenced by our dietary advice, but how about these risk markers?

\section{Implications}

As far as we know, this is the first study introducing a dietary intervention as a possible approach to alleviate complaints related to SH. Up until now, the only treatment for children with $\mathrm{SH}$ is to keep track of thyroid hormonal levels and to provide thyroxine medication when TSH increases above 10 IU/l. However, for the 'in-between' children 
with levels above 4.2 but below $10 \mathrm{IU} / \mathrm{l}$, generally no medication is given, and parents cannot do anything to alleviate the complaints of their children. For these children, the dietary intervention tested in this study can help to reduce tiredness and hence improve well-being, without increasing risk factors for long term consequences.

\section{Conclusion}

In children with $\mathrm{SH}$, a dietary intervention consisting of green vegetables, beef, whole milk and butter did not improve thyroid function in terms of thyroid hormone production, but significantly reduced tiredness. Hence, this dietary intervention can be a possible tool to improve well-being of children with $\mathrm{SH}$, independently of thyroid functioning. 


\section{REFERENCES}

1. Surks MI, Ortiz E, Daniels GH, Sawin $\mathrm{CT}$, Col NF, Cobin RH, et al. Subclinical thyroid disease: scientific review and guidelines for diagnosis and management. JAMA. 2004;291(2):228-38.

2. Wu T, Flowers JW, Tudiver F, Wilson JL, Punyasavatsut $N$. Subclinical thyroid disorders and cognitive performance among adolescents in the United States. BMC Pediatr. 2006;6:12.

3. Paoli-Valeri $M$, Maman-Alvarado $D$, Jimenez-Lopez V, Arias-Ferreira A, Bianchi G, Arata-Bellabarba G. [Frequency of subclinical hypothyroidism among healthy children and those with neurological conditions in the state of Merida, Venezuela]. Invest Clin. 2003;44(3):209-18.

4. Lazar L, Frumkin RB, Battat E, Lebenthal Y, Phillip M, Meyerovitch J. Natural history of thyroid function tests over 5 years in a large pediatric cohort. J Clin Endocrinol Metab. 2009;94(5):1678-82.

5. Canaris GJ, Manowitz NR, Mayor G, Ridgway EC. The Colorado thyroid disease prevalence study. Arch Intern Med. 2000;160(4):526-34.

6. Papi G, Uberti ED, Betterle C, Carani C, Pearce EN, Braverman LE, et al. Subclinical hypothyroidism. Curr Opin Endocrinol Diabetes Obes. 2007;14(3):197-208.

7. Shriraam M, Sridhar M. Subclinical hypothyroidism in children. Indian Pediatr. 2014;51(11):889-95.

8. Aijaz NJ, Flaherty EM, Preston T, Bracken SS, Lane AH, Wilson TA. Neurocognitive function in children with compensated hypothyroidism: lack of short term effects on or off thyroxin. BMC Endocr Disord. 2006;6:2.

9. Gawlik A, Such K, Dejner A, Zachurzok A, Antosz A, Malecka-Tendera E. Subclinical hypothyroidism in children and adolescents: is it clinically relevant? Int J Endocrinol. 2015;2015:691071.

10. Ergur AT, Taner Y, Ata E, Melek E, Bakar EE, Sancak T. Neurocognitive functions in children and adolescents with subclinical hypothyroidism. J Clin Res Pediatr Endocrinol. 2012;4(1):21-4.

11. Cerbone $M$, Capalbo D, Wasniewska $M$, Mattace Raso G, Alfano S, Meli R, et al. Cardiovascular risk factors in children with long-standing untreated idiopathic subclinical hypothyroidism. J Clin Endocrinol Metab. 2014;99(8):2697-703.

12. Ittermann T, Thamm M, Wallaschofski $H$, Rettig R, Volzke H. Serum thyroidstimulating hormone levels are associated with blood pressure in children and adolescents. J Clin Endocrinol Metab. 2012;97(3):828-34.

13. Althaus BU, Staub JJ, Ryff-De Leche A, Oberhansli A, Stahelin HB. LDL/HDLchanges in subclinical hypothyroidism: possible risk factors for coronary heart disease. Clin Endocrinol (Oxf). 1988;28(2):157-63.

14. Kvetny J, Heldgaard PE, Bladbjerg EM, Gram J. Subclinical hypothyroidism is associated with a low-grade inflammation, increased triglyceride levels and predicts cardiovascular disease in males below 50 years. Clin Endocrinol (Oxf). 2004;61(2):232-8.

15. Crisafulli G, Aversa T, Zirilli G, Pajno GB, Corica D, De Luca F, et al. Subclinical Hypothyroidism in Children: When a Replacement Hormonal Treatment Might Be Advisable. Front Endocrinol (Lausanne). 2019;10:109.

16. Vigone MC, Capalbo D, Weber G, Salerno M. Mild Hypothyroidism in Childhood: Who, When, and How Should Be Treated? J Endocr Soc. 2018;2(9):1024-39.

17. Feller $M$, Snel $M$, Moutzouri E, Bauer $D C$, de Montmollin M, Aujesky $D$, et al. Association of Thyroid Hormone Therapy With Quality of Life and 
Thyroid-Related Symptoms in Patients With Subclinical Hypothyroidism: A Systematic Review and Meta-analysis. JAMA. 2018;320(13):1349-59.

18. Andrade GRG, Gorgulho B, Lotufo PA, Bensenor IM, Marchioni DM. Dietary Selenium Intake and Subclinical Hypothyroidism: A Cross-Sectional Analysis of the ELSA-Brasil Study. Nutrients. 2018;10(6).

19. Winther $\mathrm{KH}$, Wichman JE, Bonnema SJ, Hegedus L. Insufficient documentation for clinical efficacy of selenium supplementation in chronic autoimmune thyroiditis, based on a systematic review and meta-analysis. Endocrine. 2017;55(2):376-85.

20. Dutch Food Composition Database [Internet]. Available from: https:// nevo-online.rivm.nl/.

21. example diet for young children [Internet]. Voedingscentrum. 2019 [cited january 27th 2019]. Available from: https://www. voedingscentrum.nl/nl/ service/english.aspx.

22. Zimmermann MB. Interactions of vitamin $A$ and iodine deficiencies: effects on the pituitary-thyroid axis. Int J Vitam Nutr Res. 2007;77(3):236-40.

23. Kandhro GA, Kazi TG, Afridi HI, Kazi N, Arain MB, Sarfraz RA, et al. Evaluation of iron in serum and urine and their relation with thyroid function in female goitrous patients. Biol Trace Elem Res. 2008;125(3):203-12.

24. Wasniewska M, Salerno M, Cassio A, Corrias A, Aversa T, Zirilli G, et al. Prospective evaluation of the natural course of idiopathic subclinical hypothyroidism in childhood and adolescence. Eur J Endocrinol. 2009;160(3):417-21.

25. Kuiper MWJ, van der Gaag EJ. Subclinical Hypothyroidism in Children Can Normalize after Changes in Dietary Intake. Food and Nutrition Sciences. 2012;3:411-6.
26. Stott DJ, Rodondi N, Bauer DC, Group TS. Thyroid Hormone Therapy for Older Adults with Subclinical Hypothyroidism. N Engl J Med. 2017;377(14):e20.

27. Steenbruggen TG, Hoekstra SJ, van der Gaag EJ. Could a change in diet revitalize children who suffer from unresolved fatigue? Nutrients. 2015;7(3):1965-77.

28. Baker ME, DeCesare KN, Johnson A, Kress KS, Inman CL, Weiss EP. ShortTerm Mediterranean Diet Improves Endurance Exercise Performance: A Randomized-Sequence Crossover Trial. J Am Coll Nutr. 2019:1-9.

29. O'Connor LE, Biberstine SL, PaddonJones D, Schwichtenberg AJ, Campbell WW. Adopting a Mediterranean-Style Eating Pattern with Different Amounts of Lean Unprocessed Red Meat Does Not Influence Short-Term Subjective Personal Well-Being in Adults with Overweight or Obesity. J Nutr. 2018;148(12):1917-23.

30. Yokoi K, Konomi A. Iron deficiency without anaemia is a potential cause of fatigue: meta-analyses of randomised controlled trials and cross-sectional studies. Br J Nutr. 2017;117(10):142231.

31. Hock AD. Review: Vitamin D3 deficiency results in dysfunctions of immunity with severe fatigue and depression in a variety of diseases. In Vivo. 2014;28(1):133-45.

32. Apostolova N, Victor VM. Molecular strategies for targeting antioxidants to mitochondria: therapeutic implications. Antioxid Redox Signal. 2015;22(8):686-729.

33. Filler K, Lyon D, Bennett J, McCain N, Elswick R, Lukkahatai N, et al. Association of Mitochondrial Dysfunction and Fatigue: A Review of the Literature. BBA Clin. 2014;1:12-23.

34. Da Boit M, Hunter AM, Gray SR. Fit with good fat? The role of $n-3$ polyunsaturat- 
152 Chapter 7

ed fatty acids on exercise performance. Metabolism. 2017;66:45-54.

35. Chen $\mathrm{H}, \mathrm{Xi} \mathrm{Q}$, Zhang $\mathrm{H}$, Song $B$, Liu X, Mao $\mathrm{X}$, et al. Investigation of thyroid function and blood pressure in schoolaged subjects without overt thyroid disease. Endocrine. 2012;41(1):122-9. 



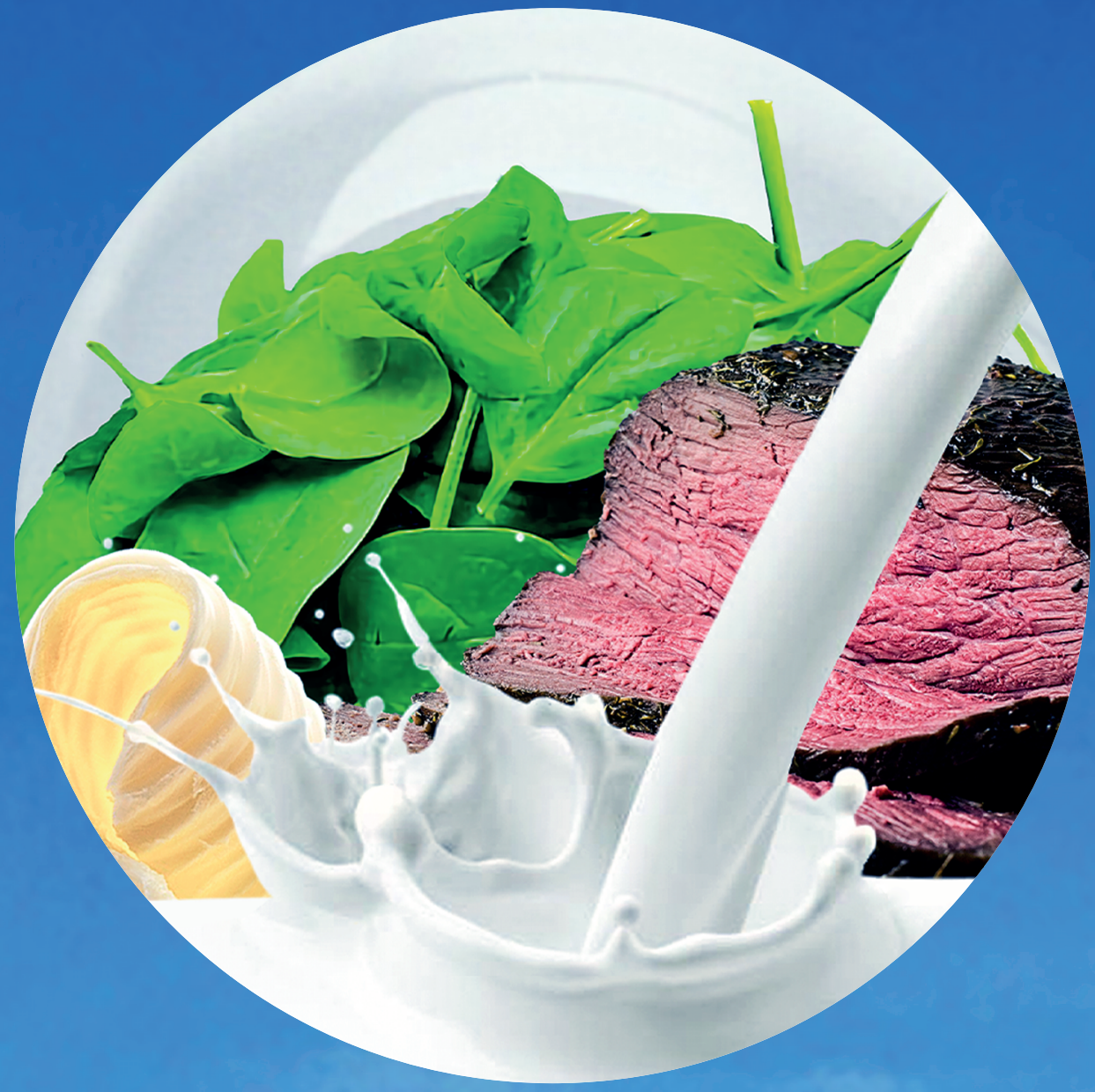


Discussion and future perspectives 



\section{Food or medication?}

Modern diseases in children are conditions that were not present about 100 years ago. They include (but are not limited to) tiredness, recurrent upper respiratory tract infections (URTIs), non-specific allergic complaints and subclinical hypothyroidism. These modern diseases do not have specific treatments, since the causes of the conditions are unknown. With an intervention of nutrient rich dietary advice, as investigated in this thesis, clinical complaints decline.

Are modern diseases a result of present-day food habits? We do not know. The results are suggestive for that hypothesis, but large prospective follow-up studies are needed to test that hypothesis.

At this moment, when I am writing the discussion of my thesis, food is more attractive as compared to medication. When using food, the responsibility of the clinical condition shifts towards the parents, the costs for society decrease and there are no significant side effects known at this point. Children with an allergy to one of the components of the dietary advice were excluded from the trials; in a later stage, an alternative should be found for these children.

The benefits of food are in contrast to medication, as almost all medication, such as antibiotics or antiviral medication, have side effects [1] and costs as well as become the responsibility of the doctor.

In this discussion, we would like to present a patient case to illustrate the everyday practice of a general paediatrician, nutritional needs in children, discuss our findings as compared to the literature, costs of health care and (possible) concerns of parents in relation to three components of the dietary advice: whole milk, butter and beef.

Peter and Karen have been in love since 2009. Peter is a lawyer, and Karen works as a hairdresser. Now, 6 years into their relationship, both are settled, and they agree that it is the time for an expansion of their family. The first attempts were not successful, no matter what they did. However, after 2 years, they became pregnant!

Karen was very excited, and she felt fully pregnant after 4 weeks. Her appetite was very good in contrast to many other women, and she quickly gained weight, especially since chocolate was her favourite food. Karen always made jokes. She was a real woman, since she could have chocolate for breakfast, lunch and dessert. With her good appetite and hormones, her chocolate intake tripled, at the cost of fruits and vegetables. She heard the customers in the hair salon talk about the health 
effects of red meat, and she decided to stop eating meat products. Well, not all meat products. She could not resist McNuggets or Kentucky Fried Chicken, so she allowed herself the indulgence as part of her diet. When her weight increased quickly, she decided to lower her carbohydrate intake by decreasing bread intake (bread with margarine and chocolate chunks). She changed from whole meal bread to Chocopops with soy milk. At other moments, she also changed to a liquid breakfast called "drink ontbijt". It contains everything her supermarket advertised: dairy, fruits and grains. On top of that, it saves time since you can drink it and do not have to chew. Peter agrees with the choices his wife makes. As long as his wife is happy, he is also happy.

Karen's regular check-ups with her mid-wife were good. She was an example for others; she did not smoke, did not drink, played sports and her weight was normalizing. The mid-wife asked Karen if she ate healthy, and Karen agreed. Her diet consisted of three meals a day, soy milk, low in carbs and fats and maybe a little high in chocolate.

Meanwhile, her child was growing inside her body, fully dependent on the nutrients provided by her (the mother).

The focus of this thesis are the health promoting effects of nutrition in children. Most parents are willing to start with dietary advice when their child has a health problem. Looking in chronological order and from a preventive point of view, it would be wise to start earlier, since nutrition is also important in the stages before a health problem arises.

Most advice about pregnancy is about things the pregnant woman should not take to protect the child from the adverse effects of drugs, alcohol, tobacco, raw fish, raw milk, raw meat, et cetera. Few guidelines are given about diet and diet quality in pregnancy, just to eat healthy. However, current insights emphasize the importance of the first 1000 days of life, starting at the conception date up to 2 years of age. These 1000 days are crucial for the prevention of diseases in adulthood [2]. Remarkable is the start of the 1000 days, which is at the time of conception, not at birth (which is after 9 months, about 270 days, after conception). Periconceptional maternal conditions, such as obesity or excessive weight gain during pregnancy, are also important for child conditions, as they are related to high birth weight, obesity and increased cardiometabolic risks in adult life [3].

The day Jayson was born, was a very special day. Breastfeeding was started and Jayson tolerated it really well. The child health care centre checked Jayson and no 
abnormalities were noticed, except for recurrent upper respiratory tract infections, which started around the introduction of supplementary feeding. They provided dietary advice regarding formula feeding and supplementary feeding on a regular basis until the age of one. After that, he is supposed to join the family meals.

After his first birthday, Jayson did not like the family meals, only infant food in jars, which was still on the shopping list of his parents. His mother lets him choose between the different dairy products and he does not like natural milk, only artificially flavoured and coloured milk ("the pink milk"). His mother did not think that was a problem, since pink milk is also a dairy product. Meat was also a problem, because chewing is not very easy with a blocked nose full of mucus. His father works the entire day and comes home late in the evening. When his father comes home, his mother goes to work, since her hair salon is open in the evenings. They do not have time to spend hours at the table because of their busy schedules, and Karen buys ready to eat meals for their convenience.

At that time, Jayson was eating half a sandwich (without crusts) with pink milk in the morning and at lunchtime. In the evening, he was eating infant food from a jar with a "danoontje" as a dessert. The in between snacks were "knijpfruitjes", fruits in a liquid form that he can drink so he does not have to chew. He did not grow well anymore according to the child health care centre, and his upper respiratory tract infections kept on bothering him; he was tired.

Karen made an appointment with the general practitioner, because she is convinced Jayson is not eating because of the recurrent infections. The general practitioner could not find any abnormalities at the physical examination and (after Karen insisting) refers Jayson to the paediatrician. The paediatrician performed a physical and laboratory examination but could not find any abnormalities and could not offer a treatment.

Karen kept on searching for a possible solution, because she believes a continuously blocked nose is not normal. At a second opinion, the paediatrician also could not find abnormalities but has just visited a conference and can possibly improve the clinical complaints of Jayson by changing his diet.

Karen thinks, "Can it really be that simple?" 


\section{Nutritional needs early in life}

Daily recommended intakes are the results of a worldwide consensus, adjusted to the specific needs of a country or population. In the Netherlands, these guidelines are described in an official guideline from the Gezondheidsraad (Dutch Health Council) [4]. However, only guidelines for adults are published at this moment (since 2018); guidelines for infants and children are under construction at the moment (December 2019). The Gezondheidsraad website mentions they follow guidelines from the European Food Safety Authority (EFSA). On the EFSA website, the Daily Recommended Intakes (RDIs) for infants and children are published [5].

Compared to adults, children need relatively higher amounts of:

- Proteins

- Fats

- Micronutrients such as iron, zinc, calcium and iodine

- Vitamins such as thiamine (B1), B11, B12, A, C, D and E

Because of the growth and development of their body, children have higher specific nutritional needs as compared to adults, since needs of adults are primarily focused on maintenance. Young pre-schoolers ( $<4$ years) especially have higher nutritional demands as compared to school-aged children and adolescents.

These facts, together with the results of our studies, underscore the importance of nutrition during the first 1000 days of life.

\section{Fatigue}

In modern diseases, we noticed clinical improvement in symptoms, such as fatigue, after following dietary advice. This was also observed in children with fatigue due to subclinical hypothyroidism, irrespective of normalization of laboratory findings. Another study in iron deficient women also showed clinical improvement with dietary intervention, independent from laboratory results [6]. In this study, iron was administered as a supplement or with a diet rich in iron (with "meat vouchers"). Iron status improved more in the supplement group as compared to the dietary group, but fatigue and general well-being improved in both groups to the same extent [6]. Therefore, the beneficial effect of food cannot be fully explained by supplementation of micronutrients to a normal level, since the clinical improvements exceed the laboratory improvements.

The effect of beef on cognitive function (also a part of the tested fatigue scale) in children has been reviewed by An et al. They concluded beef seems to improve 
cognitive domains (e.g., as shown with school exams) [7], although only small and heterogeneous studies were performed.

\section{Thyroid}

Why did we not see any effects on thyroid functioning after the dietary advice? The potential cause of subclinical hypothyroidism is still unknown. We hypothesized nutrition could have a role in the development of subclinical hypothyroidism. Our hypothesis about the effects of nutrition on thyroid functioning by possibly supplementing subclinical micronutrient deficiencies was not supported. Additionally, the second hypothesis, decreasing the auto-inflammatory state of the immune system, with involvement of the thyroid, results in decreased production of auto-antibodies against the thyroid, was not confirmed. In our study, only 6/61 (9\%) patients showed increased anti-thyroid peroxidase antibodies (anti-TPO), suggestive for an immunological abnormality. Neither the number of patients nor the level of anti-TPO values changed in both groups during the study.

We hypothesize another pathway is involved as a cause of subclinical hypothyroidism in our study population. As the cause is not yet known, we can only speculate. In conversation with the parents, we observed a decrease in stress factors in children who spontaneously normalized with their thyroid hormone levels. This observation is also supported by animal studies, in which thyroid dysfunction is induced by long-term stress [8]. This might be a direction for further research.

\section{Infections}

The clinical symptoms of infections did reduce after the dietary advice. The number of days with infections decreased, but not the total number of infections, suggesting a shorter duration. The diet contained proper quantities of vitamins, proteins, micronutrients, and fatty acids. All these components have shown the ability to positively influence the immune response in children [9-11]. Numerous immunological effects of various nutrients have been published as well as the routing of the activated immune cells to the airways, thereby linking the dietary components to chronic inflammation by means of the intestine-airway axis $[12,13]$.

RCTs with whole foods and URTIs are scarce. Positive effects on the duration or prevention of URTIs in adults or children were seen after intake of probiotics, prebiotics, growing-up milk, fish oil, kiwi fruit, garlic, xylitol and elderberry [14-21]. The aforementioned studies are studies with a single whole food product, not with a combination of food products. A combination of food products was investigated with regard to the Mediterranean diet. In a before-after comparison after the adoption of 
the Mediterranean diet, Calatayud et al. found a reduction of URTIs in children aged 1-5 years [22]. Due to the absence of a control group, it was hard to assess causality, since the number of infections declined with advancing age [23]. An RCT would solve this.

Why did the dietary advice have an effect on respiratory infections? We did not see any change in the investigated immunological parameters, such as immunoglobulins, micronutrients, or white blood cells (chapter 6), after the dietary advice. We did not measure inflammatory markers, such as inflammatory cytokines, subsets of T-cells or prostaglandins. The dietary effects may be influencing the latter inflammatory markers. Another possibility is a potential similarity with the thyroid study, with clinical improvements exceeding the laboratory improvements.

\section{IMPLICATIONS FOR THE HEALTH CARE SYSTEM}

\section{Cost aspects}

Another aspect in the disease burden of modern diseases (and nutrition) to be considered is health care costs. In children with recurrent URTIs, a clear bacterial respiratory infection needs antibiotic treatment; there is no discussion about it. In clinical practice, it usually is not that straightforward. Most of the time, doctors are visited and ineffective antibiotics are prescribed [24].

For subclinical hypothyroidism, there are no direct costs involved, apart from repeated laboratory investigations for follow up of TSH and FT4, doctors' visits, and only in rare cases thyroid hormone medication (levothyroxine (Euthyrox)).

Fatigue is usually accompanied by many repetitive laboratory investigations to rule out anaemia, deficiencies of vitamins and minerals, serologic investigations for Epstein-Barr virus, cytomegalovirus, Lyme disease, et cetera. A real treatment is difficult when laboratory abnormalities are absent, but vitamin supplementation, such as vitamin D or B12, is frequently prescribed, even when minimal or borderline deficiencies are found.

The extra costs of our dietary advice were 0.67 euro per week per child. This was calculated in 2014 (prices of Albert Heijn Supermarket) based on the differences in prices of four products: full fat milk and the average prices of semi-skimmed milk, Optimel and yoghi. In addition, calculations were made between butter and the mean prices of margarine and low-fat margarine as well as the costs of beef as compared 
with pork, chicken and fish. It was calculated with the mean portion size of children 1-4 years old, which could explain the minimal increase in costs per week.

These costs are for the parents and not for society or health insurance companies. We think this is a good thing. It is the main responsibility of the parents to guide their children to healthy adulthood. When the extra costs are for the parents, they usually feel more responsible for the result and the need for their children to eat the products. They paid a little extra for it, so it would be a waste to throw it away. In addition, the extra costs are not too high, making it affordable for all parents.

Medication for URTIs, usually non-effective antibiotics or hardly ever anti-viral medication, have their costs; oseltamivir costs $\$ 46$-\$116 per treatment, depending on the age and weight of the patient [25]. Antibiotics are less expensive, around 8 euro per treatment, without the costs of the doctor's visit [1]. The above amounts are only the price of the medication; other costs, such as the number of outpatient visits, costs of other medications, emergency department visits or hospitalisations, were not considered. Also, the costs of adverse effects (such as gastrointestinal or neuropsychiatric side effects of oseltamivir use) were not considered.

\section{Health concerns of parents}

The health benefits of the different components of the dietary advice are described in the introduction of this thesis. Due to public opinion (e.g., consuming red meat causes cancer and you can get a heart attack from whole dairy products), parents are often afraid to give these products to their children. What does the scientific evidence say at this moment?

Butter is a food product high in saturated fatty acids, about three times more as compared to margarine, cooking fats or olive oil (Table 2 of the Introduction). Yet, dairy fats seem to provide cardiovascular benefits. No RCTs have been performed with regard to butter and cardiovascular risks. A large pooled meta-analysis of 201,628 participants showed a protective effect of 14 grams of butter ( 3 slices of bread) daily for the development of type 2 diabetes mellitus ( $R R=0.96(C l=0.93,0.99) ; P=0.021)$ [26].

Milk. Since the 1980 s, modern society has associated saturated fatty acids with obesity, and saturated fats, including whole dairy products, were banned. However, the obesity epidemic is still increasing. 
How does (whole) milk fit in? Protein intake (present in dairy food) tends to be more satiating than other macronutrients. Ad libitum high protein diets tend to increase satiety and increase weight loss as compared to high-carbohydrate diets [27].

Milk (including, high-fat, low-fat and fermented milk products) was not associated with risk of all-cause mortality, with relative risks between 0.96 and 1.01 in 938,817 participants [28].

In a large prospective cohort study, 120,877 adults were followed for 24 years to identify specific dietary risk factors for long-term weight gain. Whole milk and low-fat milk were not related to weight gain. Vegetable and yoghurt intakes were related to weight loss. The following possible mechanisms are hypothesized: effects on hunger and fullness, effects on hormonal responses with respect to glucose and insulin, effects on de novo fat synthesis by the liver, effects on gut microbiome responses and effects on the body's metabolic rate [29]. Besides these findings, a systemic review and meta-analysis of 184,802 participants showed a healthier body composition after dairy consumption. Dairy consumption resulted in a reduction of fat mass and waist circumference and an increase in lean body mass. Based on the results of these large study populations, the type of dairy product (milk, cheese, yoghurt or processed yoghurt drinks) seems more important for preventing weight gain than the dairy fat content [30]. Our studies did not measure lean fat mass or waist circumference, but our results on the growth parameters are in line with these findings and do not support the hypothesis that ingestion of saturated fats in dairy causes obesity.

Milk and beef (and other natural products of ruminants) contain small amounts of trans fatty acids. However, these ruminant trans fatty acids have different effects on the human body as compared to industrial trans fatty acids (processed in some margarines, fried fast food and bakery goods, such as muffins and doughnuts). Industrial trans fatty acids promote inflammation, fat storage in the liver and cholesterol synthesis, whereas ruminant trans fatty acids do not [31-33].

Beef intake in school-aged children also influences body composition, with an increase of fat free mass after 5 years in the adolescent age [34]. These findings were in contrast to other studies, although the latter meta-analysis was performed only in adults and not in children [35].

Red meat is under scrutiny because of possible hazardous health effects, such as cancer (colon, gastric and rectal), dyslipidaemia, and cardiovascular disease [36]. However, not all studies show a clear relation between the intake of red meat and an 
increased cancer risk (e.g., gastric cancer) [37]. An increased risk for colon cancer is found in epidemiological studies with markedly elevated amounts of meat intake and lower consumption of fruits, vegetables and whole grains. Besides that, experimental studies with protective dietary compounds next to meat consumption (such as fruits, vegetables and whole grains) showed protection against colon cancer [38]. This emphasizes the importance of a balanced diet; an unbalanced diet with predominantly meat products is not healthy, but meat products in normal portion sizes, together with vegetables and fruits, is an important source of nutrients, which cannot be supplied by vegetables and fruits alone.

Beef is a kind of red meat, but red meat is not only beef. Red meat is the collective name for beef, veal, pork, goat, lamb, and horse meat. A recent review advises caution with the interpretation of the results of "muscle foods" and chronic diseases, since different types of muscle foods are not clearly categorized. Therefore, observational studies and experimental studies are only partly overlapping and sometimes investigate processed meat, luncheon meat, fish, pork, poultry or red meat. Since the studied muscle foods are not clearly defined groups, the results cannot be extrapolated to a single kind of meat [39]. A Japanese study makes a distinction between the different kinds of meat subtypes and the risk for developing colorectal cancer in a large pooled study of six cohort studies. Of the different meat subtypes, beef had the lowest hazard ratio as compared to processed red meat or pork [40].

No unfavourable effects of green vegetables are known. Patients using vitamin $\mathrm{K}$ antagonists for anticoagulation are sometimes advised to modify their dietary intake with respect to vitamin $\mathrm{K}$, which is abundant in green vegetables. A recent review shows results are conflicting, and they conclude there is no support from evidence to modify dietary habits to improve anticoagulation quality with vitamin $\mathrm{K}$ antagonists. The authors advise to maintain stable dietary habits and not to change intake of vitamin $\mathrm{K}[41]$.

Like with most things in life, "too much" can be damaging. Beef is an important source of high-quality dietary protein and nutrients, such as iron, zinc and vitamin B12, for a major part of the global population. Some of these nutrients can be supplied by fruits and vegetables, but these fruits and vegetables are not always available in all parts of the world, unlike meat sources. Excessive meat consumption, however, is often associated with overconsumption of energy and fat, resulting in overweight and an increased risk for chronic diseases [42]. We therefore advocate modest intake of beef, as well as the other three components of the dietary advice (fitting in a sustain- 
able use of food). It is about the balance in the diet and not about excess amounts to get extra good health effects.

\section{Lipid profile as a prognostic marker}

Most importantly, whole dairy products in combination with green vegetables and beef did not cause prognostic unfavourable lipid profiles, but rather caused prognostic good lipid profiles in children (chapter 5, 6 and 7). These findings are consistent with recent insights, in which fats from animal origin (dairy or meat consumption) increases HDL levels and decreased the cholesterol-HDL ratio [43]. The mechanism by which dairy fats increase HDL are not well understood, but a few hypotheses are mentioned. First, as found by Kiessling et al., sphingolipids present in dairy fat and the cell walls of bacteria are thought to be involved in raising HDL levels in women who were supplemented with fermented dairy products [44]. Second, fermented dairy products by lactic acid bacteria or bifidobacteria can directly bind to bile acids in the gut, interfering with cholesterol absorption and uptake of cholesterol particles in the nearness of bile salts [45]. Third, almost all dairy products, such as milk, cheese and yoghurt, are sources rich in calcium. Calcium can bind to fatty acids and bile acids, thereby forming irresolvable emulsifications which prevent fat uptake, followed by increased bile and fat excretions in the faeces [46, 47].

\section{Future perspectives and recommendations}

Our study focused on children with medical problems, in which a dietary intervention improved clinical complaints. However, this intervention was performed during the last 365 days of the first 1000 days of life. It would be useful to investigate the effects of dietary advice earlier in life or in the prenatal period (first 635 days). For example, dietary advice in pregnant women or for infants in the weaning period.

We now have investigated dietary advice in children with health problems, such as recurrent URTIs, subclinical hypothyroidism and fatigue. Therefore, we recommend to pay more attention to the dietary habits of children in relation to modern diseases.

At the stage of health problems, most parents are willing to consider a behavioural change because of a reduction in the problem for their child and themselves. It would be a challenge to start sooner, to investigate the effects of a healthy diet in children as a primary prevention. Those children are not visible for the paediatrician, since they are healthy.

Limited research is available with regard to whole foods; most research has been performed on single nutrients. For the future, research on whole foods could become 
more interesting, since the food matrix in which the nutrients are embedded adds a new perspective. Much is unknown about that topic, and it would be interesting to reveal its secrets. Besides that, the processing of foods is also becoming more visible as a contributing factor to health effects or harmful effects on the patient.

Besides the single foods and food matrix, the dietary pattern should be investigated. Children and adults do not eat a single product the entire day and week. They make many choices everyday about what to eat. Dietary patterns, such the Mediterranean diet, Paleo diet, Nordic diet, or dietary habits with preferences for processed or unprocessed foods would be useful to investigate. Adults can be helped making choices if they have a viewpoint or belief why they would choose certain groups of food products. For example, if they support the ideas of the Nordic diet, they can more easily resist a bottle of Coca-Cola. Diets can serve as part of a lifestyle. Studies about the Mediterranean diet (and lifestyle when combined with exercise) are emerging, but they do not fit in every country. Country-specific dietary habits could fill this gap.

Processed food, or ultra-processed food, is adjusted food and the original food matrix is manipulated. Like in whole grains, the fibres are removed and a highly palatable product remains (white flour). However, the protective fibres are removed from the product. What are the health effects of that process? This topic is of growing interest to public health, and I think research should shift from the nutritional content of food to nutritional content AND preparation and additives of food.

Subsequently, the behavioural aspects of nutrition and modern diseases would be interesting to explore. Recent insights show relations between behaviour, diet quality and the microbiome. The microbiome seems to be a missing link between behaviour/ stress and physical effects of low-quality diets [48-51]. The mechanism behind this phenomenon seems to be the gut-brain axis, with an important role for the gut microbiome in the biochemical signalling between the gastrointestinal tract and the central nervous. In low-quality diets (e.g., low in fibre), other (less beneficial) microorganisms populate the gut. Humans have a mutualistic relation with their gut microbiomes, since the gut microbiome is responsible for energy collection, production of vitamins $\mathrm{B}$ and $\mathrm{K}$ and the metabolism of sterols and bile acids. It therefore functions like an endocrine organ [52, 53]. If less beneficial microorganisms populate the gut, these functions can be performed poorly. This might also explain some medical complaints, without any medical abnormalities in physical or laboratory investigations. This interesting field needs further exploration for the possible pathways. 


\section{Conclusion}

As a result of our studies, we especially like to recommend the components of our dietary advice to the Dutch children with physical complaints without medical abnormalities. A diet with green vegetables, beef, whole milk and butter results in decreased URTIs in young children and decreased tiredness. It has shown beneficial effects in the investigated "modern" diseases: tiredness, subclinical hypothyroidism and recurrent URTIs. This can be due to favourable components of the dietary advice or because of elimination of unhealthy food components, such as trans fatty acids, now frequently present in the diets of children. Every food product has its own capacities and effects on human health, and they can augment and interact with each other, instead of eating a single (super)food.

The investigated diet consists mainly of unprocessed food and components of a traditional Dutch diet. These components can be incorporated in the Mediterranean, Asian or other kitchen, but the components can still meet the ingredients of our investigated diet. 


\section{REFERENCES}

1. Farmacotherapeutisch Kompas. www. farmacotherapeutischkompas.nl: Zorginstituut Nederland, 2019.

2. Adair LS. Long-term consequences of nutrition and growth in early childhood and possible preventive interventions. Nestle Nutr Inst Workshop Ser 2014;78:111-20. doi: 10.1159/000354949

3. Berti C, Cetin I, Agostoni C, et al. Pregnancy and infants' outcome: nutritional and metabolic implications. Crit Rev Food Sci Nutr 2016;56(1):82-91. doi: 10.1080/10408398.2012.745477

4. Council DH. Voedingsnormen voor vitamines en mineralen voor volwassenen https://www.gezondheidsraad. $\mathrm{nl} /$ documenten/adviezen/2018/09/18/ gezondheidsraad-herziet-voedingsnormen-voor-volwassenen2018 [Available from: https://www.gezondheidsraad. $\mathrm{nl} /$ documenten/adviezen/2018/09/18/ gezondheidsraad-herziet-voedingsnormen-voor-volwassenen accessed 2-112019.

5. (EFSA) EFSA. Dietary Reference Values for Nutrients Summary Report https:// www.efsa.europa.eu/sites/default/ files/2017_09_DRVs_summary_report. pdf2017 [Available from: https:// www.efsa.europa.eu/sites/default / files/2017_09_DRVs_summary_report. pdf accessed 02-11-2019.

6. Patterson AJ, Brown WJ, Roberts DC. Dietary and supplement treatment of iron deficiency results in improvements in general health and fatigue in Australian women of childbearing age. J Am Coll Nutr 2001;20(4):337-42. doi: 10.1080/07315724.2001.10719054

7. An R, Nickols-Richardson SM, Khan N, et al. Impact of beef and beef product intake on cognition in children and young adults: a systematic review. Nu- trients 2019;11(8):1797. doi: 10.3390/ nu11081797

8. Zhang J, Huang J, Aximujiang $\mathrm{K}$, et al. Thyroid dysfunction, neurological disorder and immunosuppression as the consequences of long-term combined stress. Sci Rep 2018;8(1):4552. doi: 10.1038/s41598-018-19564-y

9. Hemila $\mathrm{H}$, Chalker E. Vitamin C for preventing and treating the common cold. Cochrane Database Syst Rev 2013(1):CD000980. doi: 10.1002/14651858.CD000980.pub4

10. Hassan TH, Badr MA, Karam NA, et al. Impact of iron deficiency anemia on the function of the immune system in children. Medicine (Baltimore) 2016;95(47):e5395. doi: 10.1097/ MD.0000000000005395

11. Jimenez C, Leets I, Puche R, et al. A single dose of vitamin A improves haemoglobin concentration, retinol status and phagocytic function of neutrophils in preschool children. Br J Nutr 2010;103(6):798-802. doi: 10.1017/ S0007114509992765

12. Perdijk O, van Splunter M, Savelkoul HFJ, et al. Cow's milk and immune function in the respiratory tract: potential mechanisms. Front Immunol 2018;9:143. doi: 10.3389/ fimmu.2018.00143 [published Online First: $2018 / 02 / 28]$

13. van Splunter $M$, van Hoffen E, FlorisVollenbroek EG, et al. Oral cholera vaccination promotes homing of $\operatorname{lgA}(+)$ memory B cells to the large intestine and the respiratory tract. Mucosal Immunol 2018;11(4):1254-64. doi: 10.1038/s41385-018-0006-7

14. Hao Q, Dong BR, Wu T. Probiotics for preventing acute upper respiratory tract infections. Cochrane Database Syst Rev 2015;2:CD006895. doi: 10.1002/14651858.CD006895.pub3 
15. Hughes C, Davoodi-Semiromi Y, Colee JC, et al. Galactooligosaccharide supplementation reduces stressinduced gastrointestinal dysfunction and days of cold or flu: a randomized, double-blind, controlled trial in healthy university students. Am J Clin Nutr 2011;93(6):1305-11. doi: 10.3945/ ajcn.111.014126

16. Li F, Jin X, Liu B, et al. Follow-up formula consumption in 3- to 4-year-olds and respiratory infections: an RCT. Pediatrics 2014;133(6):e1533-40. doi: 10.1542/peds.2013-3598

17. Thienprasert A, Samuhaseneetoo $\mathrm{S}$, Popplestone $\mathrm{K}$, et al. Fish oil $\mathrm{n}-3$ polyunsaturated fatty acids selectively affect plasma cytokines and decrease illness in Thai schoolchildren: a randomized, double-blind, placebocontrolled intervention trial. J Pediatr 2009;154(3):391-5. doi: 10.1016/j. jpeds.2008.09.014

18. Adaim A. Investigating the effect of gold kiwifruit consumption on the incidence and symptoms of upper respiratory tract infections in pre-school children. Massey University, New Zealand, 2010.

19. Lissiman E, Bhasale AL, Cohen M. Garlic for the common cold. Cochrane Database Syst Rev 2014;11:CD006206. doi: 10.1002/14651858.CD006206.pub4

20. Azarpazhooh A, Lawrence HP, Shah PS. Xylitol for preventing acute otitis media in children up to 12 years of age. Cochrane Database Syst Rev 2016(8):CD007095. doi: 10.1002/14651858.CD007095.pub3

21. Zakay-Rones Z, Thom E, Wollan T, et al. Randomized study of the efficacy and safety of oral elderberry extract in the treatment of influenza $A$ and $B$ virus infections. I Int Med Res 2004;32(2):132-40.

22. Calatayud FM, Calatayud B, Gallego JG, et al. Effects of Mediterranean diet in patients with recurring colds and frequent complications. Allergol Immunopathol (Madr) 2017;45(5):417-24. doi: 10.1016/j.aller.2016.08.006

23. Gruber $\mathrm{C}$, Keil $\mathrm{T}$, Kulig $\mathrm{M}$, et al. History of respiratory infections in the first $12 \mathrm{yr}$ among children from a birth cohort. Pediatr Allergy Immunol 2008;19(6):505-12. doi: 10.1111/j.1399-3038.2007.00688.x

24. Lee GM, Friedman JF, Ross-Degnan D, et al. Misconceptions about colds and predictors of health service utilization. Pediatrics 2003;111(2):231-6.

25. Lavelle TA, Uyeki TM, Prosser LA. Cost-effectiveness of oseltamivir treatment for children with uncomplicated seasonal influenza. J Pediatr 2012;160(1):67-73 e6. doi: 10.1016/j. jpeds.2011.07.001

26. Pimpin $\mathrm{L}, \mathrm{Wu} \mathrm{JH}$, Haskelberg $\mathrm{H}$, et al. Is butter back? A systematic review and meta-analysis of butter consumption and risk of cardiovascular disease, diabetes, and total mortality. PLoS One 2016;11(6):e0158118. doi: 10.1371/ journal.pone. 0158118

27. Weigle DS, Breen PA, Matthys CC, et al. A high-protein diet induces sustained reductions in appetite, ad libitum caloric intake, and body weight despite compensatory changes in diurnal plasma leptin and ghrelin concentrations. Am J Clin Nutr 2005;82(1):41-8.

28. Cavero-Redondo I, Alvarez-Bueno $C$, Sotos-Prieto $M$, et al. Milk and dairy product consumption and risk of mortality: an overview of systematic reviews and meta-analyses. Adv Nutr 2019;10(Suppl_2):S97-104. doi: 10.1093/advances/nmy128

29. Mozaffarian D, Hao T, Rimm EB, et al. Changes in diet and lifestyle and longterm weight gain in women and men. $N$ Engl J Med 2011;364(25):2392-404. doi: 10.1056/NEJMoa1014296 
30. Geng T, Qi L, Huang T. Effects of dairy products consumption on body weight and body composition among adults: an updated meta-analysis of 37 randomized control trials. Mol Nutr Food Res 2018;62(1). doi: 10.1002/ mnfr. 201700410

31. Oteng $A B$, Kersten $S$. Mechanisms of action of trans fatty acids. Adv Nutr 2019. doi: 10.1093/advances/nmz125

32. Oteng $A B$, Loregger $A$, van Weeghel $M$, et al. Industrial trans fatty acids stimulate SREBP2-mediated cholesterogenesis and promote non-alcoholic fatty liver disease. Mol Nutr Food Res 2019;63(19):e1900385. doi: 10.1002/ mnfr.201900385

33. Bendsen NT, Christensen R, Bartels EM, et al. Consumption of industrial and ruminant trans fatty acids and risk of coronary heart disease: a systematic review and meta-analysis of cohort studies. Eur J Clin Nutr 2011;65(7):773-83. doi: 10.1038/ejcn.2011.34

34. Harris C, Buyken A, von Berg A, et al. Prospective associations of meat consumption during childhood with measures of body composition during adolescence: results from the GINIplus and LISAplus birth cohorts. Nutr J 2016;15(1):101. doi: 10.1186/s12937016-0222-5

35. Rouhani MH, Salehi-Abargouei A, Surkan PJ, et al. Is there a relationship between red or processed meat intake and obesity? A systematic review and meta-analysis of observational studies. Obes Rev 2014;15(9):740-8. doi: 10.1111/obr.12172

36. Domingo JL, Nadal M. Carcinogenicity of consumption of red meat and processed meat: A review of scientific news since the IARC decision. Food Chem Toxicol 2017;105:256-61. doi: 10.1016/j. fct.2017.04.028
37. Zhao Z, Yin Z, Zhao Q. Red and processed meat consumption and gastric cancer risk: a systematic review and meta-analysis. Oncotarget 2017;8(18):30563-75. doi: 10.18632/ oncotarget.15699

38. Turner ND, Lloyd SK. Association between red meat consumption and colon cancer: a systematic review of experimental results. Exp Biol Med (Maywood) 2017;242(8):813-39. doi: $10.1177 / 1535370217693117$

39. O'Connor LE, Gifford CL, Woerner DR, et al. Dietary meat categories and descriptions in chronic disease research are substantively different within and between experimental and observational studies: a systematic review and landscape analysis. Adv Nutr 2019. doi: 10.1093/advances/nmz072

40. Islam Z, Akter S, Kashino I, et al. Meat subtypes and colorectal cancer risk: a pooled analysis of 6 cohort studies in Japan. Cancer Sci 2019;110(11):360314. doi: $10.1111 /$ cas. 14188

41. Violi F, Lip GY, Pignatelli $P$, et al. Interaction between dietary vitamin $\mathrm{K}$ intake and anticoagulation by vitamin $\mathrm{K}$ antagonists: is it really true?: a systematic review. Medicine (Baltimore) 2016;95(10):e2895. doi: 10.1097/ MD. 0000000000002895

42. Salter $A M$. The effects of meat consumption on global health. Rev Sci Tech 2018;37(1):47-55. doi: 10.20506/ rst.37.1.2739

43. Liu Y, Poon S, Seeman E, et al. Fat from dairy foods and 'meat' consumed within recommended levels is associated with favourable serum cholesterol levels in institutionalised older adults. J Nutr Sci 2019;8:e10. doi: 10.1017/jns.2019.5

44. Kiessling G, Schneider J, Jahreis G. Long-term consumption of fermented dairy products over 6 months increases HDL cholesterol. Eur J Clin 
Nutr 2002;56(9):843-9. doi: 10.1038/ sj.ejcn.1601399

45. Pereira DI, Gibson GR. Effects of consumption of probiotics and prebiotics on serum lipid levels in humans. Crit Rev Biochem Mol Biol 2002;37(4):259-81. doi: $10.1080 / 10409230290771519$

46. Lorenzen JK, Jensen SK, Astrup A. Milk minerals modify the effect of fat intake on serum lipid profile: results from an animal and a human short-term study. Br J Nutr 2014;111(8):1412-20. doi: 10.1017/S0007114513003826

47. Lorenzen JK, Astrup A. Dairy calcium intake modifies responsiveness of fat metabolism and blood lipids to a high-fat diet. Br J Nutr 2011;105(12):1823-31. doi: $10.1017 /$ S0007114510005581

48. Michels $\mathrm{N}$, Van de Wiele $\mathrm{T}$, Fouhy $\mathrm{F}$, et al. Gut microbiome patterns depending on children's psychosocial stress: reports versus biomarkers. Brain Behav Immun 2019;80:751-62. doi: 10.1016/j. bbi.2019.05.024

49. Michels N. Biological underpinnings from psychosocial stress towards appetite and obesity during youth: research implications towards metagenomics, epigenomics and metabolomics. Nutr Res Rev 2019;32(2):282-93. doi: $10.1017 /$ S0954422419000143
50. Rampelli S, Guenther K, Turroni S, et al. Pre-obese children's dysbiotic gut microbiome and unhealthy diets may predict the development of obesity. Commun Biol 2018;1:222. doi: 10.1038/ s42003-018-0221-5

51. Michels N, Van de Wiele T, De Henauw S. Chronic psychosocial stress and gut health in children: associations with calprotectin and fecal shortchain fatty acids. Psychosom Med 2017;79(8):927-35. doi: 10.1097/ PSY.0000000000000413

52. Quigley EM. Gut bacteria in health and disease. Gastroenterol Hepatol (N Y) 2013;9(9):560-9.

53. Clarke G, Stilling RM, Kennedy PJ, et al. Minireview: Gut microbiota: the neglected endocrine organ. Mol Endocrinol 2014;28(8):1221-38. doi: $10.1210 /$ me.2014-1108 



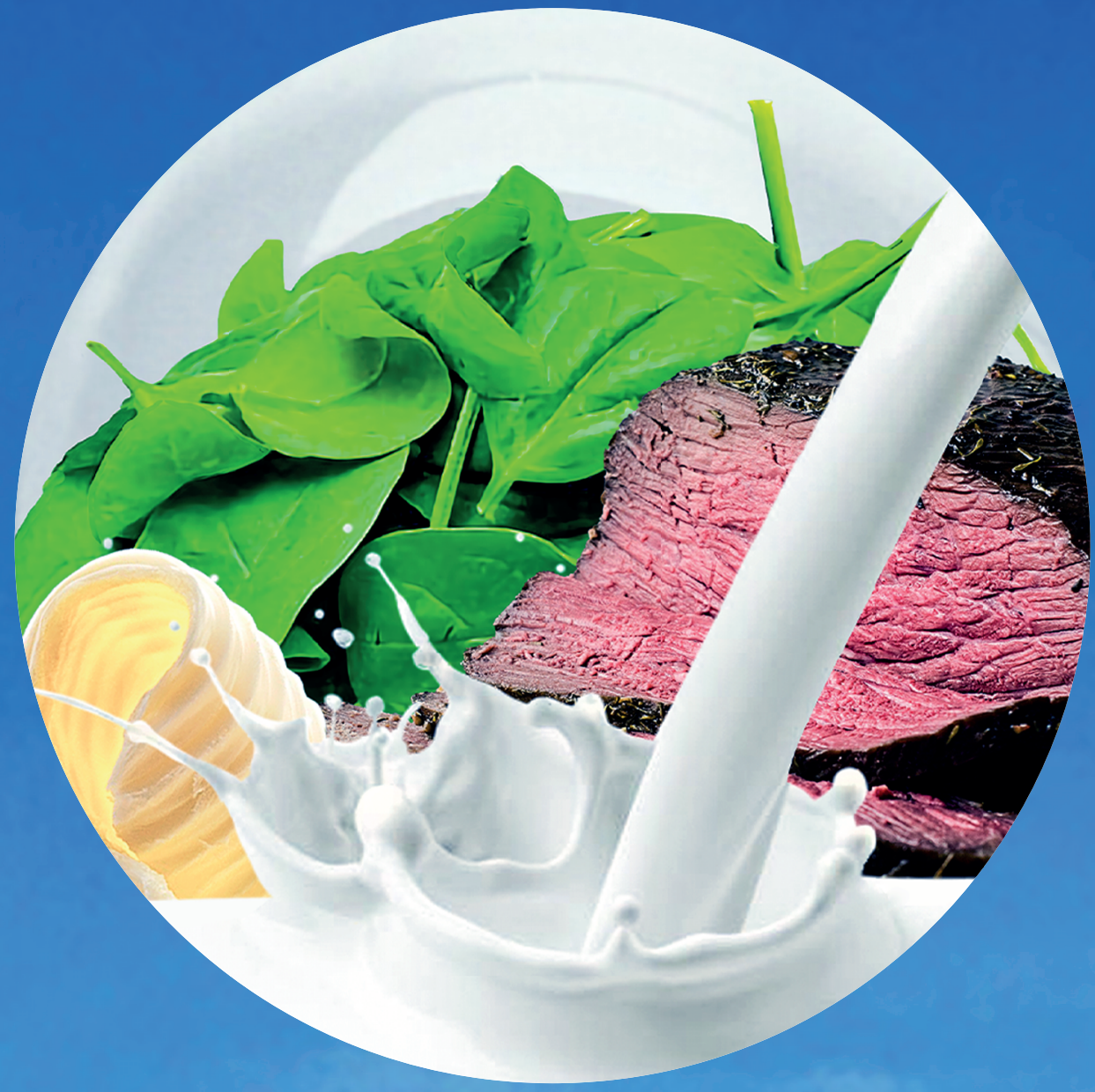


Summary, Nederlandse samenvatting, CV, Publications, Dankwoord 

The results of the review, presented in chapter 2, suggest beneficial effects of whole food in the prevention of, and shortening in duration of, upper respiratory tract infections (URTI).

Some food products show clear preventive or shortening effects on URTI; e.g. kiwi, elderberry, pre- and probiotics, fish oil and garlic [1-8].

In patients with recurrent URTI, intervention with a single whole food product can therefore be beneficial. A dietary intervention with multiple food products for URTI is rarely investigated, except for the effects of the Mediterranean diet in children with recurring colds and frequent complications in Spain. This before-after study found decreased URTIs after a change in lifestyle [9]. The effects of the Mediterranean diet are based on the concept of food synergy, meaning that the effects of a combination of foods are much stronger than the effects of single supplements with nutrients [10].

Chapter 3 describes the effects of a nutrient rich diet, consisting of beef ( 3 times a week), green vegetables ( 5 times a week), $300 \mathrm{~mL}$ whole milk daily and butter, on IgE levels in children. In this retrospective case-control study in 105 children, we observed a decrease in IgE of $9.2 \mathrm{kU} / \mathrm{L}$ (= $22 \mathrm{ug} / \mathrm{L}$ ) after the dietary advice had been followed for 4 months. We did not observe a change in IgE-levels in the control group. Subjective improvements in clinical complaints were recorded in $53 \%$ of the children in the intervention group and $29 \%$ in the control group $(p<0.001)$.

In chapter 4 we investigated the effect of the same dietary advice on fatigue in children. In this non-randomized controlled study in 98 children with unexplained symptoms of fatigue, the sleep domain improved in the intervention group. We evaluated every single food component (of the four in total) and its effect on fatigue in the studied population. Green vegetables improved cognitive tiredness scores significantly, while whole milk improved the sleep domain significantly.

Lipid profiles in young children are scarcely investigated when there is no relation with familial dyslipidaemia. What are the consequences for the lipid profile when full fat dairy products are introduced into the diet of young children? Chapter $\mathbf{5}$ describes the results of a retrospective case-control study on the lipid profiles of children with and without the dietary advice. After 5 months, the intervention group did not show unfavourable lipid profiles. On the contrary, HDL-cholesterol (a favourable prognostic factor for cardiovascular disease) increased significantly after following the dietary advice. Also, the cholesterol/HDL ratio and the non-HDL-cholesterol improved favourably following the dietary advice. No unfavourable trends in lipid profiles were 
observed. In addition, the body mass index (BMI) and BMI-z scores were not adversely affected by introducing full fat dairy products together with green vegetables and beef.

As part of this thesis, a randomized controlled dietary intervention was performed with a dietary change in 118 young children (1-4 years) with recurrent URTI. Again, we evaluated the dietary advice, consisting of green vegetables, beef, whole milk and butter, over 6 months. We found a significant decrease in infection days, catarrhal episodes, coughing and days with fever. Also, antibiotic use decreased by $66.6 \%$ over the 6-month period (chapter 6). No significant weight gain or increase in BMI was seen in the intervention group. Laboratory parameters showed decreased C Reactive Protein (CRP) levels, suggestive a lower grade of inflammation in the intervention group, but this finding should be considered with caution since the values are still in the normal range.

Fatigue scores improved in children with a subclinical hypothyroidism in our randomized controlled trial (RCT), after following the dietary advice for 6 months (chapter 7). Scores improved in the different fatigue domains, especially in the domains of sleep and total tiredness. The function of the thyroid, expressed by the values of TSH and FT4, was not influenced by the dietary advice. In this study, we could not find an effect of green vegetables on cognitive tiredness, probably because our control group also consumed considerable amounts of green vegetables, and the difference between the groups for this food product was less clear.

\section{Laboratory Observations}

\section{Recurrent infections}

In the RCT of children with recurrent URTI, after following the dietary intervention for 6 months (chapter 6), we observed no significant changes in laboratory parameters between the groups, except for CRP levels. These levels were significantly reduced in the intervention group compared with the control group, possibly indicating lower chronic inflammation, but this should be approached with caution since the values are still in the normal range.

Within the intervention group, significant changes could be found after 6 months compared to the same laboratory parameters at the start of the study. Some changes were also seen in the control group. Significant changes found only in the intervention group were: increased Mean Corpuscular Volume (MCV), decreased leucocytes, decreased ferritin, decreased IgM and increased IgE. Some parameters suggested a 
decreased immunologic activity (leucocytes, ferritin (since ferritin was significantly correlated with CRP levels) and IgM). Surprisingly, IgE levels were increased after 6 months in both our intervention group and control group, with results of 25.0 and 24.9 $\mathrm{ug} / \mathrm{L}$, respectively. The absolute difference in IgE levels between the intervention and control group was minimal, although the increase in the intervention group was significant due to a lower standard deviation (106 in the intervention group compared to 148 in the control group). This is in contrast to the decreased IgE levels observed in the case-control study described in chapter 3 . In the retrospective case-control study, the effect of dietary advice disappeared due to vitamin D supplementation. In the randomised controlled study, the children were between 1 and 4 years of age. The national advice in this group is to use vitamin D supplementation. In the latter study vitamin $D$ is therefore not a confounder. At this time, we cannot estimate the contribution of the dietary intervention to an allergic constitution. We observed that the IgE values are very widespread with some outliers, which makes the results difficult to interpret.

\section{Thyroid and fatigue}

No effects were seen on thyroid functioning in subclinical hypothyroidism in our RCT after the dietary intervention; Ft4, TSH and anti-TPO levels did not change significantly (chapter 7). Therefore, the dietary intervention did not act on the thyroid pathways that were measured in our study. Clinical improvements of fatigue (similar to those in chapter 4) were seen, but we could not relate them to the functioning of the thyroid.

\section{Lipid profile}

During our outpatient consultations, many parents had concerns about the lipid profiles of their children when starting a diet with whole dairy products. In all of our studies, there was a consistent trend in the lipid profile after the dietary advice was followed. In all 3 studies (both RCTs and the case control study, chapters 5, 6 and 7), HDL levels increased and the cholesterol/HDL ratio decreased towards prognostically favourable values. Total cholesterol and LDL remained the same or increased slightly. Triglycerides, which are highly dependent on the last ingested meal, showed no particular trend, remaining the same, increasing or decreasing in individual studies. Over the years there has been a change in the moment at which the venipuncture was taken for the laboratory tests. In the beginning, patients had to come with an empty stomach, but in recent years it was determined at any point in the day, unrelated with the ingested meals. These instructions were given by the laboratory. 


\section{Growth}

In both RCTs (chapters 6 and 7) we included measurements on growth parameters, mainly because of the fear of obesity when full fat dairy products are introduced into the diet.

No significant changes in growth were seen in either trial, neither did we see any unfavourable trends; after 6 months of follow up, the height growth remained the same in both control groups but increased slightly in the intervention groups, by 0.03 SD in the URTI study and 0.07 SD in the subclinical hypothyroidism study. These are small changes in a relative short period, and it remains to be seen whether this has any clinical meaning.

As for BMI, in the control group it increased after 6 months, by 0.27 SD in the URTI study and 0.01 SD in the subclinical hypothyroidism study. After the dietary change to full fat dairy products the BMI increased 0.04 SD in the URTI study and 0.06 SD in the subclinical hypothyroidism study. This does not suggest a BMI increase in children as a result of the consumption of whole dairy foods in combination with beef and green vegetables. 


\section{REFERENCES}

1. A. Adaim, Investigating the effect of gold kiwifruit consumption on the incidence and symptoms of upper respiratory tract infections in preschool children, Massey University, New Zealand, http://mro.massey.ac.nz/bitstream/handle/10179/2351/02_whole. pdf?sequence=1, (2010) 191.

2. D.C. Hunter, M.A. Skinner, F.M. Wolber, C.L. Booth, J.M. Loh, M. Wohlers, L.M. Stevenson, M.C. Kruger, Consumption of gold kiwifruit reduces severity and duration of selected upper respiratory tract infection symptoms and increases plasma vitamin $\mathrm{C}$ concentration in healthy older adults, Br J Nutr 108(7) (2012) 1235-45.

3. E. Tiralongo, S.S. Wee, R.A. Lea, Elderberry supplementation reduces cold duration and symptoms in airtravellers: a randomized, double-blind placebo-controlled clinical trial, Nutrients 8(4) (2016) 182.

4. F.K. Kong, Pilot clinical study on the proprietary elderberry extract: efficacy in adressing influenza symptoms, Online J. Pharmacol. Pharmacokin 5 (2009) 32-43.

5. Z. Zakay-Rones, E. Thom, T. Wollan, J. Wadstein, Randomized study of the efficacy and safety of oral elderberry extract in the treatment of influenza $A$ and $B$ virus infections, $J$ Int Med Res 32(2) (2004) 132-40.

6. Q. Hao, B.R. Dong, T. Wu, Probiotics for preventing acute upper respiratory tract infections, Cochrane Database Syst Rev 2 (2015) CD006895.

7. A. Thienprasert, S. Samuhaseneetoo, K. Popplestone, A.L. West, E.A. Miles, P.C. Calder, Fish oil $n-3$ polyunsaturated fatty acids selectively affect plasma cytokines and decrease illness in Thai schoolchildren: a randomized, doubleblind, placebo-controlled intervention trial, J Pediatr 154(3) (2009) 391-5.

8. P. Josling, Preventing the common cold with a garlic supplement: a doubleblind, placebo-controlled survey, Adv Ther 18(4) (2001) 189-93.

9. F.M. Calatayud, B. Calatayud, J.G. Gallego, C. Gonzalez-Martin, L.F. Alguacil, Effects of Mediterranean diet in patients with recurring colds and frequent complications, Allergol Immunopathol (Madr) 45(5) (2017) 417-424.

10. D.R. Jacobs, L.C. Tapsell, Food synergy: the key to a healthy diet, Proc Nutr Soc 72(2) (2013) 200-6. 



\section{NEDERLANDSE SAMENVATTING}

Dit proefschrift is ontstaan door het ontbreken van therapieën voor alledaagse lichamelijke klachten en problemen die ik als kinderarts tegenkwam. Veel voorkomende problemen zoals steeds terugkerende luchtweginfecties (het chronisch verkouden zijn), vermoeidheid, aspecifieke allergieën, een verstoorde maar nog net redelijk goed functionerende schildklier hebben vaak geen medische verklaring. Door het ontbreken van een medische verklaring, houdt het ook in dat er geen therapie voorhanden is, en dat je als arts niet iets kan bieden aan de ouders. In onze onderzoeken hebben we onderzocht of een voedingsadvies een mogelijke behandeling kan zijn, aangezien grote groepen kinderen niet alle voedingsstoffen binnenkrijgen en een aanzienlijk percentage kinderen (met name de kinderen die kwakkelen) minder dan één keer per week groente eet. Wij ontwikkelden hiervoor een voedingsadvies met onbewerkte producten; $5 x$ per week groene groenten bij de avondmaaltijd, 3x per week rundvlees bij de avondmaaltijd, dagelijks $300 \mathrm{ml}$ volle zuivel (volle melk of volle yoghurt) en roomboter op brood. Alles in leeftijdsadequate hoeveelheden volgens het voedingscentrum. De achtergronden en het ontstaan van het voedingsadvies worden beschreven in hoofdstuk 1.

Hoofdstuk 2 beschrijft een overzicht van uitkomsten van reeds gepubliceerde literatuur (een review) over de effecten van verschillende soorten voeding op luchtweginfecties bij kinderen en volwassenen. De resultaten van andere onderzoekers suggereren gunstige effecten van voeding bij het voorkomen en verkorten van de duur van infecties van de bovenste luchtwegen. De voedingsproducten die dit kunnen bewerkstelligen zijn bijvoorbeeld; kiwi, vlierbessen, pre- en probiotica, visolie en knoflook.

Bij patiënten met terugkerende infecties van de bovenste luchtwegen kan een advies met één enkel voedingsproduct dus gunstig zijn. Een dieetinterventie met meerdere voedingsproducten voor luchtweginfecties is zelden onderzocht, met uitzondering van de effecten van het mediterrane dieet in Spanje. In dit voor-na onderzoek werd een afname van luchtweginfecties vastgesteld na een verandering in de leefstijl (combinatie van mediterrane eetgewoontes en lichamelijke beweging). De effecten van het mediterrane dieet zijn gebaseerd op het concept van voedselsynergie; de effecten van (een combinatie van) voedsel zijn veel sterker zijn dan de effecten van het aanvullen van een enkele voedingsstof of product (zoals bv het aanvullen van vitamine $C$ of alleen kiwi). Door de synergie heeft het meerdere aangrijpingspunten waarbij het de afweer kan versterken. Sommige mechanismes zijn al bekend, maar er zijn ook nog niet ontdekte mechanismes. 
Hoofdstuk 3 beschrijft de effecten van ons dieetadvies, bestaande uit rundvlees ( 3 keer per week), groene groenten (5 keer per week), dagelijkse $300 \mathrm{ml}$ volle melk en roomboter, op het lgE-gehalte bij kinderen met luchtwegklachten. Een verhoogd IgE gehalte wordt o.a. gevonden bij allergieën. In deze retrospectieve case-control studie bij 105 kinderen zagen we een daling van het IgE gehalte van 9,2 kU/l (=22 ug/l) na 4 maanden volgen van het voedingsadvies. We hebben geen verandering in de IgE-gehaltes in de controlegroep waargenomen. Bij $53 \%$ van de kinderen in de voedingsadviesgroep en $29 \%$ in de controlegroep $(p<0.001)$ werden subjectieve verbeteringen van de klinische klachten genoemd door de ouders.

In hoofdstuk 4 hebben we het effect van hetzelfde voedingsadvies op de vermoeidheid bij kinderen onderzocht. In dit niet-gerandomiseerde gecontroleerde onderzoek bij 98 kinderen met onverklaarde vermoeidheidsverschijnselen verbeterde de slaap in de interventiegroep (de voedingsgroep). We evalueerden elk afzonderlijk voedingsbestanddeel (van de vier in totaal) en het effect daarvan op de vermoeidheid in de onderzochte populatie. Groene groenten verbeterden de cognitieve vermoeidheidsscores significant en volle melk verbeterde het slaapdomein significant.

Het Lipidenprofiel (cholesterol spectrum) wordt nauwelijks onderzocht bij jonge kinderen wanneer er geen relatie is met familiaire dyslipidemie (een aangeboren aanleg voor afwijkingen in de cholesterol stofwisseling). Het grootste gedeelte van de kinderen heeft dat niet. Wat zijn de gevolgen voor het lipidenprofiel wanneer kinderen zonder deze afwijking volvette zuivelproducten in hun dieet introduceren? In hoofdstuk 5 zijn de resultaten beschreven van een retrospectieve case-control studie op de lipidenprofielen van kinderen met en zonder het voedingsadvies. Na 5 maanden liet de voedingsadviesgroep geen ongunstige lipidenprofielen zien. Integendeel, HDLcholesterol (een prognostische gunstige risicofactor voor hart- en vaatziekten) nam na het volgen van het voedingsadvies aanzienlijk toe, evenals de cholesterol/HDLverhouding en het niet-HDL-cholesterol. Alle drie de waardes veranderden naar de gunstige richting. Er werden geen ongunstige trends in de lipidenprofielen waargenomen. Ook werden de BMI- en BMI-z-scores niet negatief beïnvloed door de introductie van volvette zuivelproducten in combinatie met groene groenten en rundvlees.

Als onderdeel van dit proefschrift werd een gerandomiseerde gecontroleerde dieetinterventie uitgevoerd met een dieetverandering bij 118 jonge kinderen (1-4 jaar) met terugkerende infecties van de bovenste luchtwegen. Ook hier hebben we het voedingsadvies bestaande uit groene groenten, rundvlees, volle melk en roomboter gedurende 6 maanden geëvalueerd. We vonden een significante afname in infectiedagen, verkoudheid episodes, hoesten en dagen met koorts. Ook het antibioticagebruik 
daalde met $66,6 \%$ over een periode van 6 maanden (hoofdstuk 6). Er werd geen significante gewichtstoename of verhoging van de BMI gezien in de interventiegroep.

Vermoeidheidsscores verbeterden in onze tweede gerandomiseerde studie bij kinderen met een subklinische hypothyreoïdie, na het volgen van het voedingsadvies voor 6 maanden (hoofdstuk 7). Als we kijken naar de verschillende vermoeidheidsdomeinen, verbeterden vooral de domeinen van de slaap en de totale vermoeidheidsscore. De functie van de schildklier, uitgedrukt in de waarden van TSH en FT4, werd niet beïnvloed door het voedingsadvies. In deze studie konden we geen effect van groene groenten op de cognitieve vermoeidheid vinden (wat we wel in hoofdstuk 4 gevonden hebben), waarschijnlijk omdat in de huidige studie onze controlegroep aanzienlijke hoeveelheden groene groenten consumeerde en het verschil tussen beide groepen voor de inname van groene groentes minder groot was.

\section{Effecten van het voedingsadvies op laboratoriumparameters}

\section{Luchtweginfecties}

$\mathrm{Na}$ het volgen van de dieetinterventie gedurende 6 maanden in de gerandomiseerde luchtweginfectie studie hebben we geen significante veranderingen in laboratoriumparameters tussen de groepen waargenomen, met uitzondering van de CRP-waardes. Deze waardes werden significant verlaagd in de interventiegroep in vergelijking met de controlegroep, wat mogelijk wijst op een lagere chronische ontsteking. Deze bevinding moet echter wel in perspectief gezien worden, aangezien de waardes nog steeds in het normale bereik liggen (hoofdstuk 6).

Binnen de interventiegroep werden na 6 maanden significante veranderingen gevonden ten opzichte van dezelfde laboratoriumparameters bij de start van het onderzoek. Ook in de controlegroep werden enkele veranderingen gezien. Significante veranderingen die alleen in de interventiegroep werden gevonden waren; toegenomen gemiddeld corpusculair volume (MCV), verminderde leukocyten, verlaagd ferritine, verlaagd IgM en toegenomen IgE. Sommige parameters suggereerden een verminderde immunologische activiteit (leucocyten, ferritine (aangezien ferritine significant gecorreleerd was met de CRP-waardes), en IgM). Verrassend genoeg werden IgE waardes verhoogd na 6 maanden in onze RCT in zowel onze interventiegroep en controlegroep met 25.0 en 24.9 ug/l, respectievelijk. Het absolute verschil in IgE-waardes tussen de interventie- en controlegroep was minimaal, hoewel het statistische verschil in de interventiegroep significant was door een lagere standaardafwijking (106 in de interventiegroep ten opzichte van 148 in de controlegroep). Deze bevinding was deels tegenstrijdig aan de bevinding van de verlaagde IgE-waardes in een case-control studie 
(hoofdstuk 3). In de retrospectieve case-control studie verdween het effect van het voedingsadvies door suppletie van vitamine $\mathrm{D}$. In de gerandomiseerde gecontroleerde studie zijn de kinderen tussen de 1 en 4 jaar oud. Het landelijke advies in deze groep is om vitamine $D$ te gebruiken. In de laatste studie is vitamine $D$ dan ook geen confounder. Op dit moment kunnen we de bijdrage van de voedingsinterventie aan een allergische constitutie niet inschatten. We hebben geconstateerd dat de waarden van IgE aanzienlijk uiteenlopen met enkele uitschieters, wat de interpretatie van de resultaten bemoeilijkt.

\section{Schildklier en vermoeidheid}

We zagen geen effecten op het functioneren van de schildklier na de dieetinterventie in onze gerandomiseerde studie in patiënten met subklinische hypothyreoïdie. Ft4, TSH noch anti-TPO niveaus veranderden significant (hoofdstuk 7). Daarom heeft de voedingsinterventie geen meetbaar effect gehad op de schildklier. Klinische verbeteringen van de vermoeidheid (vergelijkbaar met die in hoofdstuk 4) werden gezien, maar deze stonden los van de werking van de schildklier.

\section{Lipiden profiel}

Tijdens onze contacten met ouders werd vaak door ouders de angst uitgesproken voor het cholesterol (lipidenprofiel) van hun kinderen als ze een dieetadvies met volle zuivelproducten gaan eten. In al onze onderzoeken zagen we een consistente trend in het lipidenprofiel na het volgen van het voedingsadvies. Prognostisch gunstige HDLwaarden stegen in alle 3 de studies (zowel in de gerandomiseerde studies als de case control studie, hoofdstuk 5,6 en 7) en ook de cholesterol/HDL-verhouding daalde naar prognostische gunstige waarden (alle 3 de studies). Het totale cholesterolgehalte en LDL bleven gelijk of namen licht toe. Triglyceriden zijn sterk afhankelijk van de laatste ingenomen maaltijd. Deze bleven gelijk, stegen of daalden; in elke studie in een andere richting. Een verschil in de afgelopen jaren is het moment van het bloedprikken voor de laboratoriumtesten. In het begin moesten de patiënten nuchter komen, maar in de afgelopen jaren was dit op elk moment van de dag mogelijk, niet gerelateerd aan een nuchtere maag. Deze instructies werden door het laboratorium gegeven. Mogelijk dat dit de veranderingen in triglyceriden kan verklaren.

\section{Groei}

In beide gerandomiseerde gecontroleerde studies (hoofdstuk 6 en 7) hebben we metingen verricht naar de groeiparameters, voornamelijk vanwege de angst voor overgewicht bij het starten van volle zuivelproducten in het dieet. 
In beide gerandomiseerde studies zagen we geen significante veranderingen in de groei. Ook zagen we geen ongunstige trends; na 6 maanden follow-up bleef de lengtegroei in beide controlegroepen gelijk, maar steeg de lengtegroei iets meer in beide interventiegroepen (dwz. Een deel gewone groei en een minimaal deel inhaalgroei). Dit zijn kleine veranderingen in een relatief korte periode, follow-up studies moeten verricht worden of dit een klinische betekenis heeft.

Wat betreft de body mass index (BMI), in de controlegroep steeg de BMI na 6 maanden met 0,27 SD in de luchtweginfectie-studie en 0,01 SD in de schildklier-studie. Na de dieetverandering naar volle zuivelproducten steeg de BMI met 0,04 SD in de URTI-studie en met 0,06 SD in de SH-studie. Dit suggereert geen effect van volle zuivelproducten in combinatie met rundvlees en groene groenten op de BMI bij kinderen.

\section{Conclusie}

Naar aanleiding van onze onderzoeken adviseren wij het door ons onderzochte voedingsadvies aan Nederlandse kinderen met luchtweginfecties zonder immunologische afwijkingen of vermoeidheid zonder medische verklaring. Een dieet met groene groenten, rundvlees, volle melk en roomboter resulteert in minder luchtwegklachten bij jonge kinderen en minder vermoeidheid. Dit kan te wijten zijn aan gunstige bestanddelen van het voedingsadvies of aan de eliminatie van ongezonde voedingsbestanddelen zoals transvetzuren, die nu vaak aanwezig zijn in de voeding van kinderen. Elk voedingsproduct heeft zijn eigen kwaliteiten en effecten op de menselijke gezondheid en meerdere voedingsproducten kunnen elkaar aanvullen en met elkaar reageren. Door de combinatie van meerdere producten kunnen er bredere effecten in gang gezet worden in plaats van de effecten van één enkel (superfood)voedsel.

Het onderzochte dieet bestaat voornamelijk uit onbewerkt voedsel, en componenten van een traditioneel Nederlands dieet. Deze componenten kunnen worden verwerkt in de mediterrane, Aziatische of andere keuken, al naar gelang de eetgewoontes van het gezin. Zelfs als ze verschillend verwerkt worden, kunnen de componenten nog steeds voldoen aan de ingrediënten van ons onderzochte dieet, en de gezondheid van kinderen bevorderen. 



\section{PUBLICATIONS}

1999 Leccia MT, van der Gaag EJ, Jalbert NL, Byers HR. Zyxin redistributes without upregulation in migrating human keratinocytes during wound healing. $J$ Invest Dermatol. 1999 Oct;113(4):651-7.

2002 van der Gaag EJ, Leccia MT, Dekker SK, Jalbert NL, Amodeo DM, Byers HR. Role of zyxin in differential cell spreading and proliferation of melanoma cells and melanocytes. J Invest Dermatol. 2002 Feb;118(2):246-54.

2005 van der Gaag EJ, Roelofsen E, Tummers RF. Aeromonas caviae infection mimicking inflammatory bowel disease in a child. Ned Tijdschr Geneeskd. 2005 Mar 26;149(13):712-4.

2012 M. Kuiper and E. Gaag, "Subclinical Hypothyroidism in Children Can Normalize after Changes in Dietary Intake," Food and Nutrition Sciences, Vol. 3 No. 3, 2012, pp. 411-416.

http: / /www.scirp.org/journal/PaperInformation.aspx?paperID=17977

EJ van der Gaag and M Münow, “Diminishing demandingness of parents ; children with recurrent respiratory infections" Accepted for publication, Health vol 4, no 8, 2012

EJ van der Gaag and N van Droffelaar, "Upper respiratory tract infections in children: a normal stage or high parental concern?” Open Journal of pediatrics, Vol. 2 no. 3, 2012

2013 EJ van der Gaag “Mollusca Contagiosa can disappear after a dietary change”, Cutis, 2013, October;92(4):E3-E4

http: //www.cutis.com/uploads/media/CT092040003_e.pdf

Loes G. H. Ten Velde, Jolien Leegsma, Ellen J. Van der Gaag “Recurrent Upper Respiratory Tract Infections in Children;The Influence of Green Vegetables, Beef, Whole Milk and Butter" Food and Nutrition Sciences Vol.4 No.10A, Pub. Date: October 14, 2013

2014 EJ van der Gaag and M Münow “Hospitalization van correct behavioural feeding disorders" Open Journal of Pediatrics, Vol. 4 No.2, 2014 
Ellen van der Gaag and Lisanne Brekhoff, "Effect of Food and Vitamin D Supplements on the Serum 25(OH)D3 Concentration in Children during Winter Months" Foods vol 3 (4), 632-641, 2014

2015 Tessa Gerjanne Steenbruggen, Sietske Johanna Hoekstra and Ellen José van der Gaag

"Could a Change in Diet Revitalize Children Who Suffer from Unresolved Fatigue?" Nutrients, Vol 7 (3) 1965-1977, 2015

Kluin PM, Langerak AW, Beverdam-Vincent J, Geurts-Giele WR, Visser L, Rutgers B, Schuuring E, Van Baarlen J, Lam KH, Seldenrijk K, Kibbelaar RE, de Wit P, Diepstra A, Rosati S, van Noesel MM, Zwaan CM, Hunting JC, Hoogendoorn M, van der Gaag EJ, van Esser JW, de Bont E, Kluin-Nelemans HC, Winter RH, Lo Ten Foe JR, van der Zanden AG. “Paediatric nodal marginal zone B-cell lymphadenopathy of the neck: a Haemophilus influenzae-driven immune disorder?" J Pathol. 2015 Feb 26. 4524.

EJ van der Gaag and K. Forbes. "The Immunomodulating Effect of a Diet Consisting of Green Vegetables, Beef, Whole Milk and Full-Fat Butter for Children with Non-Specific Elevated IgE ." International Journal for vitamin and Nutrition research, Vol 84 (5-6), 310-319.

Van der Gaag EJ, Bolk-van Droffelaar N, van der Palen J, Baarsma R. "Folic Acid and Iron Supplementation in Children with Insufficient Diets in a Developed Country, a Randomised Controlled Trial." Internat J Pediatric Res 2015; $1(2)$.

2017 van der Gaag EJ, Wieffer R, van der Kraats J. “Advising Consumption of Green Vegetables, Beef, and Full-Fat Dairy Products Has No Adverse Effects on the Lipid Profiles in Children". Nutrients 2017 May 19;9(5)

Ellen J. Van der Gaag, Marlou C.E. Snijders. "The Teaspoon Method; A Simple Training Program for Feeding Disorders in High Functioning Autistic Children". Open Journal of Pediatrics Vol.7 No.2 June 6, 2017

2018 Alies Coenders, Ruben P. Portier, Felix Geeraedts, Ellen J. Van der Gaag. “A Child with Unilateral Visual Impairment Caused by Neuroborreliosis". J Pediatr Infect Dis, feb 23rd 2018 
2020 Ellen van der Gaag, Ruben Brandsema, Rosan Nobbenhuis, Job van der Palen, Thalia Hummel. "The influence of a dietary advice Including of green vegetables, beef and whole dairy products on recurrent upper respiratory tract infections in children: a randomized controlled trial”. Nutrients, 2020, 12(1), 272, /doi.org/10.3390/nu12010272

\section{Under review}

2020 Ellen van der Gaag, Thalia Hummel. "Food or medication? The therapeutic effects of food on the duration and incidence of upper respiratory tract infections: a review of the literature". Under review Critical Reviews in Food Science and Nutrition

Ellen van der Gaag, Job van der palen, Pim Schaap, Mirthe van Voorthuizen, Thalia Hummel. "A dietary intervention reduces tiredness in children with subclinical hypothyroidism, a randomized controlled trial". Under review PlosOne 



\section{CURRICULUM VITAE}

Ellen van der Gaag was born on November 9th, 1973 in Hengelo (ov). After graduation from secondary school at Rijksscholen Gemeenschap in Lochem, she was drawn in one go and could start in 1992 to study Medicine at the Leiden University. She conducted her graduation research at the dermatology research laboratory of Dr. M. Ponec at Leiden University in 1996-1997. After this she did an additional 9-month research internship in the dermatology laboratory of Prof H.R. Byers, Boston University, USA. From 1997-1999 she did her internships in several hospitals in Leiden and The Hague. In 1999 she was ANIOS pediatric oncology (prof. W.A. Kamps) at the University Medical Center Groningen. In 2000, she started her residency in pediatrics under supervision of professor P. J.J. Sauer at the University Medical Center Groningen. During these 5 years she was detached at the pediatric department of Medical Center Leeuwarden (Dr. T.W. de Vries) and Medical Spectrum Twente (Dr. R.F. H.M. Tummers, Enschede). In 2005 she started working as a general pediatrician at the Streekziekenhuis Midden Twente (Hengelo) which merged with Twenteborg Almelo until Hospital Group Twente (ZGT).

In December 2018 her official PhD trajectory at the University Twente started next to her fulltime job as a pediatrician at ZGT. Ellen is married to Thijs. Together they have a daughter, Lathére. 



\section{DANKWOORD}

Onderzoek doe je nooit alleen. Er zijn dan ook een heel aantal mensen die ik wil bedanken. Allereerst zijn er vele filosoferende avonden, middagen en weekenden geweest waarin we nadachten over ziektes, ogenschijnlijk onoplosbare problemen, voeding en koken, eetgedrag bij kinderen, wat mist er in de huidige aanpak en behandelingsmethoden, wat zijn de huidige eettrends en waar liggen de supermarkten vol mee, hoe kijken we aan tegen de rol van voeding? Deze voorbereiding was essentieel en ging gedurende het hele onderzoekstraject door. In het bijzonder ben ik dankbaar voor het contact met Johanna. We zijn er samen vanaf het begin in de volle breedte mee bezig geweest, en wat zijn we tot een mooie lijn en richting gekomen! Ik wil daarnaast dan ook iedereen bedanken die daaraan meegeholpen heeft; Thijs, Brenda en Dirk Jan. Frans, bedankt voor de hulp bij het maken van de voorkant van dit proefschrift. Ik wil jullie ook bedanken voor alle adviezen, steun en het aanhoren van mijn verhalen en ervaringen als ik ergens heel erg of helemaal niet enthousiast over was. Daarnaast hebben jullie me geleerd dat je kunt promoveren, maar dat het gewone leven ook doorgaat. Hierdoor is er een mooie balans ontstaan zonder een ontwricht prive-leven.

Wetenschappelijk gezien kon mijn onderzoekskwaliteit nog wel verbeteringen gebruiken. In eerste instantie redde Job veel van mijn gegevens. Althans, zo zag ik het. $\mathrm{Hij}$ schiep orde in de brij van gegevens die ik zonder datamanagement systeem in een excelbestand opgeslagen had. Wat heb ik daar het laatste jaar veel over geleerd, dat kan dus ook heel anders. Vanaf 2007 hebben we in meer of mindere mate contact gehouden en was je wel een constante factor. Job, ik ben blij dat je toen het een officieel promotietraject werd mijn promotor wilde worden en me hier doorheen hebt geloodst. Bedankt voor je altijd positieve instelling, kopjes thee, leuke gesprekken en vlotte correcties van mijn artikelen.

Thalia, mijn co-promotor, je was de aanzet van mijn promotietraject. Je hebt lijn, basis, en wetenschappelijke helderheid aangebracht in de RCTs en het review. We hebben toch maar mooi een voedingsadvies in een RCT gegoten, en daar zijn er niet veel van! Daarnaast hebben we meerdere "vergaderingen" gehad in de tuin, restaurants, of op congres. Deze locaties zijn veel inspirerender dan die in het ziekenhuis, maar ook daar hebben we elkaar veel ontmoet. Bedankt voor je begeleiding en het grondig doorlezen van al mijn schrijfsels de afgelopen jaren!

De leden van de promotiecommissie; Prof. Dr. T.A.J. Toonen, Prof. Dr. G.H. Koppelman, Prof. Dr. Ir. H.F.J. Savelkoul, Prof. Dr. ir. M.J.A.M. van Putten, Prof. Dr. E.G.A.H. van 
Mil, dr. M.M. Boere-Boonekamp, wil ik bedanken voor het lezen van mijn proefschrift en de bereidheid deel te nemen aan de oppositie. Prof. Dr. M.L. Eggersdorfer, thank you for reading my dissertation and the willingness to participate in the opposition.

Natuurlijk wil ik mijn maten (tegenwoordig mede grootaandeelhouders genoemd) bedanken. Jullie mogen absoluut niet ontbreken! Al jaren noem ik dat ik onderzoek wil doen naar algemene kindergeneeskunde en alledaagse problemen. Jullie hebben mij de gelegenheid gegeven dat te ontwikkelen en uit te voeren, in de vorm van een onderzoeksdagdeel de laatste 3 jaar. Ook merkte ik dat jullie trots waren dat ik het deed en stiekem ook wel blij dat jullie het niet hoefden te doen. Ik ga er graag mee door zoals jullie weten, ik heb nu helemaal de smaak te pakken!

Bedankt Jacko, Nicole, Ellen, Marije, Danielle, Renske, George, Zehre, Bas en Jorieke.

Van het ZGT wil ik ook het wetenschapsbureau bedanken. Met mijn vragen kon ik bij jullie terecht en ook brachten jullie me in contact met studenten die onderzoek wilden doen. De Raad van bestuur van het ZGT wil ik bedanken voor hun doel om wetenschap een grotere rol te geven in een algemeen ziekenhuis. Ik denk dat dat heel nuttig is, omdat juist de algemene geneeskunde onderwerpen zeer frequent voorkomen. Daarnaast wil ik ze bedanken voor hun financiële bijdrage aan het drukken van dit boekje.

Hans wil ik bedanken voor de jarenlange snotterpoli die we samen gedaan hebben. Ook na je pensioen ging je door, mede ook om de wetenschap te steunen. Helaas, maar wel begrijpelijk, is daar een einde aan gekomen. Bedankt voor je support de afgelopen jaren!

In de afgelopen jaren heb ik ook veel studenten begeleid bij hun afstudeeronderzoeken, maar zij hebben mij ook weer geholpen. De eerste student was Nicole. Je kwam zelfs met grote bigshopper tassen vol onderzoeksdata tijdens mijn zwangerschapsverlof op kraamvisite. Dat is zo goed bevallen dat er daarna nog veel meer studenten geweest zijn! Bedankt Nicole, Miriam, Marjolein, Anne, Lisanne, Tessa, Pim, Mirthe, Marlou, Jetske, Kristina, Loes, Judith, Iris, Stephanie, Kim en Rosan. Daarnaast waren er ook arts-assistenten die naast hun taken hebben geschreven of analyses gedaan. Bedankt Romy, Ruben en Wendy.

Ik wil mijn paranimfen, Thijs en Dirk Jan, bedanken dat ze me vandaag bijstaan. Het leven zit vol verrassingen... 
Mijn ouders hebben me van het begin af aan het belang van een goede opleiding en onderwijs duidelijk gemaakt. Ze hebben me daar ook alle kansen en gelegenheid voor gegeven. Pap en mam, bedankt. Pap, bedankt ook voor alle NRC artikelen over voeding en dokters, hierdoor bleef ik mooi uptodate.

En tenslotte Thijs en Lathere. Lieve Thijs, je houdt niet van dokters en niet van wetenschappers, maar je houdt wel van mij....Dat zegt wel genoeg. Ik werk niet in een hoek waar je zelf graag in zou willen werken, maar je steunt me door dik en dun. De kopjes thee, de "nu is het wel even genoeg, weet je wel hoe laat het is?" en "Moet je niet weer met je onderzoek beginnen?", het ontzorgen van de huishoudelijke taken en het meedenken, aanhoren van mijn theorieën. Het kopen van een grotere computer.... Zonder al deze steun was het niet gelukt.

Lieve Lathére, je hebt zonder dat je het weet een grote rol gespeeld. Daarnaast heb je ook geaccepteerd dat je moeder vaak achter de computer zat in de weekenden en avonden en daarom wat minder beschikbaar was. Gelukkig was voeding het centrale thema van het proefschrift, dus daar hebben we nooit op ingeleverd. De maaltijden hebben altijd alle aandacht gehad bij ons en dat zal ook zo blijven. 